\title{
REVISÃO DE ELBELLA EVANS E GÊNEROS AFINS (LEPIDOPTERA, HESPERIIDAE, PYRRHOPYGINAE) ${ }^{1}$
}

\author{
Olaf H. H. Mielke ${ }^{2}$
}

\begin{abstract}
REVISION of Elbella EVANS and RElated geneka (LePIDOPTERA, HESPERIIDAE, PYRRHOPYGINAE). A systematic study of the genera Microceris Watson, 1893, Elbella Evans, 1951, Parelbella, gen.n. (type species: Hesperia polyzona [Latreille, 1824]), Pseudocroniades, gen.n. (type species: Ericides (sic) machaon Westwood, [1852|) and Protelbella, gen.n. (type species: Pyrrhopyga (sic) alburna Mabille, 1891), a natural group of the Pyrrhopyginae, here called "Elbella Complex", is presented.

The following are spp.n. and sspp.ll.: Elbella intersecta paraensis, Brazil: Pará; Elbella intersecta rufitegula, Brazil: Pernambuco, Bahia, Minas Gerais, Espírito Santo and Rio de Janeiro State; Elbella viriditas boliviana, Bolivia: La Paz; Elbella lampra albociliata, Brazil: São Paulo, Paraná and Santa Catarina: Elbella azeta giffordi, Brazil: Distrito Federal and São Paulo; Elbella patrobas mexicana, Mexico: Chiapas and Quintana Roo; Elbella patrobas evansi, Colombia: Cauca, Caldas and Boyaca; Elbella patrobas tingo, Brazil: Rondonia and Peru: Huanuco and Madre de Dios; Elhella patrobas amazonica. Brazil: Amazonas; Parelbella peruana. Peru: Junin: Pseudocroniades machaon seabrai, Brazil: Rio de Janeiro State; Protelbella albuma brasiliensis, Brazil: Amazonas, Rondonia and Mto Grosso, and French Guiana: Montagne aux Cheveaux.

The following genus is a syn.n.: Hegesippe Evans, 1951 of Elbella Evans, 1951. The following species and subspecies are syn.n.: Pyrrhopyga (sic) semidentata Mabille, 1877 and Elbella intersecta ilona Evans, 1951 of Elbella intersecta intersecta (Herrich-Schäffer, 1869): Pyrrhopvge carriae Bell, 1931 of Elbella viriditas viriditas (Skinner. 1920): Pyrrhopyga (sic) menecrates Mabille, 1878 and Pyrthopyge margimmiscus Hayward, 1935 of Elbella lampra lampra (Hopffer. 1874): Elhella etna moda Evans, 195 ! of Elbella etna Evans, 1951: Jemadia umbrata Mabille \& Boullet. 1908 of Elbella patroclus patroclus (Plötz, 1879); Pyrrhopyga (sic) jamina Butler. 1870 and Pyrrhopyga (sic) zimra Hewitson, 1871 of Parelleella ahira ahira (Hewitson. 1857): Elbella zesta Evans, 1951 of Croniades pieria (Hewitson, 1857)

The following are comb.n.: Elhella viriditas viriditas (Skinner, 1920); Ellella viriditas chia Evans. 1951: Elbella mariae molinai (Hayward, 1940): Elbella patroclus acala Evans. 1951: Parelbella polyzona (Latreille. 11824]): Parelbella ahira ahira (Hewitson, 1866): Parelbella ahira extrema (Röber, 1925): Parelhella macleamani (Godman \& Salvin, 1893): Pseudocroniades machaon machaon (Westwood, [1852]); Protelhella alluma albuma (Mabille, 1891).

The following are stat.n.: Elhella mariae molinai (Hayward, 1940): Elbella lastra Evans. 1951: Elbella blanda Evans. 1951.
\end{abstract}

1) Contribuição número 813 do Departamento de Zoologia. Universidade Federal do Paraná. Auxílios ver agradecimentos.

2) Departamento de Zoologia. Universidade Federal do Paraná, Caixa Postal 19020, 81531-970 Curitiba. Paraná. Brasil. Pesquisador do CNPy. 
The following is a sp.rev.: Elbella patroclus patroclus (Plötz, 1879).

The following is a nom.rev.: Elbella mariae molinai (Hayward, 1940).

The following are stat.rev.: Elbella miodesmiata (Röber, 1925); Parelbella ahira ahira (Hewitson, 1866); Parelbella macleannani (Godman \& Salvin, 1893).

Lectotypes are designated for the following species or variety: Myscelus intersecta Herrich-Schäffer, 1869; Pyrrhopyga (sic) fluminis Butler, 1873; Pyrrhopyga (sic) semidentata Mabille, 1877; Pyrrhopyge lamprus Hopffer, 1874; Pyrrhopyga (sic) menecrates Mabille, 1878; Pyrrhopyga (sic) dulcinea Plötz, 1879; Pyrrhopyga (sic) luteizona Mabille, 1877; Hesperia iphinous Latreille, [1824]; Pyrrhopyga (sic) azeta Hewitson, 1866; Pyrrhopyga (sic) patrobas Hewitson, 1857; Jemadia azeta var. melanina Mabille \& Boullet, 1908; Pyrrhopyga (sic) ahira Hewitson, 1866; Pyrrhopyga (sic) jamina Butler, 1870; Pyrrhopyga (sic) zimra Hewitson, 1871: Jemadia macleannani Godman \& Salvin, 1893; Ericides (sic) machaon Westwood, [1852]; Pyrrhopyga (sic) alburna Mabille, 1891.

Neotypes are designated for the following species: Sarbia amoena Röber, 1925; Pyrrhopyga (sic) othello Plötz, 1879: Mimoniades mimetes Mabille, 1909; Jemadia miodesmiata Röber, 1925; Jemadia umbrata Mabille \& Boullet, 1908: Jemadia extrema Röber, 1925.

KEY WORDS. Lepidoptera, Hesperiidae, Elbella, related genera, neotropical

\section{CONTEÚDO}

Introdução . . . . . . . . . . . . . . . . . . . . . . . . . . . . . . . . 396

Material e Métodos . . . . . . . . . . . . . . . . . . . . . . . . . . . . . . 397

Resultados e Discussões . . . . . . . . . . . . . . . . . . . . . . . . . . . 399

"Complexo Elbella" . . . . . . . . . . . . . . . . . . . . . . . . . . . . . . . . . 399

Chave para os gêneros do "Complexo Elbella" . . . . . . . . . . . . . . 406

Microceris . . . . . . . . . . . . . . . . . . . . . . . . . . 406

Elbella................................412

Espécies incluídas em Elbella . . . . . . . . . . . . . . . . . 415

Chave para as espécies de Elbella . . . . . . . . . . . . . . . . . 416

Parelbella ...........................448

Chave para as espécies de Parelbella . . . . . . . . . . . . . . . . . 542

Pseudocroniades . . . . . . . . . . . . . . . . . . . . . . . . . . . 564

Protelbella . . . . . . . . . . . . . . . . . . . . . . . . . . . . 569

Conclusões . . . . . . . . . . . . . . . . . . . . . . . . . . . . . . . 573

Agradecimentos . . . . . . . . . . . . . . . . . . . . . . . . 575

Referências Bibliográticas . . . . . . . . . . . . . . . . . 576

Índice . . . . . . . . . . . . . . . . . . . . . . . . . . . . . . . . . 584

A subfamília Pyrrhopyginae, com aproximadamente 150 espécies conhecidas, ocorre desde o sul do Estados Unidos da América do Norte (Arizona, Texas) até a Bolívia e o norte da Argentina (Misiones), sendo ausente nas Antilhas.

Em estudo filogenético da subfamília, ainda não publicado, verificou-se a existência de um grupo de gêneros muito próximos entre si, aqui denominado de "Complexo Elbella" e constituido dos seguintes gêneros: Microceris Watson, 1893, Elbella Evans, 1951; Parelbella Mielke, gen.n., Pseudocroniades Mielke, 
gen.n. e Protelbella Mielke, gen.n. Continuando o estudo sobre as espécies, verificou-se a necessidade de uma revisão completa, pois a anterior (EVANS 1951) não concorda com as idéias obtidas do estudo dos exemplares da coleção da Universidade Federal do Paraná. Assim sendo, apresenta-se uma revisão dos gêneros e espécies incluídas neste complexo. A parte de filogenia será estudada oportunamente, pois primeiramente se faz necessário reconhecer as espécies.

\section{MATERIAL E MÉTODOS}

O presente estudo baseia-se em mais de 1500 exemplares examinados das coleções abaixo mencionadas, com seus respectivos curadores. Os acrônimos utilizados baseiam-se em HEPPNER \& LAMAS (1982) ou quando não listados, foram aqui criados.

AMNH - American Museum of Natural History, New York, USA. Drs. Frederick Rindge e James Miller.

AME - Allyn Museum of Entomology, Sarasota, Florida, USA. Drs. Lee Miller e Jacqueline Miller.

BMNH - The Natural History Museum, ex British Museum (Natural History),

Londres, Inglaterra. Drs. R. I. Vane-Wright e Phillip Ackery.

BREV - Coleção particular de Chr. Brévignon, Caiena, Guiana Francesa.

CMP - Carnegie Museum, Pittsburgh, Pennsylvania, USA. Drs. John Rawlins e Chen Young.

CU - Department of Entomology, Cornell University, Ithaca, New York, USA. Dr. John G. Franclemont.

EF - Coleção particular do Sr. Eurides Furtado, Diamantino, Mato Grosso.

IBGE - Coleção da Reserva Ecológica do Instituto Brasileiro de Geografia e Estatística (IBGE), Brasília, Distrito Federal. Dr. Braulio Dias.

IML - Instituto Miguel Lillo, Tucumán, Argentina. Dr. Kenneth J. Hayward (falecido).

INPA - Instituto Nacional de Pesquisas da Amazônia, Manaus, Amazonas. Drs José Albertino Rafael, Eloy Castellon e Roger W. Hutchings H.

IOC - Instituto Oswaldo Cruz, Rio de Janeiro. Dr. J. Jürberg e Sr. O. Ferreira.

IRSC - Institut Royal de Sciences Naturelles, Bruxelas, Bélgica. Dr. P. Grootaert. LECR - Coleção particular de J. F. Le Crom, Bogotá, Colômbia.

MCZ - Museum of Comparative Zoology, Harvard University Cambridge, Massachusetts, USA. Dra. Deane Brower.

MFPL - Museu Fritz Plaumann, Nova Teutônia, Seara, Santa Catarina. Sr. Fritz Plaumann (falecido).

MHNL - Museu de Historia Natural, Lima, Peru. Dr. Gerardo Lamas.

MLP - Facultad de Ciencias Naturales y Museo, Universidad Nacional de La Plata, La Plata, Argentina. Dr. Luis de Santis. 
MNHP - Muséum National d'Histoire Naturelle, Paris, França. Drs. Pierre Viette, G. Bernardi, Jacques Pierre e Judith Najt.

MNRJ - Museu Nacional, Universidade Federal do Rio de Janeiro, Rio de Janeiro.

Dr. Alfredo R. do Rego Barros.

MPEG - Museu Paraense Emilio Goeldi, Belém, Pará. Drs. Leslie Overall e Teresinha Chaves.

MZSP - Museu de Zoologia, Universidade de São Paulo, São Paulo (inclue a coleção Diringshofen). Drs. Ubirajara Martins, Nelson Papavero, Carlos Roberto Brandão e Francisca C. Do Val.

NT - Coleção particular do Sr. Nirton Tangerini, Rio de Janeiro.

SMTD - Staatliches Museum für Tierkunde, Dresden, Alemanha. Dr. R. Krause.

UCV - Departamento de Zoologia Agricola, Facultad de Agronomia, Universidad

Central de Venezuela, Maracay, Venezuela. Drs. Francisco F. Yépez (falecido) e Luiz D. Otero.

UFP - Departamento de Entomologia, Universidade Federal de Pelotas, Rio Grande do Sul (coleção C. M. Biezanko). Dr. Milton de Souza Guerra.

UFPC - Departamento de Zoologia, Setor de Ciências Biológicas, Universidade Federal do Paraná, Curitiba, Paraná. Inclui as colecões D’Almeida, Gagarin, Ebert, Gifford e Mielke (OM).

USNM - National Museum of Natural History, Washington, USA. Drs. Robert

K. Robbins, John Burns, Donald Davies, Robert Field (falecido) e Donald Harvey.

ZMHB - Zoologisches Museum der Humboldt Universität, Berlin, Alemanha.

Drs. H.-J. Hannemann e Wolfram Mey.

ZMUC - Zoologisk Museum, Copenhague, Dinamarca. Dr. Niels P. Kristensen. ZSBS - Zoologische Sammlung, Munique, Alemanha. Dr. W. Dierl.

ZIL - Zoological Institute, Russian Academy of Sciences, St. Petersburgo, Rússia.

Dr. A. Zinovjev.

Nas citações bibliográficas de gêneros, espécies e subespécies estão registradas todas as referências que contém dados sobre a sistemática, distribuição geográfica, etologia, ecologia, biologia e plantas hospedeiras do taxon em questão.

De cada espécie foram féitos vários preparados das genitálias masculina e feminina. Nas preparações das genitálias masculinas foi utilizada a técnica que permite a preservação do abdome; este é destacado do corpo e imerso por 24 horas em água, após a genitália é destacada e examinada. O abdome é secado em estufa a $40^{\circ}$ e recolado no exemplar, enquanto que a genitália é fervida em banho-maria dentro de tubo de vidro com hidróxido de potássio a $10 \%$ durante alguns minutos. No caso das fêmeas, todo o abdome é fervido por mais tempo; após o amolecimento das estruturas, é examinado. Os preparados estão preservados em pequenos tubos de vidro com glicerina atrás do respectivo exemplar e rotulados convenientemente para a sua identificação. As pernas e palpos foram igualmente preparados. As preparações das venações foram feitas por simples clareamento em água sanitária 
comercial (hipoclorito de sódio, diluido a 20\%), onde permanecem por alguns minutos, após rápida passagem por álcool comercial para remoção de gorduras. Após a secagem das asas entre papel mata-borrão, elas foram recoladas no exemplar.

Todos os exemplares foram rotulados com etiqueta de identificação e os holótipos, alótipos e parátipos das espécies e subespécies novas descritas, assim como os neótipos e lectótipos designados, rotulados de modo característico.

Nas descrições de algumas espécies foi mencionado um termo novo, ou seja: ângulo apical da asa anterior. Este ângulo é o formado entre a margem costal e a margem externa, obtido pela mensuração do ângulo entre duas linhas retas que partem da base e da margem externa em $2 \mathrm{~A}$ e se cruzam no ápice em R4.

As escalas nas figuras sempre significam $1 \mathrm{~mm}$ e no caso dos desenhos das genitálias, com exceção da bolsa copuladora com a menor escala e a ponta do unco com a maior escala (só em Parelbella polyzona), todas as estruturas tem o aumento da escala indicada abaixo do nono segmento da genitália masculina.

Nas distribuições espaciais só foram mencionadas as procedências de exemplares examinados e alguns dados bibliográficos confiáveis. Os sinais abertos significam procedências vagas dentro do pais ou estado.

Elbella zesta Evans, 1951 é sinônimo junior (syn.n.) de Croniades pieria (Hewitson, 1857), razão de sua exclusão deste estudo. Esta espécie possui dois tipos de fêmeas, uma com o mesmo aspecto cromático do macho, isto é, amarela e outra, mimética das espécies de Jemadia Watson,1893, ou seja, azul (zesta).

\section{RESULTADOS E DISCUSSÕES}

\section{"Complexo Elbella"}

Cinco são os gêneros aqui incluidos: Microceris Watson, 1893, Elhella Evans, 1951, Parelbella, gen.n., Pseudocroniades, gen.n. e Protelbella, gen.n.

Devida à curvatura da antena antes da clava antenal e à $\mathrm{M} 2$, na asa anterior, sempre mais próxima de M1 que de M3 na sua origem, êstes gêneros se caracterizam como Pyrrhopyginae.

Diagnose. Este "complexo" forma um grupo natural dentro dos Pyrrhopyginae pelo edeago característico, isto é, a ponta distal possui um lóbulo lateral esquerdo que parece ter a função de sustentação da vesica.

Descrição. Caracteres masculinos e femininos - Distância interorbital ao nível das terminações do quetosemata maior que o comprimento da cabeça em vista dorsal; cabeça com a margem posterior, em vista dorsal, uniformemente côncava ou reta e apenas com pequena reentrância (concavidade) no início do quetosemata (Figs 1 e 2); vértice e frontoclípeo com as escamas vermelhas a alaranjadas, raramente com algumas escamas castanho-anegradas, ou com escamas castanho-anegradas e com manchas esbranquiçadas, amareladas ou azuladas e/ou linhas transversais esbranquiçadas, amareladas ou levemente azuladas; escapo antenal sem tufo de escamas alongadas na parte externa, bem destacado das demais 

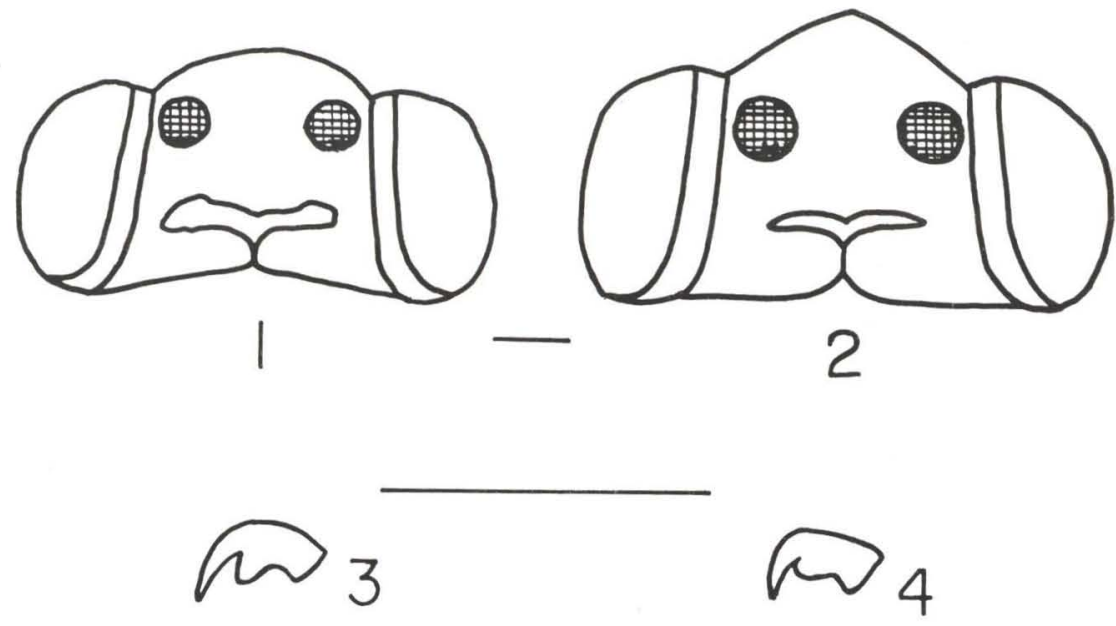

Figs 1-4. Elbella scylla, (1) cabeça em vista dorsal: Protelbella alburna, (2) cabeça em vista dorsal; Microceris varicolor, (3) garra tarsal em vista lateral; Elbella scylla. (4) garra tarsal em vista lateral.

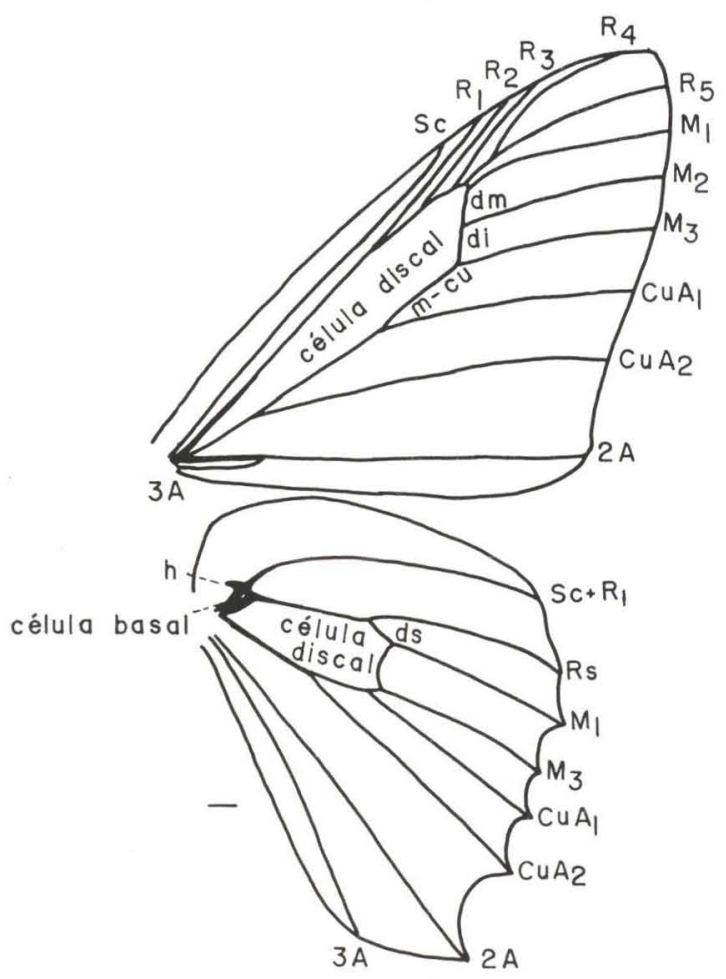

Fig. 5. Microceris variicolor, venação alar do macho. 
escamas que cobrem parte do olho; haste antenal sem fileira de escamas no lado externo, consequentemente não dando a impressão de uma haste dilatada; índice entre a largura do olho e a distância que o palpo se projeta para frente deste 1,63 a 4,0; palpo labial com o artículo distal maior que um sexto do segundo artículo; palpo labial com o artículo distal projetado além das escamas internas ou externas do segundo artículo; palpo labial com as escamas na parte ventral e central do segundo artículo achatadas, geralmente curtas e apressas; antena com a porção terminal da haste não dilatada; asa anterior com 12 veias chegando às margens costal e externa (Figs 5 a 9); asa anterior com o ápice inteiro, isto é, não truncado entre R4 e M l; garras tarsais bífidas, com o dente ventral rombudo e mais curto ou mais longo que a metade da ponta dorsal (Figs 3 e 4); tarsômeros dos três pares de pernas sem espinhos na região dorso-lateral; tarsômeros com os espinhos ventrais bem mais longos que a metade da largura do respectivo tarsômero; tarsômero proximal da perna protorácica tão ou pouco mais longo que a tíbia, isto é, menor que o comprimento do segundo tarsômero; tíbia protorácica mais curta ou mais longa que a metade do fêmur; tíbia mesotorácica mais longa que os dois tarsômeros basais, sem exceder o quarto tarsômero; tíbias meso e metatorácicas inermes; tíbia metatorácica com o esporão distal maior, menor, igual ou mais longo que a distância entre as inserções dos dois pares de esporões; tíbia metatorácica com os esporões proximais bem desenvolvidos; tíbia metatorácica rebatida sobre o tarso atingindo no máximo a articulação entre o terceiro e quarto tarsômeros; fềmur metatorácico rebatido sobre a tibia ultrapassando o meio entre os dois pares de esporões; tíbia mesotorácica com as escamas da face interna todas curtas e achatadas; fêmur metatorácico com as escamas na face interna todas curtas e achatadas ou algumas finas, alongadas e intercaladas entre as achatadas; mesoscuto e mesoescutelo iguais à coloração geral, não brilhante; pleuras torácicas (sob as axilas) sem linha contínua de escamas amarelas a vermelhas; tergos e esternos abdominais, não considerando o tufo anal, com as franjas (escamas) posteriores não diferenciadas; tergos abdominais, não considerando o tufo anal e as escamas posteriores, de um castanho-anegrado, às vezes azulado, sem brilho metálico ou com a parte proximal inteiramente acinzentada ou com manchas branco-azuladas ou amarelas, separadas pela linha mediana dorsal anegiada; esternos abdominais, não considerando o tuto anal e as escamas posteriores, de coloração uniforme castanho escuro até anegrado ou amarelos, estes mais nítidos nos segmentos basais e, às vezes, interrompidos pela linha mediana ventral anegrada ou com faixas brancas, às vezes, interrompidas ao longo da linha mediana ventral anegrada; tufo anal da coloração geral, amarelo a ocráceo ou vermelho a alaranjado, em contraste com o restante do corpo.

Caracteres masculinos - Índice entre a distância interorbital e a projeção do frontoclípeo além da tangente orbital 4,54 a 9,0; frontoclípeo em vista dorsal de contorno arqueado ou em ângulo nítido (Figs 1 e 2); índice entre a altura do olho, medida em vista dorsal, e a distância interantenal 1,0 a 1,69; índice entre os comprimentos da haste e da clava antenais 2,56 a 3,94; índice entre o comprimento e a largura máxima da clava 4,06 a 6,0; antena com clava de terminação semiag̣uda; índice entre os comprimentos da margem costal da asa anterior, medida da base 


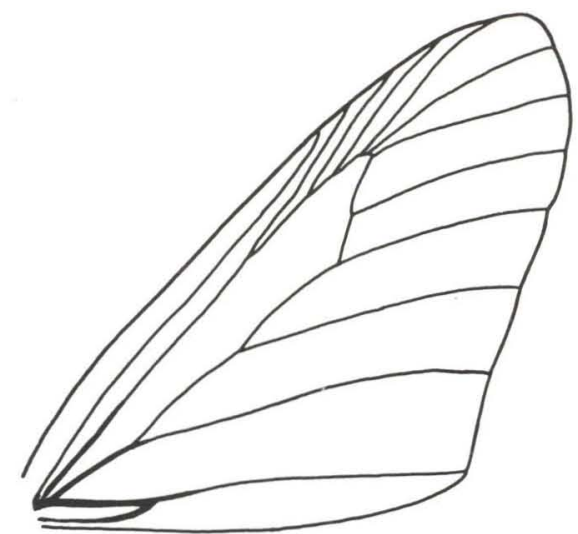

Fig. 6. Elhella scylla, venação alar do macho.

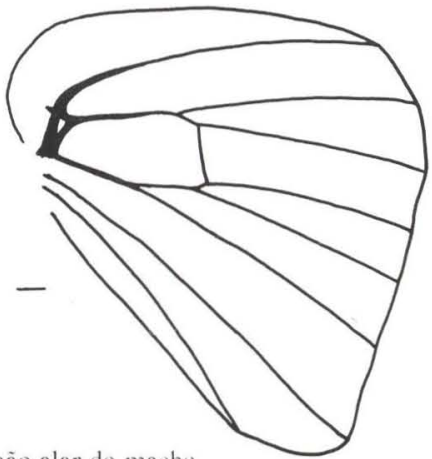

ao ápice em R4, e a haste antenal 2,49 a 3,19; na asa anterior, o ângulo externo entre uma reta imaginária que passa pelos pontos de partida de M 1 e M3 e atingindo $2 \mathrm{~A}$, forma com ela um ângulo menor que $85^{\circ}$; na asa anterior, o comprimento da célula discal menor que ou excede o comprimento de $2 \mathrm{~A}$ por uma distância menor que o comprimento das discocelulares mediana e inferior; na asa anterior sem vestígios de média na célula discal; na asa anterior, m-cu longa, isto é, m-cu sobreposta com um compasso, alcança o terço superior da discocelular mediana ou pouco além, porém não alcançando uma distância igual a esta discocelular além do ápice da célula; asa anterior com R5 e Ml divergentes desde a base; asa anterior com início de m-cu anterior, coincidente ou distal à perpendicular imaginária à $2 \mathrm{~A}$ que passa pelo início de R1; asa anterior com R4 e R5 livres ou anastomosadas na base; asa anterior com o ângulo entre $\mathrm{m}$-cu e a discocelular inferior maior que $25^{\circ}$; asa anterior fracamente projetadá, isto é, a distância à R4 de uma reta perpendicular imaginária à $2 \mathrm{~A}$, a partir do encontro desta com a margem externa e passando pelas proximidades de R4 igual ou maior que a discocelular inferior, porém menor que as discocelulares mediana e inferior; asa posterior com a célula discal curta a longa, isto é, o índice entre o comprimento de uma reta da base da célula discal até o meio entre M1 e M3 na margem externa e o comprimento da 


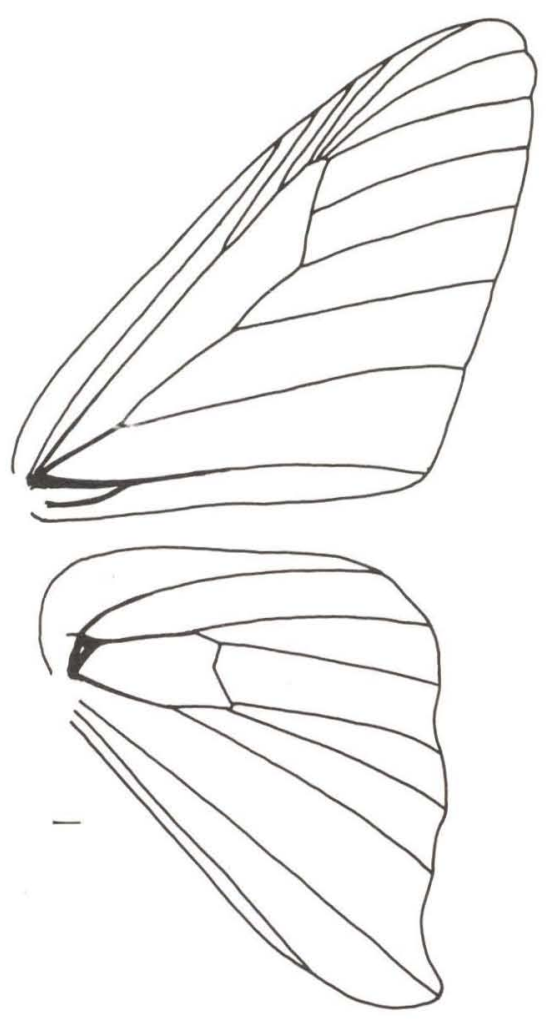

Fig. 7. Parelbella polyzona, venaçäo alar do macho.

base da mesma célula até o ponto de inserção desta reta com as veias discocelulares 2,02 a 2,76; asa posterior sem tufo de escamas brancas e alongadas no terço basal entre $2 \mathrm{~A}$ e $3 \mathrm{~A}$; na asa posterior, M3 e CuAl separadas na base por m-cu; na asa posterior, a bifurcação entre $\mathrm{CuA} 1$ e $\mathrm{CuA} 2$ anterior ou coincidente com o início de Rs; asa posterior com M2 ausente; asa posterior com a discocelular superior muito curta a longa, isto é, menor que a metade das discocelulares mediana e inferior ou igual a estas; asa posterior com o ângulo formado pelas discocelulares e M3 $101^{\circ}$ a $128^{\circ}$; asa posterior com a área anal curta a muito longa, isto é, $2 \mathrm{~A}$ sobreposta por um compasso centrado na célula basal atinge o fim ou ultrapassa Rs; na asa posterior, a margem externa com maior expansão no término de MI e/ou Rs e CuAl; tíbia mesotorácica com as escamas na face interna curtas, achatadas e apressas ou com algumas escamas finas intercaladas entre as anteriores, sem sobrepassar a largura da tíbia; tíbia metatorácica sem órgão odorífero na face interna: tíhia metatorácica com as escamas na face externa todas curtas, achatadas e apressas ou delgadas, divergentes e sobrepassando a largura da tíbia; tibia metatorácica com as escamas da face interna mais curtas que a largura da tíbia, achatadas, não divergentes ou quando divergentes, só na porção distal da tíbia e 


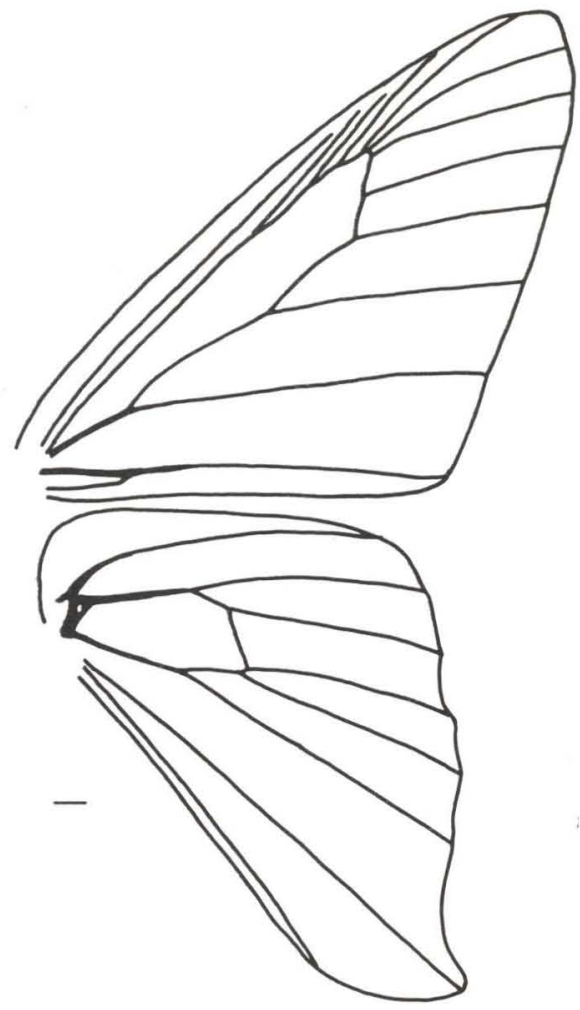

Fig. 8. Pseudocroniades machaon machaon, venação alar do macho.

menos densas que na face externa; projeção anterior do saco com ápice alongado; apófises do tegumen ausentes ou presentes; apófises do tegumen lisas ou ásperas, quando presentes; unco de terminação delgada, simples ou bífida, ou larga e bífida; unco sem constricção na base; gnato de duas peças, muito fracamente esclerosadas, como se fossem prolongamentos das apófises ventrais do unco ou ausente; comprimento do edéago menor ou igual ao da valva; extremidade distal do edeago com um lóbulo alongado ou triangular, dirigido dorso-basalmente ou dorsodistalmente em seu lado esquerdo; vesica sem cornuto; juxta grande, maior que cinco vezes o diâmetro do edeago e de terminação bilobada onde se encaixa o edeago; valva com a parte dorso-basal (costa) não atingindo os dois terços do comprimento total; sáculo da valva sem projeção dorsal; porção dorso-basal da valva (costa) sem ou com projeção virada para dentro; valva terminando ou não em processo transversal; valva não de contorno triangular com dois conjuntos de pequenos espinhos no vértice (ângulo posterior). Caracteres femininos - Índice entre os comprimentos da haste e da clava antenais 2,10 a 3,12; índice entre os comprimentos da margem costal da asa anterior, medida da base até o ápice em R4, e da haste antenal 3,03 a 3,63; asa posterior com a margem externa sem ângulo 


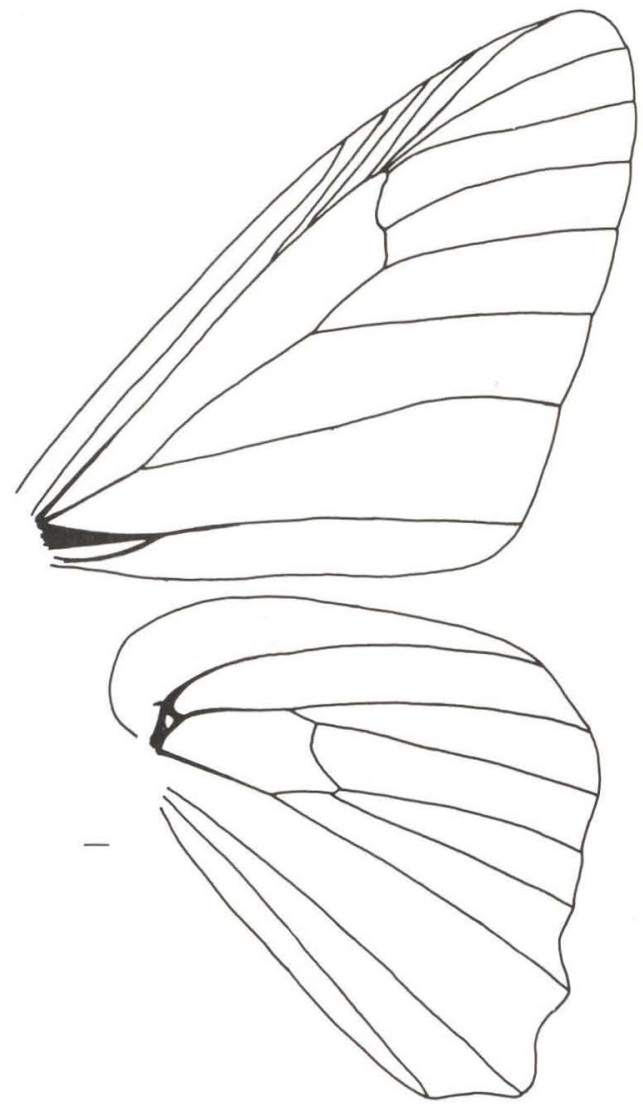

Fig. 9. Protelbella althuma alburna, venação alar do macho.

obtuso (entre $110^{\circ}$ e $125^{\circ}$ ), com um lado anterior à M3 e outro entre M3 e o ângulo anal; oitavo tergo ausente ou constituido de duas peças isoladas, não unidas ao oitavo esterno, ou constituido de duas peças unidas ao oitavo esterno; oitavo esterno sem bolsa em cada parte látero-anterior; esterigma fundido ao oitavo esterno, este às vezes membranoso na parte ventral, ou o esterigma fazendo a ligação das suas duas partes ou o esterigma ligado por membrana entre ou abaixo das duas partes do oitavo esterno, este escle rosado ou o oitavo esterno e o esterigma membranosos; oitavo esterno com as partes laterais unidas, contíguas ou separadas; oitavo esterno sem apófises posteriores pontudas situadas acima do esterigma; esterigma arredondado ou tubular, sem lóbulo ou lóbulos dorsais aparentemente fechando o óstio, ou tubular e membranoso; oitavo esterno sem apófises ao lado do esterigma; papila anal com apófisies posteriores; lamela pós-vaginal ausente; bolsa copuladora sem signos; corpo da bolsa copuladora distinto ou não e em linha reta ou curvada em relação ao duto. 


\section{Chave para os gêneros do "Complexo Elbella"}

1. Na asa anterior, R4 e R5 anastomosadas na base; margem externa das asas com linha verde em zigue-zague . . . . . . . . . . . Microceris

- Na asa anterior R4 e R5 livres . . . . . . . . . . . . . . . . . 2

2. Asa anterior com manchas amarelas hialinas entre R4 e CuAl e opacas entre $\mathrm{CuA} 1$ e 2A, em linha paralela à margem externa e bem separadas da faixa mediana de manchas hialinas; tegumen sem apófises; asa posterior com as franjas ocráceas . . . . . . . . . . . Pseudocroniades

- Asa anterior sem manchas, com manchas brancas ou amarelas, quando amarelas, estas formando uma faixa em Y pela aproximação da faixa apical-subapical com a faixa mediana; tegumen com apófises; asa posterior com franjas amarelas, brancas, castanhas ou negras . . . . . . . . . . . 3

3. Asas anterior e posterior negras ou a asa anterior com manchas brancas, então a em M3-CuAl sempre bem marcada e entre as faixas mediana e apical, sendo que a mancha em M2-M3 faz parte da faixa apical, isto é, a faixa apical com 5 manchas; quando com manchas amarelas, as faixas amarela mediana e a apical-subapical em forma de Y . . . . . . . . Elbella

- Asa anterior com as manchas brancas em M2-M3 e M3-CuA1, às vezes ausentes em macleannani (Panamá até Ecuador), entre as faixas mediana e apical .4 4. Asa anterior sem mancha branca apical em R5-M1, isto é, a faixa apical com 3 manchas, ou quando presente, bem menor que a mancha em R4-R5; unco largo e bítido . . . . . . . . . . . . . . Protelhella

- Asa anterior com mancha branca apical em R5-M 1 sempre mais larga que a em R4-R5, isto é, a faixa apical com 4 manchas apicais; unco fino e com dois pequenos dentes terminais . . . . . . . . . . . Parelbella

\section{Microceris Watson, 1893}

Microceris Watson, 1893. Proc. zool. Soc. London. p. 11, 15, pl. 1, fig. 3 (venação).- Mahille, 1903, in Wytsman. Gen.Ins. 17, p. 7, 13.- Mabille \& Boullet, 1908. Ann. Sc. nat., Paris 7: 173, 204.- Mabille, 1912. Lep. Cat. 9, p. 13.- Draudt, 1921, in Seitz. Macrolep. World 5. p. 847.Lindsey, 1925. Amm. ent. Soc. Amer. 18: 92.- Bell, 1934. Jour. N.Y. Ent. Soc. 42: 412 . Evans, 1951. Cat. Amer. Itesp. 1, p. 5, 70.- Henming, 1967. Bull. Brit. Mus. (Nat. Ilist.), Ent.. Suppl. 9: 291.- Lamas, 1969. Biota 7: 326.

Espécie tipo: Pyrrhopyga (sic) microceris Ménétriés, 1855, por designação original.

Diagnose. Tergos abdominais com a parte proximal inteiramente acinzentada; na asa anterior, o comprimento da célula discal menor que $2 \mathrm{~A}$ e menor que 2/3 do comprimento da margem costal; na asa anterior, R4 e R5 anastomosadas na base (Fig. 5); tíbia metatorácica com as escamas externas todas curtas, achatadas e apressas; parte dorso-basal da valva (costa) com processo voltado internamente; edeago com o lóbulo distal lateral esquerdo dirigido dorso-posteriormente; na fêmea, oitavo tergo constituido de duas peças isoladas; esterigma membranoso; tufo anal vermelho.

Descrição. Caracteres masculinos e femininos - Cabeça com a margem 
posterior, em vista dorsal, uniformemente côncava e apenas com pequena concavidade no início do quetosemata, como em Elbella scylla (Fig. 1); vértice e frontoclípeo com manchas e linhas amarelas; índice entre a largura do olho e a distância que o palpo se projeta para frente deste, em vista lateral, igual a 1,84; antenas negras; na asa anterior, R4 e R5 anastomosadas na base (Fig. 5); na asa anterior, a faixa apical com 2 manchas diminutas entre R4 e M l, as manchas em M1-M2, M2-M3 e M3-CuAl entre as faixas mediana e apical; garras tarsais bífidas, com o dente ventral rombudo e mais longo que a metade da parte dorsal (Fig. 3); tíbia protorácica mais longa que a metade do fêmur; tíbia metatorácica, ao menos com o esporão distal maior mais longo que a distância entre as inserções dos dois pares de esporões; tíbia metatorácica rebatida sobre o tarso sobrepassando a articulação entre os segundo e terceiro tarsômeros, mas não atingindo a articulação com o quarto tarsômero; tergos abdominais com a parte proximal inteiramente acinzentada; esternos abdominais com faixas transversais brancas nos segmentos basais, interrompidos pela linha mediana ventral; tufo anal vermelho alaranjado.

Caracteres masculinos - Índice entre a distância interorbital e a projeção do frontoclípeo além da tangente orbital 7,85; frontoclípeo, em vista dorsal, de contorno arqueado, como em Elbella scylla (Fig. 1); índice entre a altura do olho, medida em vista dorsal, e a distância interantenal 1,0; índice entre os comprimentos da haste e da clava antenais 2,59; índice entre o comprimento e a largura máxima da clava antenal 5,13; índice entre os comprimentos da margem costal da asa anterior, medida da base ao ápice em R4, e a haste antenal 2,98; na asa anterior, o comprimento da célula discal menor que 2A; na asa anterior, m-cu distal à perpendicular imaginária à $2 \mathrm{~A}$ que passa pelo início de $\mathrm{R} 1$; índice entre $\mathrm{O}$ comprimento de uma reta da base da célula discal até o meio entre Ml e M3, na margem externa da asa posterior, e o comprimento da base da mesma célula até o ponto de inserção com a discocelular 2,14; asa posterior com a discocelular superior maior que a metade das discocelulares mediana e inferior, mas não sobrepassando-as; asa posterior com o ângulo formado pelas discocelulares e M3 $103^{\circ}$; asa posterior com a área anal muito longa, isto é, 2A sobreposta por um compasso centrado na célula basal ultrapassa Rs por uma distância maior que duas vezes as discocelulares mediana e inferior; tíbia mesotorácica com as escamas externas curtas, achatadas e apressas; tíbia metatorácica com as escamas externas todas curtas, achatadas e apressas; apótises do tegumen presentes, ásperas, dorsais ao unco, retas e $1 / 4$ do comprimento do unco, em vista lateral; unco de terminação simples; gnato de duas peças, mui fracamente esclerosadas, como se fossem prolongamentos das apófises ventrais do unco; extremidade distal do edeago com um lóbulo alongado, lateral esquerdo e dirigido dorso-posteriormente, aparentemente sustentando a vesica; parte dorso-hasal da valva (costa) com uma projeção virada para dentro; valva não terminando em processo transversal.

Caracteres femininos - Índice entre os comprimentos da haste e da clava antenais 2,65; índice entre os comprimentos da margem costal da asa anterior, medida da base até o ápice em R4 e da haste antenal 3,35; oitavo tergo constituido de duas peças isoladas, contíguas na linha mediana dorsal e não unidas ao oitavo 
esterno; esterigma membranoso e ligado por membrana entre e abaixo das partes não contíguas do oitavo esterno também membranoso; corpo da bolsa pouco distinto e em linha reta com o duto.

Etimologia. Nome alusivo às antenas pequenas.

Espécie incluída. 1-Microceris variicolor (Ménétriés, 1855)

\section{Microceris variicolor (Ménétriés, 1855)}

Figs $3,5,10,39,53,54$

Pyrrhopyga (sic) variicolor Ménétriés, 1855. En. Corp. Anim. Mus. Petr. 1, p. 60, 96. Tab. 4. Fig. 9: sexo ?. Minas Gerais. Brasília: Ac. Imp. Scien. St. Petersburg: LECTÓTIPO macho aqui designado (ZIL) |Não exanunado].- Plötz, 1879. Stett. ent. Ztg. 40: 524

Myscelus variicolor: Herrich-Schäffer. 1869. Corr.-Blatt zool.-min. Ver. Regensburg, 23: 167.Kirby, 1871. Sym. Cat. diurn. Lep., p. 587.- Staudinger. 1888. Exot. Tagf., p. 295.

Microceris varicolor; Watson. 1893. Proc. zool. Soc. London, p. 15.- Mabille \& Boullet. 1908. Amn. Sc. nat., Paris 7: 204-- Mahille. 1912. Lep. Cat. 9: 13.- Draudt. 1921, in Seitz. Macrolep. World p. 847, pl. 164e.- Lindsey, 1925. Amn. Ent. Soc. Amer. 18: 92.- Bell, 1934. Jour. N. Y. Ent. Soc. 42: 412.- Evans, 1951. Cat. Amer. Hesp. 1, p. 70, pl. 8 (genitália masculina).K. Brown \& Mielke, 1967. Jour. Lep. Soc. 21: 158.

Microceris variicolov (sic): Mabille, 1903, in Wytsman. Gen. Ins. 17, p. 13

Diagnose. Frontoclípeo e vértice com linhas transversais amarelas; face dorsal das asas com linha azul ou esverdeada em zigue-zague nas margens; tufo anal vermelho.

Descrição. Macho (Fig. 53 ) - Comprimento da asa anterior entre 20 e $23 \mathrm{~mm}$. Coloração geral negra com uma série de desenhos multicolores; cabeça dorsalmente com linhas amarelas assim distribuidas: uma na parte anterior do frontoclípeo, uma entre as antenas, uma no vértice e atrás das antenas, uma pouco atrás desta, acima do quetosemata e interrompida no meio, uma no colar e outra no meio dos patágios; manchas da mesma cor antes e depois das antenas, junto aos olhos; genas e primeiro e segundo artículos dos palpos amarelo claros; tégulas com linha longitudinal amarela até o mesoscuto e duas linhas amarelas no tórax, nos bordos internos das tégulas até o mesoescutelo; tórax ventralmente amarelo claro nas axilas das asas anteriores e nos meros 2 e 3 ; coxa protorácica com a parte externa como os palpos; fêmur e tíbia protorácicos, tíbia mesotorácica e fêmur metatorácico internamente e tíbia metatorácica externamente esbranquiçados; abdome dorsalmente com as partes basais dos tergos, às vezes, só os proximais, acinzentados e não cortados pela linha mediana dorsal; ahdome com as partes proximais dos esternos acinzentados, mas de extensão muito variável, às vezes só nos segmentos proximais, e cortados pela linha mediana ventral; tufo anal vermelho alaranjado só no último segmento.

Face dorsal da asa anterior com duas faixas finas e amarelas, entre a costa e a margem interna, uma basal e outra sub-basal, esta cortada por Sc e R negras e mais esbranquiçada na célula; uma faixa mediana amarela e semihialina entre a célula e $2 \mathrm{~A}$, às vezes, só até $\mathrm{CuA} 2$, sendo a mancha da célula de largura igual à metade de sua altura e as duas outras manchas em CuA1-CuA2 e CuA2-2A 


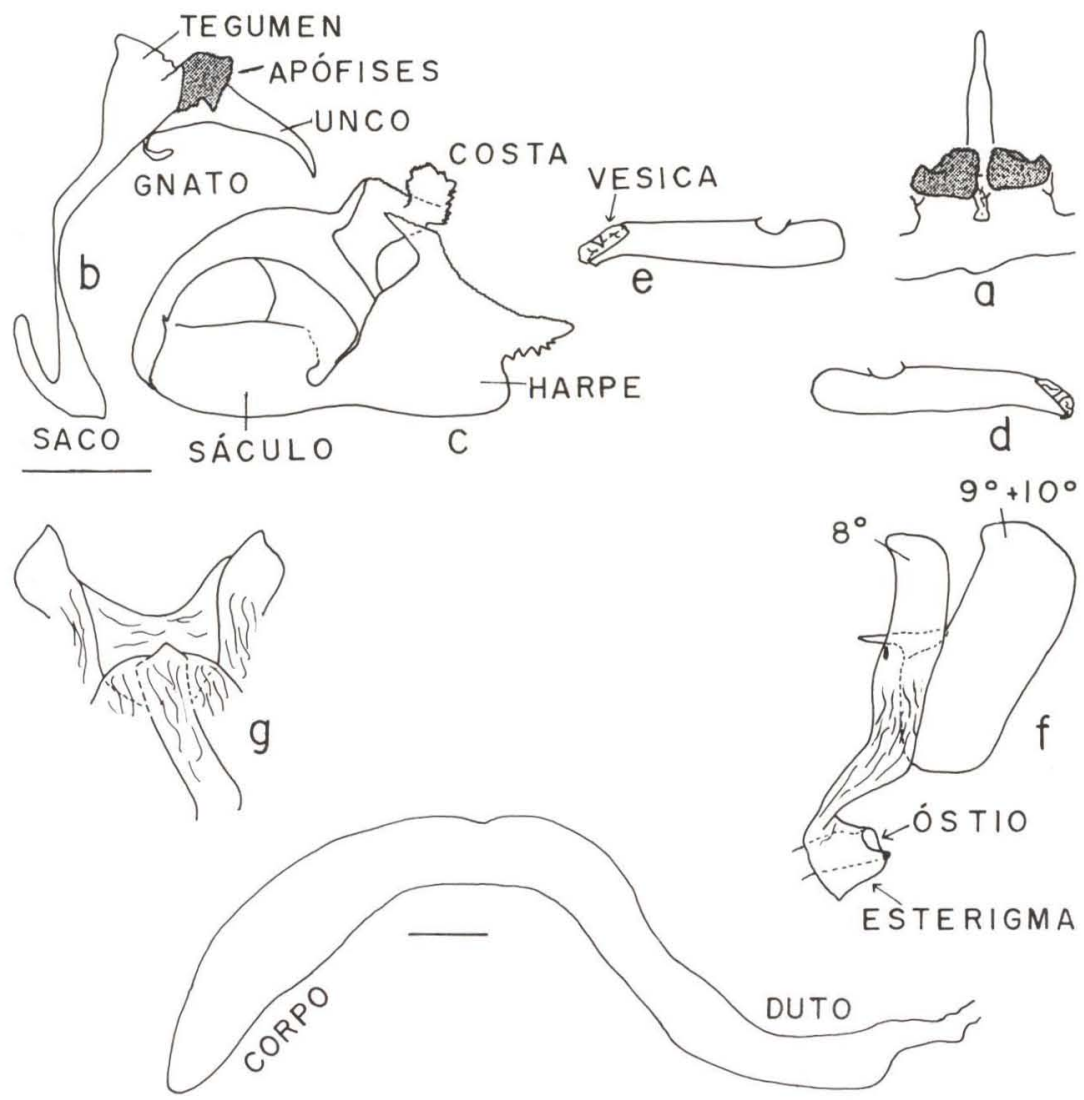

Fig. 10. Microceris varicotor, genitalias masculina e feminina. (a) Vista dorsal do tegumen com apófises e unco; (b) vista lateral esquerda do saco, tegumen com apófises, unco e gnato: (c) vista interna da valva direita: (d) vista lateral esquerda do edeago: (c) vista lateral direita do edeago: (f) vista lateral esquerda do oitavo segmento com esterigma e papila anal, bolsa copuladora destacada abaixo; (g) vista ventral do esterigma e parte do oitavo esterno.

reduzidas, lineares; manchas brancas, finas e semiquadradas, as apicais em R4-R5 e R5-M 1 contíguas, as em M1-M2, M2-M3 e M3-CuAl de largura igual à metade de sua altura, separadas e semiparalelas, a em R3-R4 pouco deslocada para a base e as em Sc-R1, R1-R2 e R2-R3 superpostas, as duas primeiras opacas e a em Sc-R I ocupando só o terço basal das seguintes; discocelulares azuis; na margem costal, acima da faixa discal, com duas manchas amarelas entre a margem costal e Sc e em Sc-R1, sendo a última 1/4 do tamanho da anterior e localizada na base desta; margem externa com linha azul ou esverdeada em zigue-zague, composta em cada espaço de um " $\mathrm{V}$ " com o vértice quase atingindo as manchas apicais e medianas, no espaço $\mathrm{CuA2}-2 \mathrm{~A}$ com dois "V", margem interna com "V" incompleto, constituido de só um traço; franjas inteiramente brancas. 
Face dorsal da asa posterior só com uma linha azul ou esverdeada em zigue-zague na margem externa, composta em cada espaço de um "V" de vértice basal e aproximadamente da metade do comprimento das mesmas manchas na asa anterior entre Rs e 2A, em CuA2-2A com dois "V" e em 2A-3A só o início do "V"; franjas brancas com as terminações das veias negras.

Face ventral da asa anterior como a face dorsal, mas as faixas basal e sub-basal azuis, só presentes na margem costal e esta até a célula; discocelulares azuis; linha azul ou esverdeada da margem externa reduzida às partes do vértice em M1-M2 e M2-M3 e dai aumentando até 2A; margem interna sem linha e mais acinzentada; franjas como na face dorsal.

Face ventral da asa posterior com a linha em zigue-zague da margem externa da face dorsal indicada por escassas escamas azuis ou esverdeadas; com faixa basal fina e difusa, constituida da mesma coloração azul ou esverdeada, entre a margem costal e $2 \mathrm{~A}$ e às vezes com uma faixa mediana, irregular, mais difusa e estreita que a faixa basal, mas de igual coloração, entre $\mathrm{Sc}+\mathrm{R} 1-\mathrm{Rs}$ e a célula; franjas como na face dorsal.

Genitália (Fig. 10). Unco delgado e com uma só ponta; apófises do tegumen truncadas e em vista lateral iguais a 1/4 do comprimento do unco; costa da valva com processo espinhoso encoberto pelo processo dorso-basal da harpe larga e esta com processo distal cuneiforme; edeago com o lóbulo lateral esquerdo dirigido dorso-distalmente.

Fêmea (Fig. 54). Semelhante ao macho. Comprimento da asa anterior 21 a $24 \mathrm{~mm}$. Face ventral da asa posterior só com a faixa basal.

Genitália (Fig. 10). Toda genitália caracteriza-se por ser quase completamente membranosa; óstio constituido por simples tubo com uma pequena projeção ventral esclerosada.

Discussão. Espécie muito bem caracterizada pelos aspectos cromáticos e pelas genitálias masculina e feminina.

Distribuição espacial (Fig. 39). BRASIL - Maranhão: Imperatriz. Goiás: Cavalcante, Chapada dos Veadeiros, Anápolis, Taguatinga. Mato Grosso: Mato Grosso, Rondonópolis, Chapada dos Guimarães 600m, Diamantino 300-400m. Distrito Federal: Brasília 1000m, Planaltina 1000m. São Paulo: Brotas 750m.

Distribuição temporal. Voa nos meses de abril, maio e julho a dezembro.

Etologia. É uma espécie típica do cerrado, sendo que os machos pousam em areias úmidas, de preferência em urina, na beira de rios.

Planta hospedeira. Desconhecida.

Etimologia. Nome alusivo à grande variedade de cores que possue.

Material estudado. BRASIL - Maranhão: Imperatriz, Exp. Departamento de Zoologia leg., 8-VII-1974, I fêmea (UFPC). Goicís: sem local, 1 macho (MNRJ); Cavalcante, 1 macho (MNRJ); Chapada dos Veadeiros, 2 machos (DZPC-OM; MNRJ); Anápolis, 10-XI-1950 1 macho (UFPC-OM); Taguatinga (Santa Maria), 1 macho (UFPC-OM). Mato Grosso: sem local, 1 macho (UFPCOM); Rondonópolis, O. Pinto leg., 28-VIII-1937 2 machos (UFPC, MNRJ); Rondonópolis, I macho (UFPC-OM); Chapada dos Guimarães (Buriti), Ebert leg., 

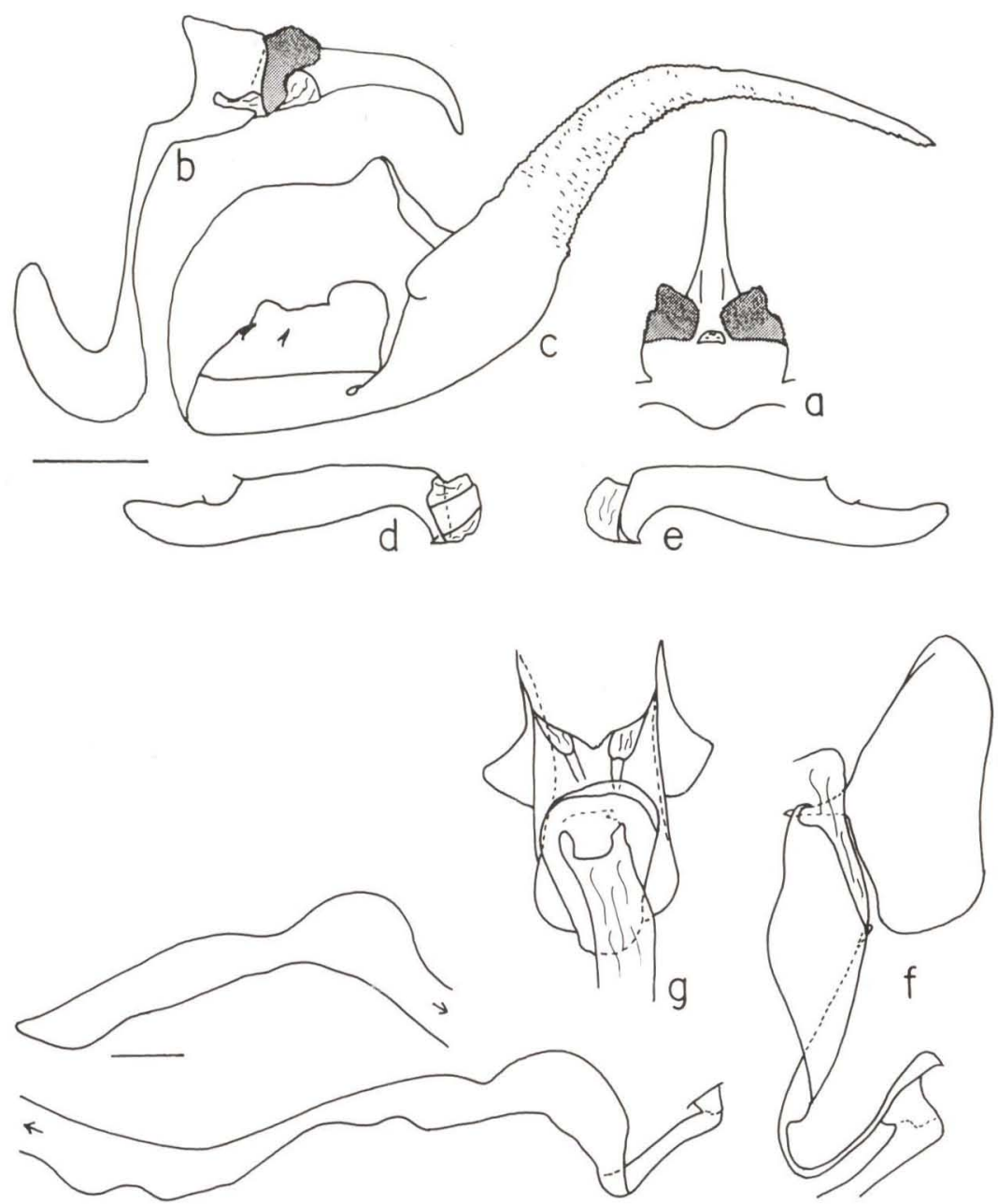

Fig. 11. Elhella meraceta mefiegula, genitalias masculina e feminina. (a) Vista dorsal do tegumen com apótises e unco: (b) vista lateral esquerda do saco, legumen com apófises e unco: (c) vista interna da valva dircita: (d) vista lateral direita do edeago: (e) vista lateral direita do edeago: (t) vista lateral esquerda do oitavo segmento com esterigma e papila anal, bolsa copuladora destacada ao lado: (g) vista ventral do esterigma e parte do oitavo esterno.

8-IX-1973 1 macho (UFPC-OM); Mato Grosso (Alto Rio Juruena, na estrada Cuiabá-Porto Velho), Mielke \& Brown leg., 620m, 5-VII-1972 1 macho (UFPC); Diamantino, Furtado leg., 300-400m, 9-XI-1975 I macho, 15-XI-1975 I macho (UFPC-OM); Diamantino (Fazenda São João), Furtado leg., 300-400m, 9-XI19752 machos (UFPC-OM, UFPC), 31-VIII- 19801 macho (UFPC-OM). Distrito Federal: Brasília, Raw \& Gifford leg., X-1977 1 macho (UFPC); Brasília (Cabę̧a do Veado), Gifford leg., 10-X-1978 I macho (UFPC); Brasília (Fazenda Água 
Limpa), Gifford leg., 25-IX-1979 1 macho (UFPC); Planaltina, Mielke \& Becker leg., 1000m, 4-XII-1982 (UFPC-OM). São Paulo: Brotas (Campo Alegre), Ebert leg., 750m, 1-V-1962 1 fềmea, 21-IV-1963 1 fềmea (UFPC).

Designa-se aqui como LECTótrPo o único síntipo macho no Zoological Institute, Russian Academy of Sciences, St.Peretershurgo, Rússia, ao qual serão anexadas as seguintes etiquetas: / Pyrrhopyga microceris Ménétriés, 1855, Lectótipo, O. Mielke det. 1994/ LECTOTIPO/.

\section{Elbella Evans, 1951}

Elbella Evans, 1951. Cat. Amer. Hesp, 1, p. 4, 38.- Bell, 1953, in Evans. Cat. Amer. Hesp. 3, p. 234.- Hemming, 1967. Bull. Brit. Mus. (Nat. Hist.), Ent., Suppl. 9: 157.- Hayward, 1973. Op. lill. 23: 13.- Beattie, 1976. Rhop. Direct., p. 20.- Okano, 1981. Tokurama 1: 26.- Bridges, 1983. Lep. Hesp., 2 p. 12.- Steinhauser, 1986. Bull. Allyn Mus. 104: 4.- Bridges, 1988. Cat. Fam. Gr. \& Gen. Gr. Nam. 4, p. 41; 5, p. 1.- Bridges, 1988. Cat. Hesp. 2. p. 19: Ap. 2. p. 1.- Llorente, Luiz-Martinez \& Vargas-Fernández, 1990. Publ. esp. Mus. Zool., Mexico 1: 17.J. Maza; White \& R. Maza, 1991. Rev. Soc. Mex. Lep. 14: 9.- R. Maza \& Carbonell, 1992; Rev. Soc. ex. Lep. 15, Add., p. 10.- Lamas: Mielke \& Rohbins, 1993. Jour. Lep. Soc. 47: 82 , etologia.

Hegesippe Evans, 1951. Cat. Amer. Hesp. 1, p. 5, 62.- Bell, 1953, in Evans. Cat. Amer. Hesp. 3, p. 234.- Evans, 1955. Cat. Amer. Hesp. 4. p. 475.- Hemming, 1967. Bull. Brit. Mus. (Nat. Hist.), Ent., Suppl. 9: 209.- Beattic, 1976. Khop. Direct., p. 27.- Bridges, 1983. Lep. Hesp. 2, p. 16.-Bridges, 1988. Cat. Fam. Gr. \& Gen. Gr. Nam. 4, p. 57: 5, p. 1.- Bridges, 1988. Cat. Hesp. 2, p. 26: Ap. 2, p. 1. Syn. n.

Espécie tipo de Elbella: Pyrrhopyga (sic) scylla Ménétriés, 1855, por designação original. Espécie tipo de Hegesippe: Sarbia hegesippe Mabille \& Boullet, 1908, por designação original.

Diagnose. Face dorsal da asa anterior negra ou com manchas amarelas ou alaranjadas, ou com manchas e faixas azuis e brancas, quando com estas, a faixa branca apical com manchas em M1-M2 e M2-M3, tendo a faixa apical cinco manchas, e com mancha branca em M3-CuA1, raras vezes ausente, entre as faixas brancas apical e mediana; tergos abdominais brancos a branco azulados ou amarelos na base, interrompidos na linha mediana, ou negros; unco de terminação simples; apótises do tegumen espessadas, com espinhos, retas, direcionadas para cima do unco; parte dorso-hasal da valva (costa) sem processo virado para dentro; esterigma esclerosado; edeago com o lóbulo distal, lateral esquerdo e dirigido dorso-posteriormente.

Descrição. Caracteres masculinos e femininos - Cabeça com a margem posterior, em vista dorsal, uniformemente côncava e apenas com pequena concavidade no início do quetosemata (Fig. 1); vértice e frontoclípeo com as escamas vermelhas ou com manchas e/ou linhas transversais brancas a levemente azuladas; índice entre a largura do olho e a distância que o palpo se projeta para frente deste, em vista lateral, entre 1,63 e 2,50; antenas negras; na asa anterior R4 e R5 livres (Fig. 6); na asa anterior, quando com manchas e faixas azuis e brancas, a faixa branca apical de 5 manchas entre R3 e M3 e a mancha branca em M3-CuA1 entre as faixas apical e mediana; garras tarsais bífidas, com o dente ventral rombudo e mais curto que a metade da parte dorsal (Fig. 4); tíbia protorácica mais longa que 

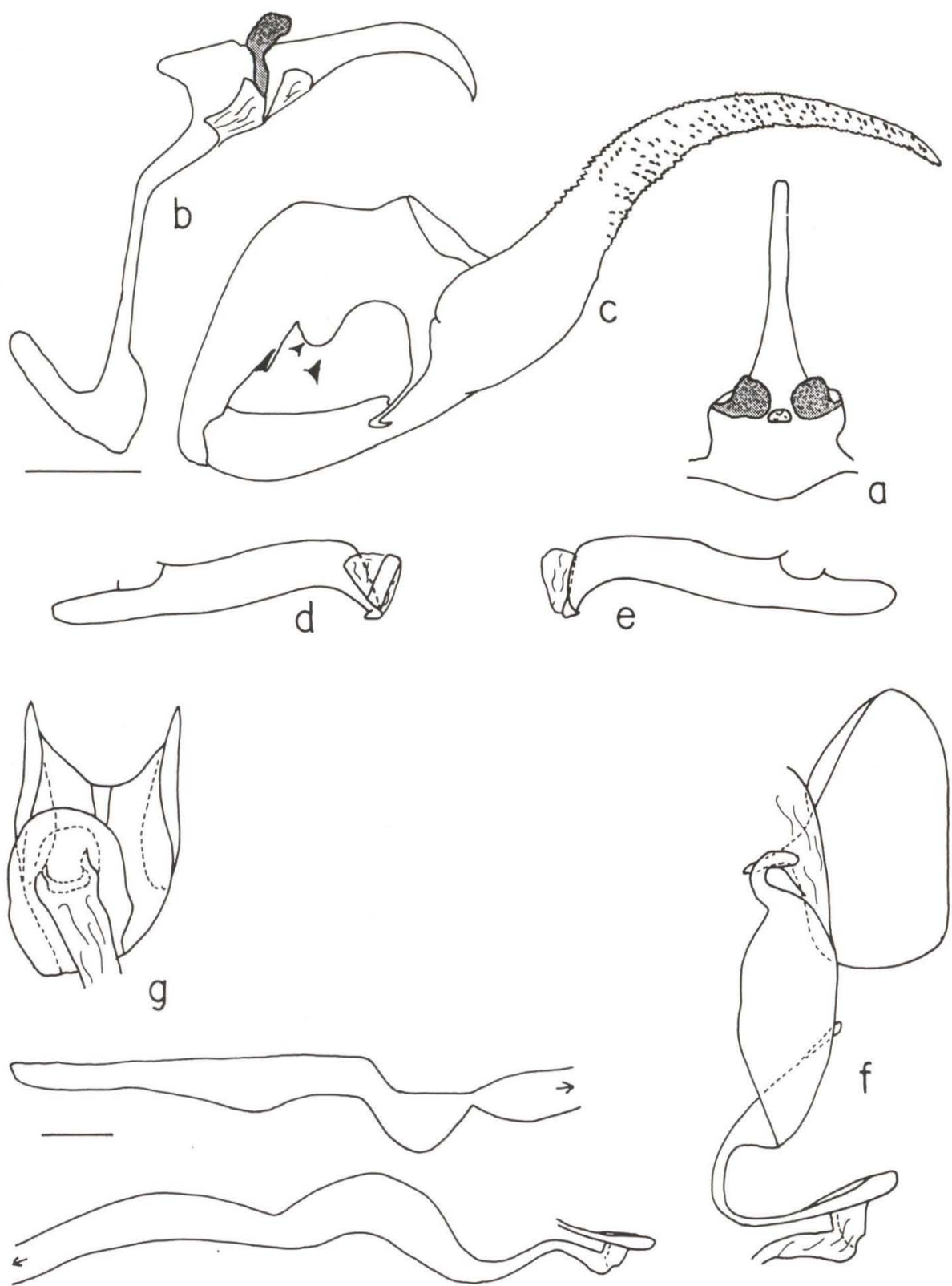

Fig. 12. Elhella lampra lampra, genitálias masculina e leminina. (a) Vista dorsal do tegumen com apófises e unco; (b) vista lateral esquerda do saco, tegumen com apófises e unco: (c) vista interna da valva direita: (d) vista lateral esquerda do edeago; (e) vista lateral dircita do edeago; (f) vista lateral esquerda do oitavo segmento com esterigma e papila anal, bolsa copuladora destacada ao lado; (g) vista ventral do esterigma e parte do oitavo esterno. 
a metade do fềmur; tîbia metatorácica com ao menos o esporão distal maior, mais curto, igual ou mais longo que a distância entre as inserções dos dois pares de esporões; tíbia metatorácica rebatida sobre o tarso atingindo no máximo a articulação entre o terceiro e quarto tarsômeros; tergos abdominais negros ou com manchas branco azuladas ou amarelas, separadas pela linha mediana dorsal; esternos abdominais negros ou com faixas transversais brancas, às vezes interrompidas pela linha mediana ventral; tufo anal negro ou vermelho.

Caracteres masculinos - Índice entre a distância interorbital e a projeção do frontoclípeo além da tangente orbital 4,89 a 9,0; frontoclípeo, em vista dorsal, de contorno arqueado (Fig. 1); índice entre a altura do olho, medida em vista dorsal, e a distância interantenal 1,05 a 1,69; índice entre os comprimentos da haste e da clava antenais 2,56 a 3,59; índice entre o comprimento e a largura máxima da clava antenal 4,06 a 6,0; índice entre os comprimentos da margem costal da asa anterior, medida da base até o ápice em R4, e a haste antenal 2,59 a 3,19; asa anterior com o comprimento da célula discal excedendo o comprimento de $2 \mathrm{~A}$ por uma distância menor que o das discocelulares mediana e inferior; asa anterior com a parte proximal de m-cuantes, coicidente ou posterior à perpen- dicular imaginária à $2 \mathrm{~A}$ que passa pelo início de R1; asa anterior com o índice entre o comprimento de uma reta da base da célula discal até o meio entre Ml e M3, na margem externa, e o comprimento da base da mesma célula até o ponto de inserção com a discocelular 2,02 a 2,76; asa posterior com a discocelular superior muito variável; asa posterior com o ângulo formado pelas discocelulares e $\mathrm{M} 3101^{\circ}$ a $128^{\circ}$; asa posterior com a área anal variável, isto é, 2A sobreposta por um compasso centrado na célula basal alcança ou ultrapassa Rs por uma distância até duas vezes as discocelulares mediana e inferior; tíbia mesotorácica com as escamas externas curtas, achatadas e apressas; tíbia metatorácica com as escamas externas delgadas e divergentes sobrepassando a sua largura; apótises do tegumen presentes, dorsais ao unco, retas, até $2 / 3$ do comprimento do unco em vista lateral; apófises do tegumen ásperas; unco de terminação delgada e simples; gnato ausente; extremidade distal do edeago com lóbulo alongado, lateral esquerdo, dirigido dorsoposteriormente, aparentemente sustentando a vesica; parte dorso-basal da valva (costa) sem projeção; valva não terminando em processo transversal.

Caracteres femininos - Índice entre os comprimentos da haste e da clava antenais 2,10 a 2,91; índice entre os comprimentos da margem costal da asa anterior, medida da base até o ápice em R4 e da haste antenal 3,05 a 3,63; oitavo tergo aparentemente ausente; esterigma fundido ao oitavo esterno ou a ele ligado por membrana; oitavo esterno com as partes laterais unidas ou contíguas por uma grande extensão ou separadas acima do esterigma; esterigma tubular ou anelar e sem lóbulo ou lóbulos dorsais, aparentemente fechando o óstio; oitavo esterno sem processos laterais; corpo da bolsa pouco distinto e em linha reta ou curvado em relação ao duto.

É um gênero dos mais interessantes entre os Lepidoptera, pois as suas espécies são sempre miméticas com espécies de outros Pyrrhopyginae. Nas descrições das espécies são feitas simples comparações miméticas, uma vez que as razões deste mimetismo ainda não foram estudadas e esclarecidas. 

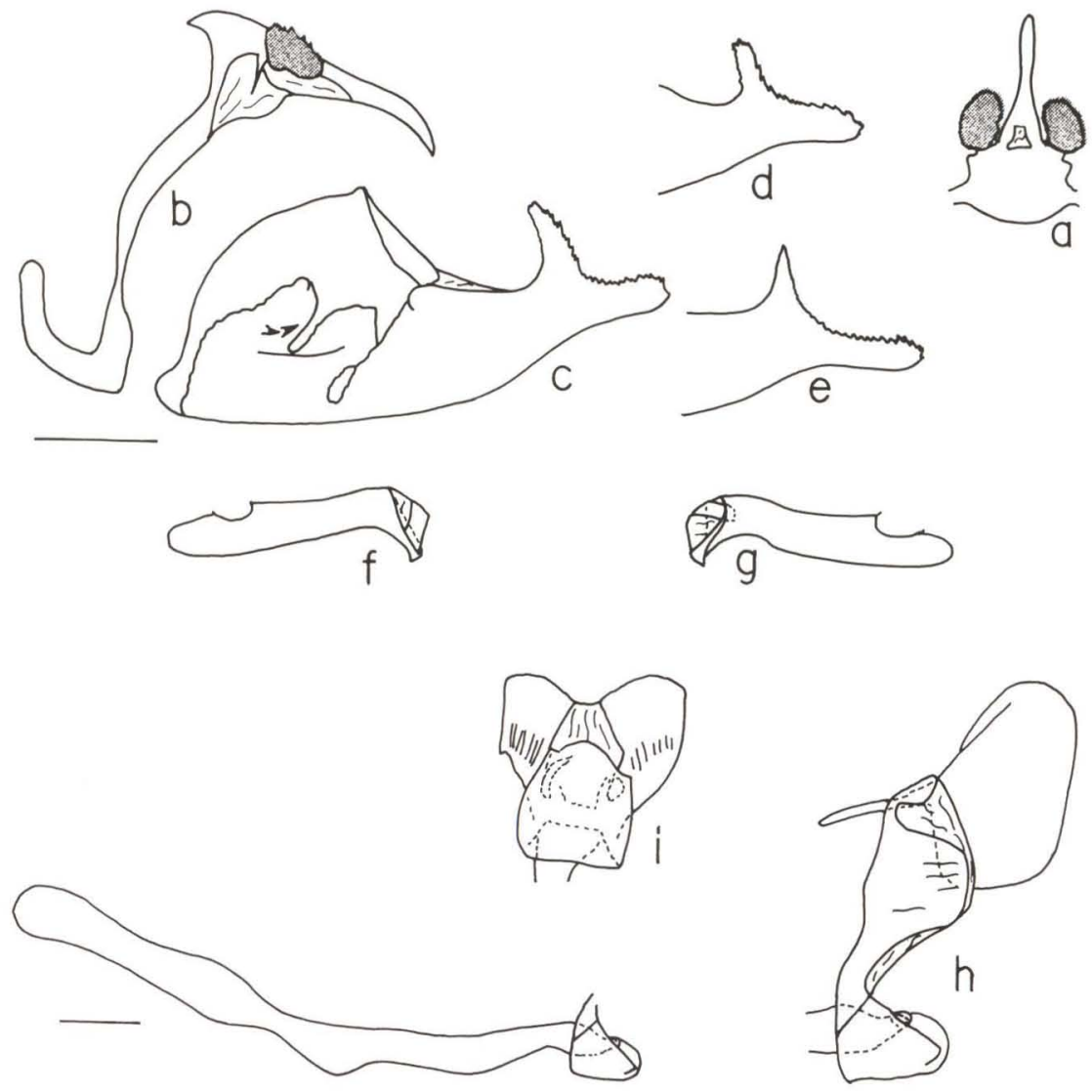

Fig. 13. Elbella mariae molinai, genitália masculina. (a) Vista dorsal do tegumen com apótises e unco: (b) vista lateral esquerda do saco, tegumen com apófises e unco; (c) vista interna da valva direita; (d) idem, variação da ponta distal: (e) idem: (f) vista lateral esquerda do edeago; (g) vista lateral direita do edeago. Elbella mariae marica, genitália feminina. (h) Vista lateral esquerda do oitavo segmento com esterigma e papila anal, holsa copuladora destacada ao lado: (i) vista ventral do esterigma e parte do oitavo esterno.

Discussão. Hegesippe Evans, 1951 é Syn.n. de Elhella Evans, 1951 por não apresentar caracteres que justifiquem a sua segregação. A antena, caráter utilizado por Evans (1951) para separar o gênero, é igual à de Elbella.

Etimologia. Elbella - Nome dedicado a Ernest Layton Bell, famoso especialista do estudo sistemático dos Hesperiidae neotropicais. Hegesippe - Um tautônimo de sua espécie tipo.

Espécies e subespécies incluídas:

1.1. Elbella intersecta intersecta (Herrich-Schäffer, 1869)

2. Elbella intersecta peter Evans, 1951

3. Elbella intersecta paraensis Mielke, ssp.n. 
4. Elbella intersecta rufitegula Mielke, ssp.n.

5. Elbella intersecta strova Evans, 1951

6. Elbella intersecta losca Evans, 1951

2.1. Elhella viriditas viriditas (Skinner, 1920), comb.n.

2. Elbella viriditas chia Evans, 1951, comb.n.

3. Elbella viriditas boliviana Mielke, ssp.n.

3.1. Elbella lampra lampra (Hopffer, 1874)

2. Elbella lampra albociliata Mielke, ssp.n.

4.1. Elbella mariae mariae (Bell, 1931)

2. Elbella mariae molinai (Hayward, 1940), nom.rev., comb.n., stat.n.

5. Elbella adonis (Bell, 1931)

6. Elbella scylla (Ménétriés, 1855)

7. Elbella dulcinea (Plötz, 1879)

8. Elbella luteizona (Mabille, 1877)

9. Elbella hegesippe (Mabille \& Boullet, 1908), comb.n.

10. Elbella iphinous (Latreille, [1824])

11. Elbella miodesmiata (Röber, 1925), stat.rev.

12. Elbella rondonia Mielke, sp.n.

13. Elbella madeira Mielke, sp.n.

14. Elbella bicuspis Jong, 1983

15. Elhella etna Evans, 1951

16.1. Elbella patroclus patroclus (Plötz, 1879), sp.rev.

2. Elbella patroclus acala Evans, 1951

17.1. Elbella azeta azeta (Hewitson, 1866)

2. Elbella azeta giffordi Mielke, ssp.n.

18. Elbella lustra Evans, 1951, stat.n.

19. Elbella merops (Bell, 1933)

20. Elbella theseus (Bell, 1933)

21. Elbella blanda Evans, 1951, stat.n.

22.1. Elbella patrobas patrobas (Hewitson, 1857)

2. Elhella patrobas mexicana Mielke, ssp.n.

3. Elbella parrobas evansi Mielke, ssp.n.

4. Elhella patrobas melanina (Mabille \& Boullet, 1908)

5. Elbella patrobas tingo Mielke, ssp.n.

6. Elbella patrobas amazonica Mielke, ssp.n.

\section{Chave para as espécies de Elbella}

Não foram examinadas fềmeas de bicuspis e miodesmiata.

1.Tufo anal vermelho; face dorsal das asas negras com reflexos azulados, esverdeados ou acinzentados, ou com manchas amarelas . . . . . . . 2

- Tufo anal negro; face dorsal das asas negras, as anteriores com manchas brancas, 
azuis ou alaranjadas . . . . . . . . . . . . . 11

2. Frontoclípeo e vértice vermelhos . . . . . . . . . . . . . .

- Frontoclípeo e vértice negros, com pontos e linhas brancas . . . . . . . . 10

3. Asa anterior com manchas amarelas, às vezes, só indicadas . . . . . . . 4

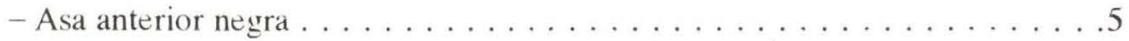

4. Asa posterior com franjas amarelas; segmento pre-anal só com algumas escamas

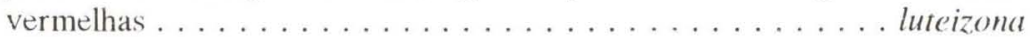

- Asa posterior com as franjas castanho claras; segmento pre-anal vermelho . . . hegesippe

5. Asa posterior, normalmente também a anterior, com as franjas brancas . . .6

- Asas posterior e anterior com as franjas amarelas . . . . . . . . . . . 9

6. Coxa protorácica inteiramente vermelha; harpe longa, levemente sinuosa e com projeção dorso-basal; esterigma tubular . . . . . . . . . . . . adonis

- Coxa protorácica negra ou só parcialmente vermelha; harpe e esterigma diferente

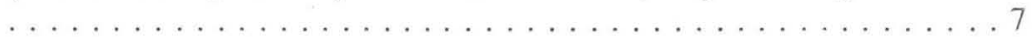

7. Coxa protorácica parcialmente vermelha; harpe bífida; esterigma globoso ...

mariae

- Coxa protorácica negra; harpe longa, sinuosa; esterigma anelar . . . . . .8

8. Asa anterior com o ângulo apical de aproximadamente $38^{\circ}$ no macho e de $40^{\circ}$ na fêmea; Panamá até Bolívia, Venezuela, Guianas e Brasil (Norte até o Espírito Santo, Minas Gerais e São Paulo, não no litoral) . . . . . intersecta

- Asa anterior com o ângulo apical de aproximadamente $45^{\circ}$ no macho e de $50^{\circ}$ na fêmea; Brasil (litoral do Rio de Janeiro até Santa Catarina, oeste de Santa Catarina e Rio Grande do Sul), Paraguai e Argentina (Misiones) . . lampra

9. Asa posterior com as franjas lisas ou crenuladas, neste caso com os patágios vermelhos; harpe longa, sinuosa; esterigma anelar . . . . . . . viriditas

- Asa posterior com as franjas crenuladas pelas veias negras na sua base; patágios negros; harpe larga e com fortes espinhos na ponta distal; esterigma anelar e com ponta distal . . . . . . . . . . . . . luteizona

10. Asa posterior com a margem externa côncava e finamente branca . . dulcinea - Asa posterior com a margem externa reta a convexa e não branca . . . . scylla 11. Asa anterior com grandes manchas alaranjadas . . . . . . . iphinous

- Asa anterior com manchas brancas semihialinas e as asas anterior e posterior com manchas e faixas azuis (espécies só identificáveis pelo exame da

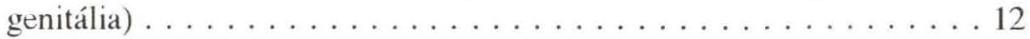

12. Harpe longa e sinuosa, terminando em ponta fina; esterigma anelar, simples theseus

- Outra combinação de caracteres . . . . . . . . . . . . . . . 13

13. Harpe alongada e terminando de modo alargada; esterigma anelar e com pequena projeção posterior . . . . . . . . . . . . merops

- Outra combinaçạ̃o de caracteres . . . . . . . . . . . . . . . . 14

14. Harpe aproximadamente retangular na base e com grande processo dorso 
posterior, mais de três vezes maior que a largura basal da harpe; esterigma tubular e em vista ventral diminuindo gradualmente para a ponta distal . 15

- Harpe sem processo dorso-posterior; esterigma tubular, não diminuindo gradualmente para a ponta distal . . . . . . . . . . . . . . . 16

15. Harpe com o processo interno, na base do grande processo dorso-posterior, inserido na margem dorsal; esterigma com o óstio alcançando a metade basal . . . . . . . . . . . . . . . patrobas

- Harpe com processo interno, na base do grande processo dorso-posterior, inserido no meio entre as margens dorsal e ventral; esterigma com o óstio na metade distal . . . . . . . . . . . . . . . . blanda

16. Harpe longa, pouco sinuosa, terminando em ponta fina e com dois processos dorso-basais finos, iguais e dirigidos para fora da valva; genas inteiramente brancas (só um exemplar examinado); edeago com espinhos subterminais em linha, no lado direito . . . . . . . . . . . bicuspis

- Harpe diferente; edeago com carena subterminal no lado direito . . . . . . . 17

17. Harpe longa, reta, terminando em ponta rombuda e se com processo dorsobasal, então dirigido para fora da valva; esterigma tubular e com processo mediano ventral ou tubular, em vista lateral diminuindo de espessura para a ponta distal e a abertura do óstio aparecendo dorsalmente no terço distal

- Harpe diferente, processo dorso-basal sempre dirigido para dentro da valva; esterigma diferente . . . . . . . . . . . . . . . . . . 19

18. Harpe com um, às vezes, dois processos curtos e rombudos dorso-basais dirigidos para fora da valva; em vista dorsal, apófises do tegumen retangulares e côncavas posteriormente; esterigma tubular, com processo mediano ventral . . . . . . . . . . . . . . . . . azeta

- Harpe com lóbulo alargado dorso-basal, não formando um processo nítido; em vista dorsal, apófises do tegumen triangulares; esterigma tubular, em vista lateral diminuindo de largura para a ponta distal e abertura do óstio aparecendo dorsalmente no terço distal . . . . . . . . . lustra

19. Parte basal da harpe larga, aproximadamente retangular; apófises do tegumen, em vista dorsal, cuneiformes e simétricas; na face dorsal da asa anterior as manchas longitudinais azuis, abaixo da faixa branca mediana, curtas e não atingindo o nível basal da mancha branca da célula; fêmea desconhecida . miodesmiata

- Outra combinação de caracteres . . . . . . . . . . . . . . . . . . 20

20. Parte basal da harpe larga, mas não aproximadamente retangular, diminuindo abruptamente para a ponta mais fina; apófises do tegumen, em vista dorsal, alongadas e de margens interna e externa não simétricas; esterigma tubular, com a parte ventral pouco mais projetada que a parte dorsal e ligado às partes laterais do oitavo esterno . . . . . . . . . . madeira

- Harpe diminuindo gradativamente a largura desde a base até o ápice; esterigma diferente . . . . . . . . . . . . . . . . . . . . 21 
21. Apófises do tegumen em vista dorsal, retangulares; harpe muito longa e fina; esterigma tubular com a parte ventro-basal prolongada ligeiramente para baixo e o óstio alcançando a metade basal no lado dorsal . . . . . . . e etna

- Apófises do tegumen, em vista dorsal, triangulares . . . . . . . . . . . . . . 22

22. Harpe com pequena concavidade na parte distal do processo dorso-basal, este duas vezes mais longo que largo; esterigma tubular e o óstio ocupando a metade distal do lado dorsal; partes laterais do oitavo esterno com uma série de pequenas manchas escuras arredondadas . . . . . . . . . . rondonia

- Harpe com acentuada concavidade na parte distal do processo dorso-basal, este três vezes mais longo que largo; esterigma tubular, com a parte ventral pouco mais projetada que a parte dorsal e o óstio terminal; partes laterais do oitavo esterno sem manchas escuras arredondadas . . . . . . patroclus

\section{Descrições das espécies}

Baseado no aspecto cromático das asas, três são os grupos de espécies, cada um mimetizando um outro gênero de Pyrrhopyğinae.

I - Grupo com tufo anal vermelho; espécies miméticas de Pyrrhopyge Hübner, 1819 e Sarbia Watson, 1893.

\section{Elbella intersecta (Herrich-Schäffer, 1869)}

Figs $11,40,55-67$

Diagnose. Vértice, frontoclípeo e segmentos preanal e anal, ou somente este, vermelhos, às vezes reduzido na cabeça; asas inteiramente de diversas nuances negras; asas alongadas: ângulo apical da asa anterior do macho de aproximadamente $38^{\circ}$ e na fêmea de aproximadamente $40^{\circ}$; franjas brancas e/ou negras ao menos na asa anterior; base das tégulas negras ou com poucas escamas isoladas vermelhas ou vermelhas em todo o centro; genitália masculina com a valva muito alongada e sem projeção dorso-basal na harpe; genitália feminina com esterigma em forma anelar.

Descrição. Macho (Figs 55-58) - Comprimento da asa anterior 21 a $26 \mathrm{~mm}$ (normalmente $25 \mathrm{~mm}$ ). Coloração geral negra, com nuances de diversas tonalidades de azul, verde ou cinza; vértice, frontoclípeo (com exceção do centro negro), primeiro e segundo artículos dos palpos, segmentos preanal e anal, ou só este, e, às vezes, as genas, o colar, os patágios, as tégulas com esparsas escamas ou mancha no centro de um vermelho escuro; raras vezes com traços azulados no tórax, ao lado da metade basal e interna das tégulas.

Face dorsal das asas uniformemente negras, com reflexos azulados, esverdeados ou bronze acinzentados, numa subespécie com larga mancha azul clara na asa posterior; franjas muito variáveis na sua extensão entre o ápice e o ângulo anal, às vezes, negras na asa anterior e nas terminações das veias; asa anterior com o ângulo apical de aproximadamente $38^{\circ}$, dando à asa um aspecto pontudo.

Face ventral das asas como a face dorsal ou com uma faixa azul clara 

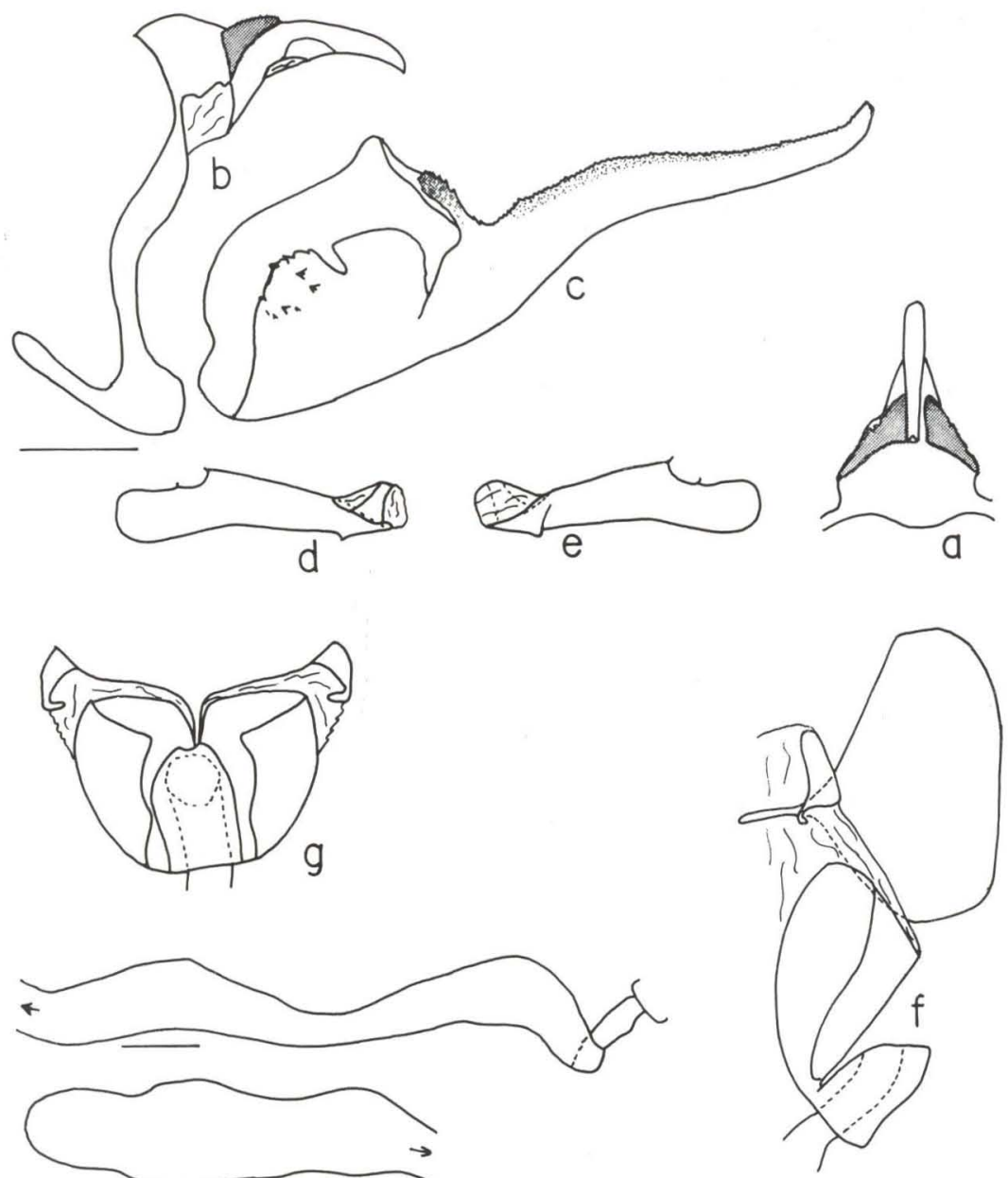

Fig. 14. Elbella adomis, genitálias masculina e feminina. (a) Vista dorsal do tegumen com apótises e unco; (b) vista lateral esquerda do saco, tegumen com apófises e unco; (c) vista interna da valva direita; (d) vista lateral esquerda do edeago; (e) vista lateral direita do edeago; (f) vista lateral esquerda do oitavo segmento com esterigma e papila anal, bolsa destacada copuladora ao lado; (g) vista ventral do esterigma e parte do oitavo esterno.

ocupando a parte basal entre a costa da asa anterior e a margem anal da asa posterior, quando totalmente desenvolvida; no entanto encontram-se exemplares com esta faixa de diversas intensidades, desde praticamente ausente até ocupando mais da metade basal da asa posterior, na asa anterior não ultrapassa o terço basal; quando com azul na face dorsal da asa posterior, na face ventral o azul prolonga-se até a margem externa; franjas como na face dorsal, mas na asa anterior no mínimo com algumas escamas brancas em CuA2-2A. 

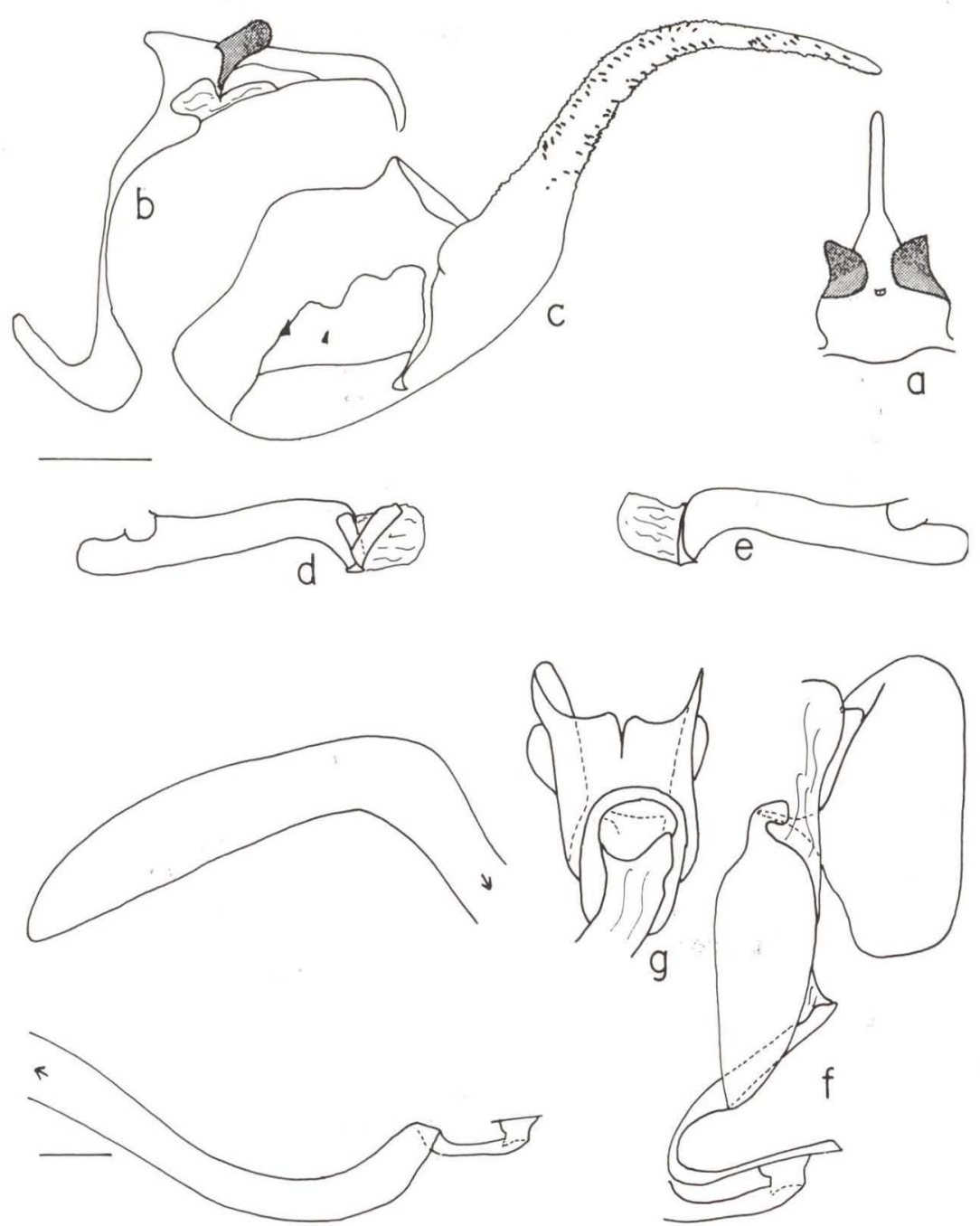

Fig. 15. Elbella scylla. genitálias masculina e feminina. (a) Vista dorsal do tegumen com apófises e unco; (b) vista lateral esquerda do saco, tegumen com apófises e unco; (c) vista interna da valva direita; (d) vista lateral esquerda do edeago; (e) vista lateral direita do edeago; (f) vista lateral esquerda do oitavo segmento com esterigma e papila anal, bolsa copuladora destacada ao lado; (g) vista ventral do esterigma e parte do oitavo esterno.

Genitália (Fig. 11). Caracteriza-se pela valva muito alongada, fortemente sinuosa e sem projeção na parte dorso-basal da harpe; projeção anterior do saco espessada; edeago com o lóbulo distal dirigido dorso-posteriormente e mais largo que a metade da abertura do edeago; ponta distal do edeago curvada ventralmente; apófises do tegumen curtas e espessas, aproximadamente 1/4 do comprimento do 
unco, em vista lateral; unco sem constricção em vista dorsal; ponta da harpe menos recurvada que em lamprus e scylla, suas espécies mais próximas.

Fêmea (Fig. 59). Semelhante ao macho. Comprimento da asa anterior 26 a $29 \mathrm{~mm}$, normalmente 27 a $28 \mathrm{~mm}$. Ângulo apical da asa anterior de aproximadamente $40^{\circ}$. Apresenta as mesmas variações cromáticas do macho.

Genitália (Fig. 11). Esterigma em forma de anel e bordos dorso-posteriores do oitavo segmento unidos, isto é, sem pequena fenda entre as duas partes do oitavo esterno, como em scylla, e em vista ventral visíveis ao nível inferior dos $9^{\circ}+10^{\circ}$ segmentos.

Discussão. Dentro do complexo das espécies próximas de intersecta, isto é, as que possuem a harpe da valva muito alongada e fina e o esterigma em forma de anel, há algumas considerações a fazer sobre as aqui incluídas, ou seja: intersecta, viriditas, scylla, dulcinea, lampra e theseus.

Como todas possuem as mesmas características morfológicas, consideradas importantes, isto é, a estrutura das genitálias masculina e feminina, torna-se necessário utilizar outras características para separar ou agregar as espécies, já que as evidências biológicas ainda não estão disponíveis.

Primeiramente é muito difícil considerar theseus, com as suas largas manchas azuis e brancas nas asas, e cabeça e tufo anal negros (Figs 118 e 119), sinônima de intersecta, esta no lado dorsal inteiramente preta ou assim e com larga mancha azul na face dorsal da asa posterior e cabeça e tufo anal vermelhos, pois ocorrem juntas no mesmo ambiente ao longo dos rios formadores do rio Amazonas, no Peru e Bolívia. As espécies scylla e dulcinea, pela substituição do vermelho da cabeça de intersecta pelas manchas brancas, além da superposição da distribuição geográfica no Panamá e Venezuela de dulcinea e intersecta, estas não devem ser da mesma espécie e ainda dulcinea apresenta pequenas diferenças morfológicas na genitália masculina que a faz ser considerada uma espécie distinta de intersecta e scylla; além disto, scylla e dulcinea ocorrem juntas no México até provavelmente a Nicarágua, dai para a Venezuela, Colômbia e Ecuador só ocorrendo dulcinea. As diferenças nas genitálias dos machos entre scylla e intersecta estão no formato das apófises do tegumen em vista lateral mais longas que largas, na projeção anterior do saco fina e a harpe mais fina na primeira, enquanto que na segunda as apófises do tegumen são curtas, a projeção anterior do saco e a harpe mais espessas. Na genitália feminina, scylla possue uma fenda na junção dos bordos dorsais das partes laterais do oitavo esterno, enquanto que em intersecta nota-se uma ligeira protuberância bilobada. Elbella dulcinea possue as apófises do tegumen curtas, a projeção anterior do saco e a harpe finas e esta menos recurvada; esterigma mais estreito na base em intersecta, enquanto que em scylla e dulcinea da mesma largura.

A separação do grupo formado por viriditas, lampra e intersecta é um pouco mais complicada, pois como dito linhas atrás, também não há informações sobre os dados biológicos. Na coleção do autor há exemplares de intersecta e viriditas coletados na mesma época e local (Bolívia: Caranavi) e que se mostram bem distintos, sem formas intermediárias, razão de serem aceitas aqui como espécies 

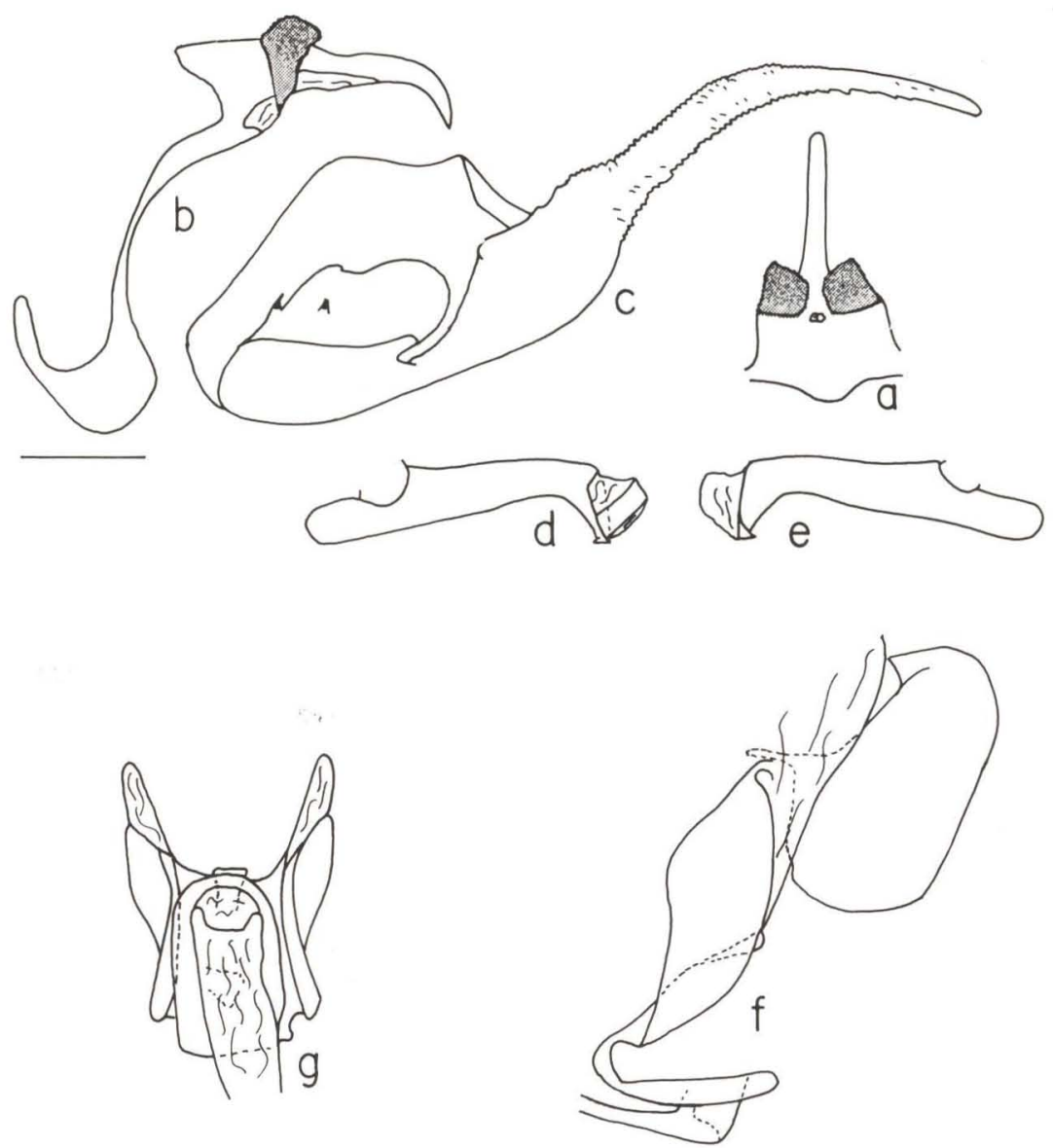

Fig. 16. Elbella dulcinea genitálias masculina e feminina. (a) Vista dorsal do tegumen com apótises e unco; (b) vista lateral esquerda do saco, tegumen com apófises e unco; (c) vista interna da valva direita; (d) vista lateral esquerda do edeago; (e) vista lateral direita do edeago; (f) vista lateral esquerda do oitavo segmento com esterigma e papila anal: (g) vista ventral do esterigma e parte ventral do oitavo esterno.

distintas. Elbella lampra foi mantida como espécie, devido ao seu tipo diferente de asa anterior mais largo e pela distribuição alopátrica, mas muito próxima da de intersecta. Enquanto que lampra ocorre, entre outras localidades, na bacia do rio Paraná no Brasil: Santa Catarina (Seara), Rio Grande do Sul (Guarani) e Paraguai: Itaquiri, localidade esta a aproximadamente $300 \mathrm{~km}$ da coleta de um exemplar de intersecta no Brasil: São Paulo (Teodoro Sampaio). Entre estas duas localidades não há uma separação fitogeográfica, sendo a vegetação igual. As espécies viriditas e lampra também ocorrem muito próximas no Paraguai, onde a parte oriental é bastante uniforme do ponto de vista fitogeográfico. 


\section{Chave para as subespécies}

1. Face dorsal da asa posterior com larga mancha azul clara . . . . . . paraensis

- Face dorsal da asa posterior sem esta mancha . . . . . . . . . . . . . . . 2

2. Tégulas com mancha central vermelha . . . . . . . . . . . rufitegula

- Tégulas sem mancha central vermelha . . . . . . . . . . . . . . 3

3. Asa anterior do macho côncava na margem externa em CuA2-2A; face ventral da asa posterior com a faixa basal normalmente ultrapassando o meio da asa. Brasil: Pará (Belém, Benevides) . . . . . . . . . . peter

- Asa anterior não côncava na margem externa em CuA2-2A; face ventral da asa posterior, quando com faixa, esta não ultrapassa o meio da asa . . . . . . .4

4. Nas duas faces da asa posterior com a margem externa finamente branca antes das franjas; patágios negros, com reflexos azulados . . . . . . . . strova

- Nas duas faces da asa posterior com a margem externa negra, ou quando finamente branca, então os patágios vermelhos . . . . . . . . . . . 5

5. Faces dorsal e ventral das asas negras com reflexos bronze acinzentados; na face ventral das asas anterior e posterior sem faixa azul clara . . . . . losca

- Faces dorsal e ventral das asas negras com reflexos azulados ou esverdeados; na face ventral das asas anterior e posterior, às vezes, com faixa azul clara de intensidade muito variável . . . . . . . . . . . . intersecta

\subsection{Elbella intersecta intersecta (Herrich-Schäffer, 1869)} Figs 40, 55-59

Myscelus intersecta Herrich-Schäffer, 1869. Corr.-Blatt zool.-min. Ver. Regensburg 23: 166; America Tropical; LECTÓTIPO macho aqui designado, sem procedência (ZMHB) [Examinado].

Pyrrhopyge intersecta; Kirby, 1871. Syn. Cat. Diur. Lep., p. 586.- Mabille, 1903, in Wytsman. Gen. Ins. 17, p. 9.- Mabille \& Boullet, 1908. Ann. Sc. nat. 7: 175, 180.- Mabille,1912. Lep. Cat. 9: 4.- Draudt, 1921, in Seitz. Macrolep. World 5, p. 838, pl. 162c.- Bell, 1931. Jour. N. Y. Ent. Soc. 39: 458.- Ureta, 1941. Bol. Mus. Nac. Hist. Nat., Chile 19: 40.- Evans, 1941. Proc. r. ent. Soc. London (A) 16: 23, fig. 1 (genitália masculina).- Williams \& Hayward, 1944. Acta zool. lill. 2: 74.- Hayward, 1947. Acta zool. lill. 4: 211.- Miles Moss, 1949. Acta zool. lill. 7: 34; planta hospedeira.- Silva et al., 1968. Quart. Cat. Ins. viv. Plant. Brasil 2 (1), p. 324. planta hospedeira.

Pyrrhopyga (sic) fluminis Butler, 1873. Cist. Ent. 1, p. 176; Santarém (Bates) e Archidona; syn.: bixae; Cramer; LECTÓTIPO macho aqui designado, Santarém (BMNH) [Examinado].- Butler, 1877. Ann. \& Mag. Nat. Hist (4) 20: 127.- Plötz, 1879. Stett. ent. Ztg. 40: 533; syn.: bixae; Cramer.

Pyrrhopyga (sic) semidentata Mabille, 1877. Pet. Nouv. Ent. 2 (179): 161; E. Peru; Mus. Nat. Paris, Mus, reg. Belg. et P. Mabille; LECTÓTIPO macho aqui designado, Nouv. Grenade, Peru (IRSC) [Examinado].- Mabille, 1878. Amm. Soc. ent. Belg. 21: 14. Syn.n.

Pyrrhopyge fluminis; Kirby, 1877. Syn. Cat. Diurn. Lep., Suppl., p. 821; syn.: bixae; Cramer.Watson, 1893. Proc. zool. Soc. London, p. 12.- Mabille, 1903, in Wytsman. Gen. Ins. 17, p. 8.- Mabille \& Boullet, 1908. An. Sc. nat. 7: 174, 180.- Mabille, 1912. Lap. Cat. 9: 4.- Draudt, 1921, in Seitz. Macrolep. World 5, p. 838, pl. 162c.- Lindsey, 1925. Denison Univ. Bull., Jour. Sc. Lab. 21: 73.- Bell, 1931. Jour. N. Y. Ent. Soc. 39: 456, pl. 38, fig. 39 (genitália 
masculina); syn.: bixae; Cramer, tiribazus Plötz.- Bell, 1934. Jour. N. Y. Ent. Soc. 42: 436.Hayward, 1938. Rev. Ent. 8: 107.- Williams \& Hayward, 1944. Acta zool. lill. 2: 74; syn. bixae; Cramer, tiribazus. - Hayward, 1947. Acta zool. lill. 4: 211; syn.: bixae; Cramer, tiribazus Pyrrhopyga (sic) intersecta: Plötz, 1879. Stett. ent. Ztg. 40: 533.

Pyrrhopyga (sic) tirihazus Plötz, 1879. Stett. ent. Ztg. 40: 533, na sinonímia de fluminis Butler; nom.nud.

Pyrrhopyge semidentata; Mabille, 1903, in Wytsman. Gen. Ins. 17, p. 8.- Mabille \& Boullet, 1908. An. Sc. nat. 7: 174, 180.- Mabille, 1912. Lep. Cat. 9: 4.- Draudt, 1921, in Seitz. Macrolep. World 5, 838.- Bell, 1931. Jour. N. Y. Ent. Soc. 39: 459.- Bell, 1933. Jour. N. Y. Ent. Soc. 41: 267.- Hayward, 1947. Acta zool. lill. 4: 211

Elbella intersecta intersecta; Evans, 1951. Cat. Amer. Hesp. 1, p. 39, pl. 5 (genitália masculina); Syn.: fluminis, tiribazus.- Biezanko \& Ruffinelli, 1962. Rev. Fac. Agron., Montevideo, 50: 150.- Jong, 1983. Tijd. Ent. 126: 236.- Lamas, 1983. Rev. Soc. Mex. Lep. 8: 21, 50, ecologia.K. Brown, 1987. An. Prim. Simp. Pantanal, Brasil, p. 166.

Elbella intersecta semidentata; Evans, 1951. Cat. Amer. Hesp. 1, p. 40.- Bridges, 1983. Lep. Hesp. 1, p. 107; 2, p. 12.- Bridges, 1988. Cat. Hesp. 1, p. 170; 2, p. 19.

Elbella intersecta ilona Evans, 1951. Cat. Amer. Hesp. 1. p. 40; [holó]tipo macho, Goyaz, R. Araguayra (sic); BMNH [Examinado].- K. Brown \& Mielke, 1967. Jour. Lep. Soc. 21: 158. Bridges, 1983. Lep. Hesp. 1, p. 56, 2, p. 12.- Bridges, 1988. Cat. Hesp. 1, p. 88, 2, p. 19 Syn.n.

Elbella intersecta; Bell, 1953, in Evans. Cat. Amer. Hesp. 3, p. 234.- Evans, 1955. Cat. Amer. Hesp. 4, Add., p. 1.- Ebert, 1968, in Silva et al. Quarto Cat. Ins. viv. Plant. Brasil 2 (2), p. 240.- Bridges, 1983. Lep. Hesp. 1, p. 44, 58, 119; 2, p. 12; syn.: fluminis, tiribazus - Bridges 1988. Cat. Hesp. 1, p. 70, 92, 188; 2, p. 19: syn.: fluminis, tiribazus.

(sem gênero) intersecta; Beattie, 1976. Rhop. Direct., p. 169.

(sem gênero) semidentata: Beattie. 1976. Rhop. Direct., p. 256.

(sem gênero) ilona; Beattie, 1976. Rhop. Direct., p. 166.

Diagnose e Descrição. Macho e fêmea (Figs 55-59) - Faces dorsais das asas totalmente negras, com reflexos azulados ou esverdeados; quando com faixa basal na face ventral das asas, esta nunca alcança a metade marginal na asa posterior; quando negra e com reflexos azuis, então o branco das franjas não invade a margem externa na asa posterior; asa anterior do macho não côncava na margem externa em CuA2-2A, isto é, reta; tégulas sem vermelho no centro; quando a faixa basal da face ventral das asas está presente, não alcança a metade marginal na asa posterior; raras vezes com traços azulados no tórax, ao lado da metade basal e interna das tégulas.

É muito variável no aspecto da faixa da face ventral e impossível separar as populações dentro de sua distribuição geográfica. Exemplares totalmente negros, exemplares com faixa totalmente desenvolvida e formas intermediárias ocorrem juntas. A extenção do vermelho no colar, nos patágios e no segmento pré-anal é muito variável em Mato Grosso, sendo que os exemplares de São Paulo possuem o segmento pré-anal, nos machos, e os patágios sempre vermelhos. Alguns exemplares machos de Óbidos e Juruty (Pará) possuem, às vezes, a faixa ventral muito larga como em peter, diferindo desta pela ausência da concavidade na margem externa em $\mathrm{CuA} 2-2 \mathrm{~A}$ da asa anterior.

A subespécie ilona é uma simples variação. 
Distribuição espacial (Fig. 40). Venezuela - Amazonas: Cerro de La Neblina 140m. - ColÔMBIA - Cundinamarca: Bogotá (Nova Granada) (procedência duvidosa). - GuIANA FRANCESA - Caiena: S. Laurent.- SURINAME - Paramaribo: Charles- burg.- ECUADOR - Napo: Rio Coca 300m; Puerto Misahualli; Yanahurco 550m; Cotundo 640m; Napo 550m; Archidona. Pastaza: Mera 1100m; Sarayacu. El Oro: El Pasaje (?). Santiago-Zamora: Macas. Loja: Loja.- PERU - San Martin: Juanjui; Yumbato. Junin: Rio Satipo; Satipo; Perené; Chanchamayo. Huánuco: Cacharas; Tingo Maria 700m. Loreto: Achinamiza; Balsapuerto; Rio Putumayo; Rio Ucayali; Iquitos. Madre de Dios: Parque Nacional de Manu 340m; Tambopata.- Bolívia - La Paz: Rio Chimate 600m; Mapiri 650m; Caranavi 600 1000m.- BRAsIL - Acre. Amazonas: São Paulo de Olivença; Manicoré; São Gabriel; Juruá. Pará: Óbidos; Juruty; Santarém; Parintins; Imperatriz. Mato Grosso: Diamantino; Rondonópolis; Comodoro. Rondônia: Pimenta Bueno; Ouro Preto do Oeste Ariquemes. Mato Grosso do Sul: Pantanal; Corumbá. Goiás: Rio Araguaia. São Paulo: São Paulo; Rio Claro; Campinas; Araçatuba; Teodoro Sampaio; Porto Cabral.

Distribuição temporal. Voa todo o ano, ao menos do Mato Grosso para o norte, enquanto que em São Paulo voa em março, abril e outubro, isto é, no outono e na primavera.

Etologia. É um habitante de florestas, sendo que os machos pousam em areias úmidas na beira dos rios onde haja nutrientes, preferencialmente em urina ou excrementos de aves.

Planta hospedeira. A larva é muito comum em Vismia guianensis (Aublet) Choisy. (Clusiaceae) no Pará (Imperatriz). Possui a cabeça de um vermelho escuro, como é o corpo, porém este com aneis amarelos entre os segmentos; os pêlos que cobrem todo o corpo brancos. A larva vive dentro de uma dobra da folha que ela faz mediante o recorte de uma pequena roda quando na primeira idade ou numa borda de folha maior dobrada ou no último ínstar, pela confecção de um tubo foliar a partir de uma ou duas folhas que permanecem vivas. A alimentação é feita durante a noite. Segundo MiLes Moss (1949) alimenta-se em três espécies de Malpighiaceae.

Etimologia. intersecta - nome alusivo às veias negras nas margens das asas que interrompem as franjas brancas em alguns exemplares; fluminis - alusivo a rio, talvez ao rio Amazonas ou rio Tapajoz, onde se localiza a cidade de Santarém, procedência de um dos síntipos; semidentata - alusivo às veias negras na margem externa da asa posterior que formam pequenos dentes entre as franjas brancas; ilona - provavelmente uma combinação arbitrária de letras.

Material estudado. Um síntipo macho de intersecta, com faixa branca e difusa na face ventral das asas, sem antenas, abdome e procedência, aqui designado LECTÓTIPO e com as seguintes etiquetas: / Coll. Staudinger/ Origin./ Coll. H.-Sch./ intersecta HS/ intersecta [ilegível]/ Intersecta H.-Sch./ LECTOTIPO/ Myscelus intersecta Herrich-Schäffer, 1869, Lectótipo, O. Mielke det. 1993/ Elbella intersecta intersecta, O. Mielke det. 1993/ (ZMHB). Um dos síntipos macho de fluminis, aqui designado LECTÓTIPO e com as seguintes etiquetas: /Braz. 

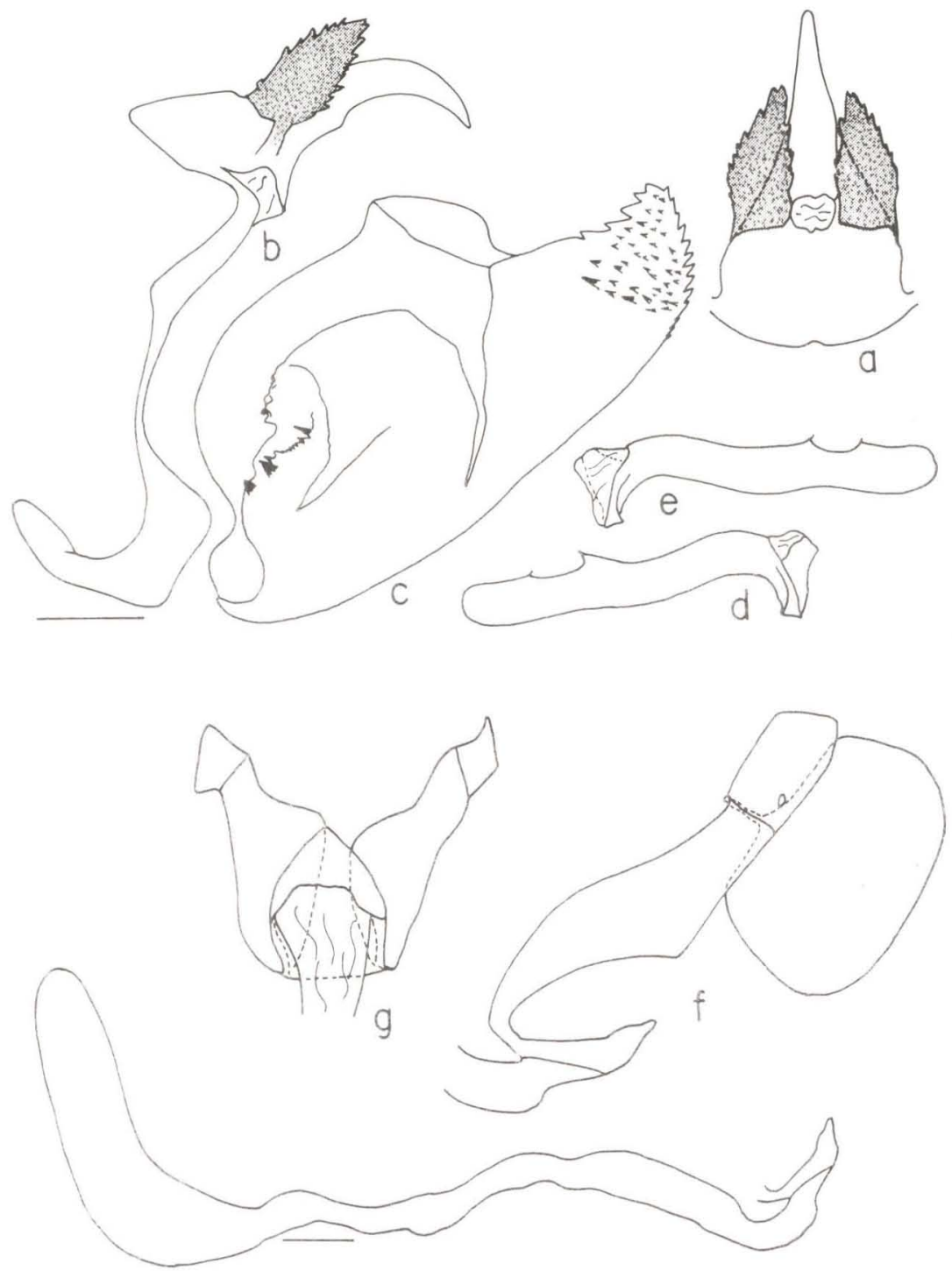

Fig. 17. Elhella luteizona, genitálias masculina e feminina. (a) Vista dorsal do tegumen com apófises e unco: (b) vista lateral esquerda do saco, tegumen com apófises e unco: (c) vista interna da valva direita: (d) vista lateral esquerda do edeago: (e) vista lateral direita do edeago; (f) vista lateral esquerda do oitavo segmento com esterigma e papila anal, holsa copuladora destacada abaixo.

Santarem/Type/ Type/ Santarem Bates 52-96/ LECTOTIPO/ Pyrrhopyga fluminis Butler, 1873, Lectótipo, O. Mielke det. 1993/ Elbella intersecta intersecta, O. Mielke det. 1993/ (BMNH). Um dos síntipos macho de semidentata, aqui 
designado LeCtótiPo e com as seguintes etiquetas: /Type/ Pyrrhopyga (sic) semidentata P. Mab. Perou, Nouv. Grenada/ semidentata P. Mab./ (ilegível) / LECTOTIPO/ Pyrrhopyga semidentata Mabille, 1877, Lectótipo, O. Mielke det. 1993/ Elbella intersecta intersecta, O. Mielke det. 1993/ (IRSC). O [holó]tipo de ilona com as seguintes etiquetas: / R. Araguayra (sic) Prov. Goyaz, June 1906 (G. A. Baer) / Rothschild Bequest B.M. 1939-1/ Type ilona Evans/ cartão com a genitália/ (BMNH). COLÔMBIA - Cundinamarca: Bogotá (AMNH). - VENEZUELA - Terr. Fed. Amazonas: Cerro de la Neblina (Basecamp), Steiner leg., 140m, 2-II-1985, 1 fềmea (USNM). - GuIANA FRANCESA - 1 macho (AMNH); St. Laurent, 1 fềmea (AMNH); Caiena, 1 fêmea (USNM); Caiena (Habitation Vidal), B. Hermier leg., 18-IX-1988 1 macho (UFPC-OM); Caiena (Pointe Macouria), B. Hermier leg., 24-I-1992 1 fêmea (UFPC-OM). - ECUADOR - 3 machos (AMNH). Napo: Rio Coca, Lafebre leg., 300m, VI-1971 4 machos, VII-1971 9 machos (AME); Puerto Misahualli, Jenkins leg., 3 machos (AME); Yanahurco, Lafebre leg., 550m, 24-IX-1978 1 macho, 15-X-1978 1 macho, 6-XI-1978 1 macho, IV-1979 2 machos (UFPC-OM); Cotundo, Lafebre leg., 640m, IV-1979 4 machos, 31-VIII-1979 1 macho (UFPC-OM); Hotel Jaguar, Lafebre leg., 550m, 2-XI-1973 1 macho (UFPC-OM); Archidona, Lafebre leg., 1 macho (UFPC-OM). Pastaza: Mera, Simm leg., $1100 \mathrm{~m}, \mathrm{VII}-19761$ macho (AME); Sarayacu, 1 macho (USNM). El Oro: El Pasaje, Lafebre leg., IV-1971 1 macho (AME) (lado ocidental dos Andes, procedência duvidosa). Morona-Santiago: Macas, 1 macho (AMNH). Loja: Loja, 1 macho (USNM). - PERU - 1 macho (USNM). San Martin: Juanjui, Le Moult leg., XI-1935 1 macho (AME), VIII-1935 1 macho (UFPC-OM); Yumbato, 1 macho (AMNH). Junin: Rio Satipo, 1 macho (AME); Perené, 1 macho (CU); Satipo, Paprzycki leg., 5-13-III-1939 5 machos (UFPC-OM); Chanchamayo, 1 macho (MNRJ). Huánuco: Tingo Maria, VIII-1964 1 macho, XI-1964 1 macho (UFPC-OM), II-1970 1 macho, V-1972 1 macho; Tingo Maria (Rondos), Villegas leg., X-1971 1 macho (UFPC-OM); Tingo Maria, Büche leg., 670m, II-1991 2 machos (UFPC-OM). Loreto: Achinamiza, 13-X-1927 1 macho, 16-X-1927 1 macho (AMNH); Balsapuerto, 1 macho (AMNH); Rio Putumayo, V-1931 1 macho (AMNH); Iquitos, Büche leg., 100m, I-1993 2 machos, V-1993 5 machos (UFPC-OM). Madre de Dios: Parque Nacional de Manu, Robbins, Lamas, Mielke \& Casagrande leg., 340m, 23-IX-1991 1 macho, 26-IX-1991 1 macho, 28-IX-1991 1 macho, 29-IX-1991 7 machos, 10-X-1991 1 macho, 11-X19914 machos, 12-X-1991 1 macho, 17-X-1991 1 macho (USNM, UFPC, MHNL). - BolíviA - La Paz: Rio Chimate, 600m, 12-IV-1926 3 machos (AMNH); Mapiri, 650m, 1-IV-1920 1 macho (AMNH); Caranavi, Tello leg., 600-1000m, IX-X-1988 3 machos, II-III-1989 13 machos (UFPC-OM). - BRASIL - Pará: Óbidos, Pohl leg., X-1931 1 fêmea, XI-1931 1 fêmea, VI-1933 1 macho (MZSP); Óbidos, sem data 1 macho 1 fềmea, 19341 fêmea, 8-XI-1930 1 macho, 16-IX-1950 1 macho (UFPC-OM), 19321 fềmea (UFPC), II-1969 (UFPC-OM); Juruty, Kesselring leg., XII-1971 1 macho (UFPC-OM); Parintins, Pohl leg., X-19331 fêmea (MZSP). Maranhão: Imperatriz, Mielke leg., 27-VII-1974 1 fêmea ex-larvae (UFPC). Amazonas: São Paulo de Olivença, 5 machos (MNRJ), May leg., VI-1935 1 macho (UFPC-OM), V-1961 1 macho (USNM); Manicoré, 1 macho 

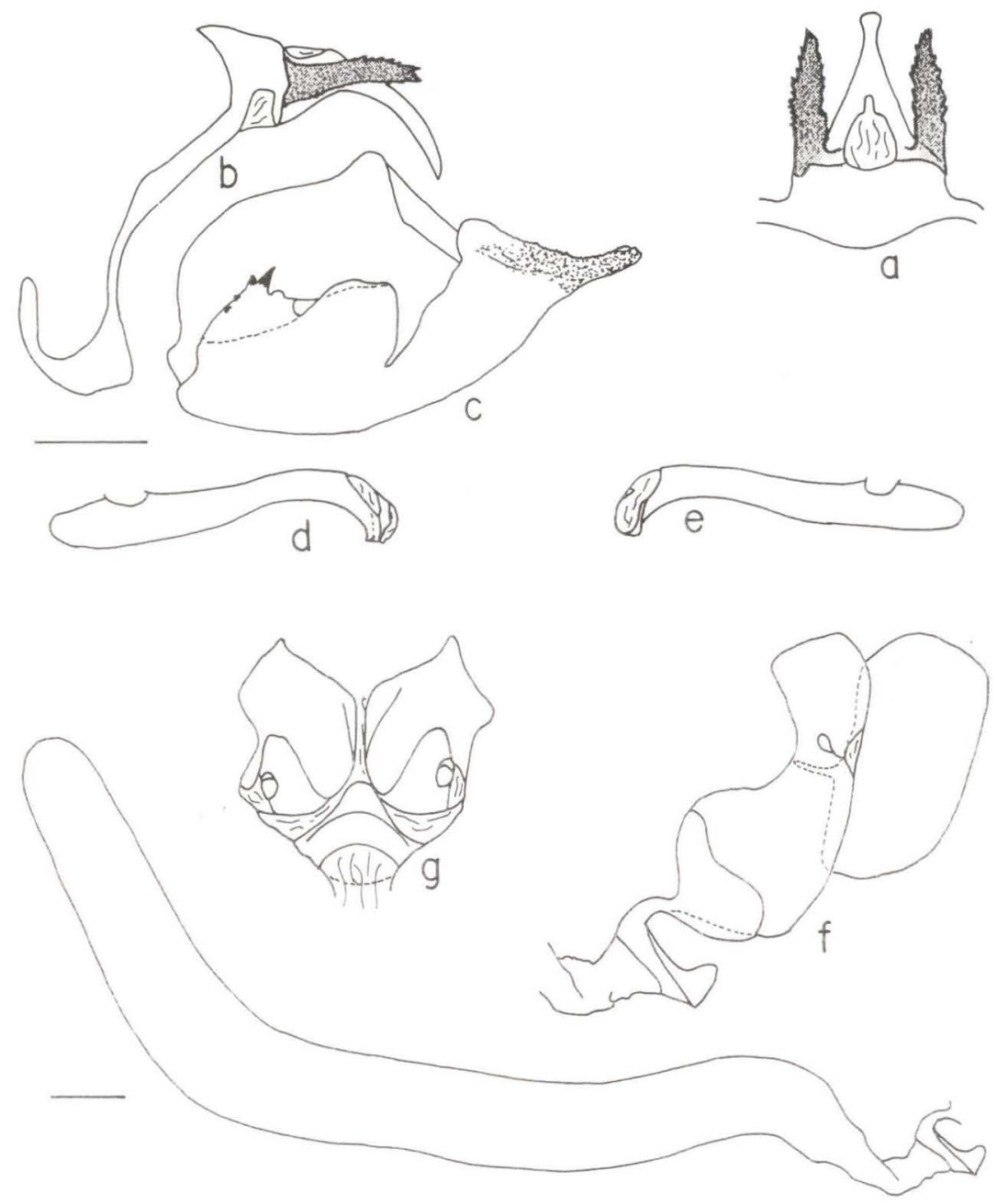

Fig. 18. Elhella hegesippe. genitálias masculina e feminina. (a) Vista dorsal do tegumen com apótises e unco; (b) vista lateral esquerda do saco, legumen com apófises e unco; (c) vista interna da valva direita: (d) vista lateral esquerda do edeago: (e) vista lateral direita do edeago: (f) vista lateral esquerda do oitavo segmento com esterigma e papila anal. bolsa copuladora destacada abaixo; (g) vista ventral do esterigma e parte do oitavo esterno.

(AMNH); São Gabriel (no Rio Negro), 29-XI-1927 1 fềmea (IOC). Acre: 19211 macho (MNRJ). Rondônia: Pimenta Bueno, VIII-IX-1970 7 machos, X-1970 1 macho (UFPC); Ouro Preto d'Oeste, C. Elias leg., 24-31-X-1987 1 macho (UFPC): Ariquemes, Mielke leg., 16-22-VII-1991 (UFPC-OM). Mato Grosso: Diamantino (Fazenda São João), Ebert leg., 300-400m, 28-VIII-1975 5 machos, 30-VIII-1975 2 machos, 8-IX-1979 1 macho (UFPC); Diamantino (Fazenda São 
João), Furtado leg., II-III-1976 1 macho, 23-I-1977 1 macho, 1-II-1977 1 macho, 6-III-1977 1 macho, 26-I-1978 9 machos, 28-I-1978 2 machos, 31-I-1978 1 macho, 4-II-1978 1 macho, 7-II-1978 1 macho, 10-II-1978 9 machos, 14-II-1978 1 macho, 16-II-1978 4 machos, 20-II-1978 3 machos, 24-II-1978 1 macho, 2-III-1978 1 macho, 4-III-1978 1 macho, 28-III-1978 1 macho, 23-IX-1978 1 macho, 27-IX19781 macho e 1 fêmea, 30-VIII-1979 2 machos, 14-IX-1979 1 macho, 30-VIII19803 machos, 31-VIII-1980 2 machos, 20 -IX-1980 1 macho, 19-I-1981 1 macho, 10-II-1982 1 macho, 7-III-1982 1 macho, 7-II-1983 1 macho, sem data 1 macho (UFPC-OM); Diamantino (Fazenda São João), Mielke \& Furtado leg. , 300-400m, 15-I-1978 3 machos, 20-I-1978 2 machos, 21-I-1978 2 machos, 22-I-1978 1 macho, 10-VIII-1978 1 macho, 2-IX-1978 2 machos, 3-IX-1978 2 machos, 6-IX-1978 3 machos, 7-IX-1978 2 machos, 11-IX-1978 7 machos, 31-IX-1978 1 macho, 13-II-1979 3 machos, 19-II-1979 5 machos, 26-II-1979 7 machos, 5-III19794 machos, 21-I-1980 1 macho (UFPC-OM); Rondonópolis, XI-1965 (UFPCOM); Comodoro, Elias leg., 9-III-1988 1 macho (UFPC). São Paulo: São Paulo (Ypiranga), Pohl leg., III-1914 1 macho (MZSP); Porto Cabral, L. Travassos Filho leg., 15-30-X-1941 1 macho (MZSP); Campinas (Santa Genoveva), K. Brown leg., 11-IV-1988 1 macho (UFPC-OM); Teodoro Sampaio (Parque Estadual do Morro do Diabo), Mielke \& Casagrande leg., 300m, 22-25-X-1987 1 macho (UFPC-OM); Rio Claro (Horto Florestal), M. Martins leg., 9-IV-1987 1 fêmea (UFPC-OM); Araçatuba, 1 macho (UFPC-OM).

\subsection{Elbella intersecta peter Evans, 1951}

Figs $40,60,61$

Elbella intersecta peter Evans, 1951. Cat. Amer. Hesp. 1, p. 40; [holó]tipo macho, Belém, Pará; BMNH [Examinado].- Bridges, 1983. Lep. Hesp. 1, p. 92; 2, p. 12.- Bridges, 1988. Cat. Hesp. 1, p. 146; 2, p. 19.

(sem gênero) peter; Beattie, 1976. Rhop. Direct., 230.

Diagnose e Descrição. Macho e fềmea (Figs 60, 61) - Comprimento da asa anterior $25 \mathrm{~mm}$ no macho e $26 \mathrm{~mm}$ na fêmea. A faixa ventral das asas muito larga, ultrapassando o meio da asa posterior; colar, genas e patágios vermelhos; asa anterior do macho com nítida concavidade na margem externa em CuA2-2A e na face ventral da asa anterior com as discocelulares, às vezes, bem definidas por uma linha branca.

Discussão. A validade da subespécie pode ser questionada após mais coletas, pois alguns exemplares masculinos de Óbidos e Juruty (intersecta intersecta) só diferem desta pela ausência da concavidade na margem externa da asa anterior em $\mathrm{CuA} 2-2 \mathrm{~A}$ e pelos patágios negros, mas estes aparecem outra vez vermelhos nos exemplares de Mato Grosso.

Distribuição espacial (Fig. 40). BRASIL - Pará: Belém e Benevides.

Distribuição temporal. Desconhecida; encontrou-se larvas, de todos os ínstares, no mês de agosto em Benevides, município próximo de Belém, mas não foram obtidos adultos. Adultos não foram vistos nos meses de janeiro a abril e agosto, quando o autor coletou na régião. 

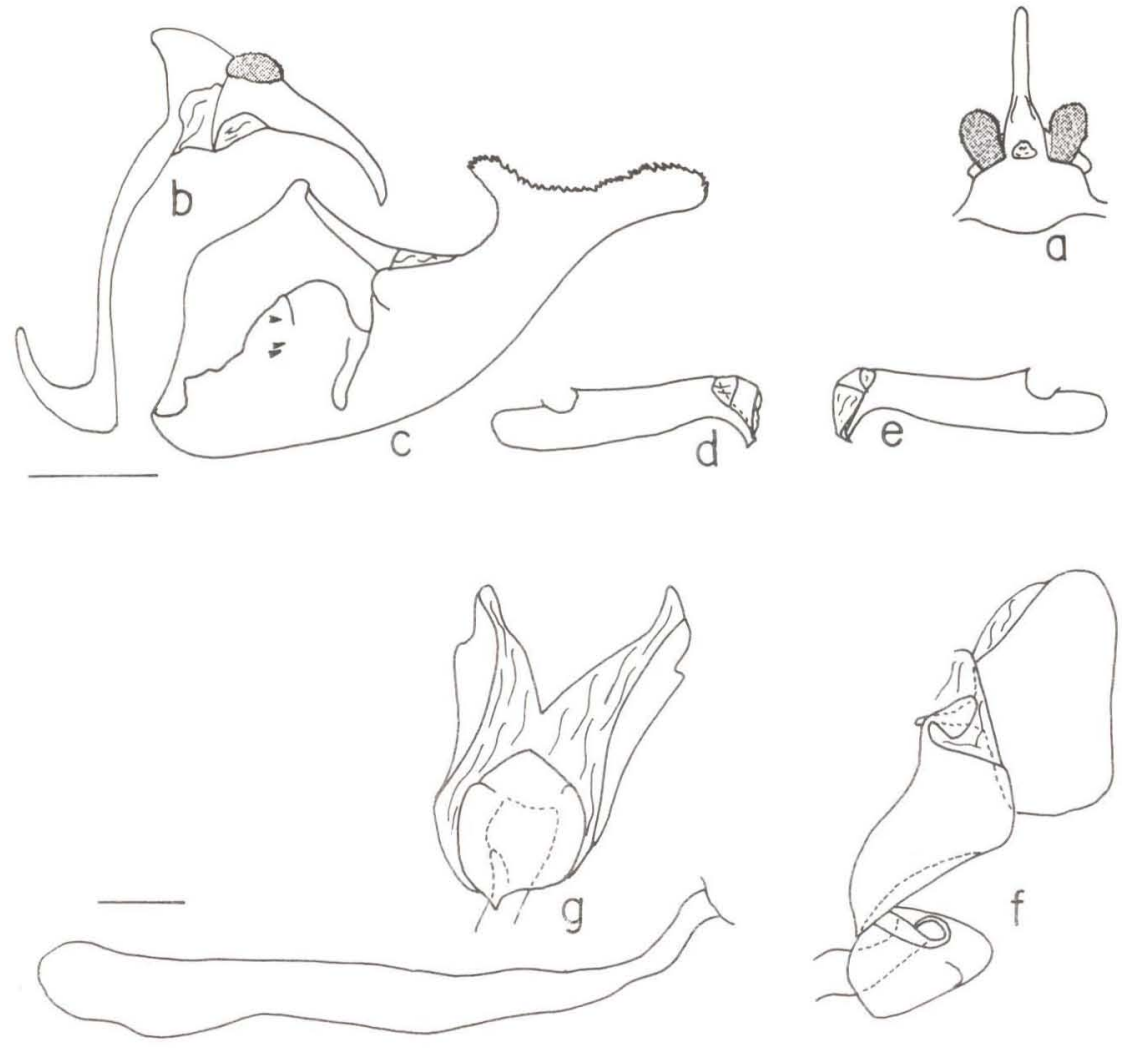

Fig. 19. Elbella iphinous, genitálias masculina e feminina. (a) Vista dorsal do tegumen com apófises e unco; (b) vista lateral esquerda do saco, tegumen com apófises e unco; (c) vista interna da valva direita; (d) vista lateral esquerda do edeago; (e) vista lateral direita do edeago: (f) vista lateral esquerda do oitavo segmento com esterigma e papila anal, bolsa copuladora destacada abaixo; (g) vista ventral do esterigma e parte do oitavo esterno.

Etologia. Desconhecida, mas provavelmente igual à intersecta intersecta. Planta hospedeira. Vismia guianensis (Aublet) Choisy. (Clusiaceae) e Banisteria mossi Morton (Malpighiaceae).

Etimologia. Provavemente uma combinação arbitrária de letras.

Material estudado. O holótipo macho com as seguintes etiquetas: /Type/ Miles Moss Coll. B.M. 1947-453./ P. semidentata ơ Pará garden bord Banisteria mossil. BRASIL - Pará: [Belém] Miles Moss leg., 3 fềmeas (BMNH); Belém, I-1970 1 macho (UFPC-OM). 


\subsection{Elbella intersecta paraensis, ssp.n. \\ Figs 40,62}

Elbella intersecta peter Evans, 1951. Cat. Amer. Hesp. 1, p. 40 (part.).

Diagnose. Face dorsal da asa posterior com larga mancha azul clara.

Descrição. Macho (Fig. 62) - Comprimento da asa anterior 24mm. Face dorsal da asa posterior com larga mancha azul clara na metade externa entre Rs e $\mathrm{CuA} 2$, cortada pelas veias escuras; a margem interna, as proximidades das discocelulares e os espaços $\mathrm{Sc}+\mathrm{R} 1-\mathrm{Rs}$ e $\mathrm{CuA} 2-2 \mathrm{~A}$ com esparsas escamas da mesma coloração; face ventral das asas com faixa basal azul esbranquiçada de $5 \mathrm{~mm}$ de largura na asa anterior e na asa posterior expandida até $2 \mathrm{~mm}$ da margem externa em M1-CuA2, 3mm entre Rs-M1 e 4mm em SC+R1-Rs e CuA2-2A; aqui separada da mancha na margem interna por traço negro no meio de $2 \mathrm{~A}-3 \mathrm{~A}$; colar vermelho; franjas negras na asa anterior, com exceção de algumas poucas franjas brancas em $\mathrm{CuA} 2-2 \mathrm{~A}$ e brancas na asa posterior.

Fêmea. Desconhecida.

Discussão. São conhecidos apenas dois machos, um mencionado por EVANS (1951) como peter, sem procedência, e o aqui estudado. São tão diferentes das demais subespécies que se acredita ser uma subespécie distinta, cuja distribuição geográfica necessita ser elucidada. A julgar pela subespeciação das espécies de Pyrrhopyge Hübner, 1819, paraensis deve ocorrer no Pará e talvez no Maranhão.

Distribuição espacial (Fig. 40). BRASIL - Pará (sem localidade exata).

Distribuição temporal. Desconhecida.

Etologia. Desconhecida; provavelmente igual à intersecta intersecta.

Planta hospedeira. Desconhecida; provavelmente igual à de intersecta intersecta.

Etimologia. O nome refere-se à procedência do holótipo: Pará.

Material estudado. Holótipo macho, com as seguintes etiquetas: / HOLOTYPUS/ Pará/ 11.996/ gen.[itália] prep.[arada] Mielke 1986/ Elbella intersecta paraensis Mielke, Holótipo, O. Mielke det. 1993/ (UFPC-OM). Parátipo: 1 macho, sem procedência (BMNH).

\subsection{Elbella intersecta rufitegula, ssp.n.}

Figs 40, 63, 64

Diagnose. Tégulas com vermelho nas partes basal e central.

Descrição. Macho (Figs 63) - Comprimento da asa anterior $24 \mathrm{~mm}$. Frontoclípeo com escamas vermelhas só junto aos olhos; vértice com linha de escamas vermelhas entre as antenas, sendo assim, o vermelho muito reduzido na cabeça; colar, partes basal e central das tégulas e só o segmento anal vermelhos; asas totalmente negras na face dorsal e na face ventral com escamas azuladas da faixa basal entre Sc e R.

Fêmea (Fig. 64). Semelhante ao macho, porém com as asas mais alongadas. 


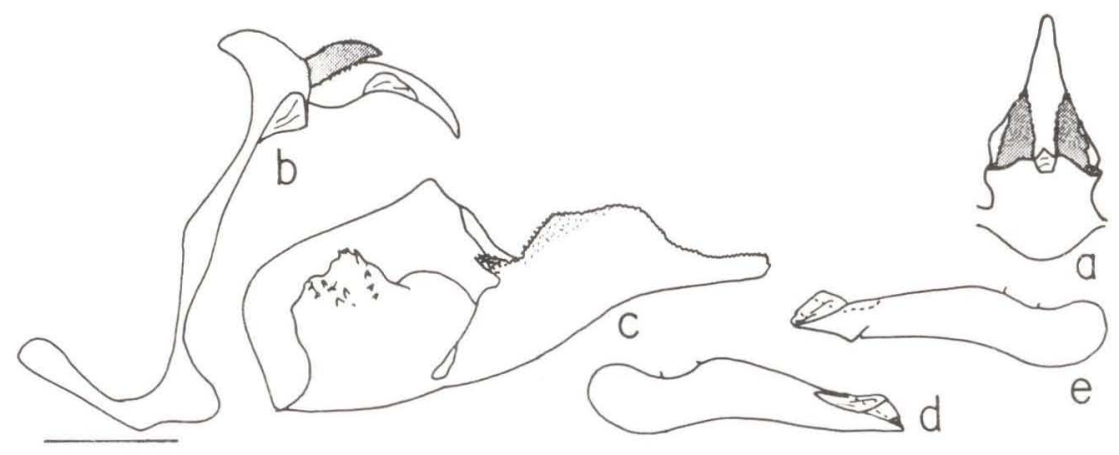

Fig. 20. Elbella miodesmiata. genitálias masculina. (a) Vista dorsal do tegumen com apófises e unco: (b) vista lateral esquerda do saco, tegumen com apótises e unco: (c) vista interna da valva direita: (d) vista lateral esquerda do edeago; (e) vista lateral direita do edeago.

Comprimento da asa anterior 26 a $27 \mathrm{~mm}$. Um exemplar com traços finos azulados no tórax, ao lado do terço basal e interno das tégulas. O azulado da face ventral da asa anterior, às vezes, alcança a costa, a parte adjacente da célula e a parte basal de $\mathrm{Cu}-\mathrm{CuA} 2$. Um exemplar com difusas escamas azuladas na hase da asa posterior.

Discussão. A subespécie caracteriza-se pelos aspectos cromáticos e pela distribuição espacial.

Distribuição espacial (Fig. 40). BRASIL - Pernambuco: Recife; São Lourenço da Mata. Bahia: Uruçuca. Espírito Santo: Linhares; Conceição da Barra. Minas Gerais: Marliéria. Rio de Janeiro: Casemiro de Abreu. vembro.

Distribuição temporal. Voa nos meses de março, abril e agosto a no-

Etologia. É um habitante de florestas. O holótipo foi atraido por papel higiênico molhado com saliva (Técnica de Ahrenholz) (LAMAS et al. 1993 e AUSTIN et al. 1993).

Planta hospedeira. Desconhecida.

Etimologia. O nome refere-se às tégulas parcialmente vermelhas nesta subespécie.

Material estudado. Holótipo macho com as seguintes etiquetas: /HOLOTYPUS/ 8-9-III-1994 Pq. Est. Rio Doce, Marliéria, M[inas| G[erais] 350m, Mielke leg./ Elbella intersecta rufitegula Mielke, Holótipo, O. Mielke det. 1993/ DZ 1876/ (UFPC). Alótipo fềmea com as seguintes etiquetas: /ALOTIPO/ Conceição da Barra, Esp.[írito] Santo, Brasil, 25-X-1969 C. \& T. Elias leg./ Elbella intersecta rufitegula Mielke, Alótipo, Mielke det. 1993/ DZ 2979/ (UFPC). Parátipos: Brasil - Pernambuco: São Lourenço da Mata, Tiuma, Ebert leg., 8-XI-1958 1 fêmea, 2226 (UFPC); São Lourenço da Mata, Kesselring leg., X-1975 1 macho (UFPC-OM); Recife, 6-VIII-1965 1 fêmea, 11676 (UFPC-OM). Bahia: Uruçuca (ex São João Água Preta), IX-X-1928 1 fềmea, 33383 (UFPCOM). Espírito Santo: Linhares, C. Elias leg. . 14-III-1973 1 macho 2982 (UFPC); 
Conceição da Barra, C. \&. T. Elias leg., 10-IV-1968 1 fềmea, 1836 (UFPC). Rio de Janeiro: Casemiro de Abreu (Barra de São João), Tangerini leg., 3-XI-1989 2 machos 1 fềmea, 18-XI-1989 1 macho (UFPC-OM, NT).

\subsection{Elbella intersecta strova Evans, 1951}

Figs 40,65

Elbella intersecta strova Evans, 1951. Cat. Amer. Hesp. 1, p. 40; [holó]tipo macho, Suapure, Venezuela; BMNH [Examinado].- Bridges, 1983. Lep. Cat. 1, p. 113; 2, p. 12.- Bridges, 1988.

Cat. Hesp. 1, p. 178; 2, p. 19.

(sem gênero) strova: Beattie, 1976. Rhop. Direct., p. 264.

Diagnose. Coloração geral das asas negra, com reflexos azulados, sem faixa ventral; o branco das franjas invade a área marginal externa na asa posterior.

Descrição. Macho e fềmea (Fig. 65) - Semelhante à intersecta intersecta. Comprimento da asa anterior $26 \mathrm{~mm}$ no macho e $28 \mathrm{~mm}$ na fêmea. Coloração geral de um negro azulado; vértice, frontoclípeo, colar e segmento anal vermelhos; sem faixa azul esbranquiçada na face ventral das asas; asa posterior nas duas faces com a margem externa finamente branca antes das franjas também brancas; franjas brancas na asa anterior entre M3 e o ângulo anal.

Distribuicão espacial (Fig. 40). PANAMÁ - Chiriqui: Bocas de Toro.VENEZUELA - Bolivar: Suapure.

Distribuição temporal. Voa em Março.

Etologia. Desconhecida; provavelmente igual à intersecta intersecta.

Planta hospedeira. Desconhecida.

Etimologia. Provavelmente uma combinação arbitrária de letras.

Material estudado. O holótipo com as seguintes etiquetas: / Suapure [Bolivar] Venez.[uela] 2-III-[18]99 (Klages) / Rothschild Bequest B.M. 1939-1/ Type strova Evans/ cartão com o preparado da genitália/ (BMNH).- VENEZUELA - Bolivar: Suapure, 21-III-1899 1 fêmea (BMNH).

\subsection{Elbella intersecta losca Evans, 1951 \\ Figs $40,66,67$}

Elbella losca Evans, 1951. Cat. Amer. Hesp. 1, p. 41; [holó]tipo macho, Chapada [dos Guimarães], Mato Grosso; BMNH [Examinado].- K. Brown \& Mielke, 1967. Jour. Lep. Soc. 21: 157. Mielke, 1967. Rev. Bras. Biol. 27: 133.- Bridges, 1983. Lep. Hesp. 1, p. 67; 2, p. 12.- Bridges, 1988. Cat. Hesp. 1, p. 106, 2, p. 19.- Martins, 1993; Trop. Zool. 6: 121; ecologia. (sem gênero) losca; Beattie, 1976. Rhop. Direct., p. 187. Elbella intersecta losca; K. Brown, 1987. An. Prim. Simp. Pantanal, Brasil, p. 166.

Diagnose. Caracteriza-se pelas faces dorsal e ventral das asas de coloração negra com reflexos bronze acinzentados.

Descrição. Macho e fêmea (Figs 66, 67) - Semelhante à intersecta intersecta, diferindo pela coloração geral negra com reflexos bronze acinzentados. Comprimento da asa anterior $24,5 \mathrm{~mm}$ no macho e 25 a $27 \mathrm{~mm}$ na fềmea. Frontoclípeo, vértice, segundo e terceiro artículos do palpo, genas, colar, patágios 

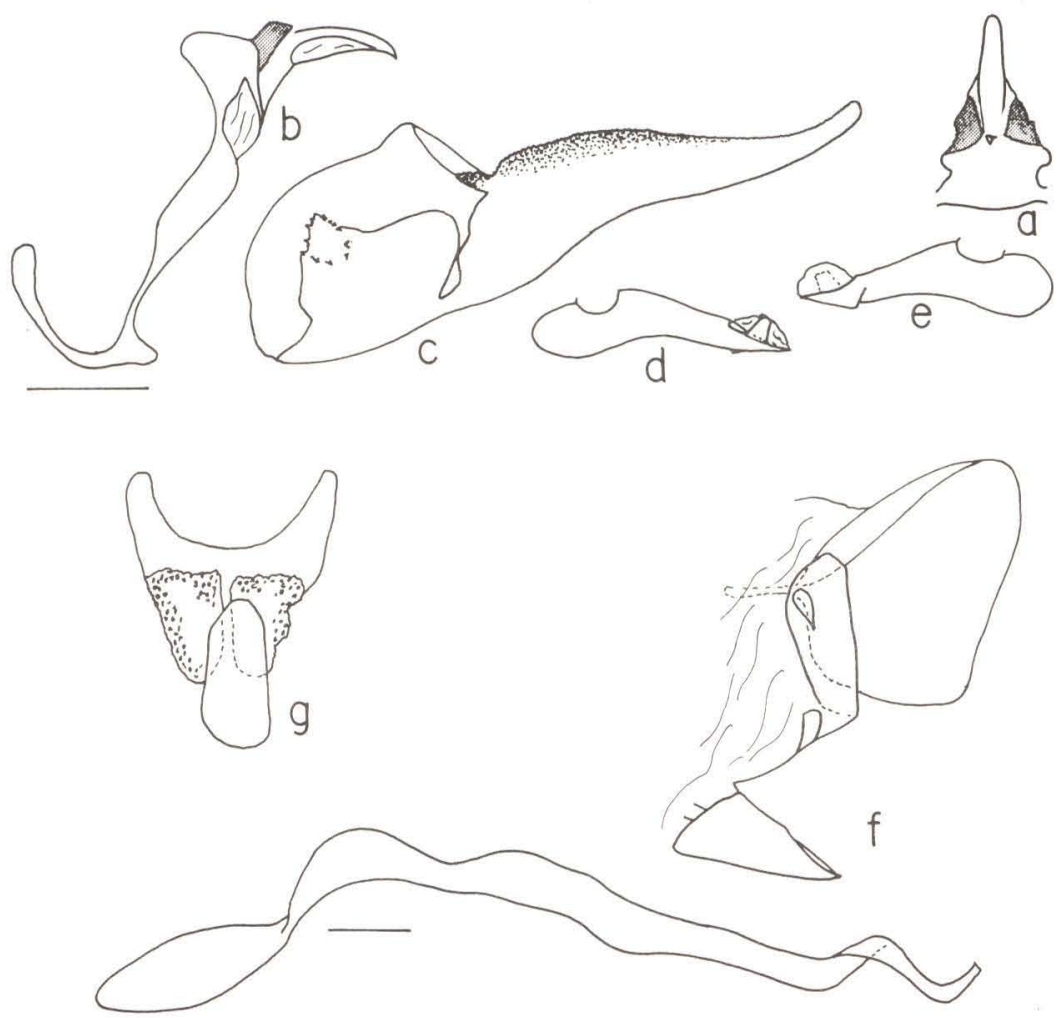

Fig. 21. Elhclla ronkenia. genitália masculina e femmina. (a) Vista dorsal do tegumen com apofises e unco; (b) vista lateral esquerda do saco, tegumen com apófises e unco: (c) vista interna da valva direita: (d) vista lateral esquerda do edeago: (e) vista lateral direita do edeago; (f) vista lateral equerda do oitavo segmento com esterigma e papila anal, bolsa copuladora destacada abaixo; (g) vista ventral do esterigma e parte do oitavo esterno.

e segmentos pré-anal e anal vermelhos; franjas e fino bordo contíguo na asa posterior brancos; sem desenhos na face ventral das asas.

Distribuição espacial (Figg. 40). Brasil - Mato Grosso: Chapada dos Guimarães 700m. Goicas: Vianópolis 1000m. Distrito Federal: Brasilia 1000m. Minas Gerais: Curvelo; Paraopeba 750m; Carmo do Rio Claro; Sete Lagoas: Corinto. Sào Paulo: Rio Claro.

Distribuição temporal. Voa em janeiro, fevereiro, abril e outubro.

Etologia. Frequenta os cerrados e matas de galeria, sendo que os machos pousam em areias úmidas na beira de rios.

Planta hospedeira. Desconhecida.

Material estudado. O holótipo macho com as seguintes etiquetas: / Type/ Jan./Biol. C. A. Lep. Rhop. Pyrhopyge menecrares, Mab./ Chapada, Matto Grosso. H. H. Smith./ Godman-Salvin coll. 1912.-23./ cartão com o preparado 
da genitália/ (BMNH). - Sem procedência, 2 machos (MNRJ).- BRASIL - Mato Grosso: Chapada dos Guimarães (Buriti), Ebert leg., 700m, 27-IV-1978 1 macho (UFPC). Goicis: Vianópolis (Ponte Funda), Tangerini leg., 1000m, 12-X-1966 1 fêmea (UFPC-OM). Distrito Federal: Brasília (Ribeirão da Contagem), Mielke leg., 1000m, 25-II-1966 1 macho (UFPC-OM); Brasília (Fazenda Água Limpa), Gifford leg., 1000m, 9-X-1966 1 macho (UFPC). Minas Gerais: Curvelo, Elias leg., IV-1980 1 fêmea (UFPC); Paraopeba, Mielke leg., 750m, 27-II-1966 1 macho (UFPC-OM); Carmo do Rio Claro, Mielke leg., 19-II-1959 2 machos (UFPC-OM); Sete Lagoas (IPEACO), V. Becker leg., 1 fêmea (UFPC-OM); Corinto, Elias leg., 1-15-X-1979 (UFPC).

\section{Elbella viriditas (Skinner, 1920), comb.n.}

Figs $41,68-72$

Diagnose. Semelhante a intersecta, porém com as franjas amarelas; quando estas crenuladas, então os patágios vermelhos.

Descrição. Semelhante a intersecta, inclusive a genitália. Macho - Comprimento da asa anterior de 23 a $26 \mathrm{~mm}$. Patágios e genas vermelhas ou castanhas, quando só o segmento anal vermelho, então a coloração geral, as genas e os patágios são castanhos, estes, às vezes, com algumas escamas isoladas vermelhas; segmentos anal e, às vezes, o pré-anal vermelhos; tórax sem traços azulados no lado interno da metade basal das tégulas; asas e corpo de várias tonalidades de negro, cinza ou castanho e sem faixas ou manchas brancas ou azuis; franjas amarelas, às vezes fracamente crenuladas na margem externa da asa posterior, quando assim então os patágios vermelhos.

Fêmea. Semelhante ao macho. Comprimento da asa anterior 26 a $27 \mathrm{~mm}$.

Discussão. Veja discussão em intersecta. Esta espécie assemelha-se, pelas franjas amarelas, a um fenótipo de Elbella luteizona em que não há manchas amarelas nas asas. Desta, viriditas difere pelo menor tamanho (até 26 e $27 \mathrm{~mm}$ de comprimento alar no macho e na fêmea, respectivamente) e pelas franjas lisas ou suavemente crenuladas na asa posterior, então os patágios vermelhos.

O exame do holótipo, embora de San Pedro Sula, Honduras, confirmou esta espécie, da qual carriae é um sinônimo.

Esta espécie possui três subespécies.

\section{Chave para as subespécies}

1. Patágios negros . . . . . . . . . . . . . . . . chia

- Patágios vermelhos . . . . . . . . . . . . . . . . . 2

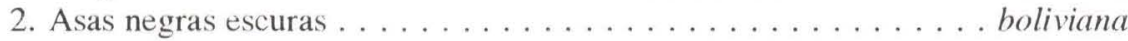

- Asas cinzas esverdeadas . . . . . . . . . . . . . . . . viriditas 


\subsection{Elbella viriditas viriditas (Skinner, 1920), comb.n.}

Figs $41,68,69$

Pyrrhopyge viriditas Skinner, 1920. Ent. News 31: 132: 1 macho |holótipol. San Pedro Sula, Honduras: Acad. Nat. Sc. Philad. |Examinadol (CMP).-Cresson, 1926. Ent. News 37: 249.- Bell. 1931. Jour. N. Y. Ent. Soc. 39: 439.- Evans, 1951. Cat. Amer. Hesp. 1, p. 20--Gillham \& Ehrlich. 1955. Traus. Amer. Ent. Soc. 80: 104-- Steinhauser, 1975. Bull. Allyn. Mus. 29: 32.- Bridges. 1983. Lep. Hesp. 1. p. 125: 2. p. 32.- Bridges, 1988. Cat. Hesp. 1. p. 198, 2. p. 51.

Pyrrhopyge carriae Bell. 1931. Jour. N. Y. Ent. Soc. 39: 459, pl. 38. fig. 40 (genitália masculina); holótipo macho. February, Sapucay, Paraguay. Heinrich leg.; Acad. Nat. Sc. Philad. (CMP) [Examinade]. Syn.n.

Elbella carriae: Evans, 1951. Catt. Amer. Hesp. 1. p. 41. pl. 6 (genitália masculina): syn.: xamhomargo-- Bridges, 1983. Lep. Hesp. 1. p. 22, 127; 2, p. 12; syn : xamthomargo--Bridges, 1988. Cat. Hesp. 1. p. 35. 201: 2. p. 19: syn.: xanthomargo.

(sem gênero) carriae: Beattic. 1976. Rhop. Direct., p. 105

(sem gênero) viriditas; Beattie, 1976. Rhop. Direct. p. 285

Diagnose. Semelhante a intersecta, porém com as franjas amarelo claras, levemente crenuladas na asa posterior; patágios vermelhos; faces dorsal e ventral das asas de um cinza esverdeado.

Descrição. Semelhante a intersecta intersecta. Macho (Fig. 68) - Comprimento da asa anterior 24 a $25 \mathrm{~mm}$. Frontoclípeo, vértice, patágios, genas e segmentos pré-anal e anal vermelhos; faces dorsal e ventral das asas de um cinza esverdeado; franjas levemente crenuladas e fino bordo adjacente da margem externa amarelo claros, mais acentuado na asa posterior.

Fêmea (Fig. 69). Semelhante ao macho, porém com as asas mais alongadas. Comprimento da asa anterior $27 \mathrm{~mm}$.

Discussão. Distingue-se de boliviana e chia pela coloração cinza esverdeada e pelas franjas amarelas claras. Pyrrhopyge xanthomargo Hayward, aceito por EVANS (1951) como sinônimo de carriae, é um sinônimo de luteizona.

Distribuição espacial (Fig. 41). PARAgUaI - San Pedro: Nueva Germânia; Rio Jejuy. Paraguari: Sapucay.

Distribuição temporal. Voa em fevereiro e março.

Etologia. Desconhecida.

Planta hospedeira. Desconhecida.

Etimologia. viriditas - refere-se ao colorido esverdeado das asas; carriae - nome dedicado à esposa de R. C. Wiliams, Jr.

Material estudado. O holótipo fêmea, não macho como mencionado na descrição original, sem abdome, de viriditas com as seguintes etiquetas: / San Pedro Sula [Honduras]/ Type No. 7058 Pyrrhopyge viriditas Skinner/; transferido para o CMP. O holótipo macho de carriae com as seguintes etiquetas: / Sapucay Paraguay II-11-25/ Rodolfo Heinrich/ Holotype Pyrrhopyge carriae Bell 7587 / Det. E. L. Bell/ Genitalia slide No. 1958/; transferido para o CMP.- PARAGUAI - sem localidade exata, 3 machos e 1 fêmea (UFPC-OM); sem localidade exata, Forster leg., 12-III-1905 1 macho (BMNH). San Pedro: Nueva Germania, 2 machos e 1 fềmea (UFPC-OM), 1 macho e 1 fềmea (ZMHU); Rio Jejuy, 1 macho 
(BMNH). Paraguari: Sapucay, W. Forster leg., 1 fêmea (BMNH).

\subsection{Elbella viriditas chia Evans, 1951, comb.n. Figs $41,70,71$}

Elbella intersecta chia Evans, 1951. Cat. Amer. Hesp. 1, p. 40; [holó)tipo macho, Madeira river; BMNH [Examinado].- Bridges, 1983. Lep. Hesp. 1, p. 25; 2. p. 12.- Bridges, 1988. Cat. Hesp. 1. p. 39, 2, p. 19.

(sem gênero) chia: Beattie, 1976. Rhop. Direct., p. 110.

Diagnose. Semelhante a viriditas viriditas, porém com as asas e os patágios castanhos; segmento pré-anal castanho.

Descrição. Semelhante a viriditas viriditas. Macho (Fig. 70) - Comprimento da asa anterior 23 a $24 \mathrm{~mm}$. Patágios castanhos, como toda coloração geral; genas castanhas ou com algumas escamas isoladas vermelhas; segmento preanal castanho; franjas amarelas, mais escuras que em viriditas e mais claras que em boliviana; asa posterior com fina borda externa amarela como as franjas.

Fêmea (Fig. 71). Semelhante ao macho, porém com as asas mais alongadas. Comprimento da asa anterior $26 \mathrm{~mm}$. Genas castanhas.

Discussão. A coloração castanha, sem brilho esverdeado ou azulado, é muito característica da subespécie, assim como as genas castanhas, às vezes, com poucas escamas isoladas vermelhas no macho. A subespécie caracteriza-se pelo aspecto cromático e pela distribuição espacial.

Distribuição espacial (Fig. 41). BRASIL - Amazonas: Rio Madeira; São Paulo de Olivença. Pará: Óbidos.

Distribuição temporal. Desconhecida.

Etologia. Desconhecida.

Planta hospedeira. Desconhecida.

Etimologia. Provavelmente uma combinação arbitrária de letras.

Material estudado. O holótipo macho com as seguintes etiquetas:/ Brazil Madeira R., Amazon R.U. Moffat. 1913-485/ Type chia Evans/ cartão com o preparado da genitália/ (BMNH).- BRASIL - Amazonas: São Paulo de Olivença, 1 macho (UFPC-OM). Pará: Óbidos, 1932, 1 macho (UFPC-OM); Óbidos, 1 fêmea (UFPC-OM).

\subsection{Elbella viriditas boliviana, ssp.n.}

Figs 41,72

Diagnose. Semelhante a viriditas viriditas, porém com as asas de um negro escuro, não cinza esverdeado; franjas pouco mais largas e de um amarelo mais escuro, alaranjado.

Descrição. Semelhante a viriditas viriditas. Macho (Fig. 72) - Comprimento da asa anterior 25 a $26 \mathrm{~mm}$. Faces dorsal e ventral das asas negras com reflexos fracos azuis escuros; franjas e fino bordo adjacente na margem externa, mais acentuadao na asa posterior, amarelo alaranjados. 

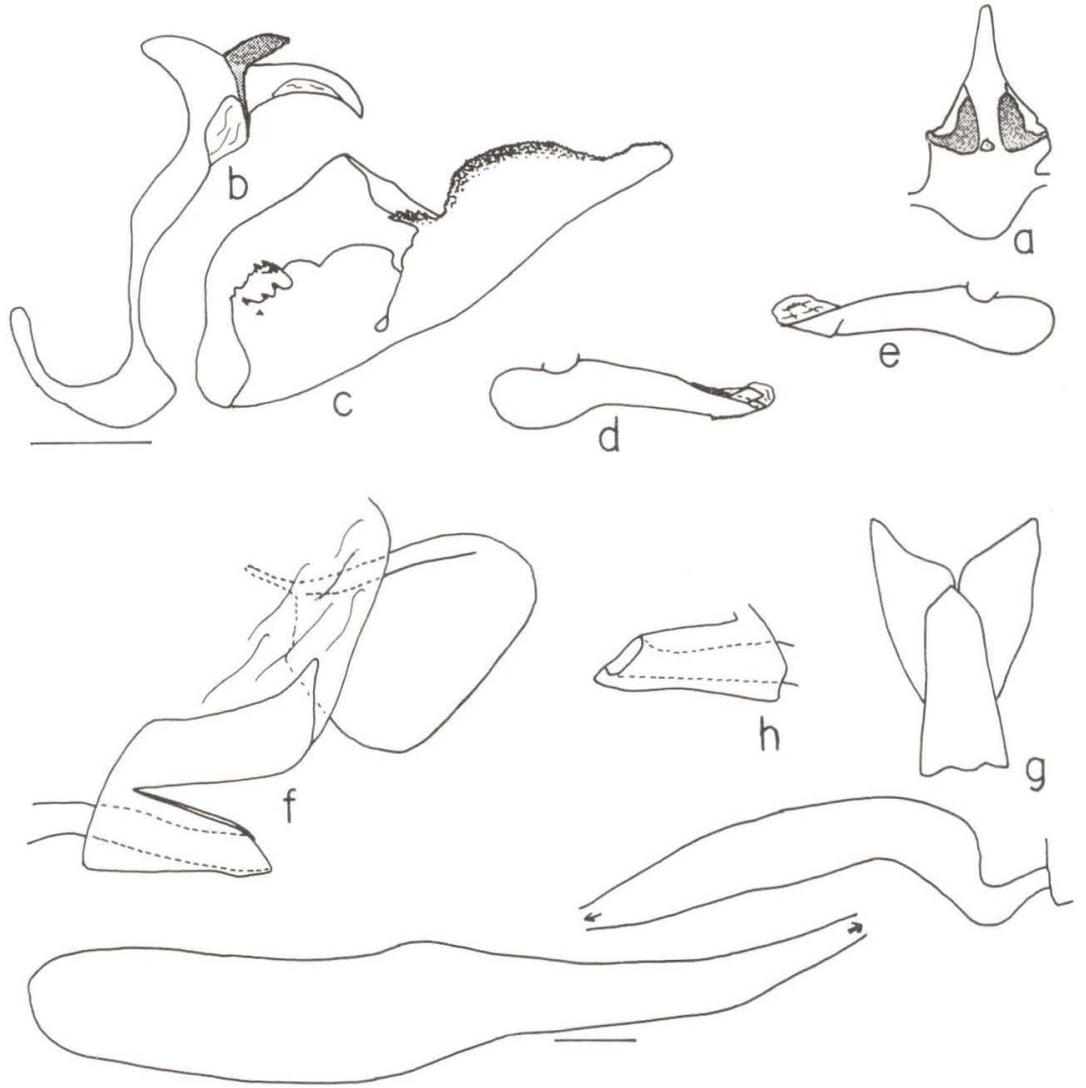

Fig. 22. Elhella meuterat gentalias masculina e feminina. (a) Vista dorsal do tegumen com apófises e unco: (h) vista lateral esquerda do saco. tegumen com apófises e unco: (c) vista interna da valva direita: (d) vista lateral esquerda do edeago: (e) vista lateral direita do edeago: (I) vista lateral esquerda do oitavo segmento com esterigma e papila anal. bolsa copuladora destacada abaixo: (g) vista ventral do esterigma e parte do oitavo esterno: (h) vista lateral direita do esterigma.

Fêmea. Desconhecida.

Discussão. Distingue-se de viriditas e chia pela coloração mais escura, assim como pelas franjas amarelo alaranjadas.

Distribuição espacial (Fig. 41). Bolívia - La Paz: Caranavi (Yungas) 500-1000m; Rio Chimate 600m.

Distribuição temporal. Voa em fevereiro a abril.

Etologia. Desconhecida.

Planta hospedeira. Desconhecida.

Etimologia. O nome refere-se à distribuição geográfica da subespécie.

Material estudado. Holótipo macho com as seguintes etiquetas: / HOLOTIPO/ Caranavi, Yungas, Bolívia, 500 - 1000m. II-III-1989, Tello leg./ 
Elbella viriditas boliviana Mielke, Holótipo, O. Mielke det. 1993/ OM 22.812/ (UFPC-OM). Parátipos: 5 machos com os mesmos dados (UFPC-OM); BolívIA - La Paz: Rio Chimate, 600m, 12-IV-1926 1 macho (UFPC-OM).

\section{Elbella lampra (Hopffer, 1874)}

Figs $12,41,73-76$

Diagnose. Vértice, frontoclípeo, genas, colar, patágios, base das tégulas e segmentos pré-anal e anal vermelhos; asas inteiramente de diversas nuances negras; ângulo apical da asa anterior no macho de aproximadamente $45^{\circ}$ e na fêmea de $50^{\circ}$, dando à asa um aspecto alargado; franjas brancas ou branco acinzentadas na asa anterior e brancas na asa posterior, às vezes, com as terminações das veias escuras; genitália masculina com a valva muito alongada, harpe fina e sinuosa; genitália feminina com o esterigma em forma anelar.

Descrição. Macho - Comprimento da asa anterior 24 a $27 \mathrm{~mm}$. Coloração geral negro azulado ou esverdeado; vértice, frontoclípeo (com exceção de pequeno ponto negro entre as antenas), palpos, genas, colar, patágios, base das tégulas e segmentos pré-anal e anal vermelhos.

Faces dorsal e ventral das asas uniformemente negras com reflexos azulados ou esverdeados; franjas brancas ou branco-acinzentadas na asa anterior e brancas na asa posterior, às vezes com as terminações das veias escurecidas; asa anterior com o ângulo apical de aproximadamente $45^{\circ}$, dando à asa um aspecto alargado.

Genitália (Fig. 12). Caracteriza-se pela harpe muito alongada, fina, sinuosa e sem projeção na parte ântero-dorsal; projeção anterior do saco não espessada; edeago com o lóbulo distal dirigido dorso-posteriormente, mais estreito que a metade da abertura do edeago e a ponta distal do edeago curvada ventralmente; apófises do tegumen curtas, aproximadamente 1/4 do comprimento do unco em vista lateral; unco com ligeira constriç̧ão em vista dorsal; sáculo com dois espinhos, às vezes, com um terceiro espinho mediano (como figurado).

Fêmea. Semelhante ao macho. Comprimento da asa anterior 27 a $32 \mathrm{~mm}$ (normalmente 30 a $31 \mathrm{~mm}$ ). Ângulo apical da asa anterior de aproximadamente $50^{\circ}$. Apresenta as mesmas variações cromáticas do macho.

Genitália (Fig. 12). Esterigma em forma de anel muito semelhante à de intersecta; em vista lateral, os bordos posteriores das duas partes do oitavo esterno unidos e aparecendo embaixo do $9^{\circ}+10^{\circ}$ segmentos.

Discussão. Veja intersecta. Verificam-se ainda pequenas diferenças entre lampra e as demais espécies mencionadas nos aspectos das apófises do tegumen; veja as figuras.

\section{Chave para as subespécies}

1. Asas negras e com reflexos esverdeados; franjas da asa anterior não inteiramente

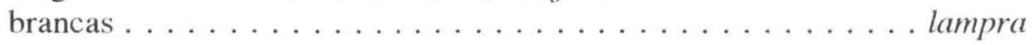
- Asas negras e com reflexos azulados; franjas da asa anterior brancas . albociliata 


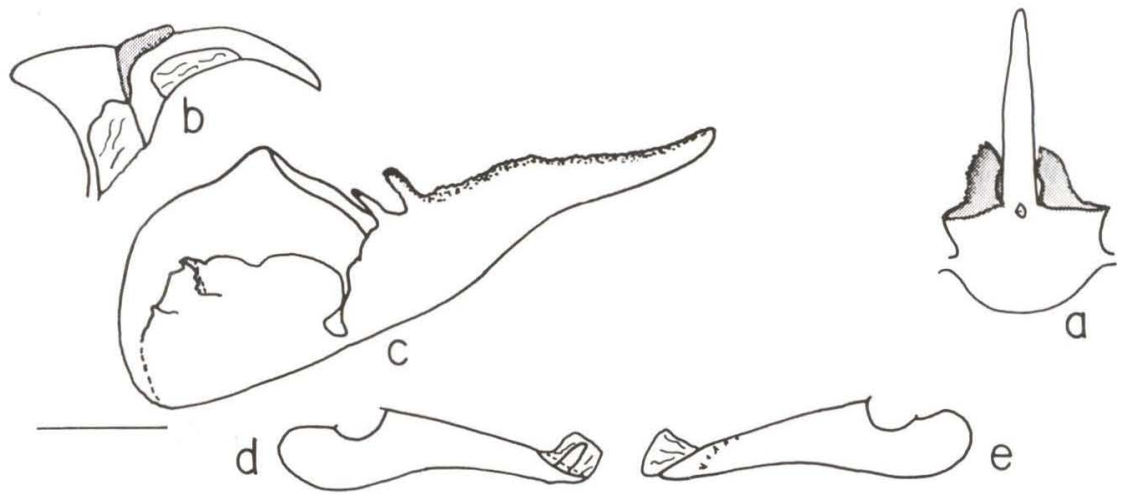

Fig. 23. Elbella bicuspis. genitália masculina. (a) Vista dorsal do tegumen com apotises e unco: (b) vista lateral esquerda do saco, legumen com apófises e unco; (c) vista interna da valva direita: (d) vista lateral esquerda do edeago; (e) vista lateral direita do edeago.

\subsection{Elbella lampra lampra (Hopffer, 1874)}

Figs $12,41,73,74$

Pyrrhopyge lamprus Hopffer, 1874. Stett. ent. Ztg. 35: 370, Brasilien, macho, fềmea: LECTÓTIPO macho aqui designado (ZMHB) [Examinado].- Kirby, 1877. Syn. Cat. Diur. Lep.. Suppl.. p. 821.- Bell, 1931. Jour. N. Y. Ent. Soc. 39: 431.

Pyrrhopyga (sic) menecrates Mahille, 1878. Ann. Soc. ent. Belg. 21: 13; 1 macho e 1 fềmea. Peru: Mus. Roy. d'Hist. Nat. Bruxelas; LECTÓTIPO fêmea aquui designado (IRSC) [Examinado|: Syil.n.

Pymrhopyga (sic) lamprus; Plötz, 1879. Stett. ent. Ztg. 40: 534.

Pyrrhopyge menecrates: Watson. 1893. Proc. zool. Soc. London, p. 11.- Godman \& Salvin. 1893.

Biol. Centr.-Amer., Lep. Rhop. 2, p. 248.- Mabille, 1903, in Wytsman. Gen. Ins. 17, p. 8.Mabille \& Boullet, 1908. Ann. Sc. nat. 7: 174, 180.- Mabille, 1912. Lep. Cat. 9, p. 4.- Draudt, 1921, in Seitz, Macrolep. World 5, p. 837, pl. 162h.- Köhler, 1923. Ztschr. wiss. Insektenbiol. 18. Sonderb., p. 31.- Köhler \& Strassberger, 1928. Cat. Lep. arg., p. 4.- Bell, 1931. Jour. N. Y. Ent. Soc. 39: 454, pl. 38, fig. 36 (genitália masculina).- Spitz, 1932. Rev. Mus. Paulista 17: 867.- Hoffmann, 1934. Ent. Rdsch. 51: 25.- Hayward. 1940. An. Soc. Cient. Arg. 130: 70.- Martin, 1941. Bol. Mus. Hist. Nat. "Javier Prado" 5: 453.- Hayward, 1941. Rev. Mus. La Plata. n. ser., Zool. 2: 231.- Hayward. 1942. Bol. Mus. Nac.. Rio de Janeiro, 14-17: 69.Hayward, 1945. Pap. Av.. Dept. Zool., S. Paulo, 5: 197.- Bell, 1946. Bol. Ent. venez. 5: 70. Hayward, 1947. Acta zool. lill. 4: 210.- Hayward, 1948. Gen. Sp. An. Arg. 1, p. 19, tab. 1. fig. 7 (genitália masculina); tab. 13, fig. 4 .

Pyrrhopyge lampros (sic): Mahille, 1903, in Wytsman. Gen. Ins. 17, p. 8.- Mabille \& Boullet, 1908. Ann. Sc. nat. 7: 174. 180.- Mabille. 1912. Lep. Cat. 9. p. 4.- Draudt. 1921. in Seitz. Macrolep. World 5, p. 837, pl. 162b.- Spitz, 1932. Rev. Mus. Paulista 17: 867.- Cardoso. 1949. Rev. Ent., Rio de Janeiro, 20: 431 .

Pyrrhopyge margimmiscus Hayward, 1935. Rev. Soc. ent. arg. 7: 124. holótipo fềmea. Misiones: coleção Breyer (MLP) [Examinado].- Hayward, 1941. Rev. Mus. La Plata, n. ser., Zool. 2: 231. Syn.n.

Pyrrhopyge margimiscus (sic): Hayward, 1948. Gen. Sp. An. Arg. 1, p. 14. 20: tab. 13, fig. 7

Elbella menecrates: Evans. 1951. Cat. Amer. IIesp. 1. p. 41: syn.: margimmiscus.- K. Brown \& 
Mielke, 1968. Jour. Lep. Soc. 22: 154, 156.- Biezanko \& Mielke, 1973. Acta biol. paran. 2: 55.- Bridges, 1983. Lep. Hesp. 1, p. 72, 74; 2, p. 12; syn.: margimmiscus, margimiscus.Bridges, 1988. Cat. Hesp. 1, p. 113, 117; 2, p. 19; syn: margimmiscus, margimiscus.

Elbella lamprus; Lesse \& K. Brown, 1971. Bull. Soc. ent. France 76: 132, 135, cromossomas.-

Bridges, 1983. Lep. Hesp. 1, p. 63; 2, p. 12.- Bridges, 1988. Cat. Hesp. 1, p. 99: 2, p. 19.

Elbella menecrates margimmiscus; Hayward, 1973. Op. lill. 23: 13.

Elbella menecrates menecrates; Hayward, 1973. Op. lill. 23: 13.

(sem gênero) lamprtus: Beattie, 1976. Rhop. Direct., p. 180.

(sem gênero) menecrates; Beattie, 1976. Rhop. Direct., p. 199

(sem gênero) margimmiscus; Beattie. 1976. Rhop. Direct., p. 194.

Diagnose e Descrição. Macho e fêmea (Figs 73, 74) - Comprimento da asa anterior 24 a $27 \mathrm{~mm}$ na macho e $31 \mathrm{~mm}$ na fềmea. Asas inteiramente negras, com reflexos esverdeados; em alguns exemplares com franjas negras na terminações das veias.

Embora possua uma distribuição espacial disjunta, não há caracteres que destinguem as populações do Estado do Rio de Janeiro das da bacia do Paraná no sul do Brasil e Paraguai.

Discussão. Um exame dos tipos mostrou que lamprus e menecrates são sinônimos.

Distribuição espacial (Fig. 41): BRASIL - Rio de Janeiro: Rio de Janeiro. Santa Catarina: Seara. Rio Grande do Sul: Guarani; Panambi.- PARAguaI - Alto Paraná: Itaquiri. Guairá: Villarica. - ARgEnTINA - Misiones. Todas as localidades estão abaixo de $250 \mathrm{~m}$.

Distribuição temporal. Voa desde o fïm de novembro até fevereiro.

Etologia. É um habitante de florestas.

Planta hospedeira. Desconhecida.

Etimologia. lamprus - de lampros (grego), brilhante; Menecrates - médico grego de Siracusa do século IV a.C.; margimmiscus - palavra composta de margo, margem e miscere, mesclado, alusivo às franjas brancas mescladas com algumas negras.

Material estudado. Um síntipo macho de lamprus, aqui designado LECTOTIPO, com as seguintes etiquetas:/4886/ lamprus Hpfr.*/ Rio v. Lgsdf./ LECTOTIPO/ Pyrrhopyge lamprus Hopffer, 1874, Lectótipo, O. Mielke det. 1993/ Elbella lampra lampra, O. Mielke det. 1993/ (ZMHB). Um síntipo fêmea de menecrates, aqui designado LECTÓTIPO, com as seguintes etiquetas:/ menecrates P. Mab./ Type/ Pyrrhopyga (sic) Menecrates P. Mabille Perou/ Hesp. Fidiers. o God. 15 Cr. pl. 199E Surinam/LECTOTIPO/ Pyrrhopyga menecrates Mabille, 1878, Lectótipo, O. Mielke det. 1993/ Elbella lampra lampra, O. Mielke det. 1993/ (IRSC); procedência obviamente errada. O holótipo fêmea de margimmiscus com as seguintes etiquetas: /Coll. Breyer, Rep. Argentina, Misiones/ No. 7, K. J. Hayward det./ Typus/ 2511/ Pyrrhopyge margimmiscus Holotipo O/ (MLP). - BRASIL - Rio de Janeiro: Rio de Janeiro: 1 fềmea (UFPC-OM); Rio de Janeiro (Covanca de Jacarepaguá), d'Almeida leg., 14-XII-1930 1 macho, 30-XII-1947 1 macho (UFPC); Rio de Janeiro (Três Rios 

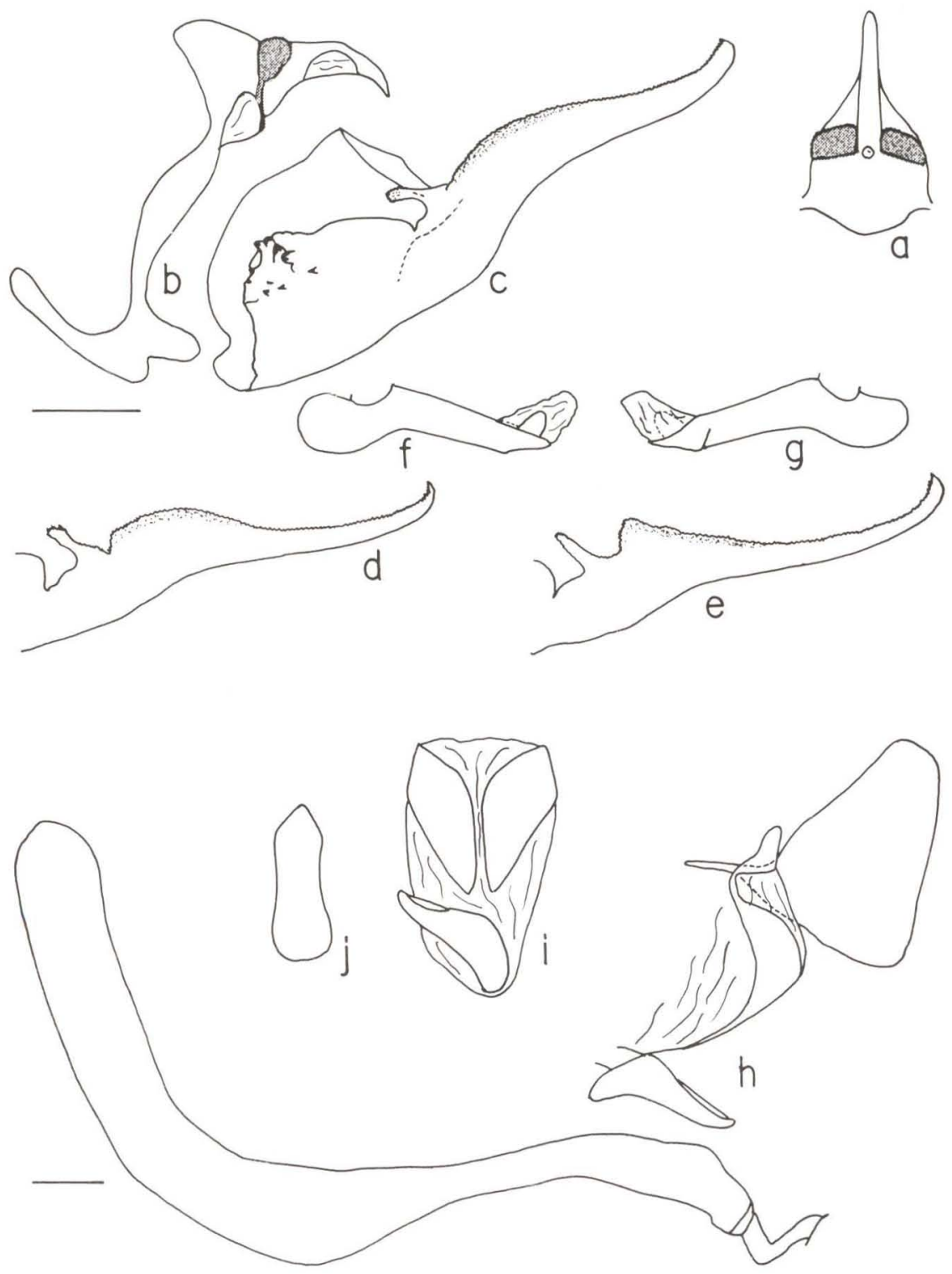

Fig. 24. Elbella etna, genitálias masculina e fiminina. (a) Vista dorsal do tegumen com apótises e uneo; (h) vista lateral esquerda do saco, legumen com apófises e unco; (c) vista interna da valva direita; (d) idem. vartuão da parte apieal: (e) idem; (f) vista lateral esquerda do edeago; (g) vista lateral direita do edeago; (h) vista lateral esquerda do oitavo segmento com esterigma e papila anal. bolsa copuladora destacada ahaixo: (i) vista ventral do oitavo esterno com esterigma ventro-lateral: (i) vista ventral do esterigma. 
- Jacarepaguá), d'Almeida leg., 14-II-1925 1 fềmea, 10-XII-1960 2 machos, 15-XII-1960 2 machos 1 fêmea, 17-XII-1960 I macho (UFPC), 4-I-1959 1 macho, 27-XI-1965 1 macho, 18-XII-1965 I macho (UFPC-OM); Rio de Janeiro (Três Rios - Jacarepaguá), Mielke leg., 4-XII-1965 1 macho (UFPC-OM); Rio de Janeiro (Urca), Ebert leg., 11-I-1952 1 fêmea (UFPC); Rio de Janeiro (Pedra de Itauna), Santos, Roppa \& Arawaki leg., 12-I-1965 1 fêmea (UFPC-OM); Rio de Janeiro (Pedra de Itauna), Mielke leg. 7-I-1966 1 fềmea (UFPC-OM); Rio de Janeiro (Gavea), 15-XI-1935 1 macho (IOC); Xerém (Serra de Tinguá), Ebert leg., 12-II-1953 1 fềmea (UFPC). Santa Catarina: Seara (Nova Teutônia), F. Plaumann leg., 300-500m, XII-1960 1 macho (UFPC). Rio Grande do Sul: Guarani, Biezanko leg., 16-XII-1932 1 fềmea, 4-I-1933 1 fềmea, 7-I-1954 1 macho, 8-I-1954 2 machos (UFPC-OM); Panambi, H. Schaal leg., 19561 fềmea (UFPC-OM). - PARAGUAI - sem localidade exata, 1 macho (ZSBS), 2 machos (AMNH). Alto Paraná: Itaquiri, Miers leg., 400m, 14-XII-1978 1 macho (UFPC-OM); Itaquiri, C. Mielke \& Miers leg., 400m, 15-20-I-1980 1 fềmea (UFPC-OM). Guairá: Villarica, 2 machos (AMNH). Sem procedência, 1 macho (MNRJ).

\subsection{Elbella lampra albociliata, ssp.n.}

Figs $41,75,76$

Elbella lamprus; Evans, 1951. Cat. Amer. Hesp. 1, p. 41, p. 5 (genitália masculina).

Diagnose e Descrição. Macho e fềmea (Figs 75, 76) - Comprimento da asa anterior 24 a $27 \mathrm{~mm}$ no macho e 30 a $32 \mathrm{~mm}$ na fềmea. Asas inteiramente negras com reflexos azulados escuros; franjas nitidamente brancas.

Discussão. Esta subespécie foi mal identificada por Evans (1951).

Distribução espacial (Fig. 41). BRASIL - São Paulo: Cubatão. Paraná: Morretes; Paranaguá. Santa Catarina: Joinvile; São Bento do Sul; Camboriu; São Francisco do Sul. Até altitudes de $700 \mathrm{~m}$.

Distribuição temporal. Ocorre nos meses de dezembro a abril.

Etologia. É um habitante de florestas.

Planta hospedeira. Em Joinvile (Santa Catarina), a larva alimenta-se em Quiina glaziovii Engler (Quiinaceae).

Etimologia. Nome alusivo às franjas brancas das asas.

Material estudado. Holótipo macho com as seguintes etiquetas: /HOLOTIPO/ Serrinha, Joinville, Santa Catarina, Brasil, 0-200m, 28-XII-1977. Miers leg./ Elbella lampra albociliata Mielke, Holótipo, O. Mielke det. 1993/ DZ 1844/ (UFPC). Alótipo fềmea com as seguintes etiquetas: /ALOTIPO/ Joinvile-S.C., Brasil, 26-II-1977 O. Mielke leg./Elbella lampra albociliata Mielke, Alótipo, O. Mielke det. 1993/ DZ 1846/ (UFPC). Parátipos: BrasIL São Paulo: Cubatão, 1 fêmea (UFPC-OM). Paraná: Morretes, Mielke leg., 700m, 1-II-1991 1 macho, 13-II-1994 1 fềmea (UFPC-OM); Paranaguá (Atami), Mielke leg., 5m, 10-IV-1993 1 macho (UFPC-OM). Santa Catarina: Joinvile, Miers leg., 2-II-1973 1 macho, 21-I-1975 1 macho, 18-I 19761 macho, 14-II-1977 1 macho 

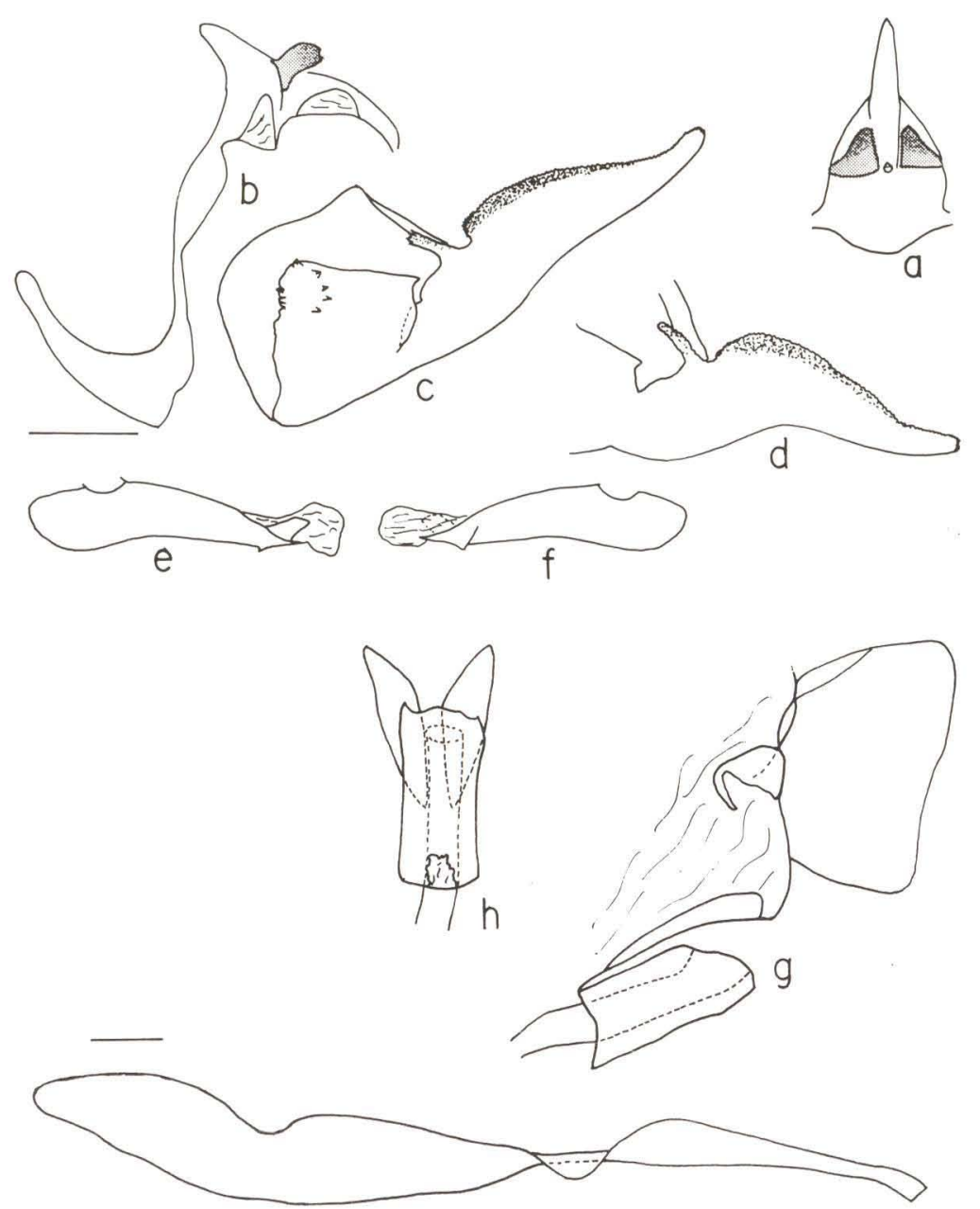

Fig. 25. Elbella patroclus patroclus, genitália masculina. (a) Vista dorsal do tegumen com apófises e unco; (b) vista lateral esquerda do saco, tegumen com apólises e unco; (c) vista interna da valva direita: (d) idem, variação da parte apical; (e) vista lateral esquerda do edeago: (f) vista lateral direita do edeago. Elbella patroclus acala, genitália feminina: (g) vista lateral esquerda do oitavo segmento com esterigma e papila anal. bolsa copuladora destacada abaixo; (h) vista ventral do esterigma e parte do oitavos esterno.

(UFPC), 17-II-1980 1 fềmea, 25-I-1981 1 macho, 6-III-1982 1 fêmea, 22-XII-1981 1 fêmea, 9-II-1989 1 fềmea (UFPC-OM); Joinvile, Mielke \& Miers leg., 9-II-1969 1 fềmea, 14-II-1971 1 fềmea, 10-I-1972 1 fềmea, 12-III-1975 (UFPC); Joinvile, Mielke, Miers \& Casagrande leg., 2-III-1987 1 fêmea (UFPC-OM); Joinvile, 1 macho (MNRJ); São Bento do Sul (Rio Natal), Rank leg., 300m, 2-I-1982 1 fêmea 
(UFPC-OM); São Bento do Sul (Rio Natal), Mielke leg., 24-I-1993 1 macho (UFPC-OM); Camboriu, Mielke leg., 27-I-1984 1 macho 1 fềmea (UFPC-OM); São Francisco do Sul (Enseada), Miers leg., 10-II-1979 1 fềmea (UFPC-OM); São Francisco do Sul (Enseada), Mielke leg., 27-30-I-1988 3 machos (UFPC).

\section{Elbella mariae (Bell, 1931)}

Figs $13,42,77-80$

Diagnose. Vértice, frontoclípeo, genas, colar, patágios, base das coxas protorácicas e segmento anal vermelhos; asas de um negro azulado a bronze esverdeado; formato alar como em lamprus; genitália masculina com a harpe bilobada e genitália feminina com o esterigma compacto, em forma de bolha.

Descrição. Macho - Comprimento da asa anterior 21 a 26mm (normalmente $23 \mathrm{~mm}$ ). Coloração geral negra, com reflexos azulados a bronze esverdeados; vértice, frontoclípeo, genas, colar, patágios, base das coxas anteriores e segmento anal vermelhos (às vezes, algumas escamas isoladas vermelhas no clorso do segmento preanal).

Faces dorsal e ventral das asascomo a coloração geral; franjas variáveis de brancas a quase concolores.

Genitália (Fig. 13). Carcteriza-se pela harpe bilobada, sendo a projeção distal igual ou pouco maior que a projeção dorsal, sem projeção na parte dorso-anterior; projeção anterior do saco não espessada; apófises do tegumen curtas, entre $1 / 3$ e $1 / 4$ do comprimento do unco, em vista lateral, e em vista dorsal parecendo pedunculadas; unco com constricção em vista dorsal; sáculo bilobado e o lóbulo proximal com dois espinhos; edeago com o lóbulo distal dirigido dorso-posteriormente e aproximadamente da largura da metade da abertura do edeago; ponta distal do edeago curvada ventralmente.

Fêmea. Semelhante ao macho, porém com as asas mais arredondadas, como em lamprus. Comprimento da asa anterior 19 a $29 \mathrm{~mm}$ (normalmente 26 a $27 \mathrm{~mm}$ ).

Genitália (Fig. 13). Caracteriza-se pelo esterigma em forma de bolha, terminando de forma arredondada, com duas pontas laterais e com o óstio na parte dorsal; partes laterais do oitavo esterno com estriações longitudinais.

Discussão. Dentro das espécies negras com cabeça e segmento anal vermelhos, esta espécie é bem caracterizada pela parte basal das coxas anteriores vermelhas e pelas genitálias masculina e feminina. Interessante é notar a semelhança das genitálias com as de iphinous, espécie sem vermelho na cabeça e no segmento anal e com largas manchas amarelo alaranjadas na asa anterior. As duas espécies são muito próximas entre si, possuindo iphinous uma distribuição geográfica mais ao norte da de mariae. Uma possível subespeciação foi descartada devida às diferenças constantes na morfologia das genitálias, principalmente masculinas onde a harpe, o sáculo e a apófise do tegumen são distintos; o esterigma é mais pontudo, em vista ventral, e o oitavo segmento não possui as estrias longitudinais em iphinous. 


\section{Chave para as subespécies}

1. Asas com reflexos bronze esverdeados; cabeça, patágios e segmento anal vermelho alaranjados . . . . . . . . . . . . . . . . . mariae

- Asas com reflexos negro azulados; cabeça, patágios e segmento anal vermelhos, com reflexos violáceos . . . . . . . . . . . . . . . . . . molinai
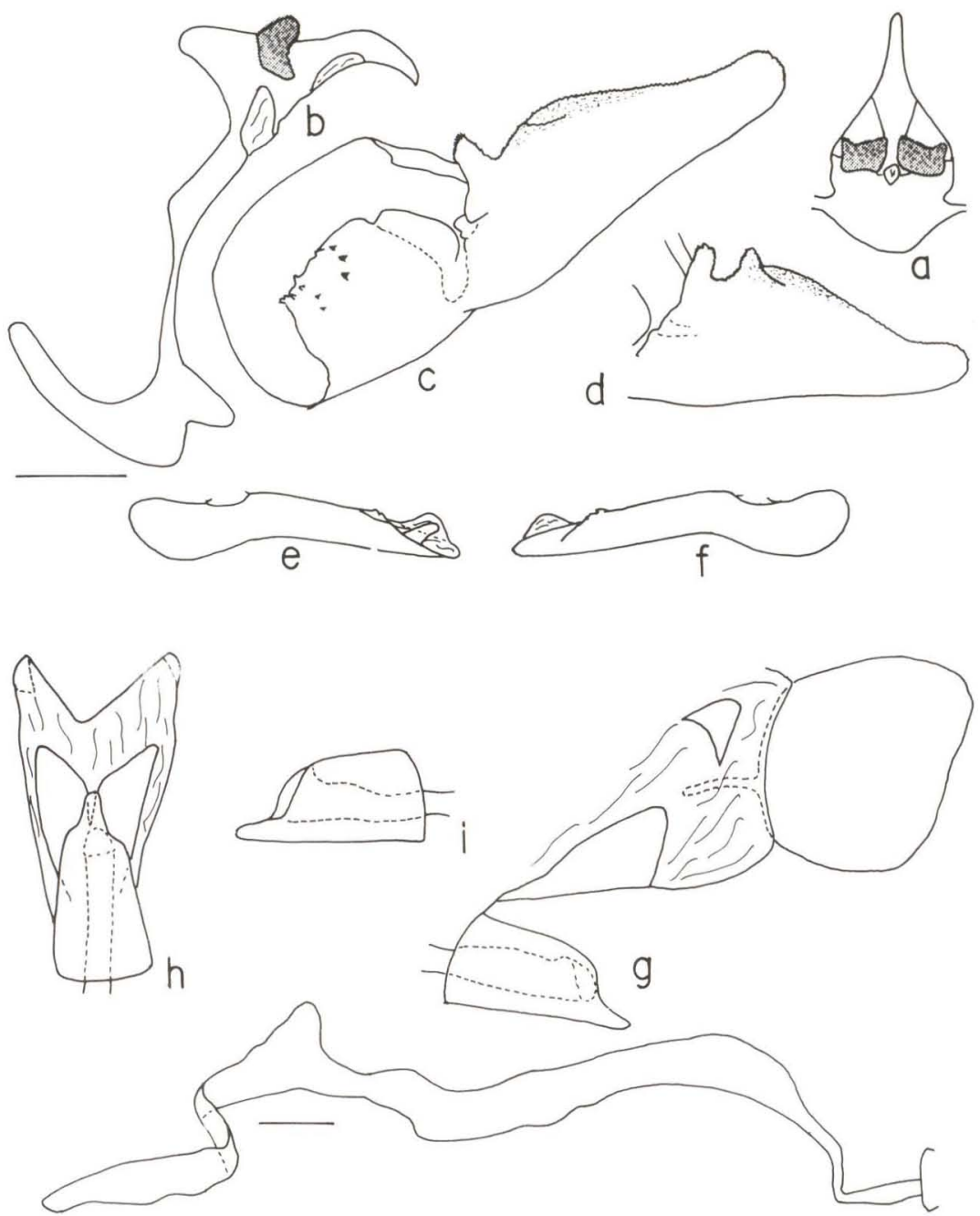

Fig. 26. Elbella azeta azeta. genitálias masculina e feminina (a) Vista dorsal do tegumen com apofises e unco: (b) vista lateral esquerda do saco. tegumen com apófises e unco: (c) vista interna da valva direita: (d) idem. variação da parte apical, (e) vista lateral esquerda do edeago; (f) vista lateral direita do edeago: (g) vista lateral esquerda do oitavo segmento com esterigma e papila anal, bolsa copuladora destacada abaixo: (h) vista ventral do esterigma e parte do oitavo esterno: (i) vista lateral esquerda do esterigma. 


\subsection{Elbella mariae mariae (Bell, 1931)}

Figs $42,77,78$

Pyrrhopyge mariae Bell, 1931. Jour. N. Y. Ent. Soc. 39: 455. pl. 38, fig. 38 (genitália masculina); holótipo macho, Rio Grande do Sul, Brasil, coleção Bell (AMNH) [Examinado].- Hoffmann, 1934. Ent. Rdsch. 51: 25.

Elbella mariae: Evans, 1951. Catt. Amer. Hesp. 1. p. 42, pl. 5 (genitália masculina), syn.: subnubilus.Biezanko, 1963. Arq. Ent., sér (A). Pelotas, p. 3.- Biezanko \& Mielke, 1973. Acta biol. paran. 2: 55.- Hayward, 1973. Op. lill. 23: 13.- Mielke, 1980. Acta biol. paran. 8-9: 8.- Bridges, 1983. Lep. Hesp. 1. p. 72; 2, p. 12.- Bridges, 1988. Cat. Hesp. 1. p. 113; 2, p. 19. (sem gênero) mariae; Beattie, 1976. Rhop. Direct., p. 195.

Diagnose e Descrição. Macho e fêmea (Figs 77, 78) - Comprimento da asa anterior 21 a $24 \mathrm{~mm}$ (normalmente $23 \mathrm{~mm}$ ) no macho e 19 a $28 \mathrm{~mm}$ (normalmente 26 a $27 \mathrm{~mm}$ ) na fêmea. Cabeça, patágios, parte basal das coxas anteriores e segmento anal vermelho alaranjados; asas com reflexos bronze esverdeados; franjas normalmente castanhas, às vezes, brancas nas asas anterior e posterior.

Discussão. Difere de mariae molinai pelos caracteres mencionados na chave. Pyrrhopyge subnubilus Hayward, 1935, mencionado por Evans (1951) como um sinônimo de mariae, é uma espécie de Pyrrhopyge Hübner, [1819].

Distribuição espacial (Fig. 42). BRASIL - São Paulo: São Paulo 850m. Paraná: São José dos Pinhais $850 \mathrm{~m}$; Curitiba 900m; São Luiz do Purunã $1000 \mathrm{~m}$; Tibagi 1000m; Prudentópolis 1200m; Lapa 900m; União da Vitória; Palmas $1100 \mathrm{~m}$. Santa Catarina: São Bento do Sul 850m; Corupá 60m; Massaranduba 300m; Mafra 850m; Santa Cecília 1200m; Rio dos Cedros; Curitibanos 1000m; Lajes 920 m. Rio Grande do Sul: Bom Jesus 1050m; Gramado 800m; Passo Fundo 640m; Pelotas 10m. - Argentina - Misiones. Entre São Paulo e Santa Catarina só ocorre entre 800 e $1200 \mathrm{~m}$, enquanto que no Rio Grande do Sul chega ao nível do mar.

Distribuição temporal. Voa entre janeiro e fevereiro, raras vezes até março ou mesmo abril, quando só exemplares muito velhos podem ser encontrados.

Etologia. Voa nas florestas, visita flores nos campos em sua proximidade. Bastante comum em flores de Escallonia bifida Link \& Otto (Saxifragaceae).

Planta hospedeira. Desconhecida; provavelmente uma espécie de Melastomataceae, como em E. mariae molinai.

Etimologia. Espécie dedicada à Sra. Maria Huntington, esposa do Dr. E. J. Huntington, um lepidopterologista.

Material estudado. O holótipo macho com as seguintes etiquetas: /391/ Rio Grande do Sul/ Type/Pyrrhopyge mariae Bell Holotype O// AMNH). - BRASIL - São Paulo: São Paulo (Mata do Governo), I-1914 1 fêmea (UFPC-OM). Paraná: Curitiba (Cascatinha), Mielke leg., 900m, 25-I-1966 5 machos 1 fềmea, 1-II-1966 1 fêmea, 4-II-1966 2 machos 1 fêmea (UFPC-OM), 29-I-1967 19 machos 1 fêmea, 8-II-1967 7 machos, 11-II-1967 1 macho, 14-II-1967 2 machos 1 fêmea, 28-II-1967 1 fêmea, 1-IV-1967 1 fêmea, 28-I-1968 1 macho, 29-I-1968 1 fêmea, 2-III-1968 1 macho, 3-III-1968 1 fềmea, 13-I-1971 2 machos, 12-II-1975 1 macho, 22-I-1977 5 machos 1 fêmea, 14-II-1980 2 machos (UFPC); Curitiba (Rio Iguaçu), Moure 
leg., 900m, 4-II-1988 I fêmea (UFPC-OM); Curitiba (Barigui), Mielke leg., 900m, 18-I-1987 1 macho (UFPC-OM); Curitiba, Ebert leg., 23-I-1971 2 machos (UFPC); São José dos Pinhais, Mielke leg., 900m, 11-II-1984 1 fêmea, 30-I-1989 2 machos (UFPC-OM); São José dos Pinhais, Mielke \& Callaghan leg., 27-II-1986 1 macho (UFPC-OM); São José dos Pinhais (Telepar), O. \& C. Mielke leg., 1000m, 6-II-1983 2 machos; Morretes (Pilão de Pedra), O. \& C. Mielke leg., 700-800m, 1-II-1991 1 macho, 11-II-1993 1 macho (UFPC-OM); São Luiz do Purunã, Mielke leg., 950m, 10-II-1985 1 macho, 7-II-1991 1 macho 1 fềmea (UFPC); Castro, Mielke leg., 1000m, 25-I-1971 1 macho (UFPC); Tibagi, Mielke \& Casagrande leg., 1200m, 4-II-1986, 3 machos 2 fềmeas (UFPC); Prudentópolis, Mielke \& Buzzi leg., 1200m, 2-II-2976 1 macho; Lapa, Pohl leg., III-1940 1 macho (MZSP); União da Vitória, Mielke \& Casagrande leg., 9-III-198I 1 macho (UFPC); Palmas, Mielke \& Buzzi leg., 1100m, 6-II-1976 I macho (UFPC). Santa Catarina: São Bento do Sul, 850m, 6-VIII-1969 1 fêmea (UFPC-OM); São Bento do Sul, Rank leg., I-III-1970 I fêmea (UFPC-OM); São Bento do Sul, Weiss leg., 18-IV-1971 1 fêmea (UFPC); São Bento do Sul, Ebert leg., 18-III-1980 2 machos (UFPC); São Bento do Sul, Miers leg., 21-II-1987 1 macho I fềmea (UFPC-OM); São Bento do Sul (Rio das Antas), Miers leg., 800m, 19-III-1982 1 fêmea (UFPC-OM); São Bento do Sul (Rio Natal), O. \& C. Mielke leg., 500m, 7-III-1987 1 fêmea (UFPC-OM); São Bento do Sul (Rio Vermelho), Rank leg., $850 \mathrm{~m}$, I-III-1970 1 macho 4 fềmeas, 5-I-1971 2 machos, 23-III-1971 1 fềmea, 5-II-1972 1 fêmea, 1-I-1973 1 macho, 30-I-1973 1 fềmea, 10-II-1973 2 machos, 11-II-1973 1 fêmea, 16-II-1973 I macho, 20-II-1973 2 fêmeas, 27-II-1973 1 fêmea, 4-III-1973 1 fềmea, 6-III-1973 1 macho, 3-I-1974 2 machos, 12-I-1974 1 macho, 29-I-1974 1 macho, 30-I-1974 1 macho, 1-II-1974 1 macho, 2-II-1974 1 macho, 7-II-1974 1 macho, 13-II-1974 1 macho, 16-II-1974 4 machos 1 fêmea, 22-II-1974 1 macho, 24-II-1974 1 macho, 2-III-1974 1 fêmea, 29-III-1974 1 fêmea, 8-I-1980 1 macho (UFPC), 20-I-1987 1 macho, 18-I-1987 1 macho, 23-II-1987 1 fêmea, I-III-1987 1 fêmea, 5-I-1988 1 macho, 17-II-1988 1 fềmea, 4-II-1989 1 fềmea, 4-III-1989 1 fêmea (UFPC-OM); Mafra (Bituva), Mielke leg., 850m, 22-II-1982 1 macho (UFPC-OM); Rio dos Cedros (Alto Rio dos Cedros), Lauterjung leg., 650m, 4-II-1972, 1 macho 1 fềmea, 15-II-1972 1 macho, 22-II-1972 1 fềmea (UFPC); Santa Cecília, Moure \& Mielke leg., 1200m, 26-II-1968 1 fêmea (UFPC); Santa Cecília (Campo Alto), Mielke \& Sakakibara leg., 1200m, 12-II-1973 3 machos (UFPC); Santa Cecília (Campo Alto), Mielke leg., 1200m, 22-II-1973 1 macho (UFPC); Curitibanos, H. \& H. D. Ebert leg., 950m, 21-24-II-1973 1 fêmea (UFPC); Curitibanos (Ponte Alta do Norte), Mielke \& Sakakibara leg., 1000m, 12-II-1973 1 macho (UFPC); Lajes, Ebert leg., 900m, 26-II-1966 1 fềmea (UFPC); Lajes (Parque das Pedras Brancas), Mielke \& Sakakibara leg., 920m, 13-II-1973 1 fềmea. Rio Grande do Sul: Gramado, H. \& H. D. Ebert leg., 800m, 19-30-I-1973 2 machos (UFPC); Bom Jesus, Mielke \& Buzzi leg., 1050m, 12-II-1976 1 macho 2 fêmeas (UFPC); Passo Fundo, Mielke \& Buzzi leg., 640m, 8-II-1976 1 macho (UFPC); Pelotas, Biezanko leg., 10m, I-II-1963 2 machos, 3-III-1963 1 fềmea (UFPC-OM). 


\subsection{Elbella mariae molinai (Hayward, 1940), nom.rev., comb.n., stat.n.}

Figs $42,79,80$

Pyrrhopyge molinai Hayward, 1940. Rev. chil. Hist. nat. 44: 33, fig. (genitália masculina); holótipo macho, Mato Grosso, Brasil; coleção Hayward (IML) [Examinado].- Hayward, 1963. Acta zool. lill. 19: 330, holótipo Argentina.

Pyrrhopyge polemon; Evans, 1951. Cat. Amer. Hesp. 1, p. 19, part. syn.: molinai. (sem gênero) molinai; Beattie, 1976. Rhop. Direct., p. 204.

Diagnose e Descrição. Macho e fềmea (Figs 79, 80) - Comprimento da asa anterior 24 a $26 \mathrm{~mm}$ no macho e 28 a $29 \mathrm{~mm}$ na fêmea. Cabeça, patágios, parte basal das coxas anteriores e segmento anal vermelhos com reflexos vióláceos; asas com reflexos negro azulados; franjas brancas, raras vezes escurecidas na asa anterior dos machos.

Discussão. Este nome nunca mais foi reconhecido, sendo por EVANS (1951) mencionado na sinonímia de Pyrrhopyge polemon Hopffer, 1874, espécie pertencente ao gênero Passova Evans, 1951 (BIEZANKo \& MielKe 1973). O tipo, ao contrário do que menciona HAYWARD (1940), não provém de Mato Grosso, Brasil, e sim de Misiones, Argentina, lapso que corrige parcialmente em 1963, citando somente Argentina como procedência. Pelo fato de não ter visto mais exemplares desta localidade em todos os museus mencionados na parte de "Material e Métodos", acredita-se em erro de procedência, pois esta subespécie só ocorre no litoral dos estados do Paraná e Santa Catarina.

Distribuição espacial (Fig. 42). BRASIL - Paraná: Morretes 800m; São José dos Pinhais (Castelhanos) 700m. Santa Catarina: Joinvile 0-200m.

Distribuição temporal. Voa entre novembro e março.

Etologia. É um habitante de florestas. Alimenta-se em flores de Escallonia bifida Link \& Otto (Saxifragaceae). Em Joinvile disputa território em topo de morros entre 13: 30 e 14: $00 \mathrm{~h}$ a aproximadamente 8 a $10 \mathrm{~m}$ de altura, pousando em ponta de galhos, quando é bastante fácil capturá-la.

Planta hospedeira. Em Joinvile, Santa Catarina, a larva alimenta-se em Miconia cabucu Hoehne e em Morretes, Paraná em Miconia cinerascens Miq., ambas Melastomataceae.

Etimologia. Espécie dedicada ao Dr. Abbott Juan Ignacio Molina, renomado naturalista chileno.

Material estudado. Holótipo macho com as seguintes etiquetas: IPyrrhopyge molinai Hayw., holotype ơ, Misiones [Argentina]. K. J. Hayward det./ Prep. 590 [genitália]/ Type/ (IML). - BRASIL - Paraná: Morretes (Alto da Serra), Mielke leg., 800m, 4-II-1989 3 machos, 7-II-1989 2 machos 1 fêmea, 19-II-1989 3 machos, 25-II-1989 10 machos 1 fêmea, 8-II-1990 1 macho, 21-II-1991 8 machos, 22-I-1993 1 macho, 28-I-1993 1 macho (UFPC-OM); São José dos Pinhais (Castelhanos), Mielke leg., 700m, 24-II-1994 1 macho, 3 fêmeas (UFPC-OM). Santa Catarina: Joinvile, Miers leg., 10-200m, 19-I-1968 1 macho, 4-II-1968 1 macho, 18-II-1968 1 macho, 9-II-1969 1 macho, 16-I-1971 1 macho, 

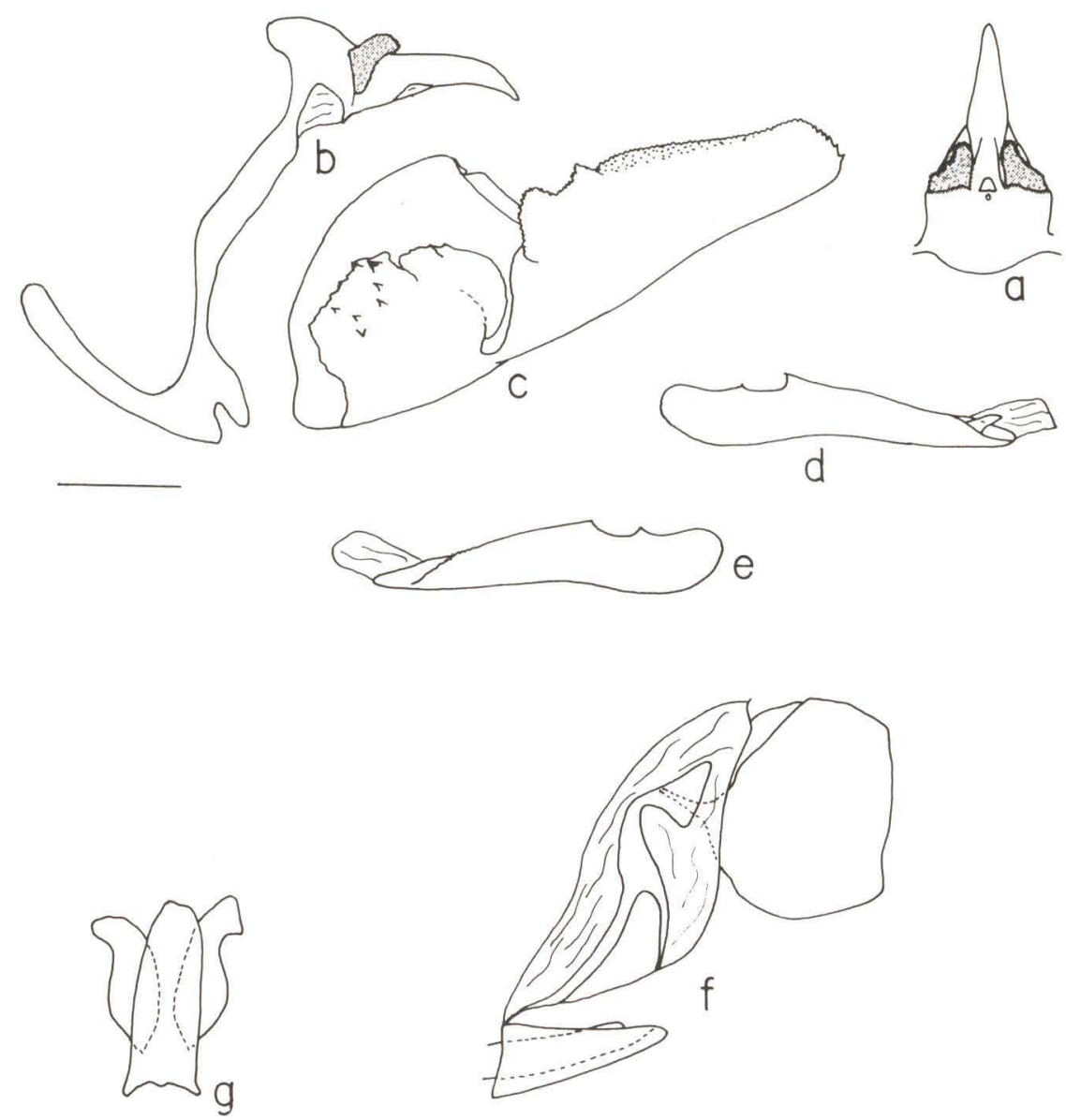

Fig. 27. Elhella ltastra, genitálias masculina e feminina. (a) Vista dorsal do tegumen com apófises e unco; (b) vista lateral esquerda do saco, legumen com apófises e unco: (c) vista interna da valva direita: (d) vista lateral esquerda do edeago; (e) vista lateral direita do edeago; (f) vista lateral esquerda do oitavo segmento com esterigma e papila anal; $(g)$ vista ventral do esterigma e parte do oitavo esterno.

20-I-1971 2 machos, 28-XII-1978 1 macho, 23-XI-1980 1 macho, 4-I-1983 1 macho (UFPC), 27-XI-1988 1 macho, 26-XII-1987 1 macho, 1-XII-1990 2 machos, 12-XII-1990 1 macho, 23-XII-1990 1 macho 1 fềmea, 14-I-1991 1 fềmea, 29-XI-1991 1 macho, 2-XII-1991 1 macho 19-XII-1991 2 machos, 6-XII-1992 2 machos (UFPC-OM); Joinvile, Mielke \& Miers leg., 10-200m, 9-II-1969 2 machos, 31-I-1971 1 macho, 3-II-1973 2 macho, 9-XI-1980 1 macho, 10-I-1985 1 macho, 29-XII-1987 1 macho, 27-XI-1993 3 machos (UFPC-OM); Joinvile, Mielke leg., 10-200m, 31-XII-1986 5 machos (UFPC-OM); Joinvile, H. \& K. Ebert leg., 17-I-1971 2 machos (UFPC); Joinvile (Rio do Júlio), 14-III-1990 1 fêmea (UFPC-OM). 


\section{Elbella adonis (Bell, 1931)}

Figs $16,43,81-83$

Pyrrhopyge adonis Bell, 1931. Jour. N. Y. Ent. Soc. 39: 455, pl. 38, fig. 37 (genitália masculina); holótipo macho, Villarica, Paraguai, novembro, coleção Bell (AMNH) [Examinado].- Hofmman, 1934. Ent.Ztschr. 51: 25.- Hayward, 1935. Rev. Soc. ent. arg. 7: 124.- Hayward, 1941. Rev. Mus. La Plata, n. ser., Zool. 2: 232.- Hayward, 1948. Gen. Sp. An. Arg. 1, p. 21, tab. 1, fig. 8 (genitália masculina); tab. 13. fig. 8 .

Elbella adonis; Evans, 1951. Cat. Amer. Hesp. 1, p. 41,pl. 5 (genitália masculina)-- Mielke, 1968. Atas. Soc. Biol. Rio de Janeiro 12: 74.- Biezanko \& Mielke, 1973. Acta biol. paran. 2: 55 .Hayward, 1973. Op. lill. 23: 13.- Mielke, 1980. Acta biol. paran. 8-9: 8; syn.: carriae; Biezanko \& Mielke, 1973.- Bridges, 1983. Lep. Hesp. 1, p. 1; 2, p. 12.- Bridges, 1988. Cat. Hesp. 1, p. 2; 2, p. 19

Elbella carriae; Biezanko \& Mielke, 1973. Acta biol. paran. 2: 55.

(sem gênero) adonis; Beattie, 1976. Rhop. Direct., p. 67.

Diagnose. Vértice, frontoclípeo, coxas anteriores e segmento anal vermelhos (preanal negro); asas inteiramente de diversas nuances negras; formato alar como em lamprus; franjas brancas a anegradas; valva com a harpe reta e alongada.

Descrição. Macho (Fig. 81) - Comprimento da asa anterior 25 a $28 \mathrm{~mm}$ (normalmente 26 a $27 \mathrm{~mm}$ ). Coloração geral negra com nuances de diversas tonalidades azuladas a esverdeadas ou acinzentadas; vértice, frontoclípeo, primeiro, segundo e, às vezes, o terceiro artículo dos palpos, colar, patágios, genas, coxas anteriores (caráter diagnóstico) e segmento anal vermelhos; no vértice e frontoclípeo a extensão do vermelho muito variável, às vezes, só com escamas desta cor nas bordas e uma linha entre as antenas.

Faces dorsal e ventral das asas da coloração geral; asa anterior com o ângulo apical de aproximadamente $44^{\circ}$; franjas normalmente brancas, às vezes, castanhas.

Genitália (Fig. 16). Caracteriza-se pela harpe muito alongada, levemente sinuosa a quase reta, com uma projeção na parte ântero-dorsal; sáculo com uma série de espinhos dispostos em círculo; apófises do tegumen aproximadamente 1/3 do comprimento do unco em vista lateral e triangulares em vista dorsal; edeago reto, com uma leve carena subterminal na parte ventral e lateral esquerda e o lóbulo distal dirigido dorso-distalmente.

Fêmea (Figs 82, 83). Semelhante ao macho. Comprimento da asa anterior 28 a $33 \mathrm{~mm}$ (normalmente 30 a $31 \mathrm{~mm}$ ).

Genitália (Fig. 16). Esterigma tubular, ligado ao 8 esterno e o óstio dorso-posterior. Uma fêmea anômala (Fig. 83) de Morretes, Paraná possui pequenas manchas semitransparentes abaixo do ponto de início de CuA1 e M3, e 4 manchas apicais entre R4 e M3.

Discussão. Espécie singular no gênero, caracterizada pelas coxas protorácicas vermelhas e asas negras. As variações cromáticas das tonalidades de negro nas asas não sugerem uma espécie politípica.

Distribuição espacial (Fig. 43). BRASIL - Minas Gerais: Poços de Caldas 1400m; Passa Quatro 915m. Rio de Janeiro: Itatiaia 900-1200m; Cachoeira de Macacu 700m. São Paulo: Campos do Jordão 1600m. Paraná: Matinhos 10m; 
Morretes 800m; São José Pinhais 850m; Curitiba 900m; São Luiz do Purunã $1000 \mathrm{~m}$; Guarapuava 1200m: Rolândia: Londrina; Palmas $1100 \mathrm{~m}$; Foz do Iguaçu 250m. Santa Catarina: Joinvile 0-200m; Dalbergia 600m (ex Neu Bremen); Massaranduha 300m; São Bento do Sul 850m; Taió; Blumenau; Santa Cecília 1200m; Seara 300-500m. Rio Grunde do Sul: Pelotas 10m.- Paraguai - Alto Paraná: Itaquiri 400m. Guairá: Villarica.- ARGENTINA - Misiones.
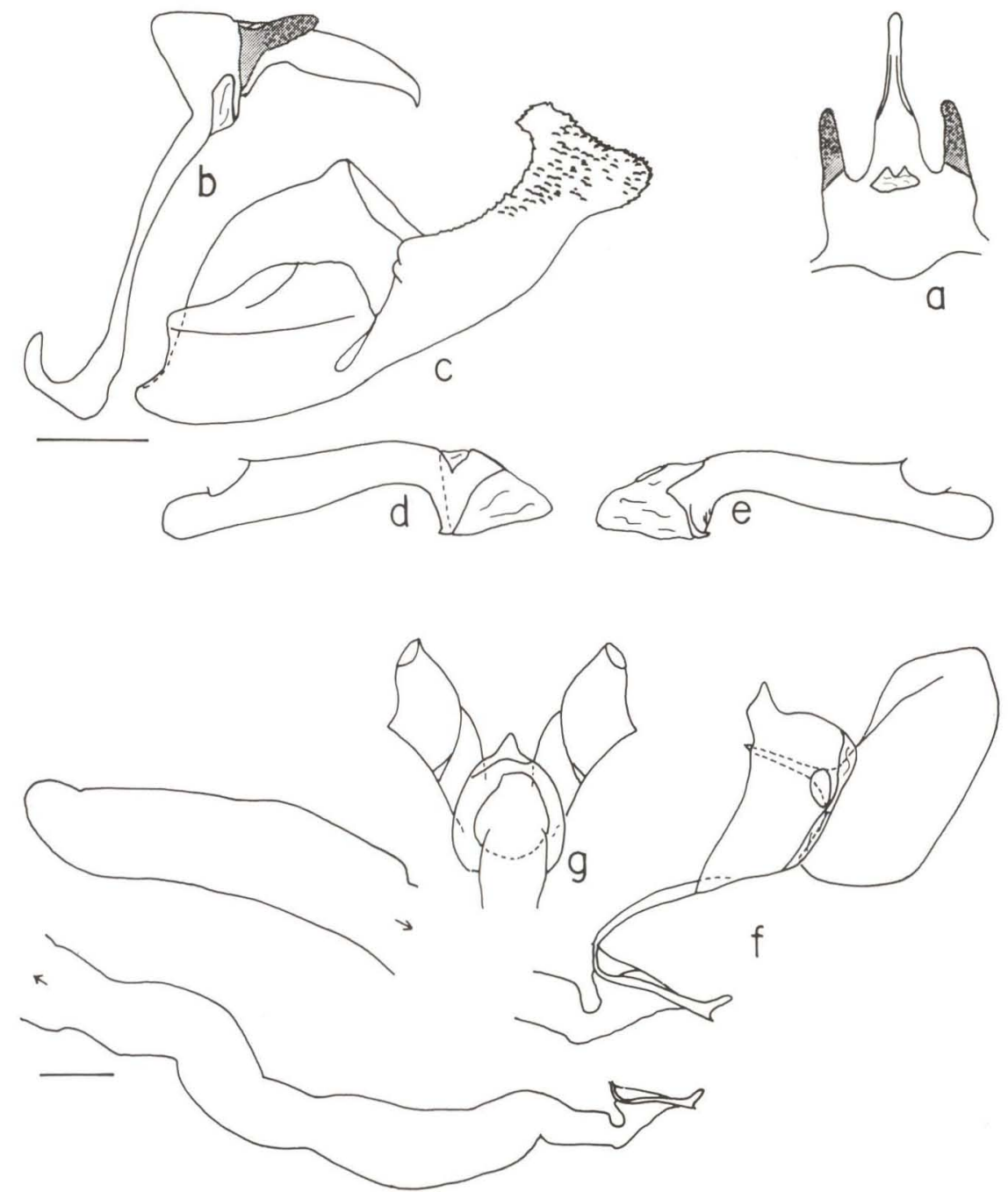

Fig. 28. Elbella merops, genitálias masculina e feminina. (a) Vista dorsal do tegumen com apófises e unco; (b) vista lateral esquerda do saco, legumen com apófises e unco, (c) vista interna da valva direita; (d) vista lateral esquerda do edeago: (e) vista lateral direita do edeago: (f) vista lateral esquerda do oitavo segmento com esterigma e papila anal, bolsa copuladora destacada abaixo; (g) vista ventral do esterigma e parte do oitavo esterno. 
Distribuição temporal. Voa desde novembro até abril, sendo que nos lugares acima de $700 \mathrm{~m}$ é frequente em janeiro e fevereiro. No Paraguai, aparentemente, há duas gerações, pois exemplares de novembro-dezembro e abril estão perfeitos.

Etologia. É um habitante de florestas, sendo frequente em flores de Escallonia bifida Link \& Otto (Saxifragaceae).

Planta hospedeira. Desconhecida.

Etimologia. Adonis, filho de Cintra e Mirra, amante de Venus; mitologia grega.

Material estudado. O holótipo macho com as seguintes etiquetas: / Type/ Villarica, Nov. Paraguay/ Pyrrhopyge adonis Bell Holotype $\sigma^{\prime \prime} /$ coleção Bell (AMNH) [Examinado].- BRAsIL - Minas Gerais: Poços de Caldas, Roppa \& Becker leg., 27-I-1965 1 fêmea (UFPC-OM); Poços de Caldas, Mielke leg., 28-III-1965 1 fềmea (UFPC-OM); Passa Quatro, Zikán leg., 915m, 6-I-1923 1 macho (IOC). Rio de Janeiro: Itatiaia, Santos leg., 900-1200m, 15-I-1973 (UFPC-OM); Itatiaia, Zikán leg., 16-I-1930 1 macho, 11-I-1939 1 macho, 23-II-1939 1 macho (IOC); Cachoeira de Macacu (Boca do Mato), Tangerini leg., 10-II-1992 1 macho (NT). São Paulo: São Paulo, Pohl leg., I-1914 1 macho (MZSP); Campos do Jordão (Fazenda da Guarda [atual Parque Estadual]), d'Almeida leg., 1600m, 19-II-1942 1 macho (UFPC). Paraná: Matinhos, Mielke leg., 10m, 8-IV-1989 1 fêmea (UFPC-OM); Morretes (Alto da Serra), Mielke leg., 800m, 4-II-1989 1 macho, 7-II-1989 1 fêmea, 19-II-1989 1 macho, 25-II-1989 1 macho, 17-III-1990 1 fềmea, 1-II-1991 2 machos, 21-II-1991 1 macho 1 fềmea (UFPC-OM); São José dos Pinhais, Mielke leg., leg., 850m, 23-II-1986 1 macho (UFPC), 30-I-1989 1 macho (UFPC-OM); Curitiba, Mielke leg., 900m, 28-I-1967 2 machos, 29-I-1967 3 fềmeas, 8-II-1967 3 machos 1 fêmea, 9-III-1967 1 fềmea, 22-IV-1967 1 fềmea, 28-I-1968 1 macho 1 fềmea, 4-II-1968 1 macho 1 fêmea, 28-II-1969 1 macho, 20-III-1970 1 macho, 13-I-1971 1 macho, 22-I-1977 1 macho 2 fêmeas, 13-II-1982 1 fềmea (UFPC), 18-I-187 1 macho (UFPC-OM); São Luiz do Purunã, C. Mielke leg., 1000m, 10-II-1991 1 macho(UFPC-OM); Guarapuava (9 km N), Mielke \& Buzzi leg., 1200m, 3-II-1976 1 macho (UFPC); Rolândia, XII-1947 1 macho (MZSP); Londrina (Heimtal), Pohl leg., XII-1943 1 macho (MZSP); Palmas, Mielke \& Buzzi leg., 1100m, 6-II-1976 1 macho (UFPC); Foz do Iguaçu, Exc. Dep. Zool. leg., 250m, 8-XII-1966 1 macho, 9-XII-1966 2 machos (UFPC). Santa Catarina: São Bento do Sul (Rio Vermelho), Rank leg., 850m, I-III-1970 1 fêmea, 31-I-1971 1 fêmea, 2-III-1974 1 macho, 9-III-1974 1 macho, 10-III-1974 1 fêmea, 25-III-1974 1 fềmea, 26-III-1974 1 fềmea (UFPC), 25-II-1988 1 fềmea, 29-I-1989 3 machos, 9-III-1989 1 fêmea (UFPC-OM); São Bento do Sul (Rio Natal), O. \& C. Mielke leg., 700m, 7-II-1987 1 macho (UFPC-OM); Taió, Pohl leg., I-1940 1 fêmea, III-1940 1 fêmea (MZSP); Dalbergia (ex Neu Bremen), 15-II-... 1 macho, 25-II-... 1 macho (AMNH); Massaranduba, 300m, 2 machos 1 fềmea (AMNH); Salto Grande (Município incerto), IV-1924 1 macho (MNRJ); Joinvile, Miers leg., 0-200m, 7-III-1979 1 fêmea (UFPC); Santa Cecília (Campo Alto), Mielke \& Sakakibara leg., 1200m, 

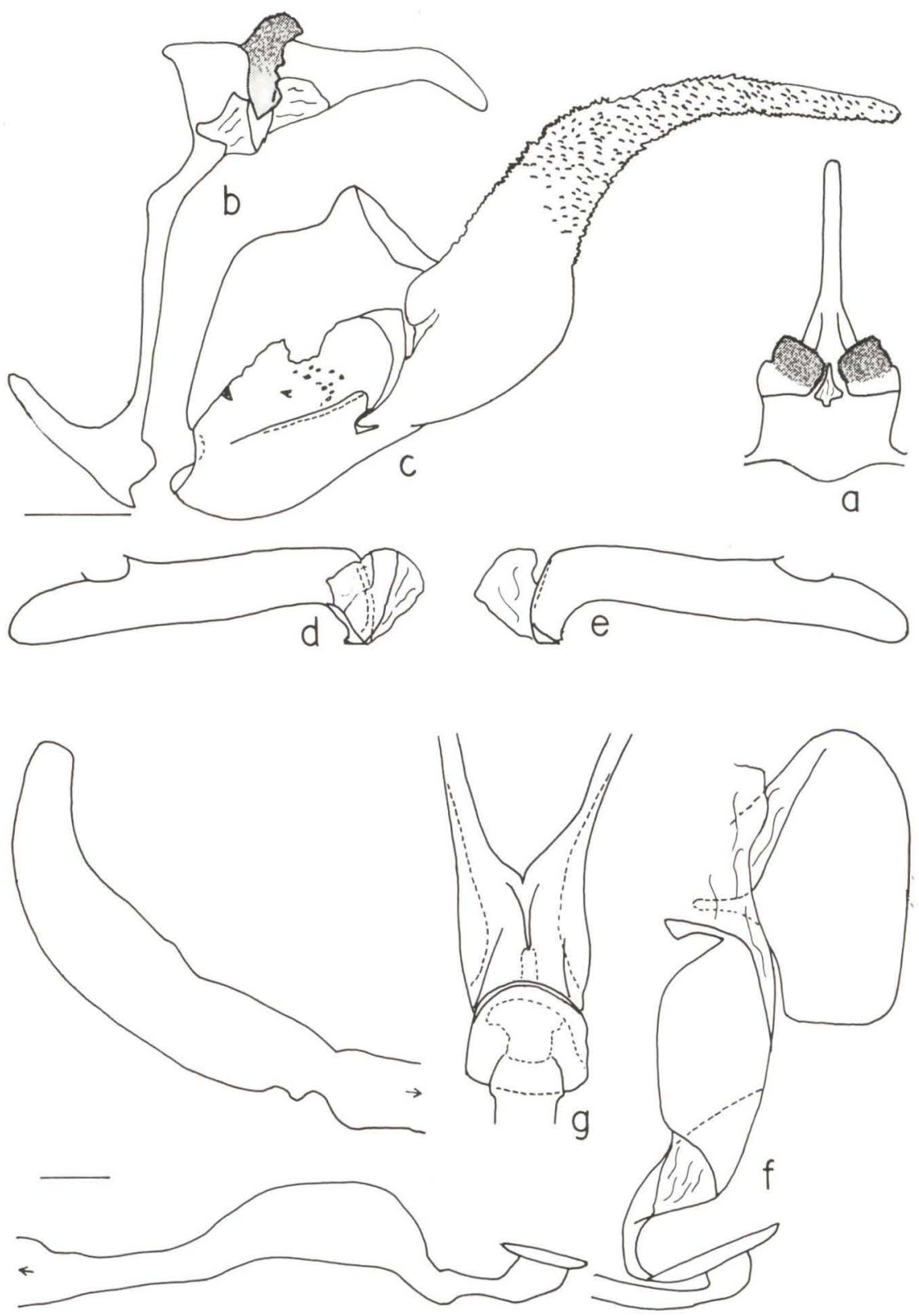

Fig. 29. Elbella theséus, genitálias masculina e feminina. (a) Vista dorsal do legumen com apófises e unco; (b) vista lateral esquerda do saco, tegumen com apófises e unco; (c) vista interna da valva direita; (d) vista lateral esquerda do edeago; (e) vista lateral direita do edeago: (f) vista lateral esquerda do oitavo segmento com esterigma e papila anal, holsa copuladora destacada ao lado; (g) vista ventral do esterigma e parte do oitavo esterno. 
12-II-1973 1 macho (UFPC); Seara (Nova Teutonia), Plaumann leg., 300-500m, I-1961 1 macho 1 fêmea (MFPL). Rio Grande do Sul: Pelotas, Biezanko leg., 10m, 13-II-1963 1 macho (UFPC-OM).- PARAGUAI - Guairá: Villarica, Anders leg., 26-IV-1965 1 macho, 7-XII-1965 1 macho, IV-V-1966 2 machos (UFPC$\mathrm{OM})$; Villarica, XII 1 macho (AMNH). Alto Paraná: Itaquiri (General Dias), Miers leg., 400m, 14-XII-1978 3 machos (UFPC-OM); Itaquiri (General Dias), C. Mielke \& Miers leg., 15-20-I-1980 5 machos 1 fêmea (UFPC-OM).

\section{Elbella scylla (Ménétriés, 1855) \\ Figs $1,4,6,15,44,84,85$}

Pyrrhopyga (sic) scylla Ménétriés, 1855. En. Corp. An. Mus. Petr. 1, p. 60, 95, Taf. IV, Fig. 7; Nicaragua; Imp. Acad. Scient. Petropolitanae; dois síntipos (ZIL) [Não examinados].Wiedemeyer, 1864. Proc. ent. Soc. Philad. 2: 537.- Herrich-Schäffer, 1869. Corr.-Blatt zool.-min. Ver. Regensburg 23: 165.- H. Druce, 1876. Proc. zool. Soc. London, p. 247.Mabille, 1878. Ann. Soc. ent. Belg. 21: 14.- Kirby, 1879. Cat. Coll. Diurn. Lep. Hew., p. 206.- Plötz, 1879. Stett. ent. Ztg. 40: 537.

Pyrrhopyge scylla; Kirby, 1871. Syn. Cat. Diurn. Lep., p. 585.- Watson, 1893. Proc. zool. Soc. London, p. 11.- Godman \& Salvin, 1893. Biol. Centr.-Amer., Lep. Rhop. 2, p. 249; 3, tab. 73, figs. 5, 6 (genitália masculina); syn.: dulcinea.- Mabille, 1903, in Wytsman. Gen. Ins. 17, p. 8.- Mabille \& Boullet, 1908. Am. Sc. nat. 7: 173, 179.-Mabille, 1912. Lep. Cat. 9, p. 3.Draudt, 1921, in Seitz. Macrolep. World 5, p. 837, pl. 162a.- Spitz, 1932. Rev. Mus. Paulista 17: 867.- Hoffmann, 1941. Amm. Inst. Biol., Mexico, 12: 240; syn.: dulcinea.- Hayward, 1942. Bol. Mus. Nac., Rio de Janeiro, 14-17: 68; syn.: dulcinea.- Gibson \& Carillo, 1959. Folleto Misc., Secr. Agric. Gan., Mexico, 9: 151.- Hughes, 1959. Ent. 92: 86.- R. Maza, 1976. Rev. Soc. Mex. Lep. 2: 22.

Elbella scylla scylla; Evans, 1951. Cat. Amer. Hesp. 1, p. 38, pl. 5 (genitália masculina).- J. A. Comstock \& Vázquez, 1961. An. Inst. Biol., Mexico, 31: 421.- Steinhauser, 1975. Bull. Allyn. Mus. 29: 3.- Llorente-Bousquets; Luiz-Martinez \& Vargas-Fernández, 1990. Publ. esp. Mus. Zool., Mexico, 1: 24.

Elbella scylla; Freeman, 1966. Jour. Lep. Soc. 20: 227.- Lewis, 1975. Marip. Mundo, p. 82, 245, fig. 41.- Bridges, 1983. Lep. Hesp. 1, p. 107; 2, p. 12.- J. Maza \& R. Maza, 1985. Rev. Soc. Mex. Lep. 9: 41.- Bridges, 1988. Cat. Hesp. 1, p. 169; 2, p. 20.- R. Maza \& White, 1990.

Rev. Soc. Mex. Lep. 13: 83.- J. Maza, White \& R. Maza, 1991. Rev. Soc. Mex. Lep. 14: 9. (sem gênero) scylla; Beattie, 1976. Rhop. Direct., p. 255.

Elebella (sic) scylla; Okano, 1981. Tokurana 1: 93

Diagnose. Vértice e frontoclípeo anegrados e com pontos esbranquiçados; asas alongadas como em intersecta e inteiramente anegradas; segmento anal vermelho; asa posterior com a margem externa aproximadamente reta, com escamas marginais negras e franjas brancas; valva semelhante com a de intersecta.

Descrição. Macho (Fig. 84) - Comprimento da asa anterior 24 a $25 \mathrm{~mm}$. Coloração geral negra, com suaves reflexos esverdeados; frontoclípeo com escamas brancas acima dos palpos e vértice com escamas semelhantes junto ao frontoclípeo, formando uma faixa transversal, junto aos olhos, atrás das antenas, e linhas transversais brancas antes e após o quetosemata; palpos com os primeiro e segundo artículos vermelhos, nestes com as áreas centrais internas, junto à espirotromba, da coloração geral; genas variáveis, vermelhas a negras; colar 

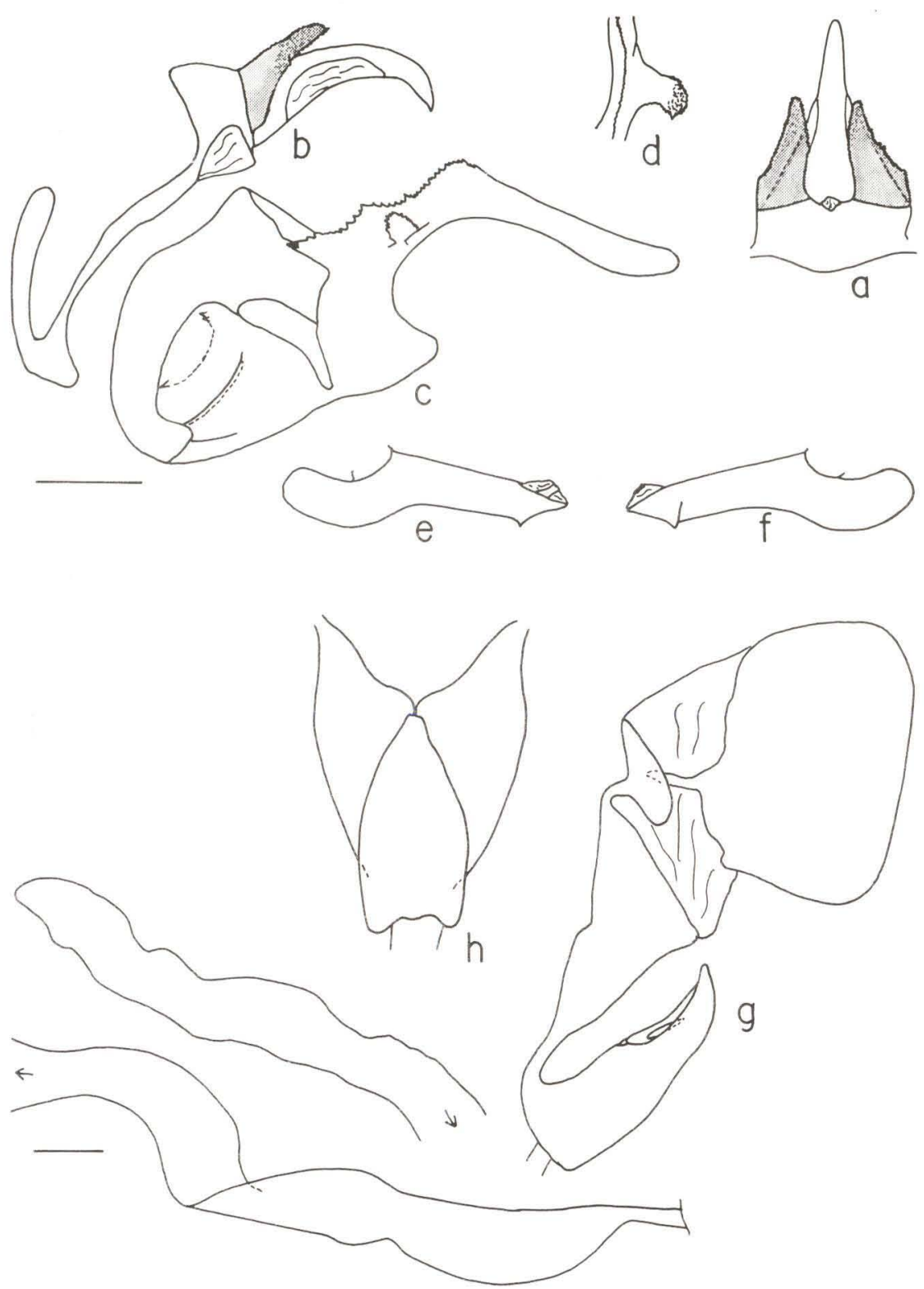

Fig. 30. Elbella blanda, genitálias masculina e femunina. (a) Vista dorsal do tegumen com apófises e unco; (b) vista lateral esquerda do saco, legumen com apófises e unco: (c) vista interna da valva direita: (d) vista dorsal do lóbulo interno da base da projeção dorso-distal da valva: (e) vista lateral esquerda do edeago; (f) vista lateral direita do edeago; (g) vista lateral esquerda do oitavo segmento com esterigma e papila anal, com bolsa copuladora destacada abaixo: (h) vista ventral do esterigma e parte do oitavo esterno. 
parcialmente, patágios e segmento anal vermelhos; tégulas com linha central, às vezes, só na base, alaranjada nos exemplares do México, vermelha nos da Guatemala e cinza ou ausente nos de Honduras; tórax com linhas cinzas, às vezes, curtas, ao longo dos bordos internas de cada uma das tégulas.

Faces dorsal e ventral das asas da coloração geral; franjas brancas e de largura uniforme; asa anterior com o ângulo apical de aproximadamente $44^{\circ}$.

Genitália (Fig. 15). Caracteriza-se pela harpe muito alongada, fortemente sinuosa e sem projeção na parte ântero-dorsal, como em intersecta, porém pouco mais recurvada; projeção anterior do saco delgada; edeago com a ponta distal curvada ventralmente e o lóbulo distal dirigido dorso-posteriormente; apófises do tegumen curtas, alongadas em vista lateral e pouco maiores que $1 / 4$ do comprimento do unco, mais delgadas que em intersecta e dulcinea; unco sem reentrâncias laterais em vista dorsal.

Fêmea (Fig. 85). Semelhante ao macho. Comprimento da asa anterior 28 a $29 \mathrm{~mm}$. Ângulo apical da asa anterior aproximadamente $40^{\circ}$.

Genitália (Fig. 15). Esterigma em forma de anel e bordos dorsais posteriores do oitavo esterno separados por fenda mediana e em vista lateral bem visíveis abaixo dos $9^{\circ}+10^{\circ}$ segmentos.

Discussão. Dentro do grupo das espécies com o segmento anal vermelho, esta espécie e a seguinte, dulcinea, caracterizam-se pela coloração negra do frontoclípeo e do vértice, no entanto a especiação entre scylla e dulcinea sempre foi questionada. FREEMAN (1966) foi o primeiro autor a distinguir corretamente as duas espécies, baseado em caracteres morfológicos não mencionados, e na distribuição geográfica parcialmente simpátrica. As pequenas diferenças na genitália masculina estão na harpe mais curvada, nas apófises do tegumen mais longas que altas em vista lateral e na genitália feminina, onde os bordos dorsais e posteriores do oitavo segmento são separados, deixando uma pequena fenda entre eles, enquanto que em dulcinea a harpe é menos recurvada, as apófises do tegumen mais altas que longas em vista lateral e na genitália feminina os bordos dorsais e posteriores do oitavo esterno são unidos e possuem uma pequena projeção no ponto de união.

Dois síntipos de scylla estão no Zoological Institute, Russian Academy of Sciences, São Petersburgo, Rússia, conforme carta do Dr. Zinovjev. Um lectótipo deverá ser designado em outra oportunidade.

Distribuição espacial (Fig. 44). MÉXICO - Guerrero: Tierra Colorada. Puebla: Matamoros (Jaullilas). Jalisco: Puerto Vallarta. Oaxaca: Candelaria Loxicha 500m. Chiapas: San Jeronimo 600m. Quintana Roo: Nuevo X-Can. Veracruz: Catemaco. Durango: Revolcaderos 2600m. San Luis Potosi: Huasteca Potosina (R. Maza \& White 1990). - Guatemala - Polochic; Motagua Valley; Cahabon; San Gerônimo; Paraiso. - Honduras. - Nicarágua - Rio San Juan: Chontales. - COSTA RICA - Ciudad Colon.

Distribuição temporal. No México voa entre junho e outubro.

Etologia. Desconhecida.

Planta hospedeira. Desconhecida. 
Etimologia. Scylla era um monstro marinho, filha de Crataeus, no poema "Odisseia" de Homero ou filha de Niso, filho do rei de Megara, transformada em garça.
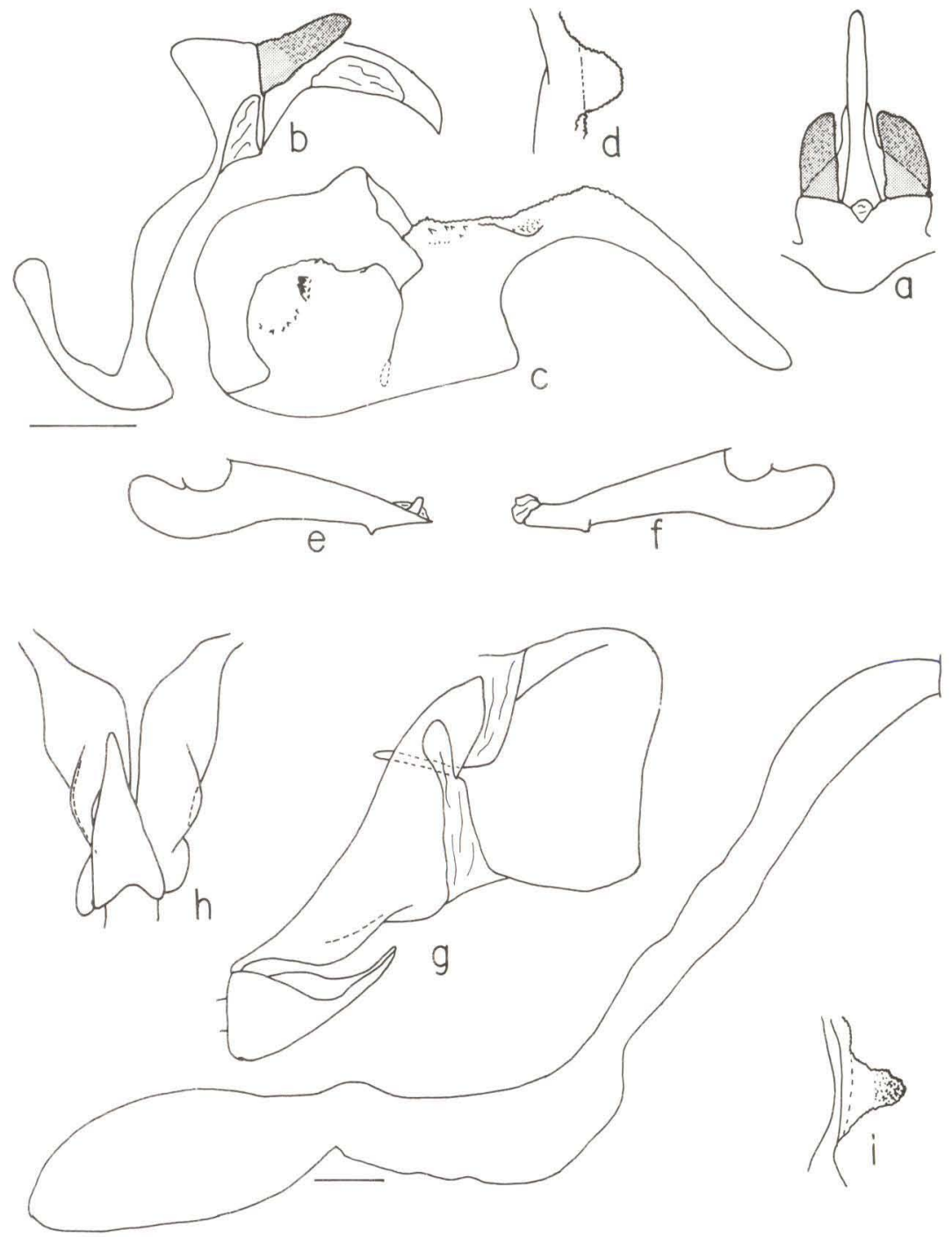

Fig. 31. Elbella parobas tingo, genitália masculina. (a) Vista dorsal do legumen com apófises e unco: (b) vista lateral esquerda do saco, tegumen com apólises e unco: (c) vista interna da valva direita: (d) vista dorsal do lóbulo interno da hase da projeção dorso-distal da valva; (e) vista lateral esquerda do edeago; (f) vista lateral direita do edeago. Elbella patrobas amazonica, genitália feminina. (g) Vista lateral esquerda do oitavo segmento com esterigma e papila anal. bolsa copuladora destacada abaixo: (h) vista ventral do esterigma e parte do oitavo esterno. Elhella patrobas parohas, genitália masculina. (i) Vista dorsal do lóbulo interno da hase da projeção dorso-distal da valva. 
Material estudado. MÉXICO - Guerrero: Terra Colorada, Francez leg., X-1965 1 macho 1 fêmea (UFPC-M). Puebla: Matamoros, Moral leg., 21-VIII-1965 1 macho (UFPC-OM); Matamoros (Jaulillas), Moral leg., 18-VIII-1968 1 macho 1 fêmea (UFPC-OM). Oaxaca: Candelaria Loxicha, Welling leg., 500m, IX-1969 1 macho, 24-IX-1969 1 macho, 25-VI-1972 1 macho, 2-VII-1972 1 macho, 18-VII-1972 1 macho, 26-VII-1972 1 macho, 10-VIII-1972 1 macho, 20-VIII-1972 1 macho, 20-VIII-1973 1 macho, 12-IX-1973 2 machos, 15-IX-1973 1 macho, 14-VII-1976 1 macho, 23-VII-1976 I macho, 25-VIII-1976 1 macho, 6-VIII-1977 2 machos, 2-IX-1977 1 macho, 6-IX-1977 1 macho, 11-VIII-1978 1 macho, 21-VIII-1978 1 macho, 1-IX-1978 1 macho, 23-IX-1978 1 macho (UFPC). Chiapas: San Jeronimo, Welling leg., 600m, 6-VII-1976 1 macho, 23-VII-1976 1 macho, 27-VI-1980 1 macho (UFPC). Quintana Roo: Nuevo X-Can, Welling leg., 2-IX-1978 1 macho, 24-X-1979 1 macho (UFPC). Veracruz: Catemaco, 10-VIII-1973 1 fềmea (UFPC-OM). Durango: Revolcaderos (11 km E), MacNeill leg., 2600m, 10-VIII-1972 1 macho (UFPC-OM). - COSTA RICA - Ciudad Colon, Pagels leg., 22-X-1987 1 macho (UFPC-OM).

\section{Elbella dulcinea (Plötz, 1879)}

Figs $16,44,86,87$

Pyrrhopyga (sic) dulcinea Plötz, 1879. Stett. ent. Ztg. 40: 532; Panama; LECTÓTIPO macho aqui designado (ZMHB) [Examinado].

Pyrrhopyge dulcinea; Mabille, 1903, in Wytsman. Gen. Ins. 17, p. 7.- Mabille \& Boullet, 1908. Ann. Sc. nat. 7: p. 174, 180.- Mabille, 1912. Lep. Cat. 9, p. 4.- Draudt, 1921, in Seitz. Macrolep. World 5, p. 838, pl. 162c.

Pyrrhopyge scylla: Williams \& Hayward, 1944. Acta zool. lill. 2: 74; syn .: dulcinia (sic).- Hayward, 1944. Acta zool. lill. 4: 210; syn .: dulcinea.- Bell, 1946. Bol. Ent. venez. 5: 70; syn.: dulcinea.

Elbella scylla dulcinea; Evans, 1951. Cat. Amer. Hesp. 1, p. 38.- Bridges, 1983. Lep. Hesp. 1, p. 37; 2, p. 12; syn.: dulcinea, dulcinia.- DeVries, 1983, in Janzen. Costa Rican Nat. Hist., p. 675.- Bridges, 1988. Cat. Hesp. 1, p. 58; 2, p. 19.- Llorente-Bousquets; Luis-Martínez \& Vargas-Fernández, 1990. Publ. esp. Mus. Zool., Mexico 1: 24.

Elbella dulcinea; Freeman, 1966. Jour. Lep. Soc. 20: 227.- Okano,1981. Tokurana 1: 51 ,- J. Maza \& R. Maza, 1985. Rev. Soc. Mex. Lep. 9: 41.- R. Maza \& White, 1990. Rev. Soc. Mex. Lep. 13: 83.- J. Maza, White \& R. Maza, 1991. Rev. Soc. Mex. Lep. 14: 9.- R. Maza \& Carbonell, 1992; Rev. Soc. Mex. Lep. 15: 34; Add., p. 10.

(sem gênero) dulcinea: Beattie, 1976. Rhop. Direct., p. 132.

(sem nome): Raymond, 1982. Marip. Venez., pl. 7, fig. 9.

Diagnose. Vértice e frontoclípeo anegrados, com pontos esbranquiçados; segmentos pré-anal e anal vermelhos; asas inteiramente anegradas; asa anterior alongada como em intersecta; asa posterior com a margem externa côncava e escamas marginais brancas como as franjas; valva com a harpe menos recurvada que em intersecta.

Descrição. Macho (Fig. 86) - Comprimento da asa anterior 23 a $24 \mathrm{~mm}$. Coloração geral negra, com suaves reflexos esverdeados; frontoclípeo com escamas brancas acima dos palpos e vértice com escamas brancas junto ao frontoclípeo, formando uma linha transversal, junto aos olhos e atrás das antenas, e linhas 

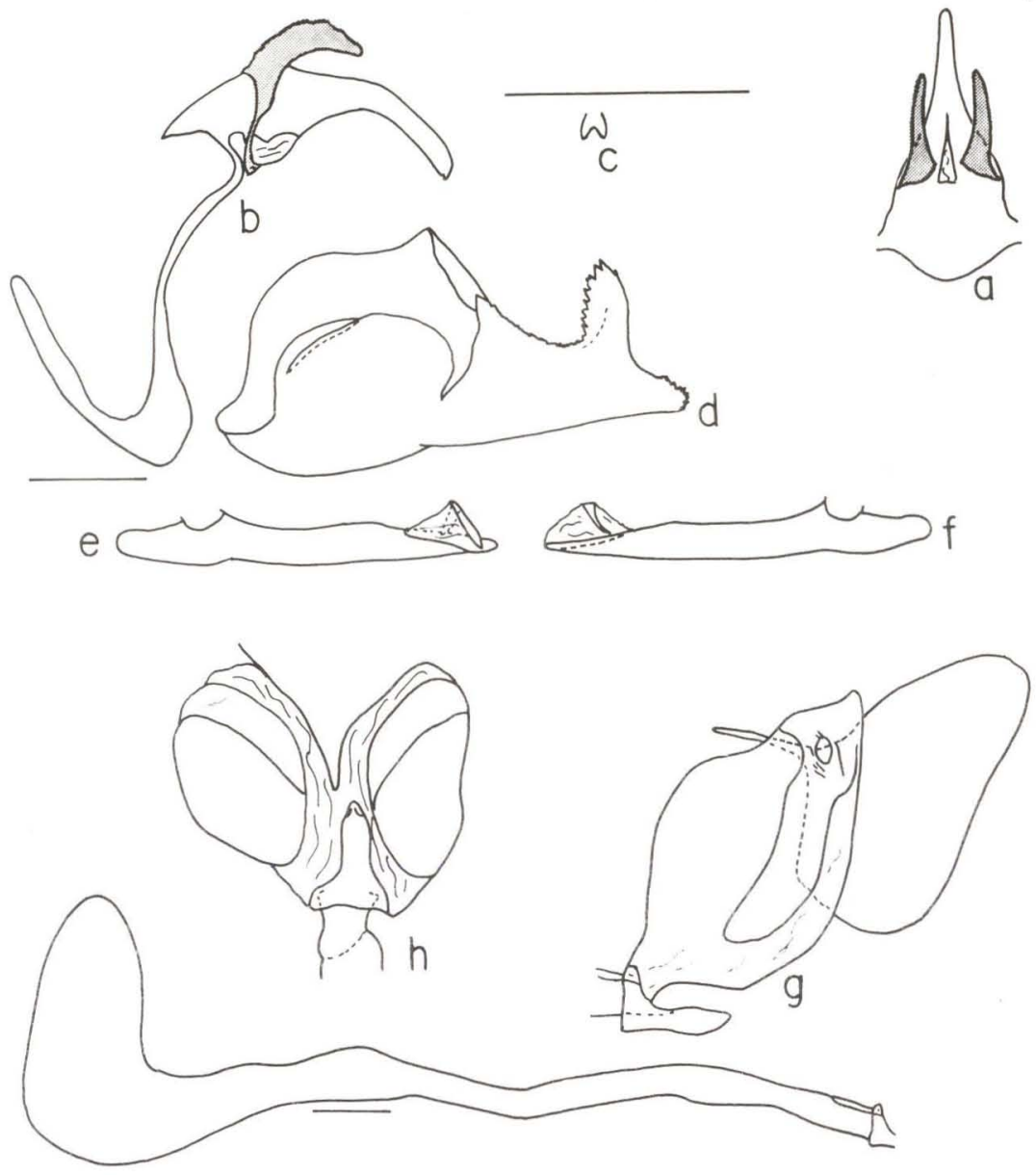

Fig. 32. Parelbella polyzona, genitálias masculina e feminina. (a) Vista dorsal do tegumen com apófises e unco; (b) vista lateral esquerda do saco, legumen com apófises, unco e gnato: (c) vista dorsal da ponta distal do unco; (d) vista interna da valva direita; (e) vista lateral esquerda do edeago; (f) vista lateral direita do edeago: (g) vista lateral esquerda do oitavo segmento com esterigma e papila anal. bolsa copuladora destacada abaixo: (h) vista ventral do esterigma e parte do oitavo esterno.

brancas antes e após o quetosemata; palpos com os primeiro e segundo artículos vermelhos e com as metades distais internas negras; genas da coloração geral; patágios, base das tégulas e segmento anal vermelhos; tégulas com linha central cinza a partir da base vermelha: tórax com linhas cinzas, às vezes, curtas ao longo dos bordos internos de cada uma das tégulas.

Faces dorsal e ventral das asas da coloração geral; asa anterior com o ângulo apical de aproximadamente $40^{\circ}$, dando à asa um aspecto mais pontudo que em scylla; asa posterior com a margem junto às franjas da mesma coloração destas, isto é, brancas, dando à asa uma margem externa aparentemente côncava, mais 
acentuado ventralmente.

Genitália (Fig. 16). Como em scylla, no entanto a harpe menos sinuosa e as apófises do tegumen mais truncadas, tanto em vista lateral como em vista dorsal.

Fêmea (Fig. 87). Semelhante ao macho. Comprimento da asa anterior 25 a $26 \mathrm{~mm}$. Ângulo apical da asa anterior de aproximadamente $40^{\circ}$.

Genitália (Fig. 16). Esterigma em forma de anel e bordos dorsais posteriores do oitavo segmento unidos, formando uma pequena saliência, e pouco visíveis em vista lateral abaixo dos $9^{\circ}+10^{\circ}$ segmentos.

Discussão. Veja em scylla.

Distribuição espacial (Fig. 44). MÉXICO - Veracruz: Tierra Blanca; Presídio (Freeman 1966). San Luiz Potosi: Huasteca Potosina (R. MAzA \& White 1990). Chiapas: Bocas del Chapel (J. MAZA \& R. MAZA 1985). - CostA RicA. - Panamá - Zona do Canal: Cerro Campana 300m. Panamá. - Colômbia. - Venezuela - Bolivar: Mantecal. Distrito Federal: Caracas. Trujillo: Valera. ECUADOR - Tungurahua: Baños.

Distribuição temporal. Voa em janeiro, março, agosto e novembro.

Etologia. Desconhecida.

Planta hospedeira. Na Venezuela: Aragua (Maracay) a lagarta foi alimentada por F. F. Yépez em "almedron" - Terminalia catappa L. (Combretaceae).

Etimologia. Nome de um personagem feminino do romance "Dom Quixote de La Mancha" de Cervantes.

Material estudado. Um síntipo macho aqui designado LECTótIPo com as seguintes etiquetas: /Origin./Dulcinea Mab. ơ/ Scylla Mén. Dulcinea Stg./Col. K./ Scylla Mén./ Coll. Staudinger/ LECTOTIPO/ Pyrrhopyga dulcinea Plötz, 1879, Lectótipo, O. Mielke det. 1993/Elbella dulcinea, O. Mielke det. 1993/ (ZMHB). - PANAmÁ - Zona do Canal: Cerro Campana, Small leg., 300m, 5-VIII-1967 1 macho (UFPC-OM). Panamá: Veragua, 18761 macho (ZMHB). - Venezuela - Trujillo: Valera, Angeles leg., 5-I-1955 1 macho (UFPC-OM). Bolivar: Montecal, Yépez \& Rosales leg., 23-27-III-1970 1 fêmea (UFPC-OM). Distrito Federal: Caracas (Puente Hierro), J. B. Rodrigues leg., 26-XI-1980 1 fêmea (UFPC-OM). Sem local exato, Romero leg., 1 macho (UFPC-OM).

\section{Elbella luteizona (Mabille, 1877)}

Figs $17,47,88-93$

Pyrrhopyga (sic) luteizona Mabille, 1877. Pet. Nouv. Ent. 2: 162; fềmea do México; Coll. Mus. Roy. Belg.; LECTÓTIPO macho (nec fềmea) aqui designado (IRSC) [Examinado].- Mabille, 1878. Ann. Soc. ent. Belg. 21: 15, fềmea, México.

Pyrrhopyga (sic) martii Plötz, 1879. Stett. ent. Ztg. 40: 525; Brasil; Mus. Berol. 4915 [Holótipo] $(\mathrm{ZMBH})$ [Examinado].

Pyrhopyga (sic) josepha Plötz, 1879. Stett. ent. Ztg. 40: 534; Brasil; Mus. Berol. 4899 [Holótipo] (ZMBH) [Examinado].- Druce, 1908. Trans. ent. Soc. London, p. 376.

Sarbia luteizona; Godman \& Salvin, 1893. Biol. Centr.-Amer., Lep. Rhop. 2, p. 259.- Mabille, 1903, in Wytsman. Gen. Ins. 17, p. 12.- Mabille \& Boullet, 1908. Ann. Sc. nat. 7: 199, 202, pl. 14, fig. 1.- Mabille, 1912. Lep. Cat. 9, p. 12.- Draudt, 1921, in Seitz. Macrolep. World 
5, p. 846, pl. 164e.- Bell. 1934. Jour. N. Y. Ent. Soc. 42: 400.- Spitz, 1932. Rev. Mus. Paulista 17: 867, 879, 884-- Hoffmann, 1941. An. Inst. Biol., Mexico, 12: 241.

Pyrrhopyge josepha: Watson, 1893. Proc, zool. Soc. London, p. 12.- Mabille \& Boullet, 1908. Ann.

Sc. nat. 7: 176, 181.- Mabille, 1912. Lep. Cat. 9: 5.- Draudt, 1921, in Seitz. Macrolep. World 5. p. 839.- Bell. 1931. Jour. N. Y. Eut. Soc. 39: 438.- Zikán \& Zikán, 1968. Pesq. agrop. bras. 3: 62 .

Sarbia martii; Mabille, 1903, in Wytsman. Gen. Ins. 17, p. 12.- Godman, 1907. Ann. \& Mag. nat.

Hist. (7) 20: 150.- Mabille \& Boullet, 1908. Ann. Sc. nat. 7: 199, 202.- Mabille, 1912. Lep.

Cat. 9. p. 12.- Draudt, 1921, in Seitz. Macrolep. World 5, p. 846, pl. 164e.- Zikán, 1922.

Dtsch. Ver. Wiss. Kunst, S. Paulo, p. 188.-Zikán, 1927. Dtsch. ent. Ztschr., p. 62, etologia.-

Spitz, 1932. Rev. Mus. Paulista 17: 867.- Zikán \& Zikán, 1968. Pesq. agrop bras. 3: 63.

Sarbia lateizona (sic): Kaye, 1915. Proc. ent. Soc. London 5: CXX.

Sarbia amoena Röber, 1925. Ent. Mitt. 14: 87; 2 machos, São Paulo, Brasil: NeótıPo macho aqui designado (ZMHB) [Examinadol.

Sarbia martyii (sic): Bell, 1934. Jour. N. Y. Ent. Soc. 42: 400; syn.: amoena.

Pyrrhopyge xanthomargo Hayward, 1942. Bol. Mus. Nac., Rio de Janeiro 14-17: 67; holótipo fềmea,

III-1917, Angatuba, São Paulo, Azevedo Marques leg., 18627 (MNRJ) [Examinadol.

Hegesippe luteizona luteizona; Evans, 1951. Cat. Amer. Hesp. 1, p. 62, pl. 7 (genitália masculina):

syn.: martii, amoena.- Biezanko, 1963. Arq. Ent., sér. A. Pelotas, p. 4.

Hegesippe luteizona josepha; Evans, 1951. Cat. Amer. Hesp 1, p. 63.- Bridges, 1983. Lep. Hesp.

1, p. 60; 2. p. 16.- Bridges, 1988. Cat. Hesp. 1, p. 95; 2, p. 26.

Hegesippe luteizona; K. Brown \& Mielke, 1967. Jour. Lep. Soc. 27: 157.- Ebert, 1969. Jour. Lep.

Soc. 23. Suppl. 1: 39.- Biezanko \& Mielke, 1973. Acta biol. paran. 2: 55.- Bridges, 1983

Lep. Hesp. 1, p. 6, 69, 72; 2, p. 16; syn.: amoena, martii-- Mielke, 1989. Revta bras. Zool.

6: 143; syn.: josepha, amoena.

(sem gênero) luteizona; Beattie, 1976. Rhop. Direct., p. 189.

(sem gênero) martii: Beattie, 1976. Rhop. Direct., 195.

(sem gênero) josepha: Beattic, 1976. Rhop. Direct., p. 174.

(sem gênero) amoena; Beattie, 1976. Rhop. Direct., p. 76.

(sem gênero) xanthomargo; Beattie, 1976. Rhop. Direct., p. 288.

Elbella luteizona; Mielke \& Casagrande, 1988. Revta bras. Ent. 32: 117, fig. 10 (fềmea, holótipo de xanthomargo): syn .: xanthomargo.- Mielke, 1989. Revta bras. Zool. 6: 143: syn.: josepha. amoena.

Diagnose. Vértice, frontoclípeo e segmento anal vermelhos (segmento pré-anal só com escamas vermelhas no dorso); asas inteiramente negras ou com indícios ou até grandes manchas amarelas; franjas amarelo claras, fortemente crenuladas nas asas posteriores, às vezes, o amarelo também na margem da asa.

Descrição. Macho (Figs 88-90) - Comprimento da asa anterior 25 a $29 \mathrm{~mm}$ (normalmente 27 a $28 \mathrm{~mm}$ ). Coloração geral negra, com diversas tonalidades de azul ou verde; vértice, às vezes, com escamas negras mescladas, parte anterior do frontoclípeo, às vezes, também a parte posterior, primeiro e segundo artículos dos palpos, colar, genas e segmento anal vermelhos; no segmento pré-anal, às vezes, com algumas escamas vermelhas no dorso. No fenótipo com manchas amarelas nas asas, a parte ântero-externa dos patágios, tégulas, partes laterais do metaescuto, partes látero-dorsais e proximais de cada tergo abdominal, pleuras abdominais, mais acentuadas nos segmentos basais, amarelos.

Faces dorsal e ventral das asas anterior e posterior da coloração geral 
(fenótipos "josepha" e "xanthomargo") ou com uma série de manchas nítidas e difusas amarelas, muito variáveis em sua extensão (fenótipo "luteizona"), às vezes, só algumas indicadas na face dorsal da asa posterior; franjas amarelas e crenuladas internamente, pelas terminações das veias parcialmente negras, às vezes, no fenótipo totalmente negro, com as margens externas das asas anterior e posterior também amarelas, sendo que na asa posterior pode atingir até $2 \mathrm{~mm}$ na fêmea (fenótipo "xanthomargo"). As manchas amarelas na face dorsal da asa anterior formam uma faixa mediana, composta de três manchas largas, entre a célula e $2 \mathrm{~A}$ e outra faixa subapical composta de cinco manchas de tamanhos decrescentes entre $\mathrm{R} 4$ e CuA1, às vezes, uma sexta diminuta em R3-R4, ambas faixas formando um Y; além destas manchas bem definidas, normalmente com outras amarelas difusas nas discocelulares, externas às manchas dos espaços M2-2A, uma abaixo da mancha em $\mathrm{CuA} 1-\mathrm{CuA} 2$, entre $2 \mathrm{~A}$ e a margem interna, e outra na base de $\mathrm{CuA1}-\mathrm{CuA} 2$. As manchas na face dorsal da asa posterior formam uma faixa mediana entre a margem costal e $2 \mathrm{~A}$, de margens interna sinuosa e externa bem irregular.

Face ventral das asas anterior e posterior, inclusive as franjas, como a face dorsal no fenótipo negro. No fenótipo com manchas amarelas, as manchas dorsais se repetem, mas na asa anterior a mancha na base de $\mathrm{CuA} 2-2 \mathrm{~A}$ se expande pela célula até $\mathrm{Sc}$ e na asa posterior aparece mais uma faixa basal de margem externa uniforme entre a margem costal e $2 \mathrm{~A}$, deixando uma faixa negra entre ambas mais estreita que a faixa basal. Em alguns exemplares, a asa anterior possui as manchas amarelas bem definidas, mas na asa posterior, estas quase imperceptíveis na face dorsal e difusas na face ventral.

Genitália (Fig. 17). Caracteriza-se pela valva truncada, com fortes espinhos no ápice e sem projeção na parte ânterro-dorsal da harpe; edeago com o lóbulo distal dirigido dorso-posteriormente e mais largo na base do que a metade da abertura do edeago; ponta distal do edeago curvada ventralmente; apófises do tegumen largas, fortemente espinhosas e maiores que a metade do comprimento do unco em vista lateral; unco, em vista dorsal, não dilatado na parte distal.

Fêmea (Figs 91-93). Semelhante ao macho, porém com as asas mais alongadas e com as mesmas variações cromáticas. Comprimento da asa anterior 27 a $30 \mathrm{~mm}$.

Genitália (Fig. 17). Esterigma anelar, simples, achatado e com uma projeção distal mediana; partes do oitavo esterno simples, ligadas ao esterigma e com as partes dorsais bem delimitadas do oitavo tergo.

Discussão. Espécie facilmente reconhecível pelos caracteres diagnósticos. O fenótipo com manchas amarelas distingue-se de sua espécie mais próxima, hegesippe, pelas franjas sempre amarelas e pelo segmento pré-anal negro nos machos, às vezes, com esparsas escamas vermelhas, pelas coxas protorácicas, axilas alares anteriores negras e pelas genitálias masculina e feminina. Os vários fenótipos voam todos no mesmo lugar, razão da não aceitação de subespécies.

Distribuição espacial (Fig. 47). BRASIL - Distrito Federal: Brasília 1000m. Minas Gerais: Serra do Cipó 1250m; Poços de Caldas 1400m; Camanducaia 

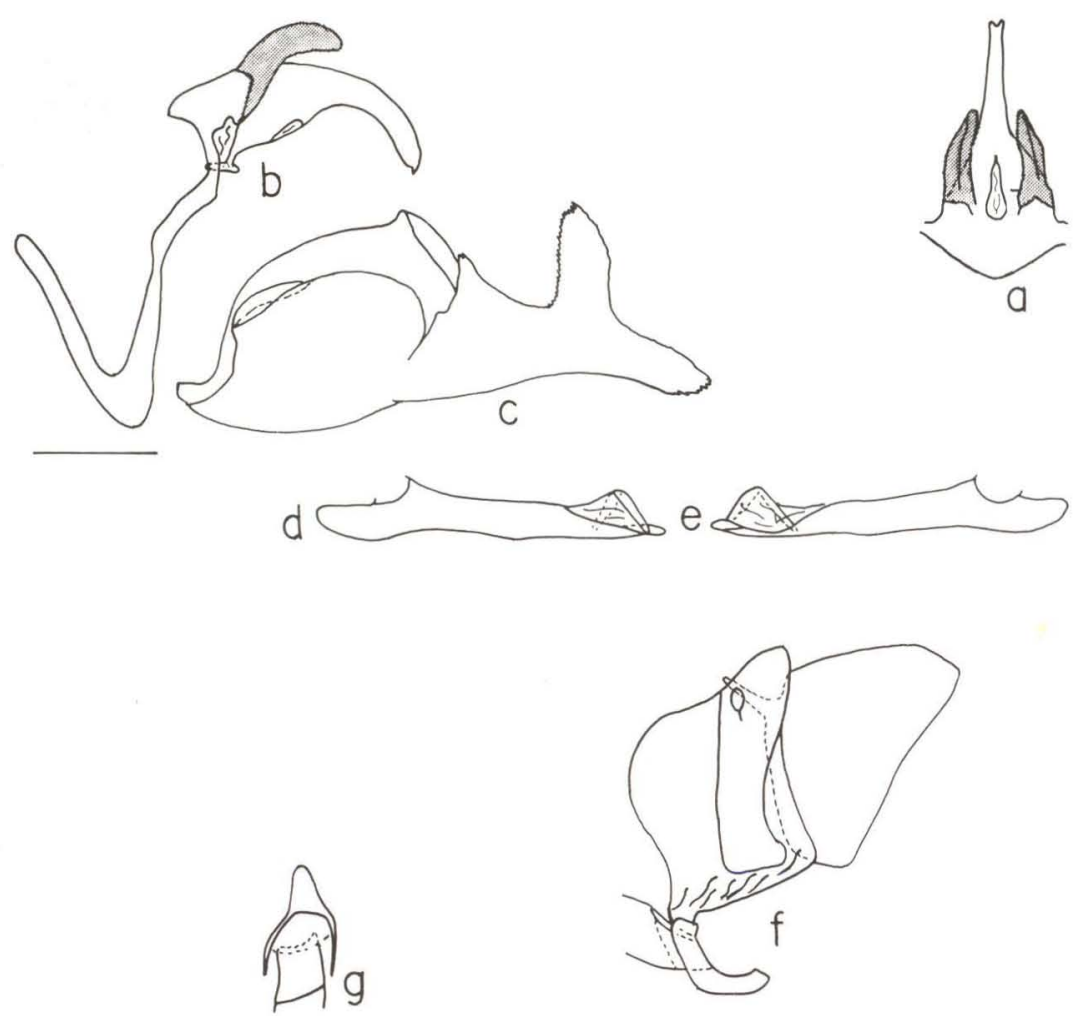

Fig. 33. Parelbella ahira ahira, genitálias masculina e feminina. (a) Vista dorsal do tegumen com apótises e unco; (b) vista lateral esquerda do saco, tegumen com apófises, unco e gnato; (c) vista interna da valva direita; (d) vista lateral esquerda do edeago: (e) vista lateral esdquerda do edeago: ( $\mathrm{f}$ ) vista lateral esquerda do oitavo segmento com esterigma e papila anal: (g) vista ventral do esterigma.

(Monteverde) 1650m; Passa Quatro 915m; São João del Rei 800-1000m. São Paulo: São Paulo 850m; Araraquara; São Bernardo do Campo; Angatuba; São José do Barreiro (Serra da Bocaina) 1550m. Paraná: Castro 1000m. Rio Grande do Sul: Pelotas $10 \mathrm{~m}$.

Distribuição temporal. Voa de janeiro a abril.

Etologia. Os machos provenientes de Poços de Caldas foram coletados na parte da tarde quando patrulhavam pequenas áreas nos campos e as fêmeas nas flores.

Planta hospedeira. Desconhecida.

Etimologia. luteizona - de luteus (latim) - amarelo e de zona (grego) - cinto, faixa; martii - espécie dedicada a Karl F. Ph. von Martius; josepha-nome de mulher; amoena - de amoenus (latim) - ameno, aprazível, encantador.

Material estudado. Um síntipo macho (nec fêmea) de luteizona, aqui designado LeCTótIPO com as seguintes etiquetas: /Type/ Luteizona P. Mab./ 

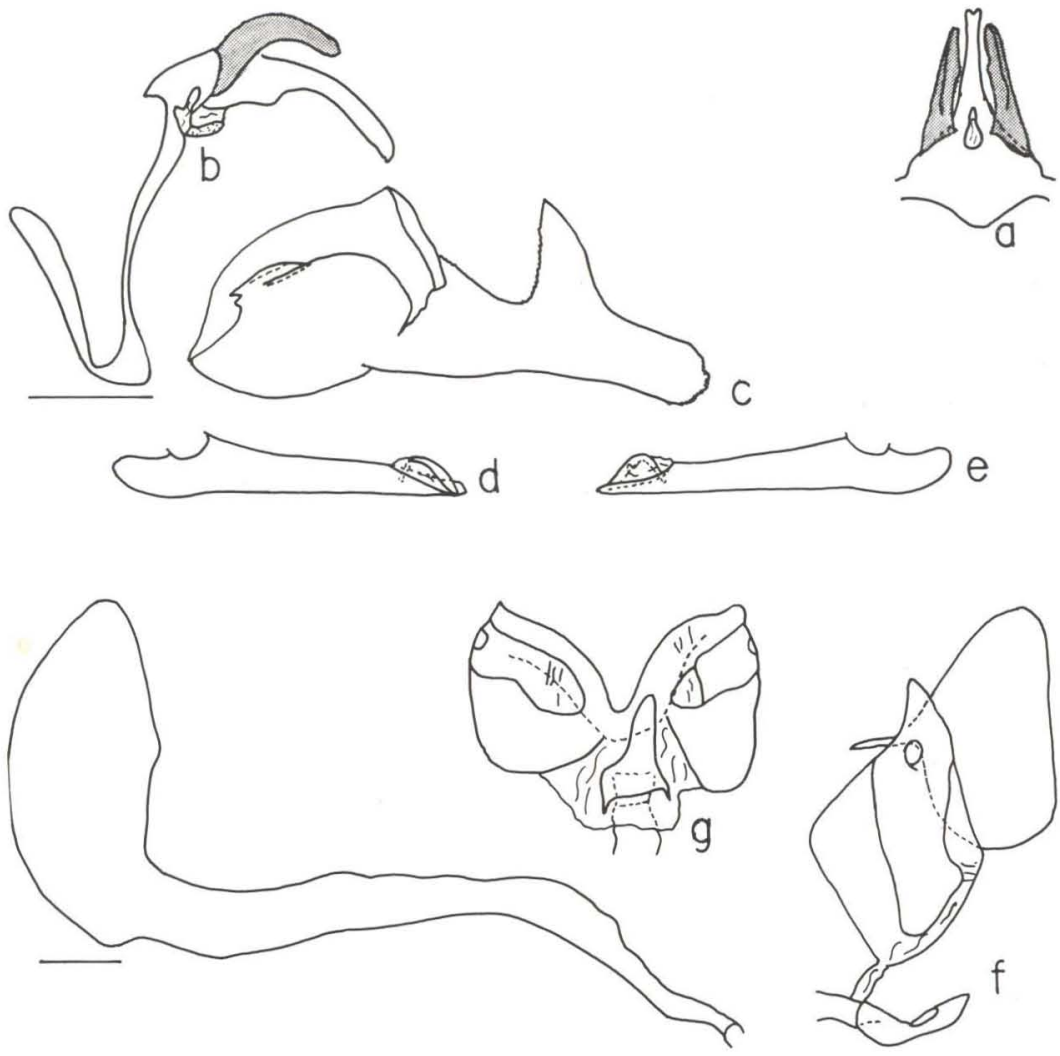

Fig. 34. Parelbella ahira extrema, genitálias masculina e feminina. (a) Vista dorsal do tegumen com apófises e unco; (b) vista lateral esquerda do saco, tegumen com apófises, unco e gnato; (c) vista interna da valva direita; (d) vista lateral esquerda do edeago; (e) vista lateral direita do edeago; (f) vista lateral esquerda do oitavo segmento com esterigma e papila anal, bolsa copuladora destacada ao lado; (g) vista ventral do esterigma e parte do oitavo esterno.

Sarbia luteizona Mab. det. Fr. J. Ball 1926/ Pyrrhopyga (sic) luteizona P. Mabille Mexique/ Mexique [ilegível]/ LECTOTIPO/ Pyrrhopyga luteizona Mabille, 1877, Lectótipo, O. Mielke det. 1993/Elbella luteizona, O. Mielke det. 1993/ (IRSC); a procedência obviamente é um erro. O holótipo de martii com as seguintes etiquetas: / Type/ 4915/ Martii Plötz */ Brasil. Virmond/ Martii Plötz Stett. Ent. Zeit. 1879, p. 525/ (ZMHB). O holótipo de josepha com as seguintes etiquetas: / 4899/ 1: 40/ Brasil Bescke/ Josepha Plötz */ Josepha Plötz. Stett. Ent. Zeit. 1879 , p. 534/ Holotypus/ (ZMHB). Como os dois síntipos de amoena estão perdidos (MIELKE 1989), designa-se aqui o Holótipo de martii como NEótIPO de amoena, a ele foram adicionadas as seguintes etiquetas: / NEOTIPO/ Sarbia amoena Röber, 1925, Neótipo, O. Mielke det. 1993/ (ZMHB). O holótipo fêmea de xanthomargo com as seguintes etiquetas: / Tipus/ Angatuba, Est. de S. Paulo III-1917, Coll. Azevedo Marques/ Pyrrhopyge xanthomargo Hayw. Q Holotipo/ 
No. 18.627/ (MNRJ). - BRASIL - Distrito Federal: Brasília (Fazenda Água Limpa), Gifford leg., 1000m, 15-III-1977 1 macho (UFPC); Brasília (Reserva Ecológica do IBGE), A Negret leg., 11 -III-1980 1 macho (IBGE). Goiás: Goiânia (Vila Brasília), Tangerini leg., 6-III-1963 I macho (NT). Mato Grosso: 1 macho (ZSBS). Minas Gerais: Lagoa Santa (Serra do Cipó), Rohbins \& Becker leg. 1250m, 19-IV-1991 3 machos (USNM); Poços de Caldas, Ebert leg., 1250m, 6-III-1964 2 machos, 28-III-1964 1 fêmea (UFPC); Poços de Caldas (Morro do Ferro), Mielke leg., 1400m, 20-III-1965 1 macho, 4-IV-1965 2 machos (UFPC-OM); Poços de Caldas (Alto de Santa Cruz), Mielke leg., 1400m, 7-IV-1965 9 machos, 3 fêmea (UFPC-OM); Poços de Caldas (Retiro Branco), Mielke leg., 1400m, 1-IV-1965 4 machos (UFPC-OM); Passa Quatro, Zikán leg., 915m, 6-Il-1923 1 macho, 4-IV-1921 1 fêmea (IOC); Camanducaia (Monteverde), Ebert leg., 1650m, 9-III-1971 I macho 1 fêmea (UFPC); São João del Rei, Ebert leg., 800-1000m, 4-IV-1955 1 macho, 8-IV-1955 I macho, I1-IV-1955 2 machos (UFPC). São Paulo: São Paulo, 850m, 3-I-1904 1 macho (UFPC); São Paulo (Ypiranga), 850m, 1 macho 1 fêmea (UFPC-OM); São Paulo (Mata do Governo), Pohl leg., 850m, II-1913 1 fêmea, I-1932 I macho 1 fêmea (MZSP); Itararé, 8-III-1910 1 macho (AME); Araraquara, 1 macho (UFPC-OM); São José de Barreiro (Serra da Bocaina), Ebert leg., 1550m, 2-4-III-1967 (UFPC). Sem procedência, 1 macho 1 fêmea (UFPC-OM).

\section{Elbella hegesippe (Mabille \& Boullet, 1908), comb.n.}

Figs $18,46,94,95$

Sarbia hegesippe Mahille \& Boullet. 1908. Ann. Sc. nat. 7: 201. 202, pl. 14, fig. 4 (= pertyi ?): 1 macho |Holótipol. Bolivia; Coll. Mabille (BMNH) |Examinadol.- Mabille, 1912. Lep. Cat. 9. p. 12.- Draudt. 1921. in Seitz. Macrolep. World 5, p. 846.- Spitz, 1932. Rev. Mus. Paulista 17: 867.- Bell. 1934. Jour. N. Y. Ent. Soc. 42: 398.- Hoffmann. 1934. Ent. Rdsch. 51. p. 26. Pyrhopyge hegesippe: Hoffmann. 1934. Eut. Rdsch. 51: 26

Hegesippe hegesippe; Evans, 1951. Cat. Amer. IIesp. 1, p. 62,pl. 7 (genitália masculina)-- Biezanko, 1963. Arq. Ent.. sér. A., Pelotas, p. 4.- Biezanko \& Mielke, 1973. Acta biol. parau. 2: 55. Mielke, 1980. Acta biol. paran. 8-9:9.- Bridges, 1983. Lep. Ilesp. 1. p. 51: 2. p. 16.- Bridges. 1988. Cat. Hesp. 1, p. 81:2, p. 26

(sem gênero) hegesippe: Beattie, 1976. Rhop. Direct., p. 157.

Diagnose. Vértice, frontoclípeo, palpos, genas, coxas anteriores parcialmente e segmentos pré-anal do macho e anal vermelhos; axilas das asas anteriores amarelas; asas negras e com grandes manchas amarelas; franjas castanho-acinzentadas.

Descrição. Macho (Fig. 94) - Comprimento da asa anterior 21 a $23 \mathrm{~mm}$. Coloração geral negra; vértice, frontoclípeo, primeiros e segundos artículos dos palpos, colar, genas, coxas anteriores e segmentos pré-anal e anal vermelhos: tégulas, com exceção de finos hordos negros, partes laterais do metascuto, partes látero-dorsais dos tergos abdominais 3 a 5 , as pleuras dos mesmos segmentos, as axilas das asas anteriores e as escamas alongadas (posteriores) das tíbias metatorácicas amarelas. 
Face dorsal da asa anterior com uma faixa mediana, composta de três manchas largas, entre a célula e $2 \mathrm{~A}$ e outra faixa subapical composta de 6 manchas de tamanhos descrescentes, em curva, entre R3 e CuAl, todas amarelas e de contornos nítidos; na margem interna, abaixo da mancha em $\mathrm{CuA2} 2 \mathrm{~A}$, uma mancha difusa da mesma coloração; franjas castanho-acinzentadas.

Face dorsal da asa posterior com larga faixa mediana amarela, cortada pelas veias negras, entre $\mathrm{Sc}+\mathrm{R} 1$ e o quarto superior de $\mathrm{CuA2}-2 \mathrm{~A}$; franjas como na mesma face da asa anterior.

Face ventral da asa anterior com as mesmas manchas da face dorsal, tendo mais uma mancha estreita de igual cor em Sc-R1, acima da mancha celular, e mais algumas escamas difusas basais e sub-basais, estas formando, às vezes, uma faixa mal indicada; franjas como na face dorsal.

Face ventral da asa posterior com a mesma faixa da face dorsal, entre a margem costal e 2A; no espaço 2A-3A, abaixo da faixa, com escamas difusas da mesma coloração; esta faixa com os bordos externo e interno difusos, às vezes, com o bordo externo muito irregular entre $\mathrm{Rs}$ e $\mathrm{CuA} 2$; na base mais uma faixa da mesma coloração entre a margem costal e a proximidade de $2 \mathrm{~A}$; o negro entre as duas faixas igual à largura da faixa basal e o negro submarginal da mesma largura da faixa mediana; franjas como na face dorsal, às vezes, tendendo para o ocráceo no ângulo anal.

Genitália (Fig. 18). Caracteriza-se pela valva truncada e a harpe terminando em pequena ponta e sem projeção na parte ântero-dorsal; edeago com a ponta distal curvada ventralmente e o lóbulo distal dirigido dorso-posteriormente e bem mais fino na base que a metade da abertura do edeago; apófises do tegumen maiores que a metade do comprimento do unco em vista lateral, delgadas e fortemente espinhosas; unco, em vista dorsal, dilatado na parte distal.

Fêmea (Fig. 95). Semelhante ao macho, porém com as asas mais arredondadas e o segmento pré-anal negro. Comprimento da asa anterior 25 a $27 \mathrm{~mm}$.

Genitália (Fig. 18). Esterigma simples, achatado e a parte mediana posterior projetada e ligado ao oitavo esterno, este não separado em duas partes, porém com dobra acima do esterigma.

Discussão. Espécie facilmente reconhecível pelos caracteres diagnósticos. Distingue-se de sua espécie mais próxima, luteizona, pelas franjas castanhoacinzentadas, pelo segmento pré-anal vermelho no macho, pelas coxas protorácicas com escamas vermelhas, pela axila alar anterior amarela e pelas genitálias masculina e feminina.

A descrição original menciona Bolívia como procedência, obviamente um lapso.

Distribuição espacial (Fig. 46). BRASIL - Paraná: Curitiba 900m; Tijucas do Sul 850m; Castro 1000m; Lapa 900m; Tibagi 1200m; Palmas 1100m. Santa Catarina: São Bento do Sul 850m; Curitibanos 850m; Lajes 900m. Rio Grande do Sul: Vacaria 850m; Bom Jesus 1000-1050m.

Distribuição temporal. Voa de janeiro a março.

Etologia. Voa nos capões de matos e em campos naturais próximos. Nunca 

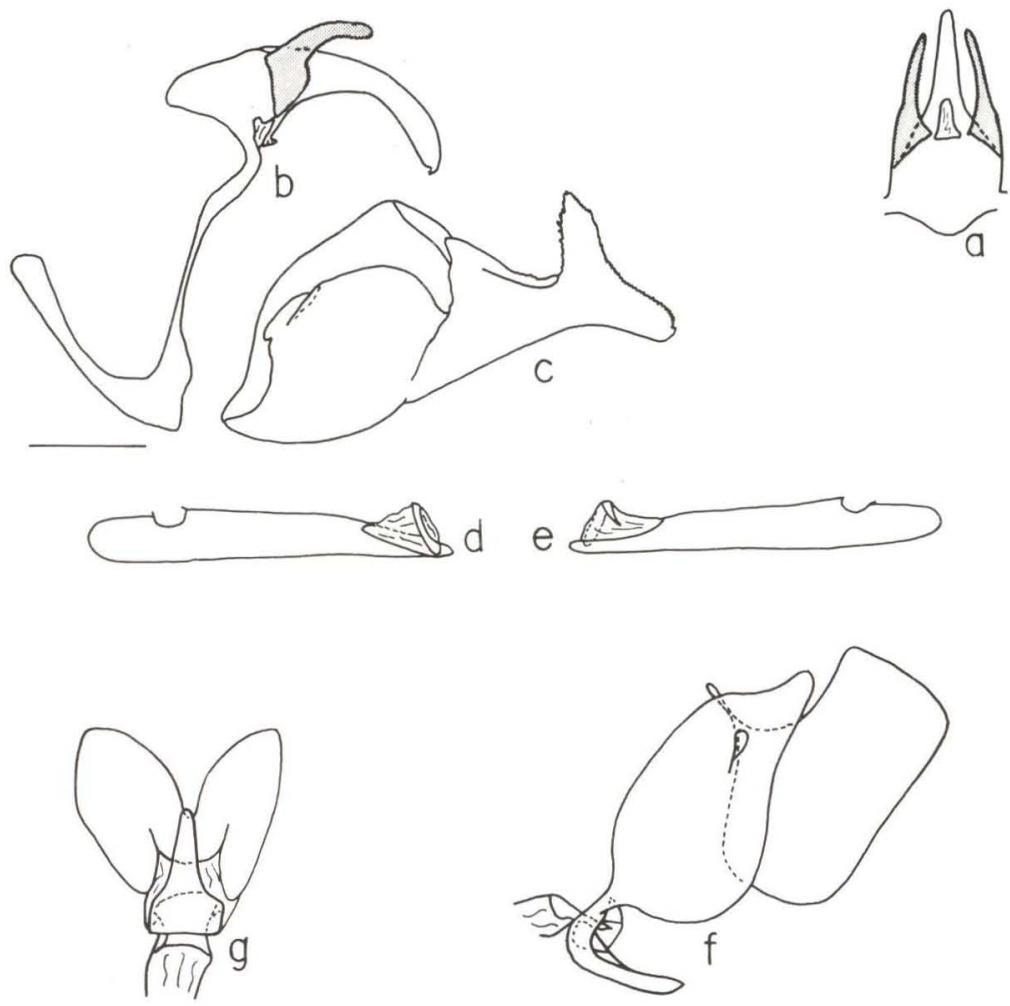

Fig. 35. Parelhella macleamami, genitálias masculina e feminina. (a) Vista dorsal do legumen com apófises e unco: (b) vista lateral esquerda do saco, tegumen com apófises. unco e gnato: (c) vista interna da valva direita: (d) vista lateral esquerda do edeago; (e) vista lateral direita do edeago: (f) vista lateral esquerda do oitavo segmento com esterigma e papila anal: (g) vista ventral do esterigma com parte do oitavo esterno.

foi vista patrulhando pequenas áreas, como o faz luteizona. É uma espécie muito rara e facilmente confundível com as espécies comuns de Sarbia Watson, 1893: xanthippe (Latreille, [1824]) e damippe Mabille \& Boullet, 1908, das quais é mimética, voando no mesmo microhahitat.

Planta hospedeira. Desconhecida.

Etimologia. Nome feminizado de Hegesippus - orador ateniano e/ou escritor eclesiástico (150-180 a.d.).

Material estudado. O holótipo macho com as seguintes etiquetas: / Type H.T./ hegesippe O"? pertyi Pl. Am. m./ Ex musaeo P. Mahille 1923/ R. Oberthür Coll. Brit. Mus. 1931-196/ (BMNH); a procedência Bolívia, mencionada na descrição original, é obviamente um erro. - Brasil - Paraná: Curitiba, Mielke leg., 900m, 4-II-1966 I macho (UFPC-OM), 28-II-1967 I macho, 25-I-1979 1 macho (UFPC), 31-I-1993 1 macho (UFPC-OM); São José dos Pinhais, Mielke 
leg., 900m, 13-II-1981 (UFPC); São José dos Pinhais, Mielke \& Callaghan leg. , 900m, 27-II-1986 1 macho (UFPC); Tijucas do Sul (Rincão), Mielke \& Laroca leg., 850m, 13-II-1969 3 fêmeas, 25-II-1969 1 fềmea (UFPC); Tijucas do Sul (Rincão), Mielke leg., 850m, 10-II-1974 1 macho (UFPC); Lapa, 900m, 1 macho 1 fêmea (MZSP); Tibagi, Mielke \& Casagrande leg., 1200m, 4-II-1986 1 macho (UFPC); Palmas, Mielke \& Buzzi leg., 1100m, 6-II-1976 1 fêmea (UFPC). Santa Catarina: São Bento do Sul, Rank leg., 850m, I-II-1988 (UFPC-OM); São Bento do Sul (Rio Vermelho), Rank leg., 850m, 15-III-1989 1 macho 1 fêmea (UFPC-OM); Curitibanos, H. \& H. D. Ebert leg., 850m, 21-II-1973 1 macho, (UFPC); Lajes, 1 fêmea (ZMHB). Rio Grande do Sul: 1 fềmea (AMNH); Vacaria, Mielke \& Casagrande leg., 850m, 21-II-1983 1 fêmea (UFPC); Bom Jesus (Arroio Tiririca), Mielke leg., 1000m, 27-II-1973 1 macho (UFPC); Bom Jesus, Mielke \& Buzzi leg., 1050m, 17-II-1976 1 macho (UFPC); Pelotas, Biezanko leg., 10m, 14-III-1960 1 macho, 23-III-1964 I fêmea (UFPC-OM), 27-III-1967 1 macho (UFPC); Pelotas, Becker leg., 10m, 12-III-1966 1 fêmea (UFPC).

II - Grupo com tufo anal negro e grandes manchas alaranjadas na asa anterior. Espécie mimética com Mimoniades ocyalus Hübner, 1823.

\section{Elbella iphinous (Latreille, [1824])}

Figs $19,46,96-98$

Hesperia iphinous Latreille, [1824]; in Godart \& Latreille. Enc. Méth. 9. p. 736; Brésil, Langsdorff leg.; Lectótiro macho aqui designado (BMNH) [Examinado].

Pyrrhopyga (sic) iphinous; Ménétriés, 1855. En. Corp. An. Mus. Petr. 1, p. 60.- Kirby, 1879. Cat. Coll. Diurn. Lep. Hew., p. 207; syn.: ocyalus.

Myscelus iphinous; Herrich-Schäffer, 1869. Corr.-Blatt zool.-min. Ver. Regensburg 23: 71, 166 ; syn.: ocyalus.

Pyrrhopyge iphinous: Kirby, 1871. Syn. Cat. Diurn. Lep., p. 586; syn.: ocyalus.- Kirby, 1880. Proc. r. Dublin Soc., 2: 327 .

Pyrrhopyga (sic) othello Plötz, 1879. Stett. ent. Ztg. 40: 522; Brasil; NEótıPo macho aqui designado (UFPC) [Examinado].

Mimoniades iphinous; Watson, 1893. Proc. zool. Soc. London, p. 14.- Mabille, 1903, in Wytsman. Gen. Ins. 17, p. 12.- Mabille \& Boullet, 1908. Ann. Sc. nat. 7: 202, 203.- Mabille, 1909. Bull. Soc. ent. France, p. 335.- Lindsey, 1925. Ann. Ent. Soc. Amer. 18: 92.

Mimoniades mimetes Mabille, 1909. Bull. Soc. ent. France, p. 335: 1 exemplar, Brasil; NeótıPo macho aqui designado (UFPC) [Examinado].- Mabille, 1912. Lep. Cat. 9, p. 12.- Draudt, 1921. in Seitz. Macrolep. World 5, p. 847.- Zikán, 1928. Ent. Rdsch. 45: 10.

Phocides iphinous; Mabille \& Boullet, 1912. Ann. Sc. nat. 16: 11, 12.- Draudt, 1921, in Seitz, Macrolep. World 5, p. 851.- Riley, 1926. Trans. ent. Soc. London 74: 232.- Shepard, 1931. Lep. Cat. 47, p. 8.- Bell, 1932. Trans. Amer. Ent. Soc. 58: 183.- Shepard, 1936. Lep. Cat. 74. p. 606 .

Hesperia othello; Riley, 1926. Traus. ent. Soc. London 74: 232; syn.: mimetes.

Mimoniades othello: Bell, 1934. Jour. N. Y. Ent. Soc. 42: 401, pl. 22, fig. 6 (genitália masculina): syn.: mimetes.- Hayward, 1942. Bol. Mus. Nac., Rio de Janeiro, 14-17: 74; syn.: mimetes.Silva et al., 1968. Quart. Cat. Ins. viv. Plant. Brasil, 2 (1), p. 323; plant. hospedeira.- Zikán \& Zikán, 1968. Pesq. agropec. bras. 3: 61 . 
Mimoniades othello var. nigrita Zikán, 1938. Rev. Ent.. Rio de Janeiro, 9: 322: 2 machos, janeiro e fevereiro, Itatiaia, $1100 \mathrm{~m}$; Lectótipo macho (IOC) [Examinado].

Elhella iphinous; Evans, 1951. Cat. Amer. Hesp. 1, p. 42, pl. 5 (genitália masculina): syn.: othello. mimetes, nigrita.- Ebert, 1968, in Silva et at. Quart. Cat. Ins. viv. Plaut. Brasil 2 (2), p. 240. Mielke, 1971. Rev. Bras. Biol. 31: 250, figs. 3-4, 49-52 (genitália masculina); syn .: var nigrita. Lectótipo.- Bridges, 1983. Lep. Catt. 1, p. 58, 76, 82, 87; 2, p. 12: syn.: othello, mimetes, nigrita.- Bridges, 1988. Cat. Hesp. 1, p. 92, 120, 129, 138: 2, p. 19: syn.: othello, mimetes, nigrita.

Mimoniades othello nigrita: Zikán \& Zikán, 1968. Pesq. agropec. bras. 3: 61, planta hospedeira.Silva et al., 1968. Quart. Cat. Ins. viv. Plant. Brasil 2 (1), p. 323: planta hospedeira.

(sem gênero) iphinous: Beattie, 1976. Rhop. Direct., p. 170.

(sem gênero) othello: Beattie, 1976. Khop. Direct., p. 221.

(sem gênero) mimetes; Beattie, 1976. Rhop. Direct., p. 202.

(sem gênero) nigrita: Beatlie, 1976. Rhop. Direct.. p. 212.

Diagnose. Face dorsal da asa anterior com uma faixa mediana larga entre a célula discal e $2 \mathrm{~A}$, uma mancha aproximadamente losangular entre M3 e CuA 1 e uma estreita faixa apical entre R2 ou R3 e M2, todas alaranjadas.

Descrição. Macho (Figs 96, 97) - Comprimento da asa anterior 23 a $26 \mathrm{~mm}$. Coloração geral castanho anegrado; com escamas brancas nas partes anterior e laterais do frontolípeo, duas pequenas manchas entre as antenas, escassas escamas no ocipício, nas partes externas dos patágios, às vezes, nas tégulas, palpos, genas e nas axilas das asas anteriores, às vezes, também nas partes proximais dos tergos e esternos abdominais, nestes mais acentuado no último, junto à genitália.

Face dorsal da asa anterior com larga faixa mediana e curva entre a célula discal (55mm de largura) e $2 \mathrm{~A}$ (6 mm de largura), uma faixa apical estreita entre R2 ou R3 e M2, mais espessa na parte superior e bem fina na parte inferior e uma mancha losangular em M3-CuAl, exatamente entre as duas faixas mencionadas. embaixo das discocelulares ou na base de M3, todas alaranjadas; às vezes, com escamas azuis difusas nas discoceluares; franjas concolores.

Face dorsal da asa posterior, às vezes, sem desenhos, mas geralmente com duas faixas vestigiais de escamas difusas azuis, uma central em CuA2-2A e outra submarginal entre Ml e 2A: franjas brancas com as terminações das veias negras. Face ventral da asa anterior com as mesmas manchas alaranjadas, sendo no entanto a em CuA2-2A amarelo clara; margem interna castanho clara, com a base amarelo clara, assim como a hase e a parte submarginal de CuA2-2A; com escamas azuis claras na margem costal acima da faixa mediana e, às vezes, nas discocelulares; franjas concolores, com exceção em CuA2-2A, algo acinzentadas.

Face ventral da asa posterior com três faixas compostas de manchas difusas azuis, uma basal entre o ângulo umeral e 2A, uma sub-basal entre Sc+R1 e $2 \mathrm{~A}$ e uma discal entre $\mathrm{Sc}+\mathrm{R} 1$ e $2 \mathrm{~A}$, sendo que a mancha em $\mathrm{Sc}+\mathrm{R} 1-\mathrm{R}$ s pouco deslocada para a base; margem interna da mesma tonalidade de azul; às vezes, com mais uma faixa submarginal muito difusa e da mesma cor ou só com a basal presente; franjas como na face dorsal, sendo a coloração geral reduzida nas terminações das veias; o azul da face ventral pode estar reduzido às faixas basal e marginal interna. Um exemplar macho aberrante (Fig. 97) de Mauá, Resende, Estado do Rio de 
Janeiro, não possui as manchas alaranjadas na asa anterior.

Genitália (Fig. 19). Caracteriza-se pela harpe bilobada, sendo a projeção distal maior que a dorsal, e sem projeção na parte ântero-dorsal; apófises do tegumen arredondadas, pequenas, aproximadamente $1 / 4$ do comprimento do unco em vista lateral, não parecendo pedunculadas como em mariae; unco com constricção em vista dorsal; sáculo unilobado; edeago com o lóbulo distal dirigido dorso-posteriormente e aproximadamente da largura da metade da abertura do edeago; edeago com a ponta distal curvada ventralmente.

Fêmea (Fig. 98). Semelhante ao macho, porém com as asas mais arredondadas. Comprimento da asa anterior 28 a $29,5 \mathrm{~mm}$. Na face ventral da asa anterior, às vezes, com escamas difusas azuis na parte externa da faixa mediana em $\mathrm{CuA2}-2 \mathrm{~A}$; na face ventral da asa posterior, às vezes, com manchas difusas, da mesma coloração das demais faixas, entre as faixas sub-basal e discal e entre esta e a margem externa.

Genitália (Fig. 46). Caracteriza-se pelo esterigma em forma de bolha, teminando em ponta mediana pouco aguda e com o óstio na parte dorsal; partes laterais do oitavo esterno sem estrias longitudinais.

Discussão. Muito bem caracterizada pelas manchas alaranjadas na asa anterior, mimetizando com Mimoniades ocyalus Hübner, 1823, outro Pyrrhopyginae. A espécie mais próxima é, sem dúvida, mariae, pois as genitálias são muito semelhantes, diferindo por alguns detalhes mencionados nas descrições das mesmas. Como estas diferenças são constantes, a hipótese de que sejam subespécies, já que ocupam áreas diferentes, está eliminada. Veja também a discussão em mariae.

Distribuição espacial (Fig. 46). BRASIL - Minas Gerais: Poços de Caldas 1400m; Passa Quatro 1500m; Virgínia 1400m; Camanducaia (Monteverde) $1650 \mathrm{~m}$. Rio de Janeiro: Teresópolis $1000 \mathrm{~m}$; Petrópolis $1100 \mathrm{~m}$; Itatiaia 1000 1600m. São Paulo: São José do Barreiro 1550-1750m; Campos do Jordão $1600-2000 \mathrm{~m}$.

Distribuição temporal. Voa entre dezembro e abril, isto é, no verão.

Etologia. Voa nas florestas, visitando flores nos campos próximos e na parte da tarde diputa território nos campos e nos topos dos morros.

Planta hospedeira. Guará-mirim Iprovavelmente Myrcia racemosa (Berg) Kiaersk. var. gaudichaudiana (Berg) Legr.] (ZIKÁN \& ZIKÁN 1968 e Silva et al. 1968) e camboim [provavelmente Myrciaria tenella (DC.) Berg, Myrtaceae] (SILVA et. al. 1968).

Etimologia. iphinous - nome de um Centauro mencionado nas "Metamorphoses" de Ovídio; othello - nome próprio; Biog. nascido em Udina, ensinou direito em Pádua; mimetes - refere-se ao mimetismo com iphinous, esta erroneamente reconhecida pelo autor como sendo uma espécie de Phocides Hübner, [1819] (Pyrginae); nigrita - nome alusivo à cor geral da variedade, isto é, sem manchas azuis na asa posterior.

Material estudado. Um síntipo macho de iphinous aqui designado LeCtótrPo, com as seguintes etiquetas: / Type H. T./ iphinoë/ H. iphinous Lat. 

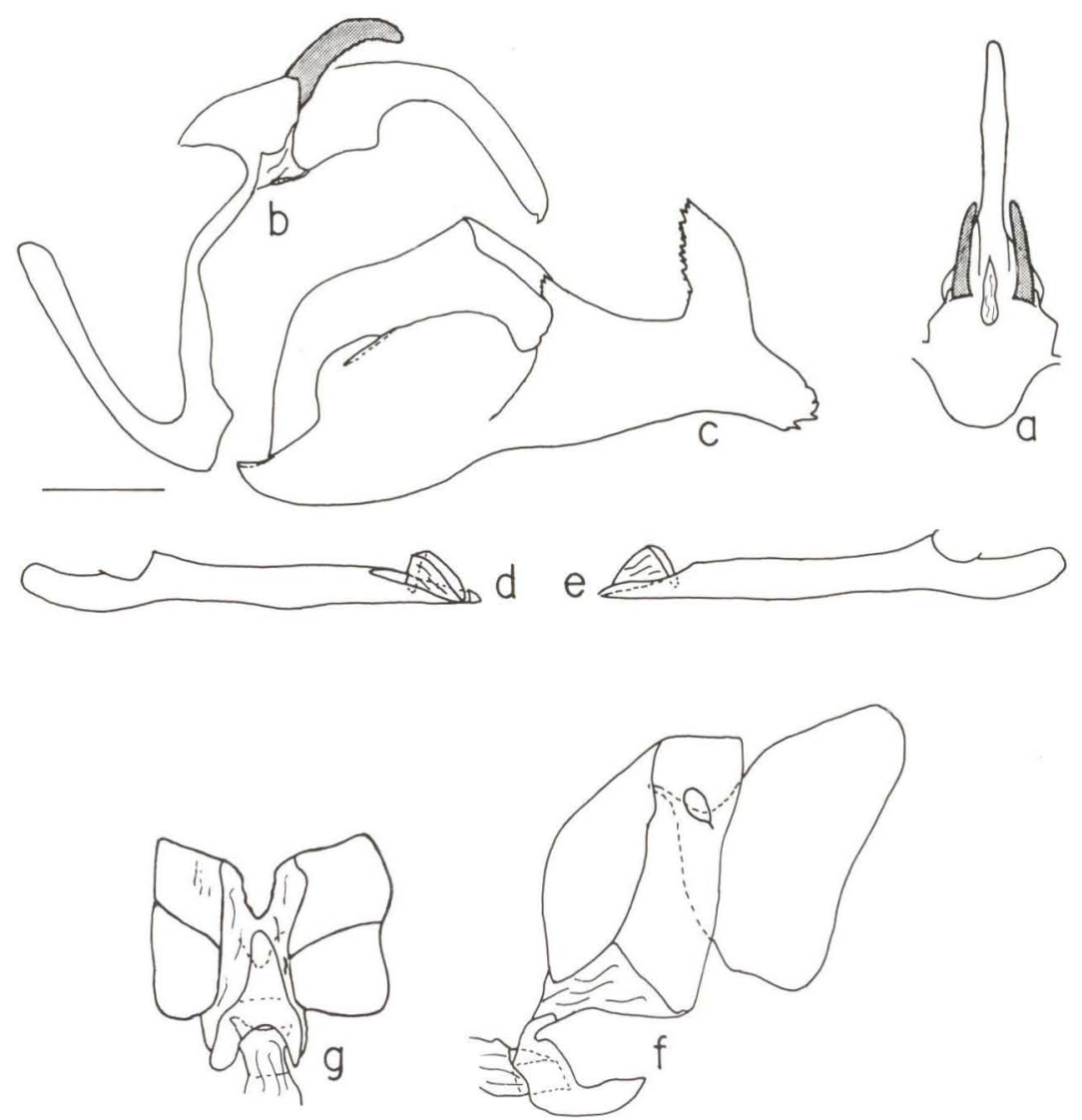

Fig. 36. Parelbella peruana, genitálias masulina e feminina. (a) Vista dorsal do tegumen com apófises e unco: (b) vista lateral esquerda do saco, legumen com apófises, unco e gnato: (c) vista interna da valva direita; (d) vista lateral esquerda do edeago; (e) vista lateral direita do edeago; (f) vista lateral esquerda do oitavo segmento com esterigma e papila anal: $(g)$ vista ventral do esterigma e parte do oitavo esterno.

Brésil/ Mimoniad. mimetes Mab. Brésil/ Ex musaeo P. Mabille 1923/ R. Oberthür Coll. Brit. Mus. 1931-136/ cartão com o preparado da genitália/ LECTOTIPO/ Hesperia iphinous Latreille, [1824], Lectótipo, O. Mielke det. 1993/ Elbella iphinous Latreille, [1824], O. Mielke det. 1993/ (BMNH). Como os tipos de othello e mimetes estão perdidos, designa-se aqui o mesmo exemplar macho como NEÓTIPO dos dois nomes, possuindo as seguintes etiquetas: / NEOTIPO mimetes, othello/ P. N. Itatiaia, Resende, RJ, 10-I-1973 1200m, Mielke [leg.]/ DZ $4179 /$ Mimoniades mimetes Mabille, 1909, Neótipo, O. Mielke det. 1993/ Mimoniades othello Plötz,1879, Neótipo, O. Mielke det. 1993/ Elbella iphinous Latreille, [1824], O. Mielke det. 1993/ (UFPC). O Lectótipo macho de nigrita (MIELKE 1971) com as seguintes etiquetas: / $\sigma^{\prime} /$ LECTOTIPO/ TYPUS/ 11.-2.-[19|26 
Mar.[omba]/ Mimoniades othello Pltz. var. nigrita Zik./ Coleção J. F. Zikán/ Mimoniades othello var. negrita Zikán, 1938, Lectótipo, O. Mielke det. 1993/ Elbella iphinous (Latr., 1824) Mielke det./ I.O.C., Lepidop. 33.001/ (IOC). BRASIL - Minas Gerais: Poços de Caldas (Morro do Ferro), Mielke leg., 1400m, 28-III-1965 5 machos, 31-III-1965 1 macho 1 fêmea, 2-IV-1965 1 macho (UFPC-OM); Poços de Caldas (Retiro Branco), Mielke leg., 1400m, 2-IV-1965 1 fêmea (UFPC-OM); Passa Quatro (Fazenda São Bento), Mielke \& Casagrande leg., 13-II-1984 2 fêmeas (UFPC-OM); Virginia (Fazenda dos Campos), Zikán leg., 1400m, 30-III-1916 1 macho (UFPC); Camanducaia (Monteverde), Ebert leg., 1650m, 9-III-1971 1 macho (UFPC). Rio de Janeiro: Teresópolis, 1 macho 1 fêmea (MNRJ); Teresópolis, A. Costa leg., 19221 macho (MNRJ); Teresópolis, II-1923 1 macho (MNRJ); Petrópolis, I macho (USNM), 1 fêmea (MNRJ); Petrópolis, Ebert leg., 1100m, 12-II-1972 1 macho (UFPC); Itatiaia (Maromba), Zikán leg., 1200m, 5-II-1926 1 macho, 14-II-1926 1 macho (MNRJ), 20-III-1916 1 macho, 23-III-1917 1 fềmea, 4-II-1925 1 macho 1 fêmea, 25-I-1926 1 macho, 4-II-1926 1 macho, 22-XII-1929 1 macho, 4-I-1930 1 macho, 5-I-1930 1 fêmea, 7-II-1930 1 fêmea, 10-I-1939 1 fêmea, 14-III-1942 1 fêmea (IOC), I-1935 1 macho, II-1935 1 fêmea (MZSP); Itatiaia (Maromba), Gagarin leg., 1200m, 24-I-1936 1 macho, 25-I-1936 1 macho, 28-I-1936 1 macho (MNRJ); Itatiaia (Maromba), Santos leg., 1200m, 15-I-1953 6 machos (UFPC-OM); Itatiaia, Ebert leg., 1500m, 21-II-1959 1 macho (UFPC); Itatiaia, Ebert leg., 1600m, 14-II-1959 1 macho (UFPC); Itatiaia, Ebert leg. , 1000-1200m, 19601 fêmea (UFPC); Itatiaia, 1 macho 1 fêmea (MNRJ); Itatiaia, Mielke leg., 1200m, 13-I-1973 4 machos 1 fêmea (UFPC); Itatiaia, Ebert leg., 1400m, 10-II-1959 1 fêmea, 14-II-1959 1 macho (UFPC); Resende (Mauá), 1200m, 18-I-1958 1 macho (aberrante) (UFPC-OM), XII-1957 1 fêmea, 29-I-1958 1 macho (UFPC). São Paulo: São José do Barreiro (Serra da Bocaina), Ebert leg., 1550-1750m, 2-III-1966 2 fêmeas, 2-4-III-1967 1 macho (UFPC), 2-III-1967 1 macho (UFPC-OM); Campos do Jordão, C. Guinle leg., II-1935 1 macho (MNRJ); Campos do Jordão, Ebert leg., 1750m, 6-III-1964 1 macho 1 fêmea (UFPC), 24-30-I-1966 1 macho, II-1966 1 fêmea, 3-II-1966 1 fêmea (UFPC); Campos do Jordão, Mielke \& Casagrande leg., 1600-2000m, 8-II-1982 1 macho (UFPC); Campos do Jordão (Umuarama), Gagarin leg., 1800m, 3-15-II-1937 2 machos 1 fêmea, 8-15-IV-1937 2 fêmeas (UFPC). Sem procedência, 1 macho (MNRJ).

III - Grupo com tufo anal negro, com manchas brancas semihialinas na asa anterior e desenhos azuis nas asas. Espécies miméticas com as de Jemadia Watson, 1893.

Este grupo, de fácil distinção dentro do gênero quanto ao aspecto cromático das asas, é de difícil separação específica. As espécies só são identificáveis com segurança pelo exame da genitália, às vezes, a distribuição geográfica ajuda para algumas espécies. Como não existem estudos sobre as fêmeas, estas foram associadas aos machos pela distribuição geográfica ou pela semelhança de suas genitálias com as de outras espécies do primeiro grupo, como é o caso de theseus. Somente de Elbella merops obteve-se um casal capturado em cópula.

A seguir uma descrição generalizada dos caracteres cromáticos de todas as 

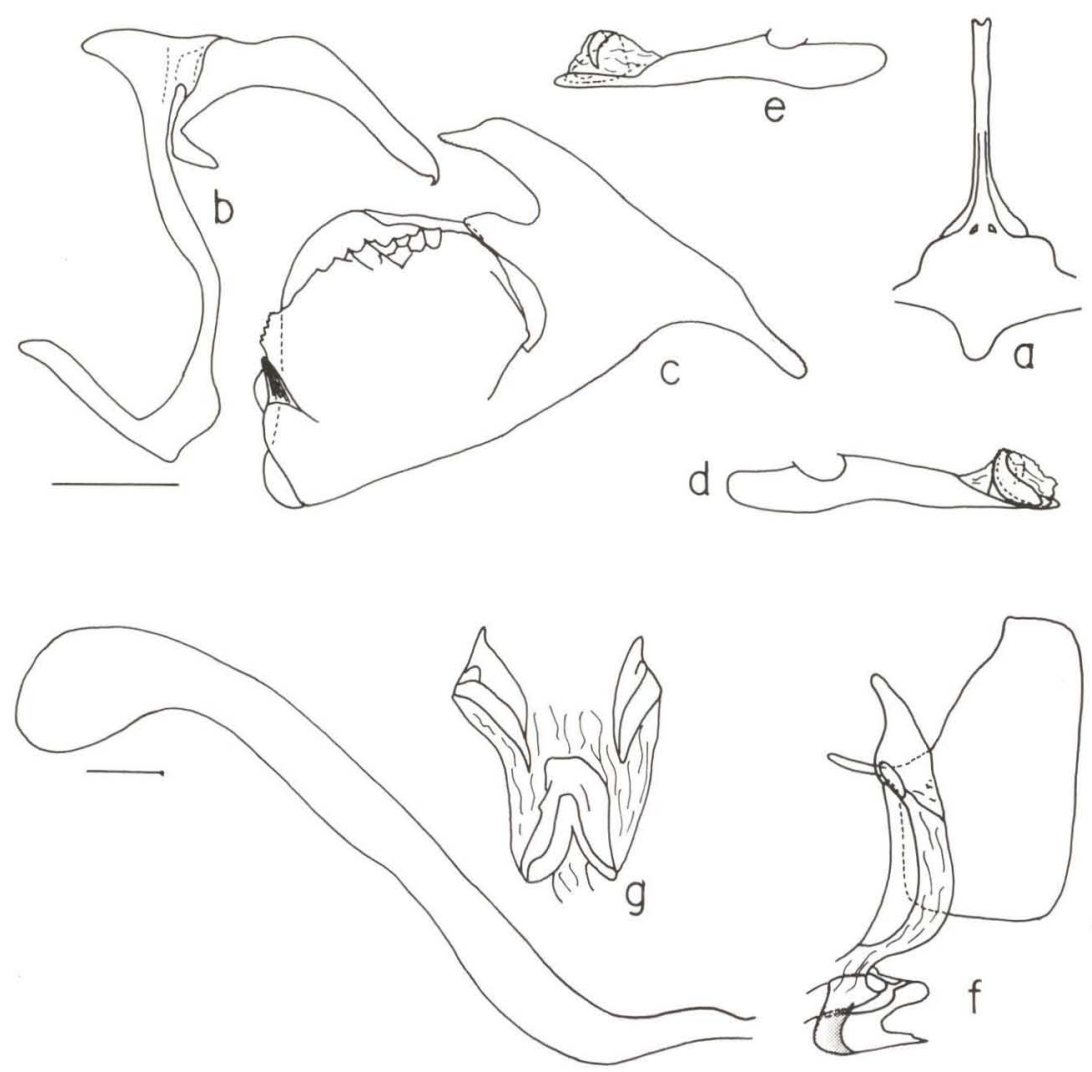

Fig. 37. Pseudocroniades machaon machaon, genitálias masculina e feminina. (a) Vista dorsal do tegumen e unco: (b) vista lateral esquerda do saco, tegumen. unco e gnato: (c) vista interna da valva direita; (d) vista lateral esquerda do edeago: (e) vista lateral direita do edeago: (t) vista lateral esquerda do oitavo segmento com esterigma e papila anal, bolsa copuladora destacada ao lado; (g) vista ventral do esterigma e parte ventral do oitavo esterno.

espécies, para quando na descrição de cada uma, só se apresentar os detalhes característicos.

Coloração geral negra, com uma série de manchas ou faixas brancas ou branco-azuladas no corpo; cabeça com manchas brancas na parte anterior (às vezes, duas contíguas) e nas partes laterais do frontoclípeo, junto aos olhos e entre as antenas (às vezes, duas contíguas) no vértice; com faixas transversais, da mesma cor, uma na parte posterior do vértice e mais alargada entre as antenas e os olhos e outra na parte anterior do colar; palpos com os primeiros artículos brancos, às vezes, com as partes centrais e internas negras; segundo artículo dos palpos branco com as partes distal e lateral externa negras; antenas negras; genas brancas, normalmente com partes negras ou castanhas; tórax dorsalmente com os patágios possuindo uma linha central e transversal branca; tégulas com linha central 
longitudinal, continuando pelo mesoscuto e mesoescutelo da mesma cor, passando a ligeiramente azulado nas duas últimas estruturas; a faixa do mesoscuto vai, às vezes, até o mesoescutelo, ao lado interno de cada uma das tégulas; parte inferior do mesoescutelo, acima da base da asa posterior, com tufo de longas escamas brancas; tórax ventralmente com manchas brancas na axila da asa anterior; parte inferior do mesepimero, infra-posterior do mesomeron e inferior do metepimero, coxas e partes internas dos artículos das pernas protorácicas, partes interna do fêmur e externa das tíbias mesotorácica e metatorácica brancas; abdome com as metades basais e laterais dos tergos brancos, levemente azulados, reduzindo-se de largura para os últimos segmentos e para a pleura em cada segmento, deixando uma linha negra, mediana e dorsal de aproximadamente $1 \mathrm{~mm}$; abdome ventralmente como no lado dorsal, somente as faixas mais estreitas, às vezes, ausentes nos últimos segmentos, deixando uma fina linha negra, mediana e ventral quase imperceptível e com pequeno tufo de escamas da mesma cor no $8^{\circ}$ segmento, ladeando as valvas retraidas.

Face dorsal da asa anterior com 3 manchas brancas semihialinas formando uma faixa mediana entre a célula discal e o meio entre $\mathrm{CuA2} 2 \mathrm{~A}$, normalmente mais estreita nos extremos e de largura variada, esta medida na mancha em $\mathrm{CuA} 1-\mathrm{CuA} 2$; com uma mancha semelhante, raras vezes ausente, de largura variada, entre a base de $\mathrm{M} 3$ e CuA1, aproximadamente paralela à faixa anterior e com 5 manchas apicais da mesma coloração, formando uma faixa entre R3 e M3, sempre mais larga na parte central (M1-M2) e de largura variando entre 1 e 2,5mm, às vezes, com mais uma pequena mancha branca e opaca em R2-R3, porém deslocada para a base. Ainda com uma série de linhas e manchas azuis assim distribuídas: uma faixa azul muito clara, basal e axilar, entre a subcosta e a margem interna; uma sub-basal entre a subcosta e a margem interna, terminando acima do espaço entre as faixas azuis basal e mediana da asa posterior; uma outra submarginal composta de manchas difusas e irregulares entre M I e 2A, externamente e abaixo das manchas apicais; outra mancha longitudinal na margem interna e partindo da parte inferior da mancha submarginal em CuA1-CuA2 até o meio da asa onde atinge normalmente o nível da mancha branca da célula e outra semelhante na metade inferior de CuA2-2A, acima da anterior, porém iniciando-se abaixo da faixa branca mediana semi-hialina e terminando junto com a anterior, normalmente dilatada na base, tocando muitas vezes $\mathrm{CuA2}$; às vezes; ainda com uma faixa nas discocelulares e escamas difusas da mesma cor entre as manchas apicais e a margem externa entre M 1 e M3 e, às vezes, acima da faixa sub-basal, em Sc-R1, na margem costal; franjas concolores.

Face dorsal da asa posterior com três faixas azuis de larguras variáveis, sendo a basal, às vezes, branco azulada e a mediana azul esbranquiçada, mas muito variável intra-especificamente, todas entre Rs e $2 \mathrm{~A}$, sendo que a discal, às vezes, penetra de modo difuso em $\mathrm{Sc}+\mathrm{R}$ 1-Rs e mais raramente com escamas difusas azuis na margem costal, e a mediana e a discal penetram no meio do espaço $2 \mathrm{~A}-3 \mathrm{~A}$; espaços $2 \mathrm{~A}$ e $3 \mathrm{~A}$ com difusas escamas azuis no centro; franjas brancas, com as terminações das veias concolores ou só brancas nos espaços da parte posterior.

Face ventral da asa anterior com os mesmos desenhos da face dorsal, 

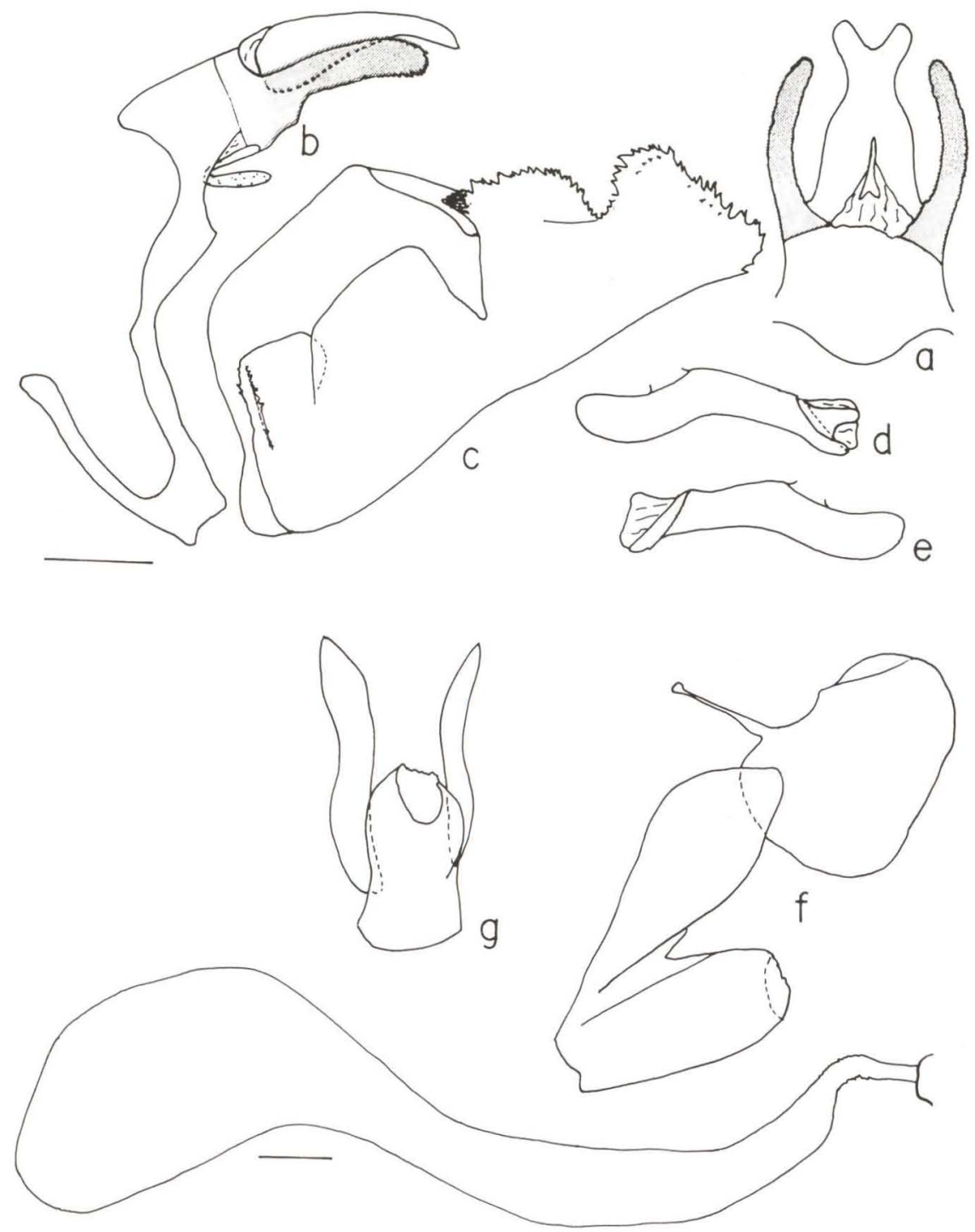

Fig. 38. Protelbella albuma albuma, genitálias masculina e feminina. (a) Vista dorsal do tegumen com apófises e unco; (b) vista lateral esquerda do saco, tegumen com apófises, uneo e gnato; (c) vista interna da valva direita: (d) vista lateral esquerda do edeago: (e) vista lateral direita do edeago: (f) vista lateral esquerda do oitavo segmento com esterigma e papila anal. bolsa copuladora destacada abaixo: (g) vista ventral do esterigna e parte do oitavo esterno. 
diferindo pela presença de escamas brancas acima da faixa semi-hialina mediana na margem costal; as escamas azuis acima das faixas basal e sub-basal mais densas e, às vezes, unidas; a faixa sub-basal mais dilatada e esbranquiçada entre o cúbito e 2A; a mancha azul longitudinal em CuA2-2A ausente; mancha na margem interna muito reduzida e difusa, às vezes, azul esbranquiçada; manchas azuis submarginais maiores e difusas; franjas como na face dorsal.

Face ventral da asa posterior com uma série de faixas azuis; uma sub-basal, reta do ângulo umeral até $2 \mathrm{~A}$; uma mediana, reta a ligeiramente curva, entre $\mathrm{Sc}+\mathrm{R} 1$ e $2 \mathrm{~A}$, uma discal entre $\mathrm{Rs}$ e $2 \mathrm{~A}$, reta e curva no espaço final e mais duas manchas aproximadamente quadradas entre $\mathrm{Sc}+\mathrm{R} 1$, acima da faixa discal, $\mathrm{e}$ partindo destas, faixas adicionais nos lados basal e distal da faixa discal, da mancha mais basal, às vezes, ausente, e da mancha mais distal podem ser até CuA2; margem interna, após $3 \mathrm{~A}$, azul; espaço $2 \mathrm{~A}-3 \mathrm{~A}$ com uma ou duas manchas difusas como se fossem continuações das faixas mediana e discal ou inteiramente azul; margem costal com difusas manchas azuis mais intensas no ápice; franjas brancas, com as terminações das veias concolores ou só brancas nos espaços posteriores.

\section{Elbella miodesmiata (Röber, 1925), stat.rev. Figs 20,47, 99}

Jemadia miodesmiata Röber, 1925. Ent. Mitt. 14: 88: 1 macho [holótipol. Rio Magdalena, West Kolumbien; Né́tró macho, aqui designado (BMNH) [Examinado].- Bell, 1933. Jour. N. Y. Ent. Soc. 41: 502.- Hayward, 1947. Acta zool. lill. 4: 222.

Elhella umbrata miodesmiala; Evans. 1951. Cat. Amer. Hesp. 1. p. 45, pl. 5 (genitália do macho).Bridges, 1983. Lep. Hesp. 1, p. 77; 2, p. 12.- Bridges, 1988. Cat. Hesp. 1, p. 121; 2. p. 19.Mielke, 1989. Revta bras. Zool. 6: 142. (sem gênero) miodesmiata; Beattie, 1976. Rhop. Direct., p. 203.

Diagnose. A genitália masculina caracteriza a espécie.

Descrição. Macho (Fig. 99) - Comprimento da asa anterior 24 a $25 \mathrm{~mm}$. Genas brancas com as partes centro-basal e interna negras.

Face dorsal da asa anterior com a faixa branca mediana entre 2 e $2,5 \mathrm{~mm}$ de largura máxima; a mancha branca em M3-CuAl fina, um quarto a um sétimo de sua altura; faixa branca apical estreita, porém pouco mais larga que a mancha anterior, a mancha em M1-M2 1,4 a 1,5 vezes mais larga que alta; escamas azuis difusas nas discocelulares; manchas da faixa azul submarginal finas em M1-CuA1; manchas azuis longitudinais, abaixo da faixa branca mediana, curtas, não atingindo o nível basal da mancha branca da célula e a superior não expandida na base até $\mathrm{CuA} 2$.

Face dorsal da asa posterior com a faixa azul discal ligeiramente mais larga que a faixa azul mediana e com poucas escamas escassas azuis em Sc+R1-Rs, acima do ângulo basal da faixa discal; franjas brancas entre as veias negras, mais nítidas nos espaços posteriores.

Face ventral da asa anterior com as discocelulares finamente azuis, manchas azuis submarginais entre $\mathrm{CuA} 1$ e $2 \mathrm{~A}$ bem marcadas.

Face ventral da asa posterior com as três faixas azuis finas, deixando 


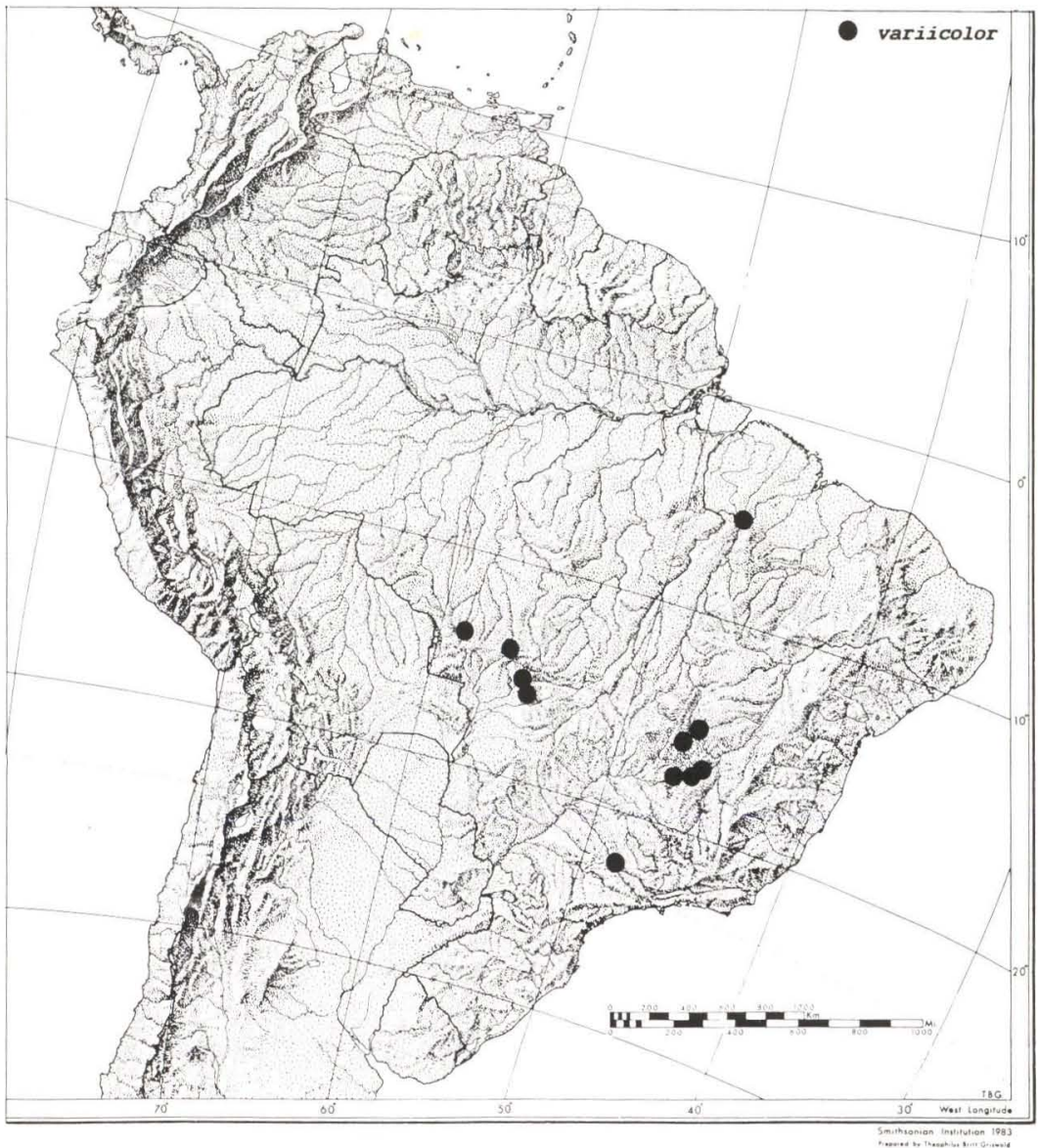

Fig. 39. Mapa de distribuiçầo geográfica. Micmecris.

espaços entre elas maiores que as suas larguras; faixas azuis adicionais basal e distal difusas, aq̣uela até M2 ou CuA2 e esta até $\mathrm{CuA} 2$; espaç̨o $2 \mathrm{~A}-3 \mathrm{~A}$ com mancha azul larga abaixo das faixas mediana e discal; franjas como na face dorsal.

Genitália (Fig. 20). Apófises do tegumen cuneiformes e contíguas ao unco em vista dorsal e quase da metade do comprimento do unco em vista lateral; harpe longa, margem inferior levemente sinuosa, terminação fina e rombuda, terço apical com 1/4 da largura da parte basal aproximadamente quadrada e com a projeção dorso-basal pequena e dirigida para dentro da valva; edeago reto e com carena subterminal nos lados ventral e direito.

Fêmea. Desconhecida.

Discussão. A genitália masculina é muito distinta da de patroclus, da qual era considerada uma subespécie (Evans 1951. como umbrata). 
Distribuição espacial (Fig. 47). PANAMÁ - Zona do Canal: Gamboa. Colômbia - Cauca: Popayan.

Distribuição temporal. Voa em janeiro.

Etologia. Desconhecida.

Planta hospedeira. Desconhecida.

Etimologia. Desconhecida.

Material estudado. Como o holótipo está perdido (MIELKE 1989), designase um NEOTIPO macho com as seguintes etiquetas: / Colombia/ Rothschild Bequest B.M. 1939-1./ NEOTIPO/ Jemadia miodesmiata Roeber, 1925. Neótipo. O. Mielke det. 1993/ Elbella miodesmiata (Roeber, 1925) O. Mielke det. 1993/ cartão com o preparado da genitália/ (BMNH) [Examinado]. - PANAMÁ - Zona do Canal: Gamboa, R. Robbins leg., 3-I-1979 2 machos (UFPC-OM).

\section{Elbella rondonia, sp.n.}

Figs $21,41,100,101$

Diagnose. As genitálias masculina e feminina caracterizam a espécie.

Descrição. Macho (Fig. 100) - Comprimento da asa anterior 24 a $26 \mathrm{~mm}$. Genas brancas com as partes internas negras.

Face dorsal da asa anterior com a faixa branca mediana entre 2,3 e $3,0 \mathrm{~mm}$ de largura máxima; mancha branca em $\mathrm{M} 3-\mathrm{CuA} 1$ com a largura mediana entre $1 / 3$ e $2 / 3$ da sua altura; faixa branca apical com a largura máxima igual à mancha anterior; discocelulares sempre azuis; manchas da faixa azul submarginal diminutas, às vezes, presentes entre M1 e M3; manchas azuis longitudinais, abaixo da faixa mediana, grandes, atingindo o nível proximal da mancha branca da célula e a superior normalmente expandida na base até $\mathrm{CuA2}$.

Face dorsal da asa posterior com as três faixas azuis da mesma largura, não prolongadas em $\mathrm{SC}+\mathrm{R} 1-\mathrm{Rs}$; franjas concolores e brancas entre $\mathrm{CuAl}$ e $3 \mathrm{~A}$, com as terminações das veias negras.

Face ventral da asa anterior com as discocelulares azuis; manchas da faixa azul submarginal bem marcadas entre CuAl e $2 \mathrm{~A}$ e, às vezes, com escassas escamas azuis em M3-CuA1.

Face ventral da asa posterior com as três faixas azuis de larguras uniformes e separadas entre si por distâncias iguais às suas larguras; faixas azuis adicionais basal até M1, M3 ou CuA2 e distal normal ou reduzida, então quase indistinta até M3; espaço 2A-3A com uma mancha azul abaixo da faixa distal e, às vezes, outra abaixo da faixa mediana; franjas como na face dorsal.

Genitália (Fig. 21). Apófises do tegumen triangulares e contíguas ao unco em vista dorsal e 1/3 do comprimento do unco em vista lateral; harpe longa, sinuosa e diminuindo para a ponta distal finamente rombuda, com a projeção dorso-basal pequena e dirigida para dentro da valva, depressão distal à projeção dorso-basal pequena; edeago reto e com a carena subterminal nos lados ventral e direito.

Fêmea (Fig. 101). Semelhante ao macho. Comprimento da asa anterior $28 \mathrm{~mm}$. Face dorsal da asa anterior com a faixa branca mediana de $4 \mathrm{~mm}$ de largura 


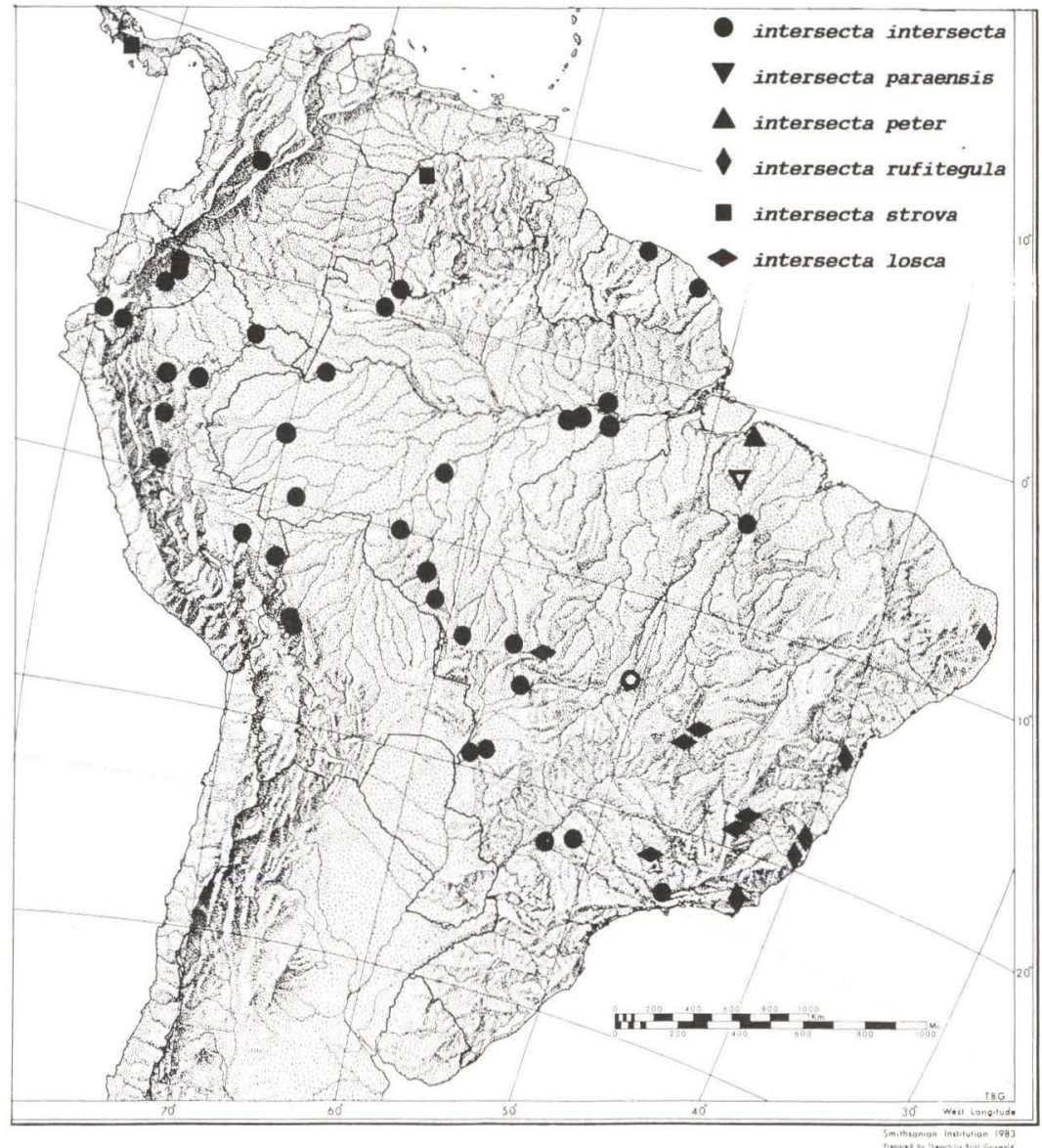

Fig. 40. Mapa de distribuição geográfica. Elbella.

máxima; face ventral da asa anterior com a mancha da faixa azul submarginal em M3-CuA1 nítida.

Genitália (Fig. 21). Partes laterais do oitavo esterno bipartidas, com as partes superiores pouco esclerosadas e não ligadas ao esterigma; oitavo esterno com pontuações grosseiras em vista ventral; esterigma tubular, em vista lateral adelgaçando-se suavemente para a parte distal e em vista ventral só assim a partir do sexto distal; óstio ocupando a metade dorso-distal do esterigma.

Discussão. A genitália caracteriza a espécie.

Distribuição espacial (Fig. 41). PERU - Junin: San Ramon 1100m; La Merced 1000m; Satipo 500m. Huánuco: Tingo Maria 850m.- Brasil - Mato Grosso: Diamantino 300-400m. Rondônia: Pimenta Bueno.

Distribuição temporal. Voa em janeiro, março e julho a novembro.

Etologia. É um habitante de florestas, sendo que os machos pousam em 
areias úmidas na beira de rios, principalmente em excrementos de aves ou urina.

Planta hospedeira. Desconhecida.

Etimologia. O nome é alusivo ao Estado de Rondônia, Brasil, onde um dos exemplares foi coletado.

Material estudado. Holótipo macho com as seguintes etiquetas: / HOLOTIPO/ 28-I-1978 Alto Rio Arinos, Faz.[enda] São João, Diamantino, MT [Mato Grosso], Furtado leg./ Elbella rondonia Mielke, Holótipo, O. Mielke det. 1993 / gen.[itália] prep.[arada] Mielke 1987/ OM 32.893/ (UFPC-OM). Alótipo fêmea com as seguintes etiquetas: / ALLOTYPUS/ 20-X-1989, 10 km W Foz Rio Colorado, La Merced, Junin, Peru, 1000m, Mielke \& Casagrande leg./ Elbella rondonia Mielke, Alótipo, O. Mielke det. 1993/ gen.[itália] prep.[arada] Mielke 1993/ OM 23.249/ (UFPC-OM). Parátipos: PERU - Junin: Satipo, Paprzycki leg. , 11-III-1939 1 macho, 12-III-1939 1 macho, 13-III-1939 1 macho (UFPC-OM); Rio Perene (Puhanaki), Schunke leg., 500m, VII-1981 1 macho (UFPC-OM); Rio Perene, 550m, I-1982 (UFPC-OM); La Merced, 10 km W Foz Rio Colorado, Mielke \& Casagrande leg., 1000m, 20-X-1989 1 macho (UFPC-OM); San Ramon, 5 km SE Vitoc, Rio Tulumayo, Mielke \& Casagrande leg., 1100m, 19-X-1989 1 macho (UFPC-OM). Huánuco: Tingo Maria (Rondos), Villegas leg., $850 \mathrm{~m}$, 16-20-X-1971 1 macho, 27-X-1971 1 macho, XI-1971 4 machos (UFPC). - BRASIL - Mato Grosso: Diamantino (Fazenda São João), Furtado leg., 300-400m, 2-III19781 macho, 7-III-1982 1 macho (UFPC-OM), 5-III-1979 1 macho (EF); Diamantino (Fazenda São João), Mielke \& Furtado leg., 11-IX-1978 1 macho (UFPC). Rondônia: Pimenta Bueno, VIII-IX-1970 î macho (UFPC).

\section{Elbella madeira, sp.n.}

Figs 22, 42, 102, 103

Elbella umbrata umbrata; Jong, 1983. Tijd. Ent. 126: 249, fig. 4 (genitália masculina).

Diagnose. As genitálias masculina e feminina caracterizam a espécie.

Descrição. Macho (Fig. 102) - Comprimento da asa anterior 23 a $25 \mathrm{~mm}$. Genas brancas, com as partes medianas castanho escuras.

Face dorsal da asa anterior com a faixa branca mediana entre 2 e 2,6mm de largura máxima; mancha branca em M3-CuA1 com a largura mediana entre $1 / 2$ e 1/3 da sua altura; faixa branca apical com a largura máxima igual à da mancha anterior; discocelulares sempre azuis; manchas da faixa azul submarginal diminutas, às vezes, presentes entre M1 e M3; manchas azuis logitudinais, abaixo da faixa mediana, grandes, atingindo o nível do limite proximal da mancha branca da célula discal e a superior normalmente expandida na base até CuA2.

Face dorsal da asa posterior com as três faixas azuis da mesma largura e não prolongadas em Sc+R1-Rs; franjas concolores e brancas entre CuAl e 3A, com as terminações das veias negras.

Face ventral da asa anterior com as discocelulares azuis; manchas da faixa azul submarginal bem marcadas entre $\mathrm{CuA} 1 \mathrm{e} 2 \mathrm{~A}$, às vezes, com escassas escamas azuis entre M3 e CuA1. 


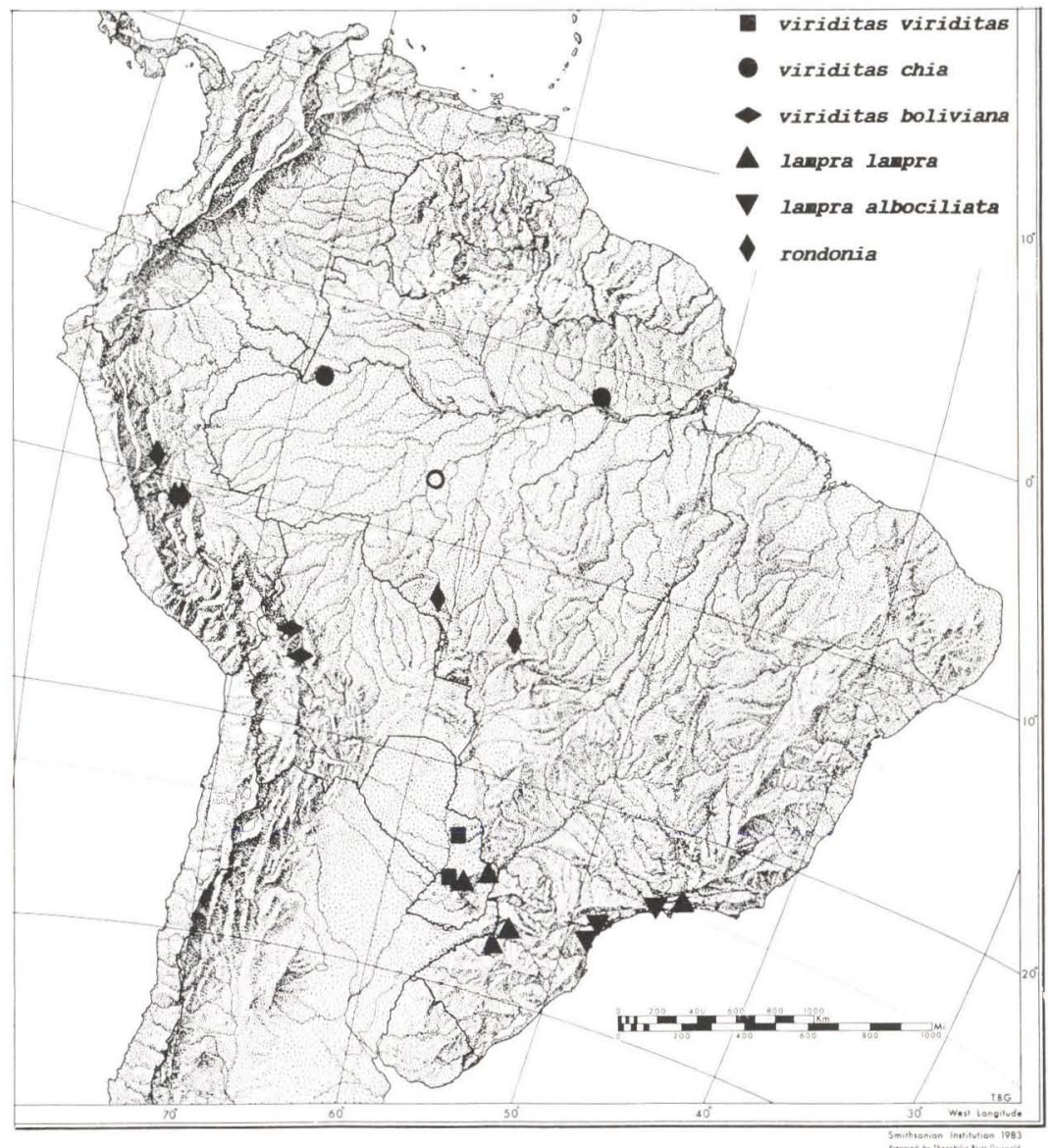

Fig. 41. Mapa de distrihuiçâo geográlica. Elbella.

Face ventral da asa posterior com as três faixas azuis de larguras uniformes e separadas entre si por distâncias iguais às suas larguras; faixas azuis adicionais basal até M1, M3 ou CuA2 e distal até CuA2 ou reduzida, quase indistinta, até M3; um exemplar com mancha azul, fina e transversal em Sc+R1-Rs, entre a faixa mediana e a faixa adicional basal, como é normal em azeta azeta; espaço 2A-3A com uma mancha azul abaixo da faixa distal e, às vezes, outra abaixo da faixa mediana; franjas como na face dorsal.

Genitália (Fig. 22): Apófises do tegumen alongadas e contíguas ao unco em vista dorsal e com a metade do comprimento do unco em vista lateral; harpe longa, margem inferior levemente sinuosa, terminação finamente rombuda, quarto apical com 1/4 da largura da parte basal e com a projeção dorso-basal pequena e dirigida para dentro da valva; edeago reto e com carena subterminal nos lados ventral e direito. 
Fêmea (Fig. 103). Semelhante ao macho. Comprimento da asa anterior $28 \mathrm{~mm}$. Face dorsal da asa anterior com a faixa mediana com $3 \mathrm{~mm}$ de largura máxima; face ventral da asa anterior com a mancha da faixa azul submarginal em M3-CuA1 nítida.

Genitália (Fig. 22). Partes laterais do oitavo esterno inteiras e ligadas ao esterigma; esterigma tubular, adelgaçando-se suavemente para e porção distal, esta ventralmente projetada em ponta e óstio terminal.

Discussão. As genitálias masculina e feminina caracterizam a espécie.

Distribuição espacial (Fig. 42). PERU - Madre de Dios: Parque Nacional de Manu 340m, 100km Oeste de Puerto Maldonado 250m. - BRASIL - Amazonas: São Paulo de Olivença. Mato Grosso: Diamantino 300-400m.

Distribuição temporal. Voa de fevereiro a abril e agosto a novembro.

Etologia. É um habitante de florestas, sendo que os machos pousam em areias úmidas na beira dos rios, principalmente em excrementos de aves e urina.

Planta hospedeira. Desconhecida.

Etimologia. O nome é alusivo a bacia do Rio Madeira, região de onde é descrita a espécie.

Material estudado. Holótipo macho com as seguintes etiquetas: / HOLOTIPO/ 23-IV-1978 Alto Rio Arinos, Faz.[enda] S.[ão] João, Diamantino, MT [Mato Grosso], Furtado leg./gen.[itália] prep.[arada] Mielke 1987/ OM 33.030/Elbella madeira Mielke, Holótipo, O. Mielke det. 1993/ (UFPC-OM). Alótipo fêmea com as seguintes etiquetas: /ALLOTYPUS/ 18-XI-1992 Carret. Pt. Maldonado-Cuzco, $100 \mathrm{~km}$ Oeste Pto. Maldonado, Peru, $250 \mathrm{~m}$, C.Tello leg./ gen.[itália] prep.[arada] Mielke 1993/OM 33.320/Elbella madeira Mielke, Alótipo, O. Mielke det. 1993/ (UFPC-OM). Parátipos: PERU - Madre de Dios: Parque Nacional de Manu (Pakitza), 340m, Mielke leg., 11-X-1991 1 macho (UFPC), 12-X-1991 1 macho (USNM); Parque Nacional de Manu (Pakitza), 340m, Lamas leg., 12-X-1991 1 macho (MHNL). - BrasIL - Mato Grosso: Diamantino (Fazenda São João), 300-400m, Furtado leg., 16-II-1978 1 macho, 1-III-1978 1 macho (UFPC-OM), 31-VIII-1980 (UFPC), 31-VIII-1980 1 macho, 20-II-1982 1 macho, 2-III-1982 1 macho (EF); Diamantino (Fazenda São João), 300-400m, Mielke \& Furtado leg., 6-IX-1978 1 macho, 11-IX-1978 1 macho (UFPC). Amazonas: São Paulo de Olivença (Ticunas, Igarapé Preto), 1 macho (UFPC-OM).

\section{Elbella bicuspis Jong, 1983}

Figs $223,43,104$

Elbella bicuspis Jong, 1983. Tijd. Ent. 126: 236, 250, figs. 2 (genitália maseulina), 49, 50; holótipo macho, Paramaribo, Suriname, E. H. Jonkers leg.; Rijksmus. Leiden [Não examinado].Bridges, 1988. Cat. Hesp. 1, p. 25; 2, p. 19.

Diagnose. A genitália masculina (fêmea desconhecida) caracteriza a espécie; única espécie com genas totalmente brancas internamente.

Descrição. Macho (Fig. 104) - Comprimento da asa anterior 25mm. Genas inteiramente brancas. 


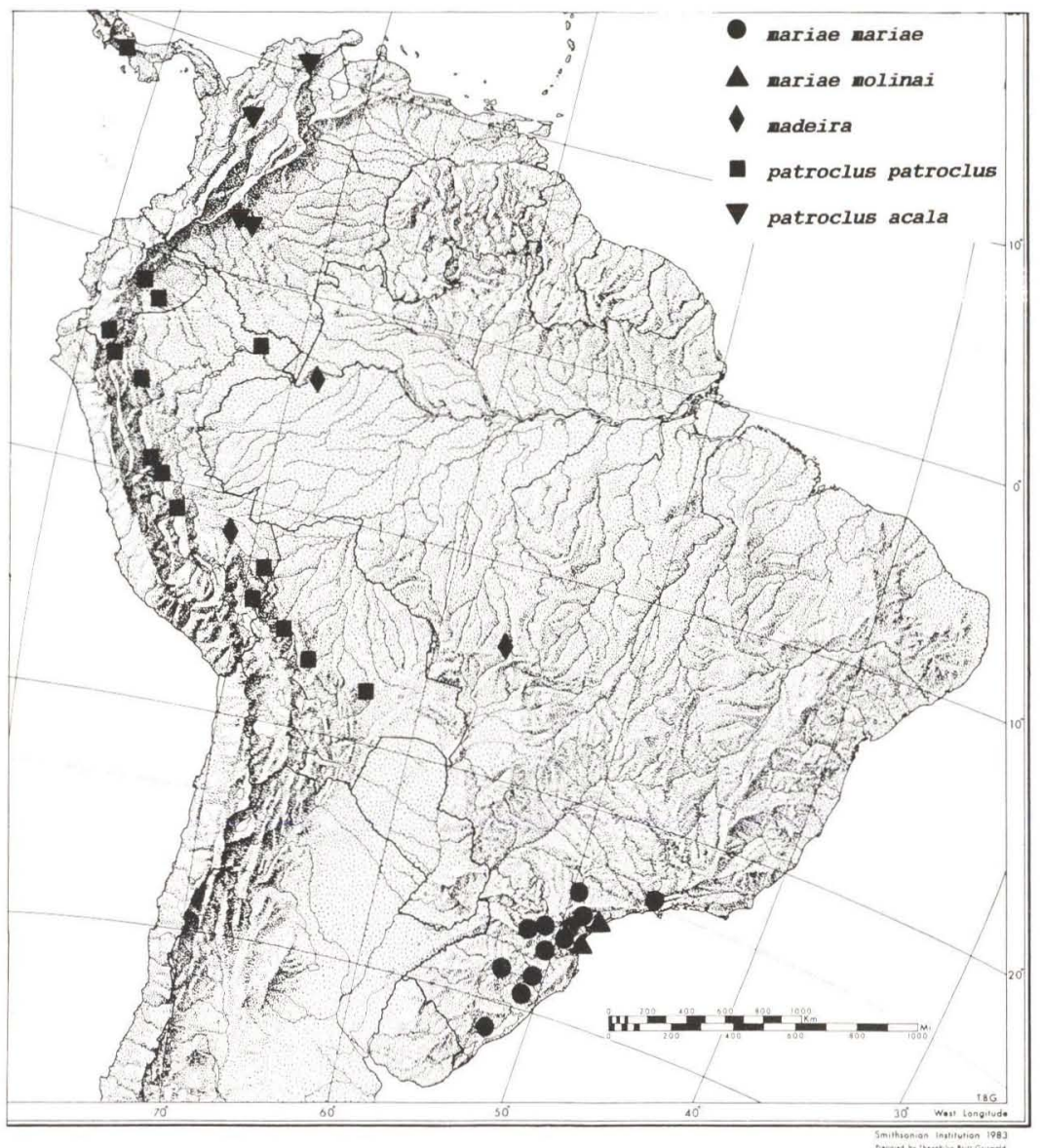

Fig. 42. Mapa de distribuição geogrática. Elbella.

Face dorsal da asa anterior com a faixa branca mediana com $2,3 \mathrm{~mm}$ de largura máxima; mancha branca em M3-CuAl com a largura máxima igual à metade de sua altura; faixa branca apical com a sua largura máxima igual à largura da parte inferior da mancha anterior; com pequena mancha branca em R2-R3; faixa azul submarginal nítida entre $\mathrm{CuAl}$ e $2 \mathrm{~A}$ e constituida só de poucas escamas escassas em M3-CuA1; manchas azuis longitidinais, abaixo da faixa mediana, grandes, atingindo o nível do limite proximal da mancha branca da célula discal e a superior com parte basal expandida até $\mathrm{CuA} 2$, esta expansão parcialmente destacada da parte inferior.

Face dorsal da asa posterior com as três faixas azuis da mesma largura e não prolongadas em $\mathrm{Sc}+\mathrm{R} 1-\mathrm{Rs}$; franjas inteiramente brancas entre $\mathrm{Sc}+\mathrm{R} 1$ e $3 \mathrm{~A}$, interrompidas pelas terminações das veias negras. 
Face ventral da asa anterior com as discocelulares azuis; manchas da faixa azul submarginal bem marcadas entre CuAl e $2 \mathrm{~A}$.

Face ventral da asa posterior com as faixas azuis basal e mediana separadas por distância menor que as suas larguras, a faixa discal mais estreita que as basal e mediana e separada desta por distância igual à largura da mesma; margem costal, com exceção da base e pequena mancha acima da faixa mediana negras, inteiramente azul; espaço 2A-3A azul até abaixo da faixa discal, deixando pequena área negra abaixo da faixa mediana; faixas azuis adicionais basal e distal até entre CuAl e CuA2 e com pequena mancha azul fina e transversal em Sc+R1-Rs, entre a faixa mediana e a faixa adicional basal; o azul na parte basal algo esbranquiçado; franjas como na face dorsal.

Genitália (Fig. 23). Apófises do tegumen alongadas, contíguas ao unco em vista dorsal e 1/3 do comprimento do unco em vista lateral; harpe longa, sinuosa e diminuindo para a parte distal finamente rombuda e com duas projeções dorso-basais, grandes, paralelas e dirigidas para fora da valva; edeago reto e com uma série de pequenos espinhos subterminais no lado direito.

Fêmea. Desconhecida.

Discussão. A genitália caracteriza a espécie.

Distribuição espacial (Fig. 43). SURINAME - Paramaribo: Paramaribo. Brasil - Amazonas: São Paulo de Olivença.

Distribuição temporal. Desconhecida.

Etologia. Desconhecida, mas provavelmente igual às demais espécies próximas.

Planta hospedeira. Desconhecida.

Etimologia. O nome é alusivo às duas projeções na base da harpe.

Material estudado. BRASIL - Amazonas: São Paulo de Olivença, 1 macho (BMNH).

\section{Elbella etna Evans, 1951}

Figs 24, 43, 105, 106

Elbella ętna etna Evans, 1951. Cat. Amer. Hesp. 1, p. 46, pl. 5 (genitália masculina); [holó|tipo macho, Teffé, Amazonas; BMNH [Examinado]-- Cock, 1984. Living World, 1983/84, p. 36.Lamas, Robbins \& Harvey, 1991. Publ. Mus. Hist. nat., Lima, 40: 16.

Elbella etna moda Evans, 1951. Cat. Amer. Hesp. 1, p. 46; [holó]tipo macho, La Merced, Peru; BMNH [Examinado].- Hayward, 1973. Op. lill. 23: 14.- Bridges, 1983. Lep. Hesp. 1, p. 77; 2, p. 12.- Bridges, 1988. Cat. Hesp. 1, p. 122; 2: 19. Syn.n.

Elbella etna; Bridges, 1983. Lep. Hesp. 1, p. 40; 2, p. 12.- Bridges, 1988. Cat. Hesp. 1, p. 64; 2, p. 19 .

(sem gênero) etna; Beattie, 1976. Rhop. Direct., p. 139.

(sem gênero) moda; Beattie, 1976. Rhop. Direct., p. 204.

Diagnose. As genitálias masculina e feminina caracterizam a espécie.

Descrição. Macho (Fig. 105) - Comprimento da asa anterior 22 a $25 \mathrm{~mm}$.

Genas brancas com as partes internas negras. 


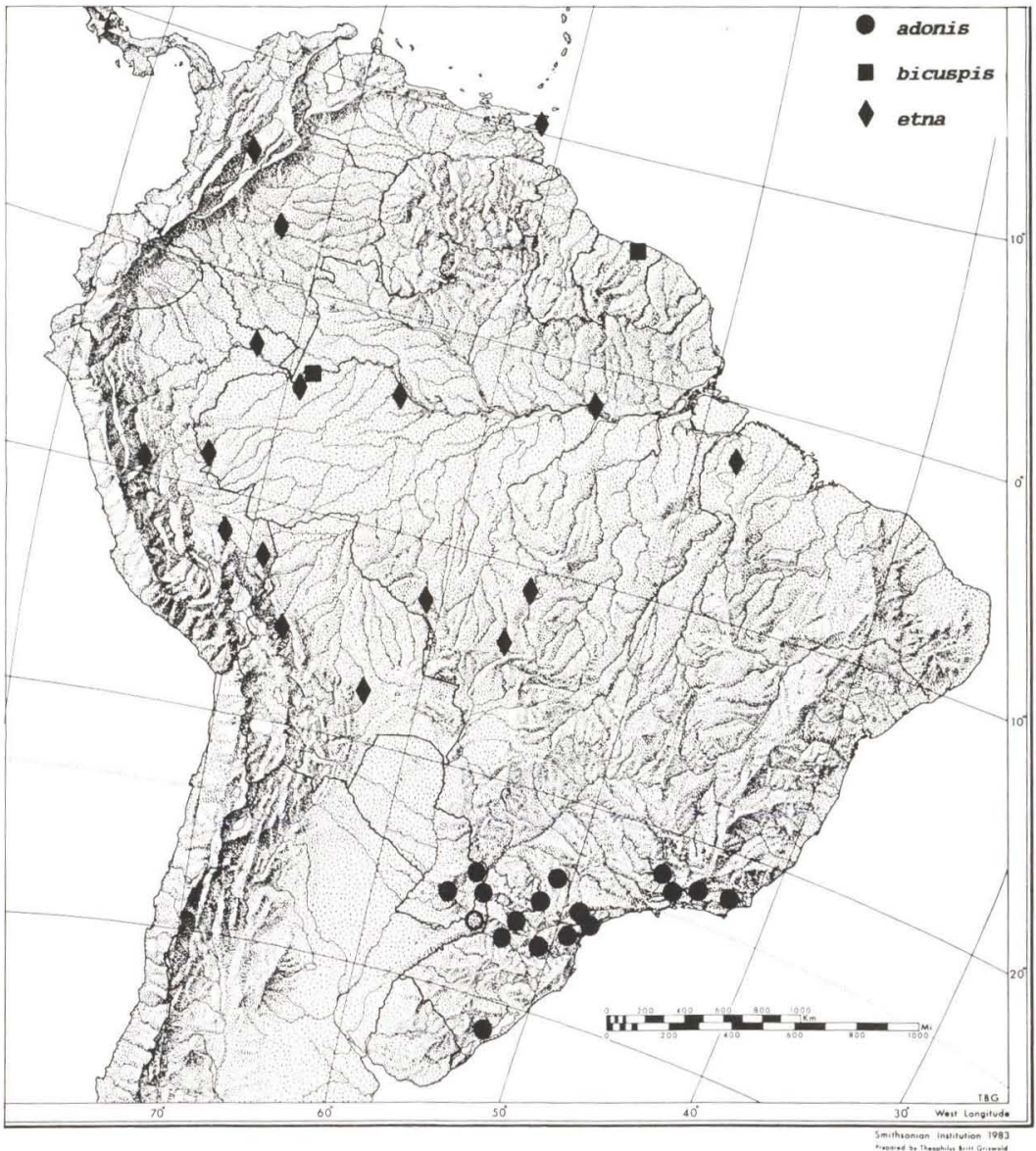

Fig. 43. Mapa de distribuiçào geográfica. Elbella.

Face dorsal da asa anterior com a faixa branca mediana entre 2,3 e $3,3 \mathrm{~mm}$ de largura máxima; mancha branca em M3-CuA1 quadrada ou, normalmente, com a largura mediana até pouco menor que a metade da sua altura; faixa branca apical com a largura máxima igual à mancha anterior; normalmente com pequena mancha branca em R2-R3; discocelulares azuis; faixa azul submarginal raras vezes com manchas de escamas difusas azuis entre M1 e M3; manchas azuis longitudinais, abaixo da faixa mediana, grandes, atingindo o nível do limite proximal da mancha branca da célula discal e a superior expandida na base até $\mathrm{CuA} 2$.

Face dorsal da asa posterior com a faixa azul discal igual ou mais fina qua as faixas azuis basal e mediana e não prolongadas em $\mathrm{Sc}+\mathrm{R} 1-\mathrm{Rs}$; franjas concolores e brancas entre $\mathrm{CuAl}$ e $3 \mathrm{~A}$, com as terminações das veias negras. 
Face ventral da asa anterior com as discocelulares azuis e as manchas da faixa azul submarginal mais largas que na face dorsal.

Face ventral da asa posterior com a faixa azul discal igual ou mais estreita que as faixas azuis basal e mediana e separadas entre si por distâncias iguais às larguras das faixas basal ou mediana; faixas azuis adicionais basal até CuAl ou $\mathrm{CuA} 2$ e distal até $\mathrm{CuA} 2$; espaço 2A-3A com uma mancha azul abaixo da faixa discal e, às vezes, ainda outra abaixo da faixa mediana e quando assim, podem estar unidas deixando um centro negro; franjas como na face dorsal.

Genitália (Fig. 24). Apófises do tegumen retangulares, mais curtas que largas, retas distalmente e contíguas ao unco em vista dorsal; harpe longa, sinuosa e diminuindo para a ponta distal fina, recurvada e com projeção dorso-basal grande, fina e dirigida para dentro da valva; edeago reto, com carena subterminal nos lados ventral e direito.

Fêmea (Fig. 106). Semelhante ao macho. Comprimento da asa anterior $26,5 \mathrm{~mm}$.

Face dorsal da asa anterior com a faixa branca mediana $2,9 \mathrm{~mm}$ de largura máxima; mancha branca em M3-CuAl com a largura máxima 1,6 vezes menor que a sua altura.

Face dorsal da asa posterior com as faixas azuis distal e mediana mais estreitas que a faixa azul basal.

Face ventral da asa posterior com as três faixas azuis da mesma largura e separadas entre si por uma distância pouco maior que as suas larguras; faixas adicionais basal até $\mathrm{CuA} 2$ e distal muito difusa até M3.

Genitália (Fig. 24). Partes laterais do oitavo esterno bipartidas e não ligadas ao esterigma; esterigma tubular, em vista ventral adelgaçando-se desde o quinto distal, em vista lateral expandido ventralmente na porção basal e o óstio na parte dorsal, ocupando os dois terços distais.

Discussão. A genitália caracteriza a espécie. A subespécie moda nada mais é do que simples variação.

Distribuição espacial (Fig. 43). COLÔMBIA - Vaupes: San Jose del Guaviare. Boyaca: Otanche. - PERU - Huánuco: Tingo Maria 850m. Loreto: Pebas. Madre de Dios: Puerto Maldonado 300m; Parque Nacional de Manu 340m. Bolívia - La Paz: Caranavi 500-1000m. Santa Cruz. - Trinidad (?). - Guiana Francesa. - Brasil - Amazonas: Benjamin Constant; Teffé. Pará: Vila Nova; Óbidos. Acre: Cruzeiro do Sul 200m. Rondônia: Pimenta Bueno. Mato Grosso: Diamantino 300-400m; Sinop.

Distribuição temporal. Voa nos meses de fevereiro, março, maio e junho a outubro.

Etologia. É um habitante de florestas, sendo que os machos pousam em areias úmidas na beira dos rios, principalmente em excrementos de aves e urina.

Planta hospedeira. Desconhecida.

Etimologia. etna e moda devem ser combinações arbitrárias de letras, característica de quase todos os nomes estabelecidos por Evans (1951).

Material estudado. O holótipo macho de etna com as seguintes etiquetas: 
/Type/ Teffé (Ega) Amazonas M. de Mathan [leg.] 7bre 8bre 1879/ R. Oberthür Coll. Brit. Mus. 1931-136/ cartão com o preparado da genitália/. O holótipo macho de moda com as seguintes etiquetas: / Type/ Peru. La Merced. $2500 \mathrm{ft}$. V \& VI. [19]03. Watkins \& Tomlinson. 1904-133/ R. Oberthür Coll. Brit. Mus. 1931-136/ cartão com o preparado da genitália/. - ColômBIA - Vaupes: San Jose del Guaviare, J. Urbina leg., VII-1990 I macho (LECR). Boyaca: Otanche, J. Urbina leg., X-1992 1 macho (LECR). - PERU - Hucinuco: Tingo Maria (Rondos), Villegas leg., 850m, 27-X-1971 I macho (UFPC). Junin: Satipo, Paprzycki leg., 9-III-1939 1 macho, 11-III-1939 1 macho, 14-III-1939 1 macho, 15-III-1939 I macho (UFPC-OM). Madre de Dios: Puerto Maldonado (Comunidad Infierno), Mielke \& Casagrande leg., 300m, 16-17-X-1983 1 macho (UFPC-OM); Parque Nacional de Manu (Pakitza), Mielke leg., 340m, 29-IX-1991 1 macho, 11-X-1991 3 machos, 17-X-1991 1 macho (MHNL, USNM, UFPC); Parque Nacional de Manu (Pakitza) Lamas leg., 340m, 27-IX-1991 1 macho, 13-X-1991 1 macho (MHNL, USNM, UFPC). - Bolívia - La Paz: Caranavi (Yungas), Telloleg., 500-1000m, 1 macho II-III-1989, I macho V-VII-1989 (UFPC-OM). Chapare: Cochabamba (Cristal Mayo), Steinbacher leg., 600m, 1 macho X-1976 (UFPC-OM). - BRASIL Amazonas: Benjamn Constant, Parko leg., I macho V-1942 (MNRJ). Pará: Óbidos, 1 macho (UFPC-OM); Óbidos, Kesselring leg., 1 macho IX-1968 (UFPC-OM). Acre: Cruzeiro do Sul, K. Ebert leg., 200m, 1 macho 23-X-1973 (UFPC). Rondônia: Pimenta Bueno, 2 machos X-1970 (UFPC). Mato Grosso:

Diamantino (Fazenda São João), Furtado leg., 300 - 400m, 3 machos 28-VIII-1971, 1 macho 7-II-1978, 2 machos 10-II-1978, 1 macho 20-II-1978, 4 machos 25-VIII-1978, 11 machos 30-VIII-1979, 2 machos 14-IX-1979, 4 machos 31-VIII-1980 (UFPC, UFPC-OM); Diamantino (Fazenda São João), Mielke \& Furtado leg., 300-400m, 1 macho 25-VIII-1978, 1 macho 2-IX-1978, 3 machos 3-IX-1978, 9 machos 11-IX-1978, I fềmea 12-IX-1978, I macho 13-IX-1978, 1 macho 20-II-1979 (UFPC-OM); Diamantino (Fazenda São João), H. Ebert leg., 300-400m, 1 macho 8-IX-1977 (UFPC); Sinop, Alvarenga leg., 1 macho X-1974 (UFPC).

\section{Elbella patroclus (Plötz, 1879), sp.rev.}

Figs 25, 42, 107-109

Diagnose. As genitálias masculina e feminina caracterizam a espécie.

Descrição. Macho - Comprimento da asa anterior 26 a $31 \mathrm{~mm}$. Genas brancas, com as partes centro-hasais negras.

Face dorsal da asa anterior com a faixa branca mediana entre 2,5 e $3,8 \mathrm{~mm}$ de largura máxima; mancha branca em M3-CuAI de largura variável; faixa branca apical de largura variável; às vezes, com pequena mancha branca em R2-R3; discocelulares negras ou azuis; faixa azul submarginal variável na sua extensão; manchas azuis longitudinais, abaixo da faixa mediana, atingindo ou não o nível do limite proximal da mancha branca da célula discal.

Face dorsal da asa posterior com as faixas azuis de larguras iguais ou não; 
às vezes, com escamas azuis em $\mathrm{Sc}+\mathrm{R} 1-\mathrm{Rs}$; franjas brancas com as terminações das veias negras, mais nítidas nos espaços do ângulo anal.

Face ventral da asa anterior com as discocelulares nitidamente ou difusamente azuis; manchas azuis da faixa submarginal variáveis.

Face ventral da asa posterior com as faixas azuis iguais ou de larguras e espaços entre elas diferentes; faixas azuis adicionais basal ausente ou até CuA1 e distal até $\mathrm{CuA} 1$ ou $\mathrm{CuA2}$; espaço 2A-3A com uma ou duas manchas azuis.

Genitália (Fig. 25). Apófises do tegumen triangulares em vista dorsal e com $1 / 3$ do comprimento do unco em vista lateral; harpe longa, sinuosa e diminuindo para a ponta distal finamente rombuda, com a projeção dorso-basal grande e dirigida para dentro da valva, depressão distal à projeção profunda; edeago reto e com carena sub-terminal nos lados ventral e direito.

Fêmea. Só uma fêmea de patroclus acala é conhecida.

\section{Chave para as subespécies}

1. Face dorsal da asa anterior com a faixa branca mediana até $2,5 \mathrm{~mm}$ de largura máxima; mancha branca em M3-CuAl com a sua largura normalmente igual à metade de sua altura ou mais larga . . . . . . . . . patroclus

- Face dorsal da asa anterior com a faixa branca mediana entre 3,3 e 3,8mm de largura máxima; mancha branca em M3-CuA1 mais estreita, a sua largura igual a $1 / 3$ da sua altura $\ldots \ldots \ldots$ acala

\subsection{Elbella patroclus patroclus (Plötz, 1879), sp.rev.} Figs 25, 42, 107

Pyrrhopyga (sic) patroclus Plötz, 1879. Stett. ent. Ztg. 40: 522; [Holótipo] Peru; Mus. Berol. 18362 (ZMHB) [Examinadol.

Jemadia patroclus; Mabille, 1903, in Wytsman. Gen. Ins. 17, p. 12.- Weeks, 1905. Ill. Diurn. Lep. 1, p. 30.- Mabille, 1912. Lep. Cat. 9, p. 11.- Draudt, 1921, in Seitz. Macrolep. World 5, p. 844, pl. 166c.- Bell, 1933. Jour. N. Y. Ent. Soc. 41: 495.- Lamas, 1969. Biota 7: 326.

Jemadia umbrata Mabille \& Boullet, 1908. Aun. Sc. nat. 7: 193, 196; 1 macho, Bolívia; Col. Mabille; NEÓTIPO macho aqui designado (UFPC-OM) [Examinado].- Mabille, 1912. Lep. Cat. 9, p. 10.Draudt, 1921, in Seitz. Macrolep. World 5, p. 845.- Bell, 1933. Jour. N. Y. Ent. Soc. 41: 504. Syn.n.

Jamadia (sic) patrochus; Weeks, 1901. Ill. unfig. Lep., p. 30.

Elbella umbrata umbrata; Evans, 1951. Cat. Amer. Hesp. 1: 46, pl. 5 (genitália masculina).Hayward, 1973. Op. lill. 23: 14.- Lamas, 1983. Rev. Soc. Mex. Lep. 8: 21.- Lamas, 1983.

Rev. Soc. Mex. Lep. 8: 50, ecologia.

(sem gênero) patroclus; Beattie, 1976. Rhop. Direct., p. 227.

(sem gênero) umbrata: Beattie, 1976. Rhop. Direct., p. 280.

Elbella umbrata: Bridges, 1983. Lep. Hesp. 1, p. 122; 2, p. 12.- Bridges, 1988. Cat. Hesp. 1, p. 193; 2, p. 19.

Diagnose. Face dorsal da asa anterior com a faixa branca mediana até 2,5 mm de largura máxima e a mancha branca em M3-CuA1 mais larga que 1/3 da sua altura. 


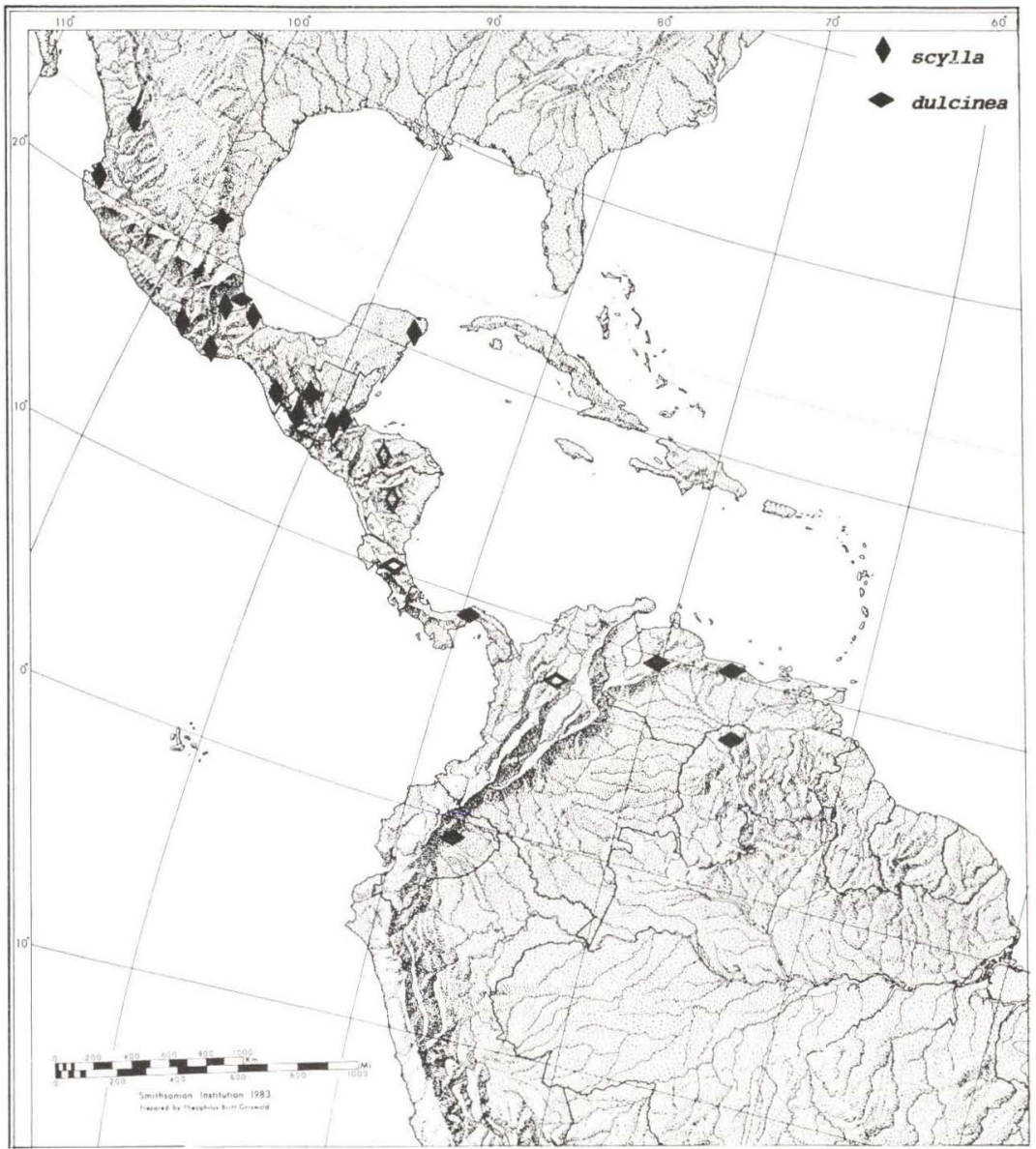

Fig. 44. Mapa de distribuicāo geogrática. Elhella

Descrição. Macho (Fig. 107) - Comprimento da asa anterior 26 a $29 \mathrm{~mm}$.

Face dorsal da asa anterior com a faixa branca mediana estreita, no máximo $2,5 \mathrm{~mm}$ na sua largura máxima: mancha branca em M3-CuAl estreita, normalmente igual à metade da sua altura, mas, às vezes, subquadrada; faixa branca apical não mais larga que a mancha anterior; às vezes, com pequena mancha branca em R2-R3; a faixa azul sub-basal de $\mathrm{R}$ até a margem interna, às vezes, a partír da costa, mas então interrompida em R; manchas da faixa azul submarginal, às vezes, com poucas escamas difusas azuis na parte externa das duas manchas apicais inferiores; discocelulares normalmente com escamas azuis; manchas azuis longitudinais, abaixo da faixa mediana, grandes, ultrapasando o nível do limite proximal da mancha branca na célula e a superior expandida na hase até CuA2. 
Face dorsal da asa posterior com as três faixas azuis aproximadamente da mesma largura entre Rs e $2 \mathrm{~A}$, às vezes, com difusas escamas azuis acima das faixas mediana e discal em Sc+R1-Rs; franjas brancas com as terminações das veias negras, às vezes, concolores no ápice, passando a brancas nos espaços do ângulo anal.

Face ventral da asa anterior com as discocelulares azuis; manchas da faixa azul submarginal variáveis, mas geralmente mais largas que na face dorsal entre CuA1 e 2A e ausentes ou difusas entre M3-CuA1.

Face ventral da asa posterior com as três faixas azuis de larguras uniformes e separadas entre si por distâncias iguais às suas larguras; faixas adicionais basal ausente ou até $\mathrm{M} 3$ e distal até $\mathrm{CuA} 1$ ou $\mathrm{CuA2}$; espaço 2A-3A com manchas azuis difusas junto à $3 \mathrm{~A}$, como se fossem prolongamentos das faixas mediana e discal, a mais basal unida à distal, formando uma mancha única com o centro negro ou, às vezes, ausente; franjas como na face dorsal.

Fêmea. Desconhecida. A fêmea do Ecuador, mencionada por Evans (1951), é a fềmea de Elbella lustra.

Discussão. Na identificação de umbrata segue-se a interpretação de EVANS (1951), que diz o tipo estar no BMNH. Um exame do mesmo confirma esta identificação, mas como a procedência deste exemplar é Peru, certamente não é o holótipo, este descrito da Bolívia e na coleção Mabille. Também não foi encontrado nos museus mencionados no "Material e Métodos". Designa-se então um Neótipo.

Distribuição espacial (Fig. 42). PANAMÁ - Chiriqui (erro de procedência ?). - ECUADOR - Zamora-Chinchipe: Zamora*. Tunguruahua: Ambato*. Loja: Loja*; Rio Pastaza*. - Peru - Huánuco: Tingo Maria 850. Pasco: Pozuzo*. Junin: Rio Perené 300-800m; Chanchamayo*. Puno: Rio Carabaya*. Amazonas: Huambo*. Cajamarca: Charapi*. Madre de Dios: Tambopata*. Loreto: Pebas*. - Bolívia - Santa Cruz: Santa Cruz de la Sierra*. Cochabamba: Cochabamba $1100 \mathrm{~m}$. La Paz: Caranavi $600-1000 \mathrm{~m}$.

As procedências marcadas com asterístico $(*)$ são as mencionadas por EVANS (1951) e LAMAS (1983) e podem referir-se à outras espécies que ocorrem na mesma região; o material não foi estudado.

Distribuição temporal. Voa nos meses de fevereiro e agosto a dezembro.

Etologia. É um habitante de florestas e provavelmente os machos pousam em areias úmidas na beira dos rios, principalmente em excrementos de aves e urina.

Planta hospedeira. Desconhecida.

Etimologia. Patroclus - heroi grego, amigo de Aquilles, morto por Heitor no cerco de Troia; umbrata - sombreado.

Material estudado. O holótipo macho de patroclus, com as seguintes etiquetas: / Holotypus/ Type/? Ecuador, ? Peru Schmettr/ 18262/ 9: 26/9: 7+9: 26/ patroclus Plötz type Pl. gibt [???] 18362/ gen.[itália] prep.[arada] Mielke 1979/Genital-Unters. Nr. 4.719, Zool. Mus. Berlin/ (ZMHB). O NEÓTIPO macho de umbrata, aqui designado, com as seguintes etiquetas: / NEOTIPO/ Caranavi, 


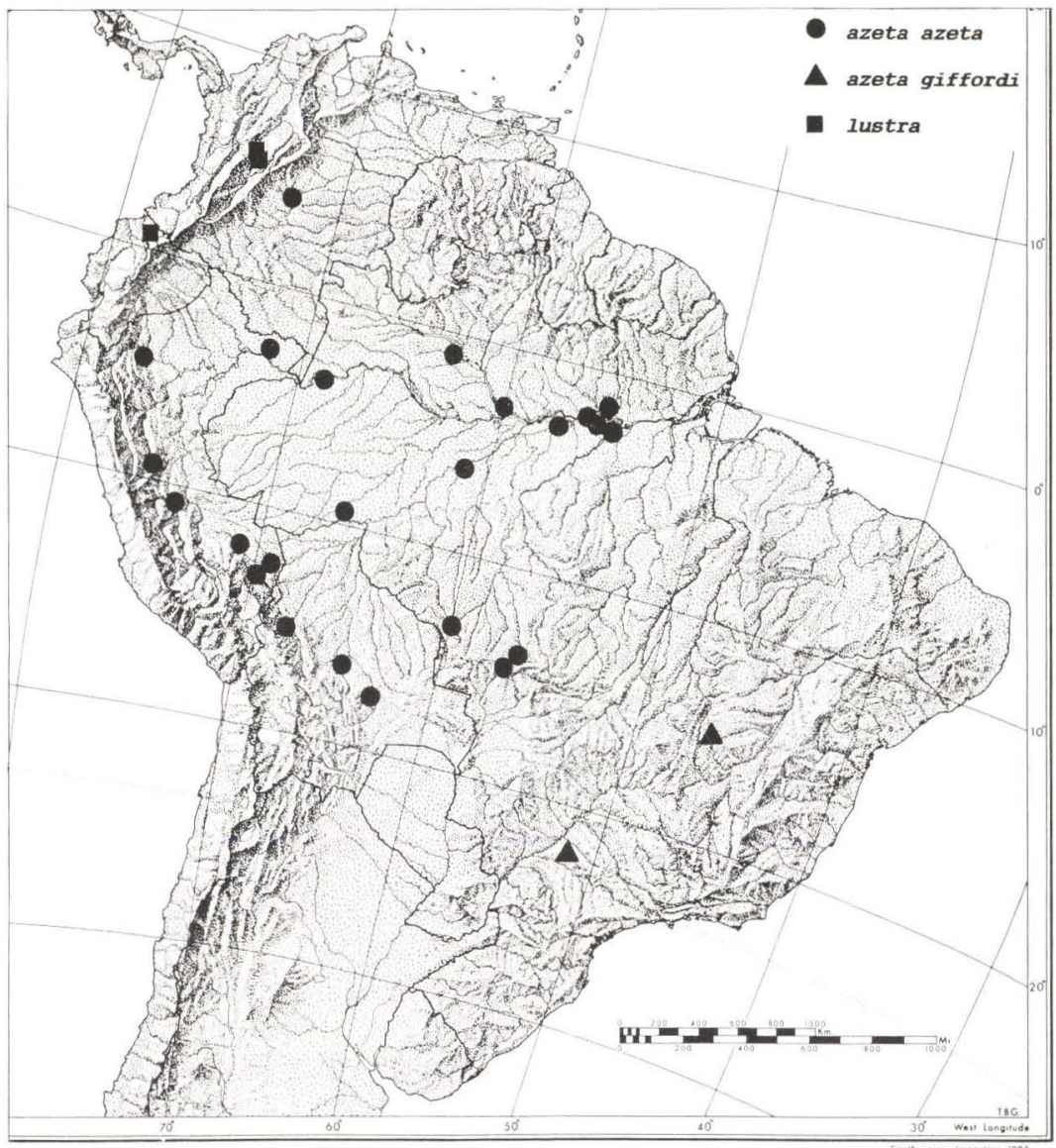

Fig. 45. Mapa de distribuiçăo geográfica. Elbella.

Bolívia, 600-1000m, IX-X-1988. Tello leg./ Jemadia umbrata Mabille \& Boullet, 1908, Neótipo, O. Mielke det. 1993/Elhella parroclus patroclus (Plötz), O. Mielke det. 1993/gen.|itália| prep.|arada| Mielke 1993/20.253/(UFPC-OM). - PANAMÁ - Chiriqui, Rolle leg. (MZSP). - ECUADOR - Zamora-Chinchipe: Zamora, G.T. Baron leg. . 1000 - 1300m, 2 machos (UFPC). - PERU - Huánuco: Tingo Maria, VIII-1964 4 machos, XI-1964 4 machos (UFPC-OM), II-1965 5 machos (UFPC-OM, UFPC); Tingo Maria (Rondos), Villegas leg.. 16-X-1971, 27-X-1971 5 machos, XI-1971 2 machos (UFPC). Junin: Rio Perené, Tello leg., 300-800m, IX-XI-1987 2 machos (UFPC-OM). - Bolívia - La Paz: Yungas, Simon leg., 1200m, XI-1901 1 macho (BMNH); Caranavi, 600-1000m, IX-X-1988, Tello leg., 42 machos (UFPC-OM). Cochahamba: Cochabamba (Rio Chapare, Alto Palmar), Steinhach leg., $1100 \mathrm{~m}$, XII-1976 1 macho (UFPC-OM). 


\subsection{Elbella patroclus acala Evans, 1951, comb.n.}

Figs 25, 42, 108, 109

Jemadia patrobas; Godman \& Salvin, 1893. Biol. Centr.-Amer. Lep. Rhop. 2, p. 260, 263; 3, tab. 74, figs. 13, 14, 15 (genitália masculina).- Bell, 1933. Jour. N. Y. Ent. Soc. 41 : p. 501, fig.

30 (genitália masculina).

Elbella umbrata acala Evans, 1951. Cat. Amer. Hesp. 1, p.45; [holó]tipo macho, Manaure, Colômbia;

BMNH [Examinado].- Jong, 1983. Tijd. Ent. 126: 249, fig. 3 (genitália masculina).- Bridges,

1983. Lep. Hesp. 1, p. 1; 2, p. 12.- Bridges, 1988. Cat. Hesp. 1, p. 1; 2. p. 19.

(sem gênero) acala; Beattie, 1976. Rhop. Direct., p. 65.

Diagnose. Face dorsal da asa anterior com a faixa branca mediana entre 3,3 e 3,8mm de largura máxima e a mancha branca em M3-CuA1 com a sua largura no máximo $1 / 3$ da sua altura.

Descrição. Macho (Fig. 108) - Comprimento da asa anterior 26 a $31 \mathrm{~mm}$.

Face dorsal da asa anterior com a faixa branca mediana larga, entre 3,3 e $3,8 \mathrm{~mm}$ na sua largura máxima; mancha branca em M3-CuA1 estreita, no máximo $1 / 3$ da sua altura; faixa branca apical mais larga que a mancha anterior; às vezes, com pequena mancha branca em R2-R3; discocelulares negras ou com escassas escamas azuis; a faixa azul sub basal ausente acima de $\mathrm{R}$; as manchas da faixa azul submarginal só abaixo das manchas apicais ou só entre CuA1 e $2 \mathrm{~A}$; as manchas azuis longitudinais, abaixo da faixa mediana, atingindo o nível do limite proximal da mancha branca da célula e fracamente expandida, geralmente não atingindo $\mathrm{CuA} 2$.

Face dorsal da asa posterior com a faixa azul discal mais larga que as faixas azuis basal e mediana e com difusas escamas azuis entre Sc+R1-Rs, acima da faixa discal.

Face ventral da asa anterior com escassas escamas azuis nas discocelulares e as manchas da faixa azul submarginal reduzidas.

Face ventral da asa posterior com as três faixas azuis estreitas, deixando entre elas espaços bem maiores que as suas larguras; faixas azuis adicionais basal até $\mathrm{CuA} 1$ e distal mais larga até $\mathrm{CuA} 2$ e muito próxima da discal, todas três unidas por manchas azuis entre a margem costal e Rs; $\mathrm{CuA} 2-2 \mathrm{~A}$ com uma pequena mancha azul abaixo da faixa discal.

Fêmea (Fig. 109). Semelhante ao macho. Comprimento asa anterior $41 \mathrm{~mm}$.

Face dorsal da asa anterior com a faixa branca mediana $3,6 \mathrm{~mm}$ de largura máxima; mancha branca em M3-CuAl estreita, a largura igual a 1/4 da sua altura; faixa branca apical com $1,5 \mathrm{~mm}$ de largura máxima, isto é, mais larga que a mancha anterior; sem pequena mancha branca em R2-R3; discocelulares sem azul; as manchas azuis longitudinais, abaixo da faixa mediana, curtas, atingindo o nível do centro da mancha branca em CuA1-CuA2.

Face dorsal da asa posterior com poucas escamas azuis entre $\mathrm{Sc}+\mathrm{R} 1-\mathrm{Rs}$, acima das faixas mediana e discal; franjas brancas entre $\mathrm{Sc}+\mathrm{R}$ I-Rs e $3 \mathrm{~A}$, com as terminações das veias negras.

Face ventral da asa anterior com as manchas azuis das discocelulares e da faixa submarginal entre CuAl e $2 \mathrm{~A}$ bem marcadas. 


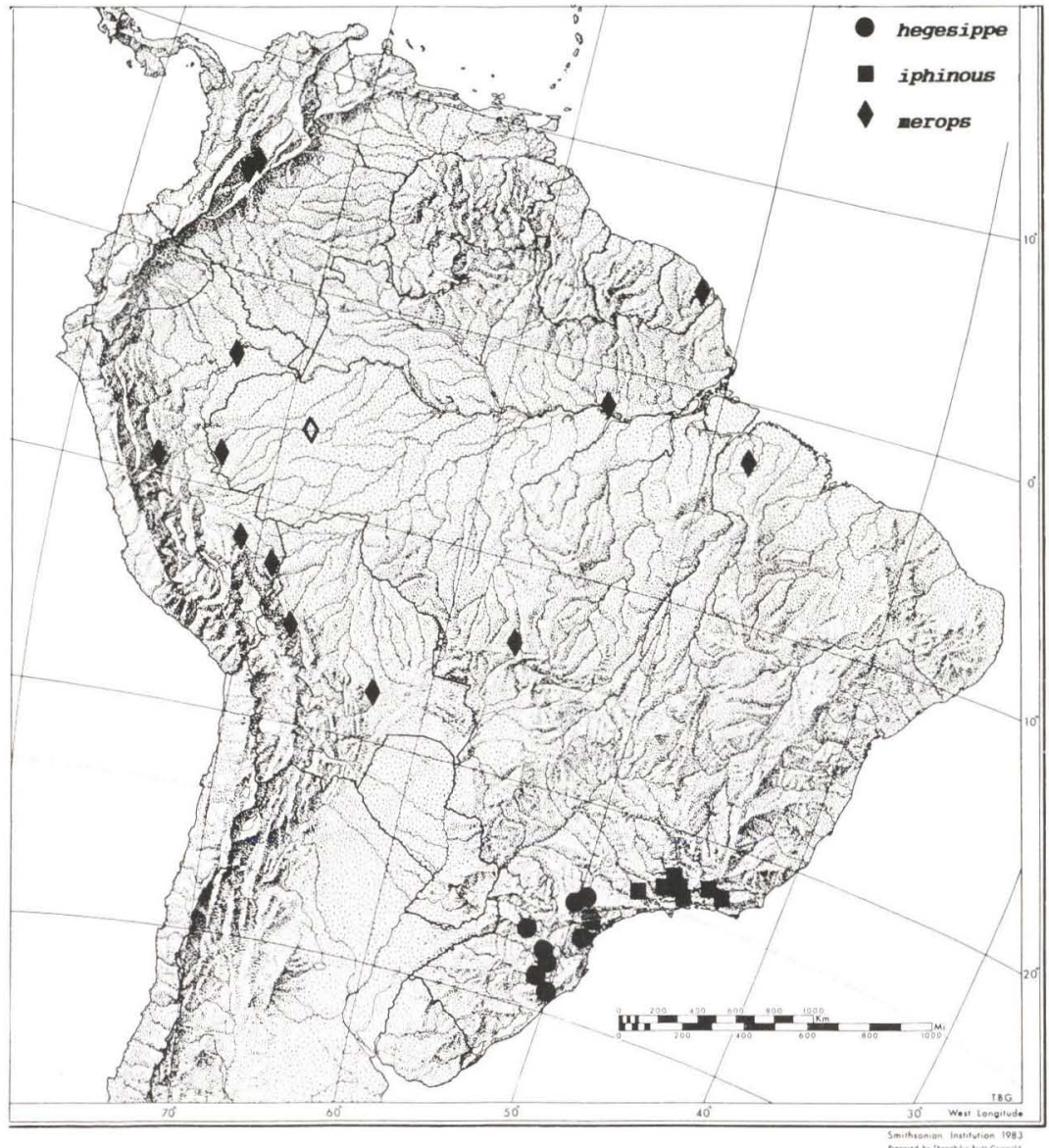

Fig. 46. Mapa de distribuiçào geográfica. Elbella.

Face ventral da asa posterior com as faixas azuis adicionais basal e distal até CuA2; mancha azul em CuA2-2A grande e abaixo da faixa discal.

Genitália (Fig. 25). Partes laterais do oitavo esterno divididas em partes superior e inferior, bem separadas, as partes inferiores quase contíguas acima do esterigma; esterigma tubular, mais longo que largo, lado ventral 1,5 vezes maior que o lado dorsal é óstio terminal, esta em vista ventral terminando com pequenos dentes laterais, sendo o esquerdo maior que o direito.

Discussão. Distingue-se principalmente de patroclus patroclus pela mancha branca em M3-CuAl da asa anterior mais estreita. A fêmea possui as faixas azuis longitudinais, abaixo da faixa mediana branca, curtas.

Distribuição espacial (Fiğ. 42). Colômbia - Cézar: Manaure. Meta: Aama de Caharral. Cundinumarca: Guyabetal 1700m. Antioquia: Valdívia. 
Distribuição temporal. Voa em agosto e setembro.

Etologia. Deve habitar as florestas e os machos provavelmente pousam em areias úmidas na beira de rios, principalmente em excrementos de aves e urina, como as demais espécie que ocorrem na bacia Amazônica.

Planta hospedeira. Desconhecida.

Etimologia. Provavel combinação arbitrária de letras.

Material estudado. O holótipo macho com as seguintes etiquetas: / Type/ B.C.A.Lep. Rhop. Jemadia patrobas, Hew./ Godman-Salvin Coll. 1912.-23./ Manaure, N. Colombia, F. Simons.[leg.]/ Elbella umbrata acala Evans, 1951, Holotype, O. Mielke det. 1993/ (BMNH). - ColômBIA - 1 fềmea (BMNH). Cundinamarca: Chirajara-Guyabetal, Sch.-Mumm leg., 1700m, 12-IX-1965 1 macho (UFPC-OM). Meta: Aama de Cabarral, K. Brown leg., 22-VIII-1989 1 macho (UFPC).- Sem procedência, 2 machos (BMNH).

\section{Elbella azeta (Hewitson, 1866)}

Figs 26, 45, 110-113

Diagnose. As genitálias masculina e feminina caracterizam a espécie.

Descrição. Macho - Comprimento da asa anterior 25 a $27 \mathrm{~mm}$. Genas brancas com as partes internas negras.

Face dorsal da asa anterior com a faixa branca mediana entre 2,3 e $4,5 \mathrm{~mm}$ de largura máxima; mancha branca em $\mathrm{M} 3-\mathrm{CuA} 1$ com a largura 2,3 a 1,4 vezes menor que a sua altura; faixa branca apical com a largura máxima igual à da mancha anterior; às vezes, com pequena mancha branca em R2-R3; discocelulares normalmente azuis, raras vezes com escassas escamas desta cor; manchas diminutas da faixa azul submarginal às vezes presentes em M1-M2, as demais bem marcadas ou a em M3-CuAl difusa; manchas azuis longitudinais, abaixo da faixa mediana, grandes, atingindo o nível do limite proximal da mancha branca da célula discal e a superior expandida na base até CuA2.

Face dorsal da asa posterior com a faixa azul discal mais fina ou igual às faixas azuis basal e mediana e, às vezes, praticamente ausente em CuA2-2A, e, às vezes, com manchas difusas azuis em $\mathrm{Sc}+\mathrm{R} 1-\mathrm{Rs}$ acima das faixas mediana $\mathrm{e}$ discal; franjas concolores, brancas a partir de Sc+R1-Rs ou CuAl até $3 \mathrm{~A}$, com as terminações das veias negras.

Face ventral da asa anterior com as discocelulares azuis; manchas da faixa azul submarginal bem marcadas entre $\mathrm{CuAl}$ e $2 \mathrm{~A}$ e, às vezes, com escassas escamas azuis em M3-CuAl.

Face ventral da asa posterior com as três faixas azuis de larguras uniformes e separadas entre si por distâncias iguais às suas larguras, ou a distal mais estreita e então separadas por distâncias diferentes; faixas azuis adicionais basal até CuAl ou $\mathrm{CuA} 2$ e distal até $\mathrm{CuA} 2$ e com pequena mancha azul transversal em Sc + R1-Rs entre as faixas mediana e adicional basal, raras vezes ausente; espaço 2A-3A com uma ou duas manchas azuis abaixo das faixas discal e mediana, às vezes, com a parte basal azul; franjas como na face dorsal. 
Genitália (Fig. 26). Apófises do tegumen retangulares, mais curtas que largas, concavas distalmente e contíguas ao unco em vista dorsal e pouco menores que 1/3 do comprimento do unco em vista lateral; harpe longa, com a ponta rombuda e com uma projeção dorso-basal espessa e dirigida para fora da valva, às vezes, com outra projeção pequena, distal desta; edeago reto e com carena e espinhos suhterminais no lado direito.

Fêmea. Semelhante ao macho. Comprimento da asa anterior 27 a $29 \mathrm{~mm}$. Face dorsal da asa anterior com a faixa hranca mediana entre 2,6 e $4.5 \mathrm{~mm}$ de largura máxima.

Genitália (Fig. 26): Partes laterais do oitavo esterno bipartidas e não ligadas ao esterigma; esterigma tubular, em vista ventral adelgaçando-se suavemente para a porção distal e esta com processo distinto, mediano e ventral; óstio terminal.

Discussão. As genitálias masculina e feminina diagnosticam a espécie.

\section{Chave para as subespécies}

1. Face dorsal da asa anterior com a mancha branca em M3-CuA 1 quase quadrada, sua largura $1 / 10$ menor que a sua altura; faixa branca mediana com $4,5 \mathrm{~mm}$ de largura máxima no macho e 3,7 e $4,5 \mathrm{~mm}$ na têmea . . . . . . . giffordi

- Face dorsal da asa anterior com a mancha branca em M3-CuA1 de largura 2,3 a 1,4 vezes menor que a sua altura; faixa branca mediana com 2,3 a $4 \mathrm{~mm}$ de largura máxima no macho e de 2,1 a $2,9 \mathrm{~mm}$ na têmea . . . . . . azęa

\subsection{Elbella azeta azeta (Hewitson, 1866)}

Figs 26, 45, 110, 111

Pyrhopyga (sic) azeta Hewitson, 1866. Trans. ent. Soc. London, p. 479; St. Paulo /de Olivenéal. Amazon: col. Hewitson; Lectótro macho aqui designado (BMNH) |Examinado|.- Butler. 1870. Ent. monthly Makg. 7: 58.- Kirhy, 1879. Cat. Coll. Diurn. Lep Ilew.. p. 207.- H. Druce. 1876. Proc. zool. Soc. London. p. 248.- Godman \& Salvin, 1880. Traus, ent. Soc. London. p. 126.

Erycides azeta: Herrich-Schäfer. 1869. Corr.-Blatt zool.-min. Ver. Regensburg 23: 169.- Kirby, 1871. Syn. Cat. Diurn. Lep.. p. 588.- Plöt\%. 1879. Stett. ent. Ztg. 40: 410

Jemadia azeta: Watson, 1893. Proc. zool. Soc. London, p. 14.-Mahille, 1903, in Wytsman. Genl. Ins. 17. p. 12.- Weeks. 1905. III. Diurn. Lep. 1. p. 30.- Mabille \& Boullet. 1908. Ann. Sc. nat. 7: 193, 196.- Mahille, 1912. Lep. Cat. 9. p. 11.- Draudt, 1921, in Seitz. Macrolep. World 5, p. 845, pl. 163b.-Lindscy, 1925. Denison Univ. Bull., Jour. S. Lab. 21: 74.- Campos. 1927. Rev. Col. Nac. V. Kocafuerte 9 (27-28): 97.- Bell, 1932. Amer. Mus. Novit. 555: 3. Hayward, 1942. Bol. Mus. Nac.. Rio de Janeiro, 14-17: 71.- Williams \& Hayward, 1944. Acta zool. lill. 2: 81.- Bell, 1946. Jour. N. Y. Eut. Soc. 54: 200: syn.: patroches. patrobas: Godman \& Salvin. Bell.-Hayward, 1947. Acta zool, lill. 4: 222: syn.: patrochs, patrohas: Godman \& Salvin. Bell.- Martin. 1941. Bol. Mus. Ilist. Natt. "Javier Prado" 5: 454

Jamadia (sic) azeta: Weeks. 1901. Ill. unfig. Lep., p. 30.

Jemadia azeta azeta: Ureta, 1941. Bol. Mus. Nac. Hist. Nat. Chile, 19:41.

Elbella azeta azeta: Evans, 1951. Cat. Amer. llesp. 1. p. 45, pl. 5 (genitália masculina): syn : parochus - Lamas, 1983. Rev. Sic. Mex. Lep. 8: 21.

Elhella azela: Pallister, 1956. Amer. Mus. Novit. 1763: 20, 24--Bridges, 1983, Lep. Hesp. 1. p. 
13, 90; 2, p. 12; syn.: patroclus.- Bridges, 1988. Cat. Hesp. 1, p. 21, 143; 2, p. 19; syn.: patroclus.

(sem gênero) azeta; Beattie, 1976. Rhop. Direct.. p. 91.

Diagnose. Face dorsal da asa anterior com a mancha branca em M3-CuA1 com a largura 2,3 a 1,4 menor que a sua altura.

Descrição. Macho (Fig. 110) - Comprimento da asa anterior 25 a $27 \mathrm{~mm}$.

Face dorsal da asa anterior com a faixa branca mediana entre 2,3 a $4 \mathrm{~mm}$ de largura máxima; mancha branca em M3-CuAl com a largura 2,3 a 1,4 menor que a sua altura; faixa branca apical com a largura máxima igual à mancha anterior; normalmente com pequena mancha branca em R2-R3; discocelulares normalmente azuis, raras vezes com escassas escamas desta cor; manchas diminutas da faixa azul submarginal, às vezes, presentes entre Ml e M3, as demais bem marcadas; manchas azuis longitudinais, abaixo da faixa mediana, grandes, atingindo o nível do limite proximal da mancha branca da célula e a superior expandida na base até $\mathrm{CuA} 2$.

Face dorsal da asa posterior com a faixa azul discal igual ou um pouco mais fina que as faixas azuis basal e mediana, às vezes, praticamente ausente entre CuA2 e $2 \mathrm{~A}$ e, às vezes, com manchas difusas azuis em Sc+R1-Rs acima das faixas mediana e distal.

Face ventral da asa anterior com as discocelulares azuis; manchas da faixa azul submarginal bem marcadas entre $\mathrm{CuAl}$ e $2 \mathrm{~A}$ e, às vezes, com escassas escamas azuis em M3-CuAl.

Face ventral da asa posterior com as faixas azuis adicionais basal até CuAl ou $\mathrm{CuA} 2$ e distal até $\mathrm{CuA} 2$ e com pequena mancha, raras vezes ausente, azul, fina e transversal em Sc + Rl-Rs, entre a faixa mediana e a faixa adicional basal.

Fêmea (Fig. 111). Semelhante ao macho. Comprimento da asa anterior 27 a $28 \mathrm{~mm}$; face dorsal da asa anterior com a faixa branca mediana entre 2,1 e 2,9 $\mathrm{mm}$ de largura máxima; mancha branca em M3-CuA1 com a largura igual a 1/3 a 1/4 da sua altura.

Distribuição espacial (Fig. 45). COLÔMBIA - Meta: Villavicencio. - PERU - Loreto: Pebas. Junin: Satipo; Rio Perené. San Martin. Madre de Dios: Puerto Maldonado 300m; Tambopata; Parque Nacional de Manu 340m. Huánuco: Tingo Maria 850m. Cuzco: Quincemil. - Bolívia - Cochabamba: Cochabamba 1100m. La Paz: Sarampiuni; Caranavi 500-1000m. Santa Cruz: Buenavista. - Brasil Amazonas: Barcellos; Manicoré; São Paulo de Olivença; Manaus; Maués. Acre: Rio Branco. Rondônia: Vilhena. Mato Grosso: Diamantino 300-400m; Barra do Bugres 150m. Pará: Santarém; Juruti; Rio Arapiuns; Óbidos.

Distribuição temporal. Voa de janeiro a março, junho a outubro e dezembro.

Etologia. É um habitante de florestas, sendo que os machos pousam em areias úmidas na beira dos rios, principalmente em excremento de aves e urina.

Planta hospedeira. Desconhecida.

Etimologia. Desconhecida.

Material estudado. Um síntipo macho aqui designado LECTóTIPO, com 


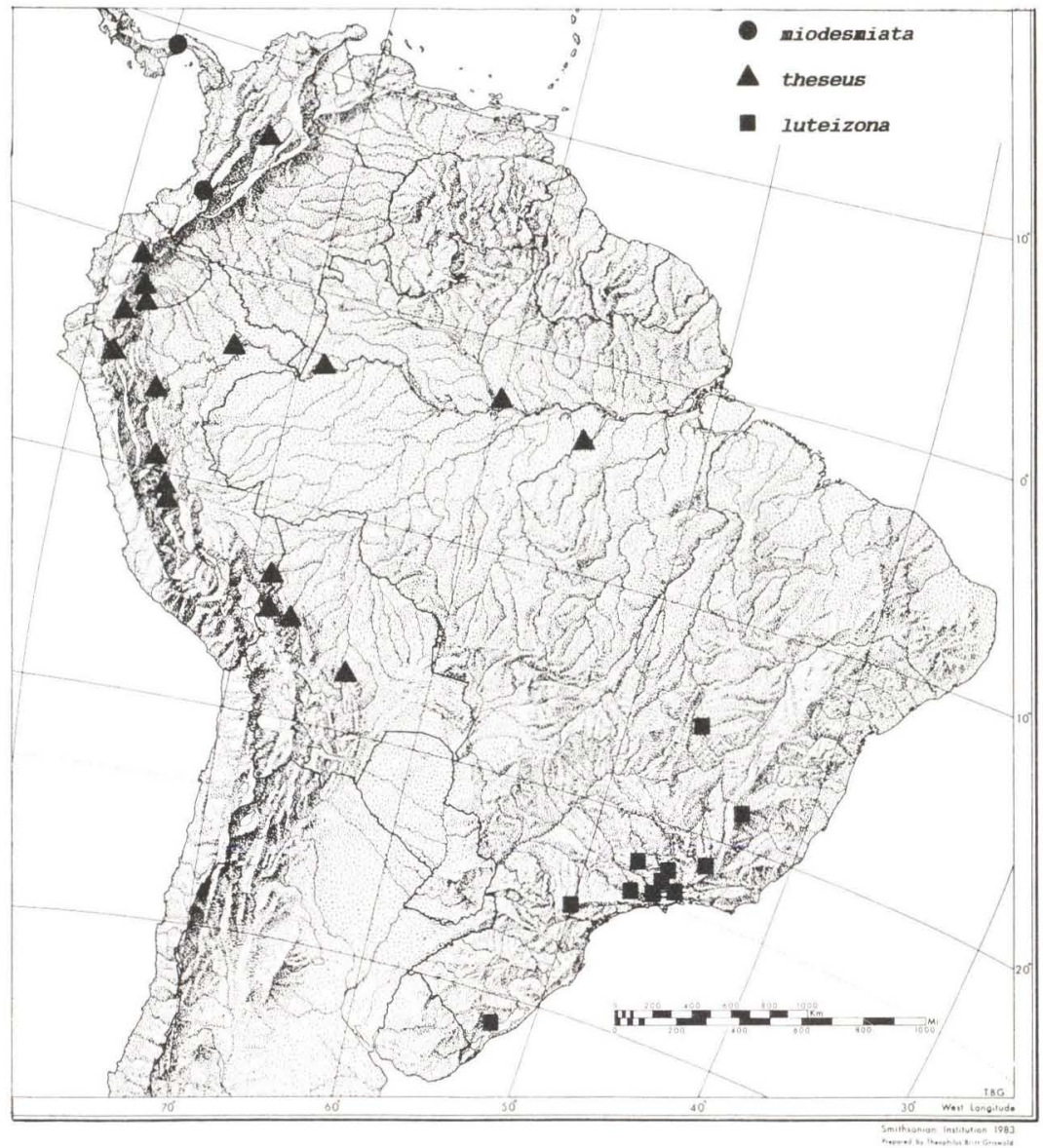

Fig. 47. Mapa de distribuiçao gesogralica. Elhella.

as seguintes etiquetas: /St. Paulo |de Olivença| Hewitson Coll 79-89 Pyrhopyga (sic) azeta 2./ Type/ cartãocom preparado da genitália/LECTOTIPO/Pyrhopyga azeta Hewitson, 1866, Lectótipo, O. Mielke det. 1993/ Elhella azeta azéta, O. Mielke det. 1993/(BMNH). - Colômbia - Mera: Villavicencio. Callaghan leg., 4-X-1980 I fêmea (UFPC-OM); Villavicencio, Sch.-Mumm leg., 24-V-1981 1 macho (UFPC-OM). Vaupes: San Jose del Guaviare, J. Urhina leg., VII-1990 I macho (LECR). - PERU - Jumin: Satipo, Paprzycki leg., 13-III-1939 1 macho (UFPC-OM). San Martin, III-1990 I macho(UFPC-OM). Hucinuco: Tingo Maria (Rondos), Villegas leg., $850 \mathrm{~m}, 16-20-\mathrm{X}-1971$ I macho (UFPC). Madre de Dios: Parque Nacional de Manu (Pakitza), Mielke leg., 340m, 29-IX-2991 I macho (MHNL, USNM, UFPC ?); Parque Nacional de Manu (Pakitza), Lamas leg., 27-IX-1991 I macho (MHNL, USNM, UFPC ?); Puerto Maldonado, $30 \mathrm{~km} \mathrm{SW,}$ Nicolay leg., 300m, 17-X-1983 I macho (USNM); Puerto Maldonado, Nicolay 
leg., 300m, 14-X-1983 1 macho (USNM). Cuzco: Quinzemil, 800m, 15-IV-1947 1 macho (AMNH). - BolíviA - Cochabamba: Cochabamba (Chapare, Alto Palmer), Steinbach leg., $110 \mathrm{~m}$, XII-1976 1 macho (UFPC-OM). La Paz: Caranavi, Tello leg., 500-1000m, II-III-1989 14 machos, VIII-1989 3 machos (UFPC-OM). Santa Cruz, 2 machos (AMNH). - BRAsIL - Amazonas: Barcellos, Zikán leg., 3-VIII-1927 1 macho (IOC); Manicoré, Parko leg., X-1941 1 macho (UFPC-OM); Manaus, 1 fêmea (UFPC-OM); Maués, 1 fềmea (MNRJ). Acre: Rio Branco, Miers leg., 30-IX-1985 I fềmea (UFPC-OM). Rondônia: Vilhena, Elias leg., 26-IX-1986 1 macho, 27-XII-1986 I macho (UFPC). Mato Grosso:

Diamantino (Fazenda São João), Furtado leg., 300 - 400m, 31-III-1993 1 fêmea (EF), 6-II-1977 1 macho, 15-II-1977 1 macho, 24-IX-1977 1 macho, 14-I-1978 I macho, 26-I-1978 1 macho, 28-I-1978 1 macho, 31-I-1978 1 macho, 4-II-1978 1 macho, 7-II-1978 3 machos, 10-II-1978 6 machos, 14-II-1978 1 macho, 16-II-1978 3 machos, 20-II-1978 3 machos, 24-II-1978 1 macho, 11-III-1978 1 macho, 25-VIII-1978 1 macho, 10-II-1982 1 macho, 12-II-1982 1 macho, 18-II-1982 1 macho, 28-II-1982 2 machos, 2-III-1982 2 machos (UFPC-OM), 28-VIII-1979 2 machos (UFPC); Diamantino (Fazenda São João), Mielke \& Furtado leg., 300400m, 21-I-1978 1 macho, 2-IX-1978 2 machos, 5-IX-1978 1 macho, 10-IX-1978 1 macho, 11-IX-1978 1 macho, 7-II-1979 2 machos, 10-II-1979 2 machos, 19-II-1979 1 macho, 20-II-1979 2 machos, 26-II-1979 3 machos, 5-III-1979 1 macho (UFPC-OM); Barra do Bugres, Furtado leg., 150m, 11-II-1977 1 macho (UFPC). Pará: Santarém, 2 machos (UFPC-OM, MNRJ); Juruti, Kesselring leg., III-1980 1 macho (UFPC-OM); Rio Arapiuns, Kesselring leg., III-1980 1 macho (UFPC-OM); Óbidos, 1 fềmea (MNRJ), V-1968 1 fềmea, VI-1969 1 macho (UFPC-OM); Óbidos, Kesselring leg., VII-1977 (UFPC-OM).

\subsection{Elbella azeta giffordi, ssp.n.}

Figs 45, 112, 113

Diagnose. Face dorsal da asa anterior com a mancha branca em M3-CuA 1 praticamente quadrada; faixa branca com a largura máxima de $4,5 \mathrm{~mm}$ no macho e 3,7 a $4,5 \mathrm{~mm}$ na fềmea.

Descrição. Macho (Fig. 112) - Comprimento da asa anterior $26 \mathrm{~mm}$.

Face dorsal da asa anterior com a faixa branca mediana $4,5 \mathrm{~mm}$ de largura máxima; mancha branca em M3-CuA1 com a largura 1/10 menor que a sua altura; faixa branca apical com a largura máxima igual à mancha anterior; com pequena mancha branca em R2-R3; discocelulares com difusas manchas azuis; manchas da faixa azul submarginal entre CuAl e $2 \mathrm{~A}$ estreitas e difusas; manchas azuis longitudinais, abaixo da faixa mediana, grandes, atingindo o limite proximal da mancha branca da célula discal, difusas e a superior expandida na base até CuA2.

Face dorsal da asa posterior com a faixa azul discal mais fina que as faixas azuis basal e mediana; sem manchas azuis em Sc + R 1-Rs, acima das faixas mediana e discal; franjas concolores, passando a brancas a partir de M3 até pouco além de $2 \mathrm{~A}$ e terminações das veias negras. 


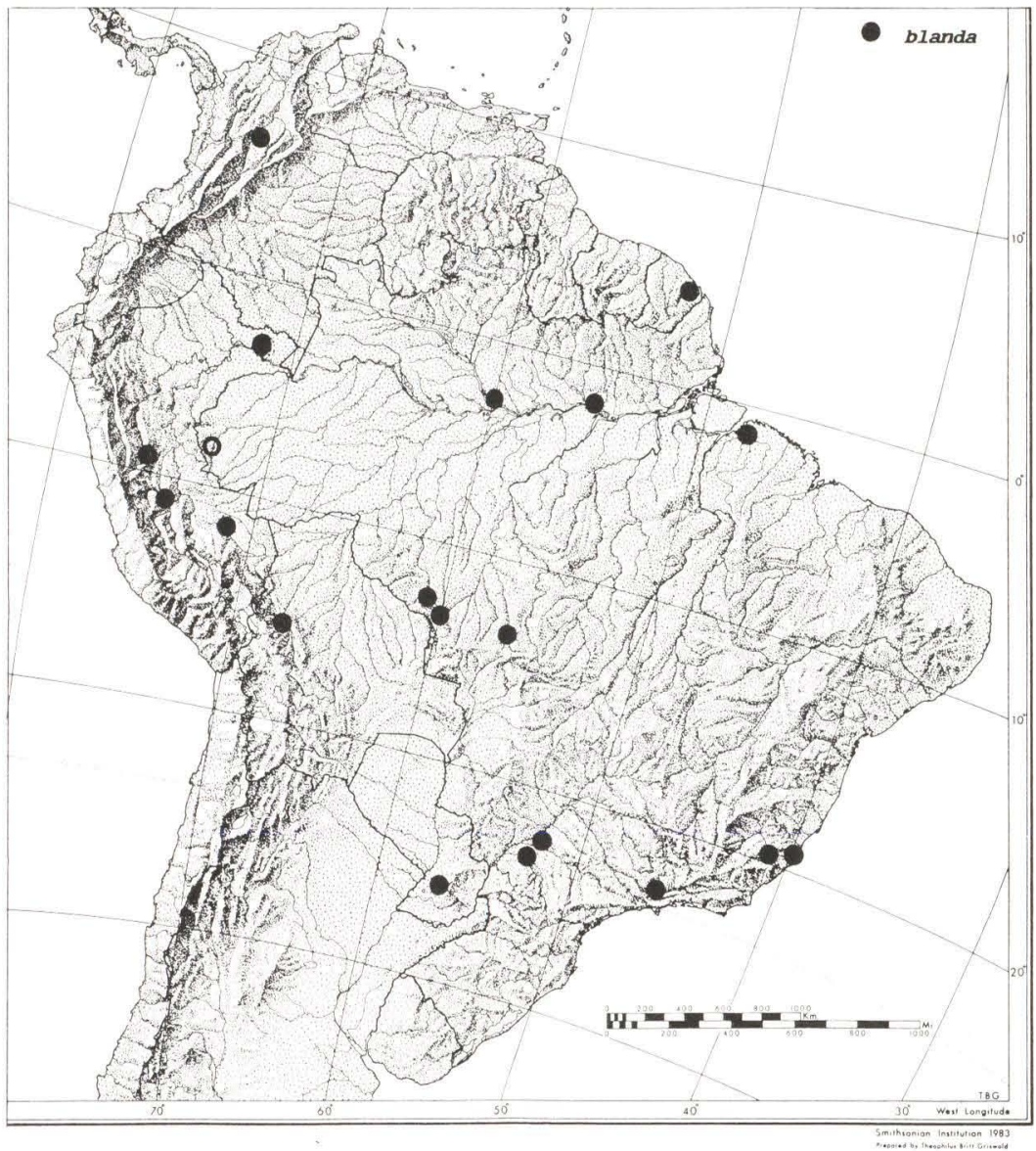

Fig. 48. Mapa de distributçáa geogrativa. Elhella

Face ventral da asa anterior com as discocelulares azuis; manchas da faixa azul submarginal pouco mais largas.

Face ventral da asa posterior com a faixa azul discal mais fina e separada da faixa azul mediana por uma distância maıor yue a larģura desta; distância entre as faixas azuis hasal e mediana igual a largura desta; faixas azuis adicionais hasal até Ml e distal até CuAl; sem pequena mancha azul transversal em Sc + RI-Rs, entre a faixa mediana e a faixa adicional hasal; espaço $2 \mathrm{~A}-3 \mathrm{~A}$ com uma mancha azul difusa ahaixo da faixa discal; franjas como na tace dorsal.

Fêmea (Fiğ. 113). Semelhante ao macho. Comprimento da asa anterior $29 \mathrm{~mm}$.

Face dorsal da asa anterior com a faixa hranca mediana entre 3,7 e $4,5 \mathrm{~mm}$ de largura máxima; mancha hranca em M3-CuA l com a largura igual a 1/3 cla sua 
altura; discocelulares azuis; faixa azul submarginal mais larga entre M3 e 2A; manchas azuis longitudinais, abaixo da faixa mediana, nítidas.

Face ventral da asa posterior com as faixas azuis adicionais basal e distal até $\mathrm{CuA} 2$; com pequena mancha azul transversal em $\mathrm{Sc}+\mathrm{R} 1-\mathrm{Rs}$ entre a faixa mediana e a faixa adicional basal; espaço 2A-3A danificado nos dois exemplares.

Discussão. Subespécie bem caracterizada pelas grandes manchas brancas da asa anterior.

Distribuição espacial (Fig. 45). BRASIL - Distrito Federal: Brasília 1000m. São Paulo: Rancharia 400m.

Distribuição temporal. Voa em setembro e novembro.

Etologia. Desconhecida, mas provavel como em azeta azeta.

Planta hospedeira. Desconhecida.

Etimologia. Espécie dedicada ao Dr. David Gifford, já falecido, professor da Universidade de Brasília e orientador da Dra. Lourdes Ferreira, a coletora do holótipo.

Material estudado. Holótipo macho com as seguintes etiquetas: / HOLOTIPO/29-XI-1980 ESAF, Brasilia, D[istrito] F[ederal], Ferreira leg./ DZ $1882 /$ gen.[itália] prep.[arada] Mielke 1993/ Elbella azeta giffordi Mielke, Holótipo, O. Mielke det. 1993/ (UFPC). Alótipo fêmea com as seguintes etiquetas: / ALLOTYPUS/ XI-1938 Rancharia, São Paulo/ 11.931/gen.[itália] prep. [arada] Mielke 1993/Elbella azeta giffordi Mielke, Alótipo, O. Mielke det. 1993/ (UFPC-OM). Parátipo: sem procedência, 1 fềmea (UFPC-OM).

\section{Elbella lustra Evans, 1951 , stat.n.}

Figs $27,45,114,115$

Elhella azeta lustra Evans,1951. Cat. amer Ilesp. 1. p. 45: [holóltipo macho, Bogotá: BMNH [Examinado].- Bridges, 1983. Lep. IIesp. 1, p. 68: 2, p. 12.- Bridges.1988. Cat. Hesp. 1. p. 108: 2. p. 19 ,

(sem gênero) lustra: Beattie, 1976. Rhop Direct.. p. 188.

Diagnose. Face dorsal da asa anterior com a mancha branca em M3-CuA1 linear, ou seja, a largura $1 / 5$ da sua altura; face dorsal da asa posterior com a faixa azul distal mais larga que as faixas azuis basal e mediana.

Descrição. Macho (Fig. 114) - Comprimento da asa anterior $29 \mathrm{~mm}$.

Face dorsal da asa anterior com a faixa branca mediana $3,6 \mathrm{~mm}$ de largura máxima; mancha branca em M3-CuA1 igual a 1/5 da sua altura; manchas brancas apicais alcançam quatro vezes a largura da mancha anterior; sem mancha branca em R2-R3; discocelulares com escassa escamas azuis; mancha da faixa azul submarginal em M3-CuAl constituida de escamas isoladas, as entre CuAl e 2A estreitas; manchas longitudinais azuis, abaixo da faixa mediana, curtas, alcançando o nível do meio da mancha em CuA1-CuA2, a superior não expandida até CuA2.

Face dorsal da asa posterior com a faixa azul discal mais larga que as faixas azuis basal e mediana; com mancha azul difusa em Sc+R1-Rs, acima da faixa discal; franjas brancas entre $\mathrm{Sc}+\mathrm{R} 1-\mathrm{Rs}$ e $3 \mathrm{~A}$, com as terminações das veias negras. 


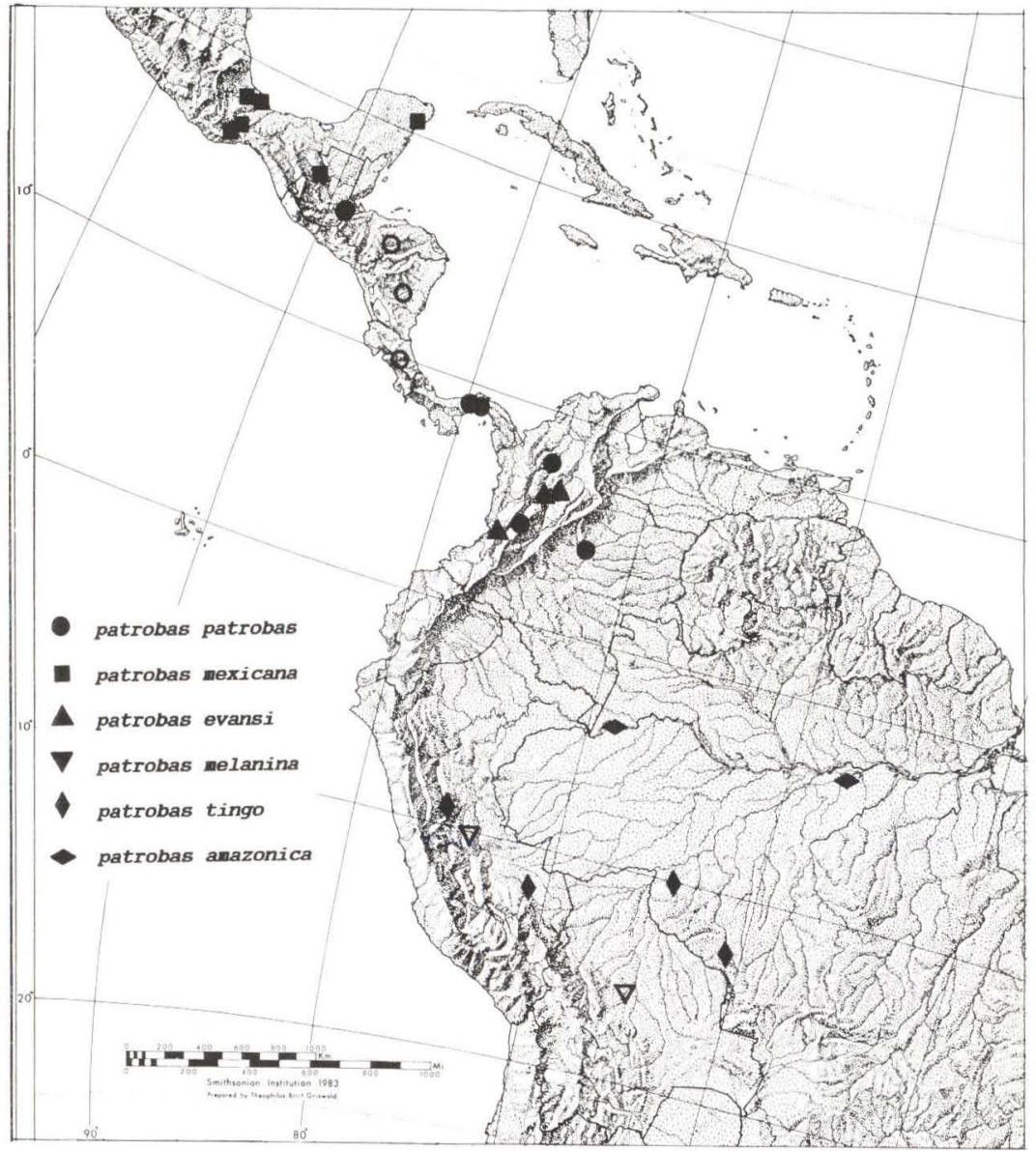

Fig. 49. Mapa de distribuiçào geogrática. Elbella.

Face ventral da asa anterior com as discocelulares azuis; manchas da faixa azul submarginal como na face dorsal, mas ausente em M3-CuAl e, às vezes, em $\mathrm{CuAl-CuA2}$.

Face ventral da asa posterior com as três faixas azuis de larguras uniformes e separadas entre si por distâncias pouco maiores que as suas larguras; faixas azuis adicionais hasal e distal até CuA2 e com pequena mancha transversal em $\mathrm{Sc}+\mathrm{R} 1-\mathrm{Rs}$, entre as faixas mediana e adicional hasal; espaço 2A-3A com duas manchas azuis abaixo das faixas discal (maior) e mediana (menor e difusa); espaço 2A-3A azul; franjas como na face dorsal.

Genitália (Figg. 27). Apófises do tegumen triangulares, em vista dorsal e pouco menores que $1 / 3$ do comprimento do unco em vista lateral; harpe longa, com a ponta rombuda e com um lóhulo arredondado dorso-basal (único no gênero) 
e uma pequena projeção triangular distal deste lóbulo; edeago reto, com carena parcialmente espinhosa e subterminal no lado direito.

Fêmea (Fig. 115). Semelhante ao macho. Comprimento da asa anterior $29 \mathrm{~mm}$.

Face dorsal da asa anterior com a faixa branca mediana entre 2,6 e 3,2 mm de largura máxima; discocelulares azuis; mancha da faixa azul submarginal ausente ou bem marcada em M3-CuA1.

Face ventral da asa anterior com a mancha da faixa azul submarginal ausente em M3-CuAl.

Face ventral da asa posterior com as três faixas azuis de larguras uniformes e separadas entre si por distâncias maiores que as suas larguras; faixas azuis adicionais basal difusa até $\mathrm{M} 1$ ou $\mathrm{CuA} 1$ e distal até $\mathrm{CuA} 2$, às vezes, muito larga, parecendo que a mancha distal azul em $\mathrm{Sc}+\mathrm{R} 1-\mathrm{Rs}$ faz parte dela; espaço $2 \mathrm{~A}-3 \mathrm{~A}$ com as manchas bem marcadas.

Genitália (Fig. 27). Partes laterais do oitavo esterno inteiras, finas e não ligadas ao esterigma; esterigma tubular, em vista lateral diminuindo a altura para a ponta distal e a abertura do óstio aparecendo dorsalmente no terço distal, em vista ventral com os lados aproximadamente paralelos.

Discussão. Pelas diferenças nas genitálias masculina e feminina, é considerada uma espécie distinta de azeta. O casal estudado de Otanche, Boyaca, Colômbia é muito semelhante. A fêmea de Paramba, mencionada abaixo, foi citada por Evans (1951) como sendo a de patroclus (=umbrata; Evans).

Distribuição espacial (Fig. 45). COLÔMBIA - Cundinamarca: Bogotá (provavelmente a localidade não é correta). Boyaca: Otanche. - ECUADOR Imbabura: Paramba, $1200 \mathrm{~m}$.

Distribuição temporal. Voa em fevereiro, abril e agosto.

Etologia. Desconhecida, mas provavel como em azeta azeta.

Planta hospedeira. Desconhecida.

Etimologia. Provavel combinação arhitrária de letras.

Material estudado. O holótipo macho com as seguintes etiquetas: / Type/ Bogota/ Rothschild Bequest B.M. 1939-1./ cartão com o preparado da genitália/ (BMNH). - Colômbia - Boyaca: Otanche, J. Urbina leg., VIII-1985 1 fêmea, IV-1992 I macho (LECR). - ECUADOR - Imbabura: Paramba, Rosenberg leg., $1200 \mathrm{~m}$, III-1897 1 fềmea (BMNH).

\section{Elbella merops (Bell, 1933)}

Figs 28, 46, 116, 117

Jemadia merops Bell, 1933. Jour. N. Y. Ent. Soc. 41: 502, figs. 31 (genitália masculina), 40, 41: holótipo macho, Colômbia; AMNH [Exaninado].- Hayward, 1947. Acta zool. lill. 4: 222.

Elbella merops; Evans, 1951. Cat. Amer. IIesp. 1, p. 43, pl. 5 (genitalia masculina).- Lamas, 1981.

Rev. Soc. Mex. Lep. 6: 35.- Lamas, 1983. Rev. Sox. Mex. Lep. 8: 50, ecologia.- Bridges. 1983. Lep. Hesp. 1, p. 75; 2, p. 12.- Bridges, 1988. Cat. Hesp. 1. p. 118; 2, p. 19.

(sem gênero) merops; Beattie, 1976. Rhop. Direct., p. 200. 
Diagnose. As genitálias masculina e feminina caracterizam a espécie.

Descrição. Macho (Fig. 1 16) - Comprimento da asa anterior 25 a $27 \mathrm{~mm}$. Genas brancas com as partes internas negras e às vezes com escassas escamas negras nas partes centrais.

Face dorsal da asa anterior com a faixa branca mediana entre 1,8 a $4 \mathrm{~mm}$ de largura máxima; mancha branca em M3-CuAl com a largura até 1/3 da sua altura; faixa branca apical sempre pouco mais larga que a mancha anterior; raras vezes com escassas escamas azuis na hase da margem costal, pela redução das faixas hasal e sub-basal; discocelulares, às vezes, com leve pontuação azul, nunca formando faixa; manchas da faixa azul submarginal entre M3 e 2A difusas; manchas azuis longitudinais, abaixo da faixa mediana, pouco brilhantes, grandes. alcançando o nível do limite proximal da mancha da célula discal e a superior expandida às vezes na base até CuA2.

Face dorsal da asa posterior com as três faixas azuis iguais, ou a externa um pouco mais larga ou mais estreita, chegando a desaparecer entre CuAl e $2 \mathrm{~A}$, às vezes, a faixa discal com pequena mancha difusa em $\mathrm{Sc}+\mathrm{R} 1-\mathrm{Rs}$; franjas concolores, passando a brancas a partir de $\mathrm{Ml}$ ou CuAl com as terminações das veias negras.

Face ventral da asa anterior com as discocelulares finamente azuis e as manchas da faixa azul submarginal pouco maiores que na face dorsal.

Face ventral da asa posterior com as três faixas azuis de larguras uniformes e separadas entre si por distâncias maiores que as suas larguras; faixas azuis adicionais basal até M1, M3 ou CuAl e distal até CuA2; espaço 2A-3A pode ter manchas azuis difusas abaixo das faixas basal, mediana e distal, podendo faltar qualquer delas ou mesmo haver a união entre duas contíguas; franjas como na face dorsal.

Genitália (Fig. 28). Apófises do tegumen alongadas, finas e não contíguas ao unco em vista dorsal e pouco menores que a metade do unco em vista lateral; harpe de largura aproximadamente uniforme e a parte distal nitidamente dilatada e sem projeção dorso-basal; edeago com o lóbulo distal dirigido dorso-posteriormente e mais largo na base do que a metade da largura da abertura do edeago; edeago com a ponta distal curvada ventralmente.

Fêmea (Fiğ. 117). Semelhante ao macho. Comprimento da asa anterior 30 a $31 \mathrm{~mm}$.

Face dorsal da asa anterior com a faixa branca mediana entre 3,2 e $3,4 \mathrm{~mm}$ de largura máxima; mancha branca em M3-CuAl com a largura igual a I/4 da sua altura; discocelulares azuis.

Face dorsal da asa posterior com as três faixas azuis iguais.

Face ventral da asa anterior com as discocelulares bem azuis.

Genitália (Fig. 28). Partes laterais do oitavo esterno inteiras e ligadas ao esterigma; esterigma anelar e com protuberância na ponta distal.

Discussão. As genitálias masculina e feminina caracterizam a espécie.

Distribuição espacial (Fig. 46). COLÔMBIA - Cundinamarca: Bogotá (?). Tolima: Rio Chili. Boyaca: Otanche. - PERU - Loreto: Iquitos. Madre de Dios: 
Parque Nacional de Manu 340m; Tambopata. Huánuco: Tingo Maria $850 \mathrm{~m}$. Bolívia - La Paz: Caranavi 600-1000m. Santa Cruz. - GuiAnA FrancesA Caiena. - BRASIL - Acre: Porto Walter. Amazonas: São Felipe. Pará: Vila Nova; Óbidos. Mato Grosso: Diamantino 300-400m.

Distribuição temporal. Voa em janeiro, abril, maio, julho e setembro a novembro.

Etologia. É um habitante de florestas, sendo que os machos pousam em areias úmidas na beira dos rios, principalmente em excrementos de aves e urina.

Planta hospedeira. Desconhecida.

Etimologia. Talvez de Merope, da mitologia grega, filha de Cypseius, Rei da Arcádia.

Material estudado. Holótipo macho com as seguintes etiquetas: / sp. Columbia/ G 1178/Jemadia merops Bell Holotype o/ (AMNH). - COLÔMBIA - 1 macho (AMNH). Vaupes: San Jose del Guaviare, J. Urbina leg., VII-1990 1 macho (LECR). Meta: Villavicencio, J. Salazar leg., 20-XI-1989 I macho (LECR). Boyaca: Otanche, Le Crom leg., IV-1993 1 macho (UFPC-OM). - PERU - Loreto: Iquitos, 1 fêmea (UFPC-OM). Madre de Dios: Parque Nacional de Manu (Pakitza), Lamas leg., 340m, 5-X-1991 1 fêmea (MHNL. USNM, UFPC); Parque Nacional de Manu, Casagrande leg., 340m, 1 X-1991 1 fềmea (MHNL, USNM, UFPC). Huámuco: Tingo Maria (Rondos), Villegas leg., 850m, 27-X-1971 3 macho (UFPC). - Bolívia - Santa Cruz, 1 macho (AMNH). La Paz: Caranavi, Tello leg., 600-1000m, IX-X-1988 I macho (UFPC-OM). - GUIANA FrancESA - Caiena (Habitacion Vidal), Lalanne-Cassou leg., 16-V-1989 1 macho 1 fêmea (em cópula) (UFPC-OM). - BRASIL - Acre: Porto Walter, 1 macho (UFPC-OM). Amazonas: São Felipe (médio rio Juruá), 20-VI-1948 1 fềmea (UFPC). Mato Grosso: Diamantino (Fazenda São João), Furtado leg., 300-400m, 26-I-1978 1 macho, 28-I-1978 1 macho (UFPC-OM), 27-I-1980 1 macho (EF). Pará: Óbidos, 1 macho (USNM).

\section{Elbella theseus (Bell, 1933)}

Figs 29, 47, 118, 119

Jemadia theseus Bell, 1933. Jour. N. Y. Ent. Soc. 41: 503, figs 32 (genitália masculina), 44, 45; holótipo macho, Brasil, coleção Bell (AMNH) [Examinado].- Williams \& Hayward, 1944. Acta zool. lill. 2: 82.- Hayward, 1947. Acta zool. lill. 4: 223.

Elbella theseus; Evans, 1951. Cat. Amer. Ilesp. 1, p. 43, pl. 5 (genitália masculina)-- Bridges, 1983.

Lep. Hesp. 1, p. 118; 2, p. 12.- Bridges, 1988. Cat. Hesp. 1, p. 187; 2, p. 20.

Elbella polyzona; Lewis, 1975. Marip. Mundo, p. 82, fig. 40 (?).

(sem gênero) theseus; Beattie, 1976. Rhop. Direct., p. 273.

Diagnose. As genitálias masculina e feminina caracterizam a espécie.

Descrição. Macho (Fig. 118) - Comprimento da asa anterior 26 a 30mm. Genas brancas com até as metades basais e as partes internas negras.

Face dorsal da asa anterior com a faixa branca mediana entre 2,4 e 3,9mm de largura máxima; mancha branca em M3-CuAl com a largura entre 1/7 e 1/2 da sua altura; faixa branca apical com a largura máxima igual à mancha anterior 


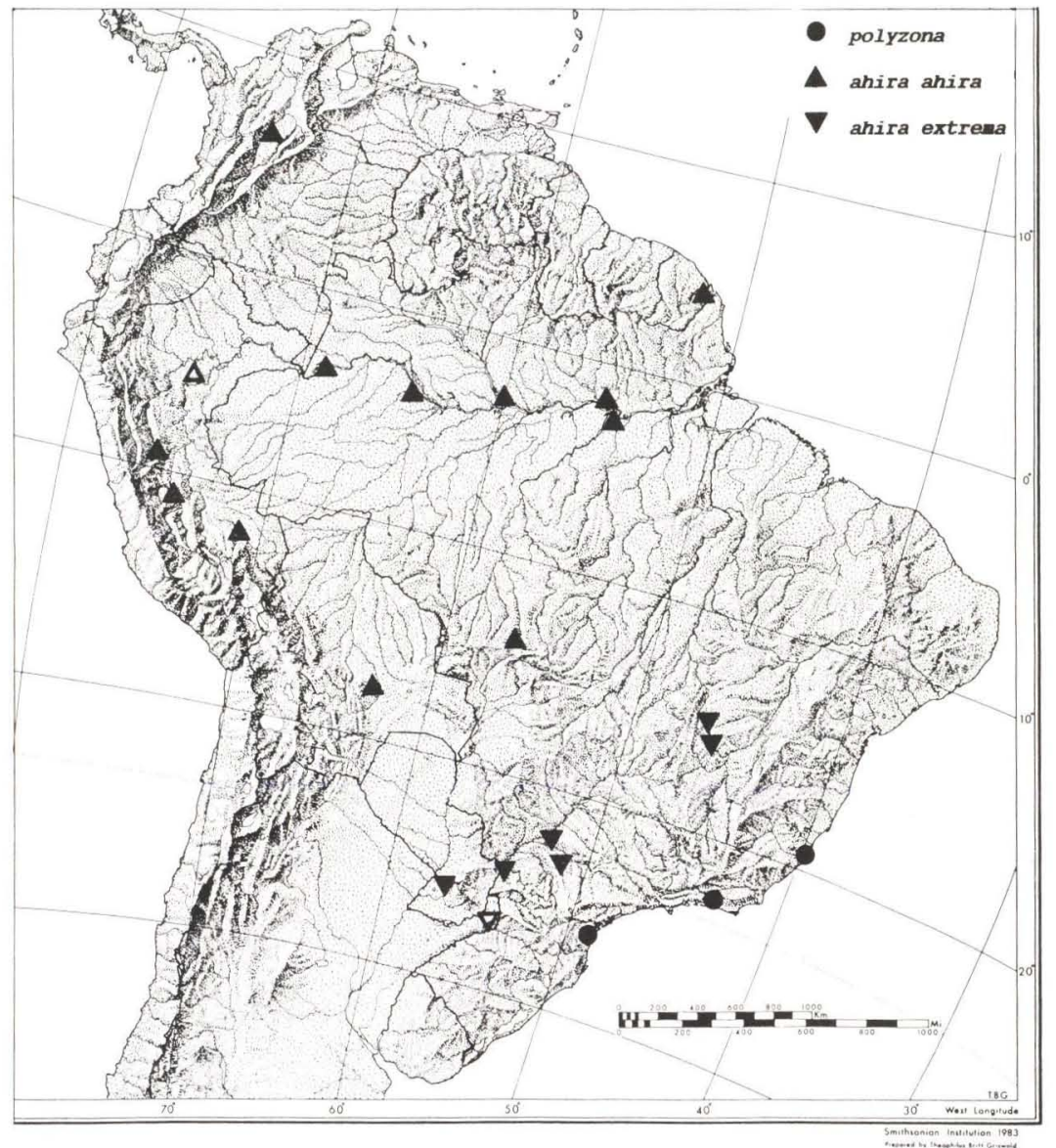

Fig. 50. Mapa de distrihuição geográfica. Parelleella.

ou mais larga; normalmente com pequena mancha branca em R2-R3; discocelulares raras vezes com escamas difusas azuis; manchas diminutas da faixa azul submarginal, às vezes, presentes entre $\mathrm{Ml} \mathrm{e} \mathrm{CuAl}$, as entre CuAl e $2 \mathrm{~A}$ bem marcadas; manchas azuis longitudinais, ahaixo da faixa mediana, grandes, atingindo o nível do limite proximal da mancha da célula discal e a superior, às vezes, expandida na base até $\mathrm{CuA2}$.

Face dorsal da asa posterior com as três faixas azuis iguais ou a discal mais larga que as demais, deixando um espaço entre as faixas basal e mediana maior que entre esta e a discal, faixa discal normalmente prolongada em Sc + R I-Rs; franjas concolores, passando a brancas a partir de $\mathrm{CuAl}$ até $3 \mathrm{~A}$ e interrompidas pelas veias negras. 
Face ventral da asa anterior com as discocelulares finamente marcadas de azul; manchas da faixa azul submarginal muito variáveis, desde estreitas até muito largas, mais que a largura da faixa branca mediana, entre CuAl e $2 \mathrm{~A}$ e reduzida a poucas escamas difusas em M3-CuAl.

Face ventral da asa posterior com as três faixas azuis de larguras uniformes e separadas entre si por distâncias iguais às suas larguras, mas exitem variações nas larguras das faixas; faixas azuis adicionais basal até M1, M2 ou CuAl e distal até $\mathrm{CuA} 2$; parte apical da margem costal azul; espaço $2 \mathrm{~A}-3 \mathrm{~A}$ com ou sem manchas azuis abaixo das faixas mediana e discal; franjas como na face dorsal.

Genitália (Fig. 29). Apófises do tegumen retangulares, mais curtas que longas e margens internas mais recuadas que as margens externas, contíguas ao unco em vista dorsal e $1 / 4$ do comprimento do unco em vista lateral; harpe longa, fortemente curvada e diminuindo gradativamente a largura para a ponta distal fina; edeago com a ponta distal curvada ventralmente e com entumescimento terminal nos lados ventral e direito.

Fêmea (Fig. 119). Semelhante ao macho. Comprimento da asa anterior 29 a $30 \mathrm{~mm}$.

Face dorsal da asa anterior com a faixa branca mediana entre 2,2 e $2,8 \mathrm{~mm}$ de largura máxima; mancha branca em M3-CuAl com a largura igual a 2,4 vezes menor que a sua altura; faixa branca apical com a largura máxima igual à mancha anterior; discocelulares azuis; manchas da faixa azul submarginal presentes e estreitas só entre CuAl e 2A; faixa longitudinal, abaixo da faixa mediana, expandida na base até $\mathrm{CuA} 2$.

Face dorsal da asa posterior com a faixa azul discal pouco mais estreita que as demais.

Face ventral da asa anterior com as discocelulares azuis; manchas da faixa azul submarginal mais largas que na face dorsal entre $\mathrm{CuA} 1$ e $2 \mathrm{~A}$ e presente em M3-CuAl.

Face ventral da asa posterior com a faixa azul adicional basal bem marcada em CuA1-CuA2; espaço 2A-3A totalmente azul, com exceção de pequena área abaixo e entre as faixas mediana e discal e a margem externa.

Genitália (Fig. 29): Partes laterais do oitavo esterno inteiras e ligadas ao esterigma; esterigma anelar, sem protuberância na ponta distal, como em intersecta.

Discussão. As genitálias masculina e feminina caracterizam a espécie.

Distribuição espacial (Fig. 47). COLÔMBIA - Boyaca: Muzo. - ECUADOR - Morona-Santiago: Macas. Tungurahua: Yunguila. Pichincha: Santo Domingo de los Colorados. Pastaza: Pastaza; Abitagua. Loja: Loja. Zamora-Chinchipe: Zamora. - PERU - Loreto: Iquitos. Cajamarca: Charapi. Junin: Chanchamayo; La Merced. Huámuco: Tingo Maria 850m. Pasco: Pozuzo. San Martin: Tarapoto. Puno: Yahuarmayo; Chaquimayo. - Bolívia - Cochabamba: Cochabamba (Cristal Mayo) 600m. La Paz: Apolohamba; Mapiri 700m; Caranavi 500-1000m. - BrasIL - Amazonas: São Paulo de Olivença; Manaus. Pará: Monte Cristo; Itaituba.

Distribuição temporal. Voa em fevereiro, março e agosto a dezembro. 


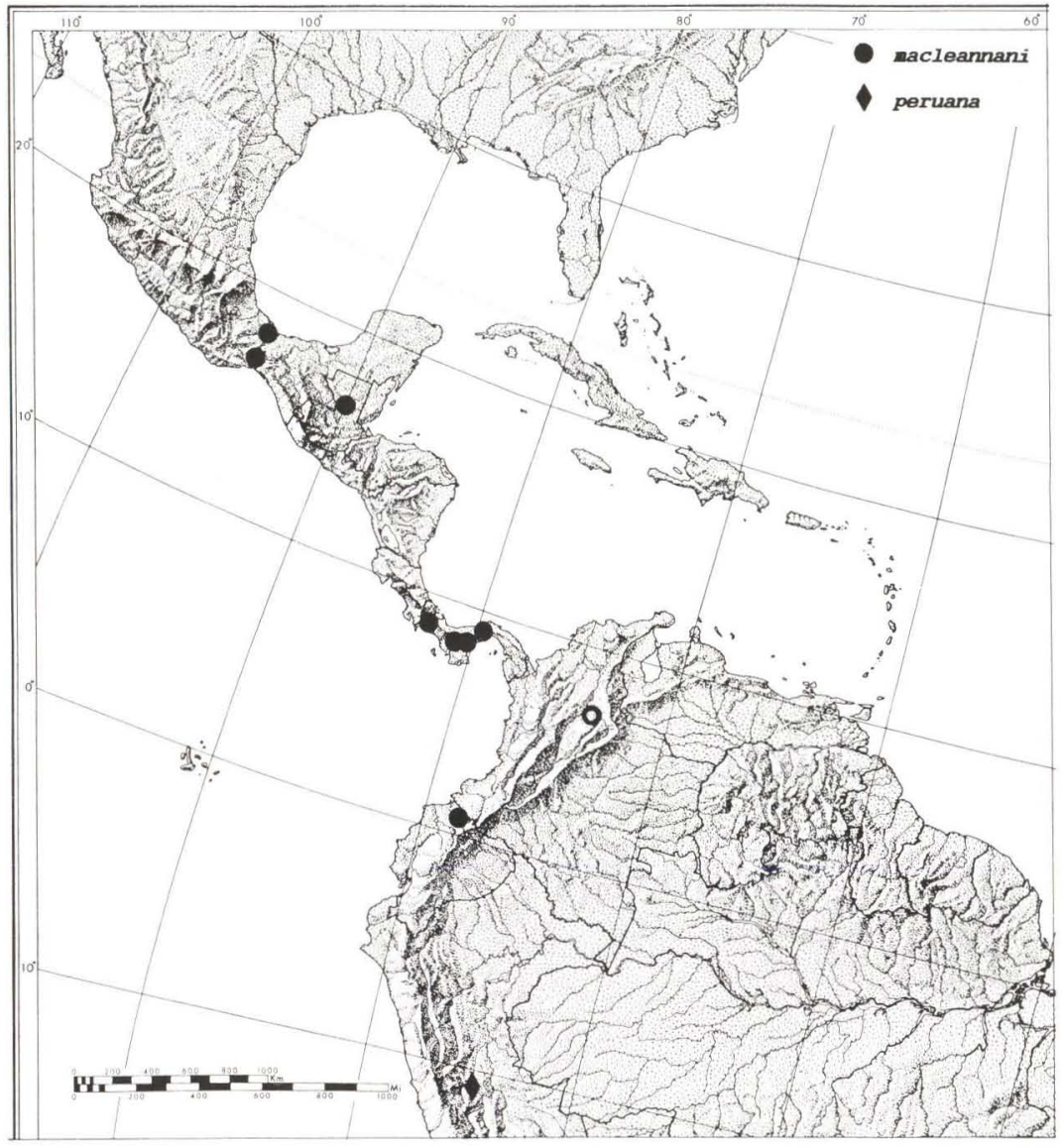

Fig. 51. Mapa de distribuiçáo geograilica. Parelbella.

Etologia. É um habitante de florestas, sendo que os machos pousam em areias úmidas na beira de rios, principalmente em excrementos de aves e urina.

Planta hospedeira. Desconhecida.

Etimologia. Theseus, herói da mitologia grega, originário da África e filho de Egeo, Rei de Atenas.

Material estudado. O holótipo macho com as seguintes etiquetas: /Type/ G53I/ Brazil/ Jemadia theseus Bell Holotype O/ (AMNH). - COLÔMBIA - sem localidade, 2 machos (AMNH). - ECUADor - sem localidade, 600-950m. X-XII-1934 (AMNH). Pichincha: Santo Domingo de los Colorados, 28-VIIİ-1973 1 macho (USNM). Pastaza: Abitagua, 28-VII-1939 1 macho (AMNH). Morona-Santiago: Macas, 1 macho (AMNH). - PERU - Junin: Chanchamayo, 1 macho (MNRJ). Pasco: Pozuzo, 1 macho (ZSBS). Huánuco: Tingo Maria, VIII-1964 I macho (UFPC), XI-1964 2 machos, II-1965 1 macho, 20-II-1982 1 
macho (UFPC-OM); Tingo Maria (Rondos), Villegas leg., 850m, 16-20-X-1971 3 machos, 27-X-1971 (UFPC); Tingo Maria, Büche leg., 670m, 16-VI-1993 4 machos (UFPC-OM). Madre de Dios: Parque Nacional de Manu (Pakitza), Mielke leg., 340m, 28-IX-1991 I macho, 12-X-1991 1 fêmea, 13-X-1991 I macho 1 fêmea (MHNL, USNM, UFPC); Parque Nacional de Manu (Pakitza), Casagrande leg., 12-X-1991 1 macho (MHNL, USNM, UFPC ?).- BolíviA - La Paz: Caranavi, Tello leg., 500-1000m, IX-X-1988 30 machos, II-III-1989 48 machos (UFPC-OM); Mapiri (S. Carlos), Buchtien leg., 700m, VIII-1907 I macho (ZSBS). Cochahamba: Cochabamba (Alto Palmar), Steinbach leg., $1100 \mathrm{~m}$, XII-1976 1 macho(UFPC); Cristal Mayo, Nicolay leg., 600m, 1-III-1959 1 macho (USNM). - Brasil - Amazonas: São Paulo de Olivença, 1 fềmea (UFPC-OM); Manaus, 1 macho (UFPC-OM). Pará: Monte Cristo (rio Tapajós), 1 fêmea (UFPC-OM); Itaituba, Pohl leg., V-1923 1 macho (MZSP). - Sem procedência, 1 macho (UFPC-OM).

\section{Elbella blanda Evans, 1951, stat.n. \\ Figs $30,48,120,121$}

Jemadia azeta; Bell, 1933. Jour. N. Y. Eut. Soc. 41: 500, pl. 32, fig. 29 (genitália masculina). Jemadia patrobas: Miles Moss, 1949. Acta zool. lill. 7: 36. pl. 1, fig. 8 (larva) (?).

Elbella patrobas blanda Evans. 1951. Cat. Amer. Ilesp. 1, p. 44; [holó]tipo macho. Pebas, Amazonas; BMNH [Examinado].- Ehert. 1968, in Silva et cl.. Quart. Cat. Ins, viv. Plant. Brasil 2 (2), p. 240 [?].- Lamas, 1983. Rev. Soc. Mex. Lep. 8: 21.- Lamas, 1983. Rev. Soc. Mex. Lep. 8: 50. ecologia.- Jong, 1983. Tịd. Ent. 126: 236.- Bridges, 1983. Lep. Hesp. 1, p. 17: 2. p. 12.- K. Brown, 1987. An. prim. Simp. Pantanal, Brasil, p. 166.- Bridges, 1988. Cat. Hesp. 1, p. 26: 2. p. 19.

Elhella patrobas; Silva et al., 1968. Quart. Cat. Ins. viv. Plant. Brasil 2 (1), p. 323, planta hospedeira

[?].- Austin, Brock \& Mielke, 1993. Trop. Lep. 4, Suppl, 2, p. 5, fig. 1, ecologia. (sem gênero) blanda: Beattie, 1976. Rhop. Direct., p. 96.

Diagnose. As genitálias masculina e feminina caracterizam a espécie.

Descrição. Macho (Fig. 120) - Comprimento da asa anterior 23 (anormal), 25 a $28 \mathrm{~mm}$. Genas brancas com as partes internas negras.

Face dorsal da asa anterior com a faixa branca mediana entre 2,3 e 4,8 mm de largura máxima; mancha branca em M3-CuAl com a largura mediana entre 4,5 a 1,4 menor que a sua altura; faixa branca apical com a largura máxima igual ou maior que a largura da mancha anterior; discocelulares azuis, às vezes, não destacadas; manchas da faixa azul submarginal entre CuAl e 2A, raras vezes com escamas difusas em M3-CuA1; manchas azuis longitudinais, abaixo da faixa mediana, grandes, alcançando o nível do limite proximal da mancha da célula discal e a superior expandida na base até $\mathrm{CuA} 2$.

Face dorsal da asa posterior com as três faixas azuis da mesma largura ou com a distal mais estreita e não prolongadas em $\mathrm{Sc}+\mathrm{R} 1-\mathrm{Rs}$; franjas concolores, passando a brancas a partir de $\mathrm{Ml}, \mathrm{M} 3$ ou CuAl até $3 \mathrm{~A}$ e com as terminações das veias negras.

Face ventral da asa anterior com as discocelures azuis; manchas da faixa 


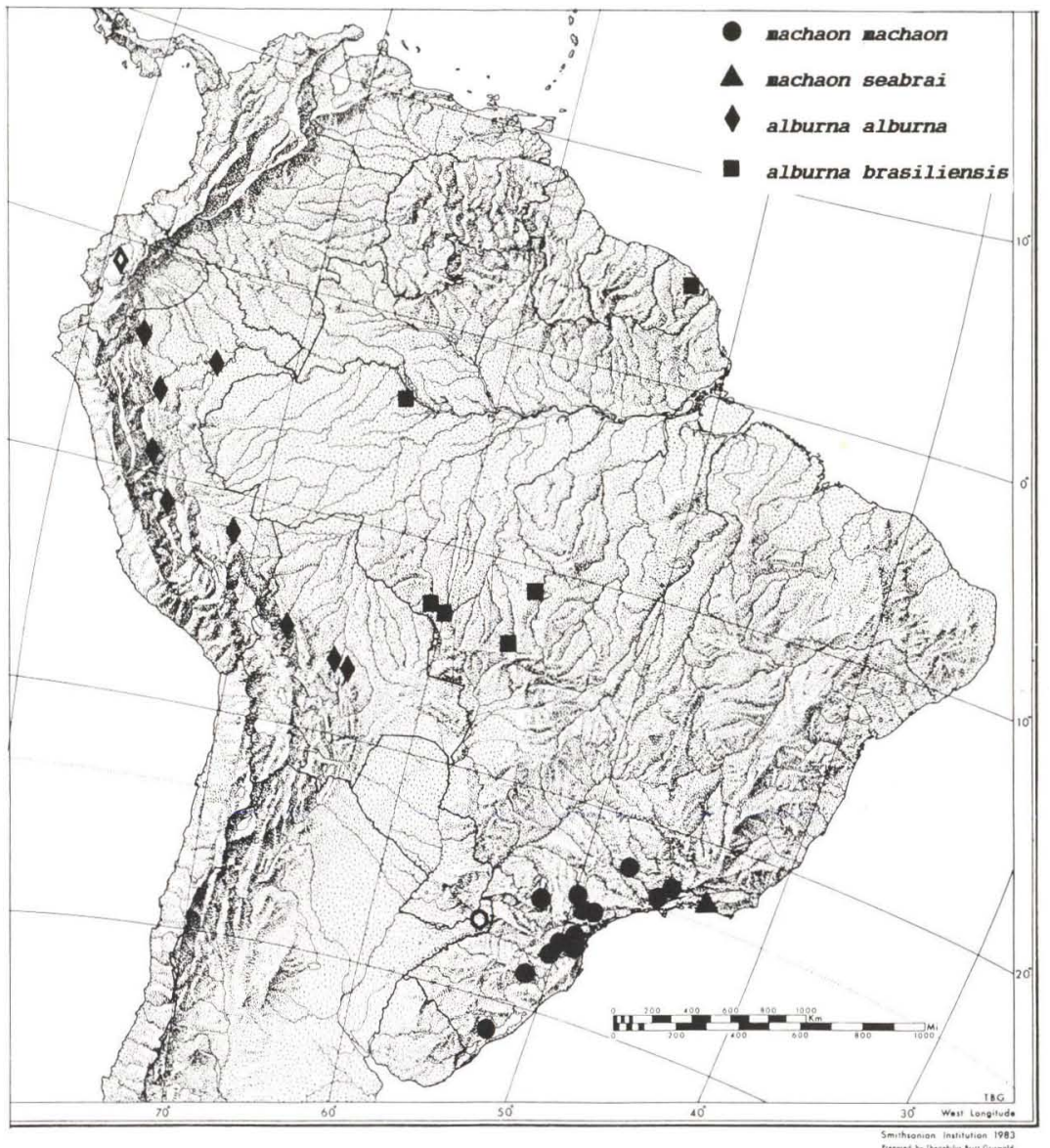

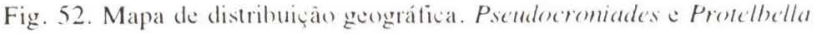

faixa suhmarginal variáveis, a em $\mathrm{CuA1-CuA2}$ nítida ou reduzida a algumas escamas e a em CuA2-2A larga, pouco mais estreita que a faixa discal mediana.

Face ventral da asa posterior com as três faixas azuis de larguras uniformes e separadas entre si por distâncias iguais às suas larguras ou as faixas pouco mais estreitas que os espaços entre elas, principalmente nas populações do sul do Brasil e Paraguai; faixas azuis adicionass hasal até M1, M3 ou CuAl e distal até CuA1: às vezes, com pequena mancha azul. fina e transversal em $\mathrm{Sc}+\mathrm{R} 1-\mathrm{Rs}$ entre a faixa mediana e a faixa adicional hasal: espaço 2A-3A com manchas azuis abaixo das faixas basal, mediana e distal, às vezes, a mediana ausente; franjas como na face dorsal.

Genitália (Fig. 30). Apótises do tegumen cuneiformes, contíguas ao unco em vista dorsal e pouco menores que a metade do unco em vista lateral; harpe 
larga na base, com uma projeção dorso-posterior recurvada ventralmente, na base desta com pequeno lóbulo, mais longo que a espessura da valva, saindo do meio e dirigido para a base, e projeção dorso-basal pontuda; edeago reto e com carena subterminal nos lados ventral e lateral direito.

Fêmea (Fig. 121). Semelhante ao macho. Comprimento da asa anterior 29 a $33 \mathrm{~mm}$.

Face dorsal da asa anterior com a faixa branca mediana entre 3,8 e $3,9 \mathrm{~mm}$ de largura máxima; discocelulares azuis; faixa azul submarginal com escamas escassas em M3-CuAl.

Face ventral da asa posterior com a faixa azul adicional distal indicada por escassas escamas azuis até M3 ou inteira até CuA2.

Genitália (Fig. 30). Partes laterais do oitavo esterno inteiras e ligadas ao esterigma; esterigma tubular, em vista ventral adelgaçando-se desde o meio até a ponta distal e o óstio na metade dorso-distal.

Discussão. Devido às pequenas diferenças nas genitália masculina (lóbulo interno na base da harpe dirigido para a base) e feminina, e ainda devido à simpatria de sua distribuição geográfica com várias subespécies de patrobas, não há dúvida ser uma espécie distinta.

Distribuição espacial (Fig. 48). COLÔMBIA - Boyaca: Otanche. - PERU Loreto: Pebas. Junin: Satipo. Huánuco: Tingo Maria $850 \mathrm{~m}$. Madre de Dios: Parque Nacional de Manu 340m. - Bolívia - La Paz: Caranavi 500-1000m. Guiana Francesa: Caiena, Montagne de Kaw. - Brasil - Amazonas: Manaus; Alto Rio Juruá. Rondônia: Vilhena; Pimenta Bueno. Pará: Óbidos; Belém. Mato Grosso: Diamantino 300-400m. Espírito Santo: Baixo Guandu; Linhares. Sào Paulo: Teodoro Sampaio 250-500m; Campinas; Indiana. Paraná: São Jorge. PARAGUAI - Guairá: Villarica.

Distribuição temporal. Voa de janeiro a abril e julho a dezembro.

Etologia. É um hahitante de florestas, sendo que os machos pousam em areias úmidas na beira de rios, principalmente em excrementos de aves e urina. Os exemplares do Parque Estadual do Morro do Diabo foram capturados brigando no topo do morro, voando violentamente e em seguida pousando em folhas de algumas árvores a uns $5 \mathrm{~m}$ acima do solo.

Planta hospedeira. Miles Moss (1949) e Silva et al. (1968) mencionam cupuaçu - Theobroma grandiflora (Willd. ex Spreng.) Schum. e cupuahi Theobroma subincanum Mart. (Sterculiaceae) como planta hospedeira no Pará, no entanto a identificação da espécie de Elbella é duvidosa.

Etimologia. Provavelmente uma combinação arbitrária de letras.

Material estudado. O holótipo macho com as seguintes etiquetas: / Type/[Peru, Loreto] Pebas [rio] Amazones (sic) M. de Mathan fin X.ere e 1.er

Figs 53-56. (53) Microceris variicolor, macho, Brasil, Mato Grosso, Rondonópolis, faces dorsal e ventral: (54) Microceris variicolor. fêmea. Brasil. São Paulo, Brotas (Campo Alegre), 24-IV-1963, faces dorsal e ventral; (55) Elbella intersecta intersecta, macho, Brasil, Mato Grosso, Diamantino (Fazenda São João), 10-II-1978, faces dorsal e ventral; (56) Elbella intersecta intersecta, macho, Brasil, Mato Grosso, Diamantino (Fazenda Sāo João), 10-II-1978, faces dorsal e ventral. 

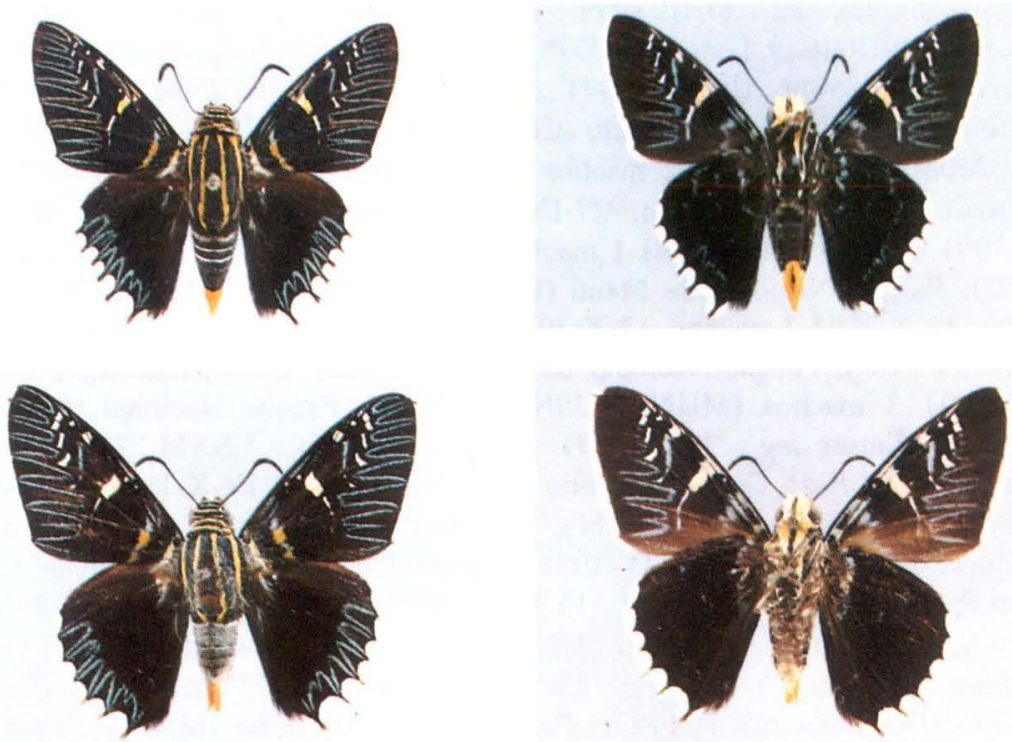

54
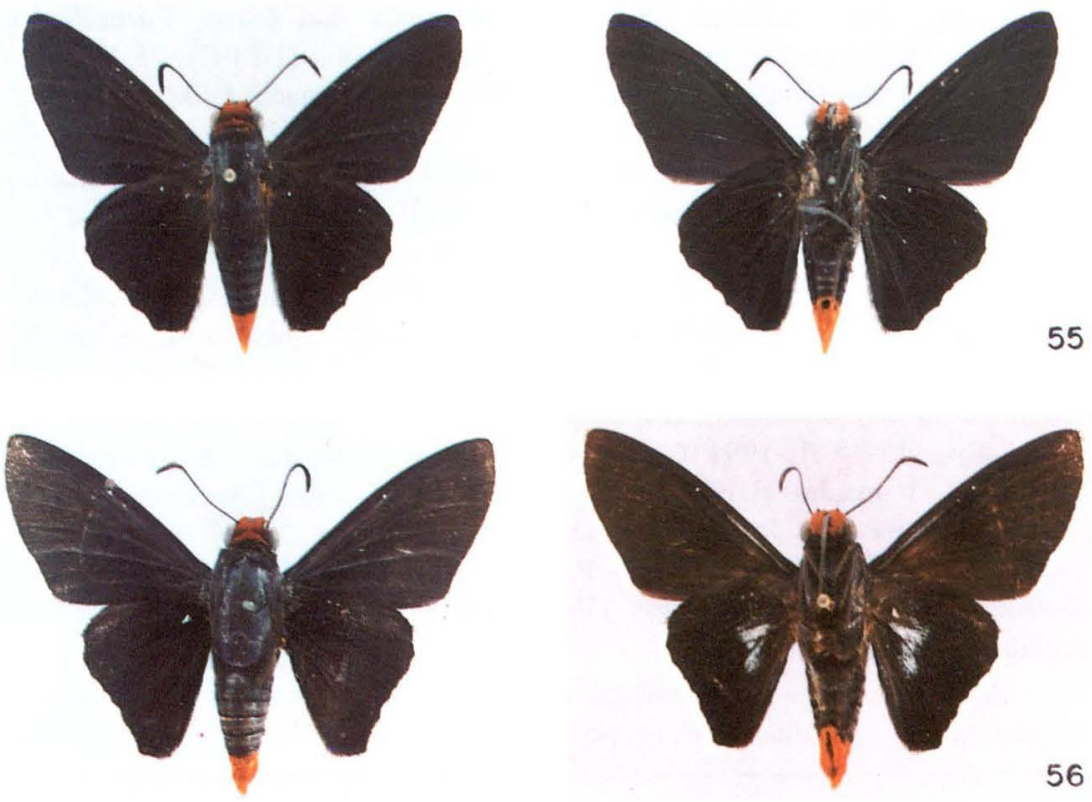
Tr. 1880/ R. Oberthür Coll. Brit. Mus. 1931-136/ (BMNH). - COlômbia Boyaca: Otanche, Le Crom leg. . IV-1993 1 macho (UFPC-OM). - PERU - Junin: Satipo, Paprzycki leg., 11-III-1939 1 macho, 13-III-1939 2 machos, 14-III-1939 1 macho, 15-III-1939 1 macho (UFPC-OM). Huánuco: Tingo Maria (Rondos), Villegas leg., 850m, 16-20-X-1971 2 machos, 27-X-1971 2 machos (UFPC). Madre de Dios: Puerto Maldonado (Comunidad Infierno), Mielke \& Casagrande leg., 300m, 16-17-X-1983 2 machos (UFPC-OM); Parque Nacional de Manu (Pakitza), Lamas leg., 340m, 27-IX-1991 1 macho, 29-IX-1991 1 macho, 1-X-1991 I macho, 10-X-1991 I macho, 20-X-1991 I macho (MHNL, USNM, UFPC); Parque Nacional de Manu (Pakitza), Mielke leg., 340m, 3-X-1991 1 macho, 11-X-1991 2 machos, 12-X-1991 I macho, 15-X-1991 I macho (MHNL, USNM, UFPC); Parque Nacional de Manu (Pakitza), Casagrande leg., 340m, 17-X-199I 3 machos (MHNL, USNM, UFPC); Parque Nacional de Manu (Pakitza), Hauser leg., 29-IX-1991 1 macho (MHNL, USNM, DZPC ?). Bolívia - La Paz: Caranavi, Tello leg., 500-1000m, IX-X-1988 1 macho, II-III-1989 3 machos (UFPC-OM). - Guiana Francesa - Caiena: Pointe Macouria, D. Hermier leg., 9-IV-1991 I macho(UFPC-OM). Montagne de Kaw: Camp Patawa, J.-Y. Gallard leg., 15-VIII-1992 1 macho (UFPC-OM). - BRASIL - Amazonas: Manaus, 1 macho (MNRJ); Alto Juruá, 1 macho (UFPC-OM). Rondônia: Vilhena, C. Elias leg., 23-X-1986 1 macho (UFPC); Pimenta Bueno, VIII-IX-1970 2 machos (UFPC). Parú: Óbidos, 1 macho (MNRJ), 1 macho (UFPC-OM), IX-1968 I macho (UFPC-OM); Belém, II-1965 I macho (UFPC-OM). Mato Grosso: Diamantino (Fazenda São João), Furtado leg., 300-400m, 28-VII-1979 I macho, 28-VIII-1979 1 macho (UFPC), 25-VIII-1978 1 macho (EF), 23-IX-1978 1 macho, 30-VIII-1979 3 machos, 31-VIII-1980 5 machos, 18-II-1982 1 macho (UFPC-OM); Diamantino (Fazenda São João), Mielke \& Furtado leg., 300-400m, 15-I-1978 1 macho, 6-IX-1978 2 machos, 11-IX-1978 5 machos, 13-II-1979 2 machos, 20-II-1979 2 machos, 5-III-1979 2 machos, 5-VII-1979 1 macho (UFPC-OM); Diamantino (Fazenda São João), Ebert leg. 300-400m, 27-VII-1979 1 macho, 8-IX-1979 1 macho (UFPC). Espírito Santo: Baixo Guandu, II-1921 I macho (UFPC-OM); Linhares, C. Elias leg., II-1978 1 macho, XI-1982 1 fêmea (UFPC). Sào Paulo: Teodoro Sampaio (Parque Estadual do Morro do Diabo), 250-500m, Mielke \& Casagrande leg., 5-8-III-1989 14 machos, 15-18-III-1991 6 machos (UFPC); Campinas, K. Brown leg., 21-IX-1981 1 macho (UFPC-OM); Indiana, Pohl leg., fevereiro, I macho (UFPC). Paraná: São Jorge (Copacabana), Furtado leg., 31-X-1971 1 macho, 31-X-1972 1 macho (UFPC-OM). - PARAgUAI - 1 macho 1 fêmea (UFPC-OM). Guairá: Villarica, Anders leg., IV-V-1964 1 macho (UFPC-OM). - Sem procedência: 1 fêmea (MNRJ).

As procedências mencionadas por Evans (1951) não foram levadas em consideração porque duas espécies podem estar confundidas (blanda e patrobas).

Figs 57-60. (57) Elhella intersectra imersecta, macho, Ecuador. Napo, Cotundo, IV-1979, faces dorsal e ventral: (58) Elhella intersecta intersecta, macho, Brasil, Pará, Juruti, XII-1971, faces dorsal e ventral: (59) Elhella interiecta intersecta. fêmea. Brasil. Pará. Óbidos, II-1969. faces dorsal e ventral; (60) Elbella intersecta peter. macho: Brasil. Pará, Belém. I-1970. faces dorsal e ventral. 

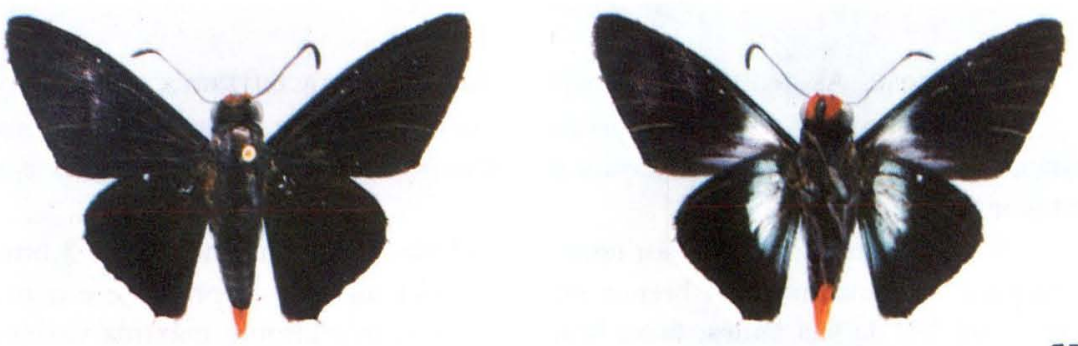

57
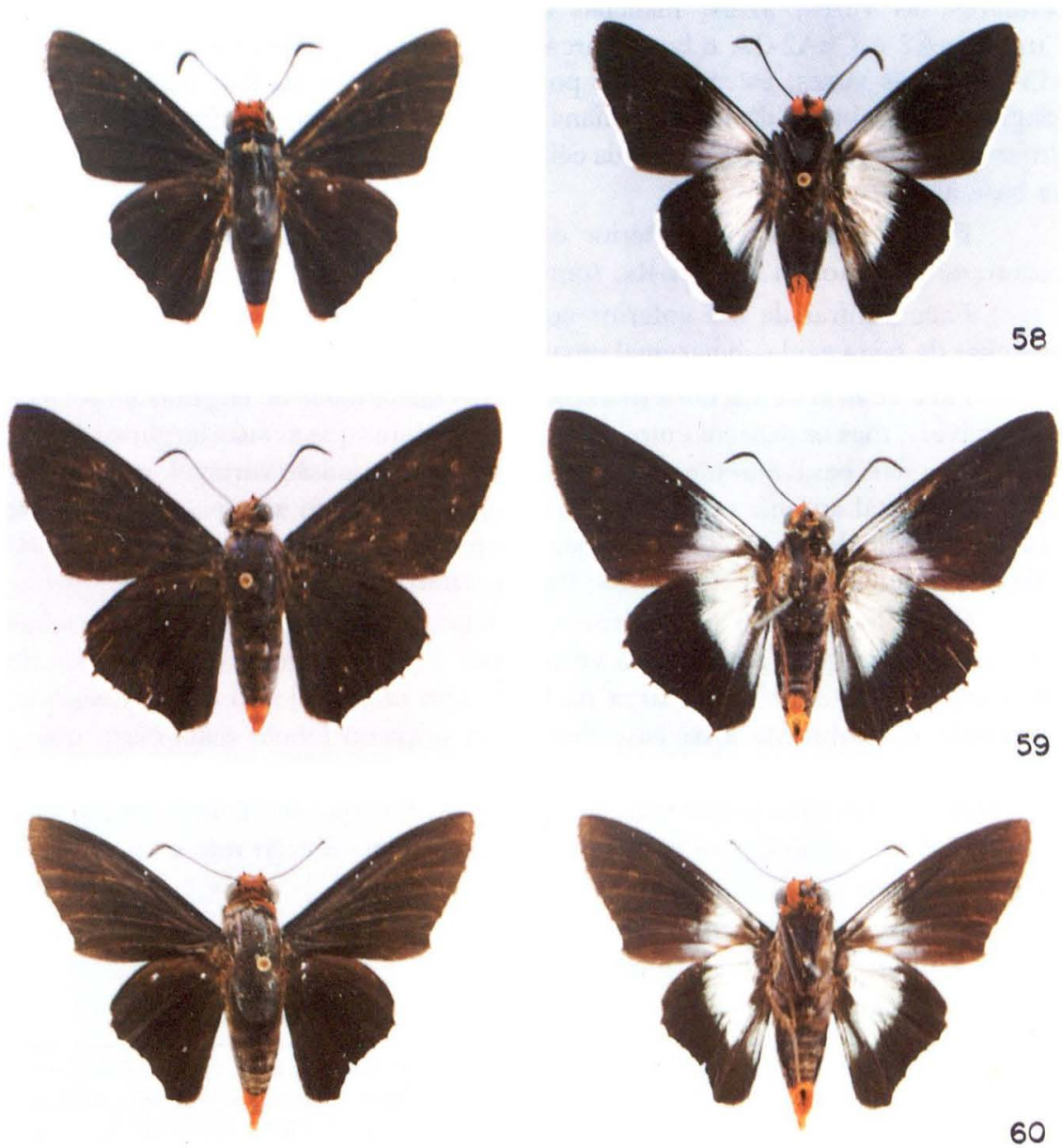


\section{Elbella patrobas (Hewitson, 1857)}

Figs $31,49,122-129$

Diagnose. As genitálias masculina e feminina caracterizam a espécie.

Descrição. Macho - Comprimento da asa anterior 27 a $30 \mathrm{~mm}$. Genas brancas, com as partes centro-basais providas de escassas escamas negras e as partes internas negras.

Face dorsal da asa anterior com a faixa branca mediana entre 2,5 e $3,6 \mathrm{~mm}$ de largura máxima; mancha branca em M3-CuAl ausente ou presente e com a largura até $1 / 2$ da sua altura; faixa branca apical com a largura máxima variável entre 0,8 e $1,7 \mathrm{~mm}$; ̀̀s vezes, com pequena mancha branca em R2-R3; discocelulares, às vezes, azuis; manchas da faixa azul submarginal, estreitas em $\mathrm{CuA} 1-\mathrm{CuA} 2$ e $\mathrm{CuA} 2-2 \mathrm{~A}$ e bem marcada ou indicada por escassas escamas em M3-CuAl, às vezes, estendendo-se por escamas difusas até R4; manchas azuis longitudinais, abaixo da faixa mediana, curtas ou grandes, atingindo o nível do limite proximal da mancha branca da célula discal e a superior, às vezes, expandida na base até $\mathrm{CuA} 2$.

Face dorsal da asa posterior com as três faixas azuis muito variáveis, penetrando ou não em $\mathrm{Sc}+\mathrm{R} 1-\mathrm{Rs}$; franjas brancas de extensão variável.

Face ventral da asa anterior com as discocelulares, às vezes, azuis; as manchas da faixa azul submarginal iguais ou pouco mais largas que na face dorsal.

Face ventral da asa posterior com as três faixas azuis de larguras uniformes ou variáveis, mas os espaços entre elas sempre maiores que as suas larguras; faixas azuis adicionais basal ausente ou quando presente de extensão variável, no máximo até M3, e distal ausente ou até CuA2; espaço 2A-3A com uma pequena mancha azul no término de $3 \mathrm{~A}$ ou com duas manchas paralelas e abaixo das faixas mediana e discal, oblíquas à margem interna; franjas como na face dorsal.

Genitália (Fig. 31). Apófises do tegumen alongadas, de terminações rombudas e contíguas ao unco em vista dorsal e pouco maiores que a metade do unco em vista lateral; harpe larga na base, com uma projeção dorso-posterior, recurvada ventralmente e na base desta com pequeno lóbulo mais curto que a espessura da valva, partindo da margem superior e dirigido para o meio (em $p$. patrobas e $p$. melanina pouco mais delgado - Fig. $31 \mathrm{i}$ - que nas demais subespécies - Fig. 31d), projeção dorso-basal rombuda, indistinta; edeago reto e com carena subterminal nos lados ventral e direito.

Fêmea (só conhecidas de p. patrobas, p. amazonica). Semelhante ao macho. Comprimento da asa anterior $32 \mathrm{~mm}$.

Genitália (Fig. 31). Partes laterais do oitavo esterno inteiras e ligadas ao

Figs 61-64. (61) Elbella intersecta peter, fêmea, Brasil, Pará, faces dorsal e ventral; (62) Elbella intersecta paraensis, macho, Brasil, Pará, holótipo, faces dorsal e ventral; (63) Elbella intersecta rufitegula, macho, Brasil. Estado do Rio de Janeiro, Casemiro de Abreu (Barra de São João), 3-XI-1989, holótipo, faces dorsal e ventral; (64) Elhella intersecta rufitegula, fêmea. Brasil, Estado do Rio de Janeiro. Casemiro de Abreu (Barra de São João), 18-XI-1989, parátipo, faces dorsal e ventral. 

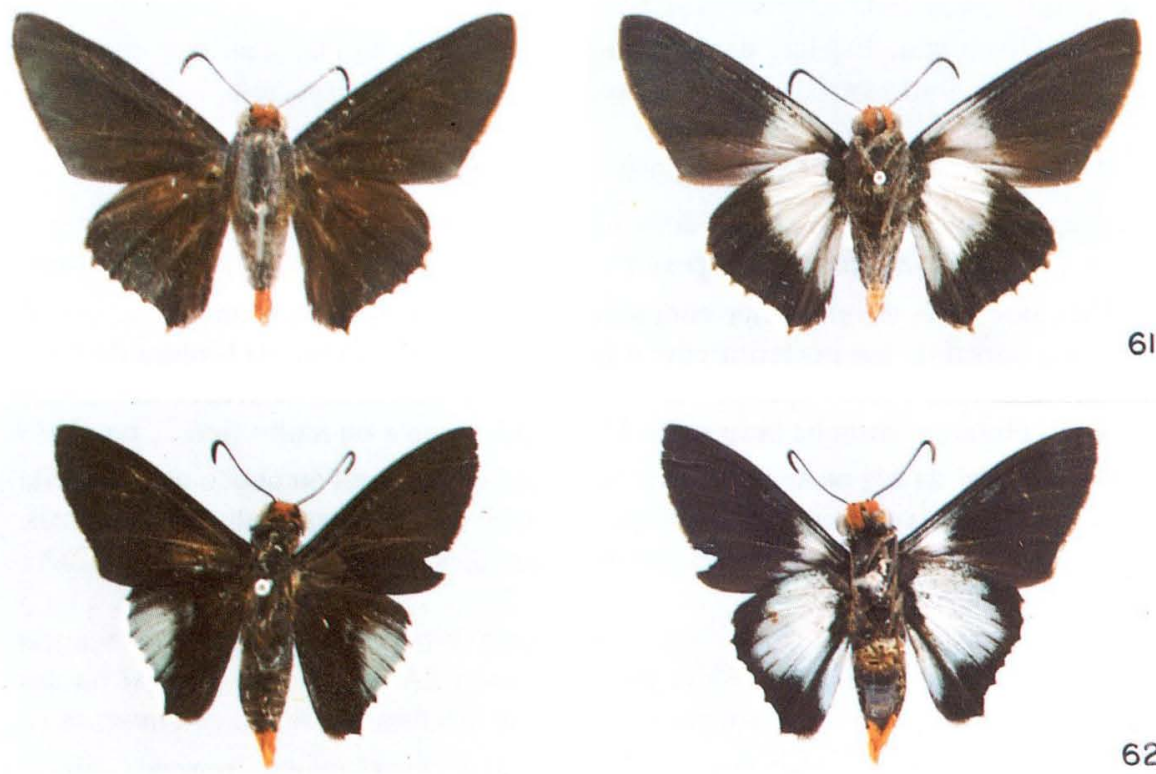

62
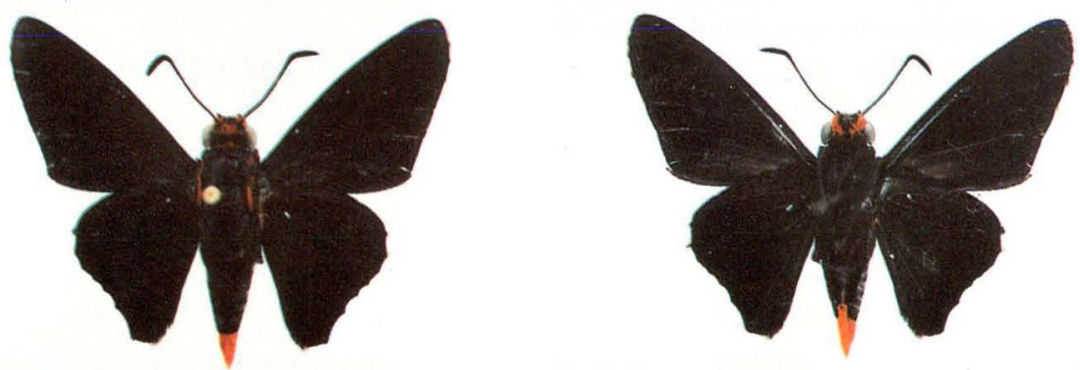

63
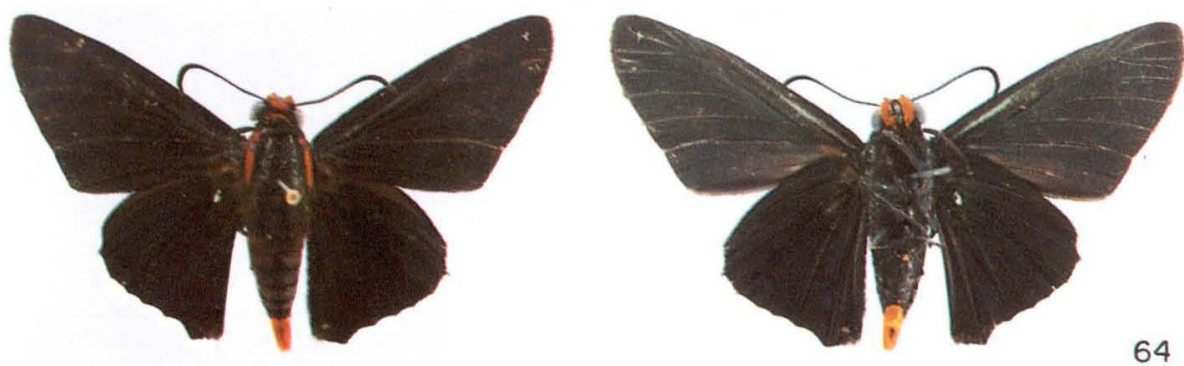

Revta bras. Zool. 11 (3): 395 - 586, 1994 
esterigma; esterigma tubular, em vista ventral adelgaçando-se desde a base e óstio ocupando quase toda extensão dorsal.

Discussão. Espécie de distribuição geográfica ampla, mas rara em todos os lugares e muito variável no aspecto cromático das subespécies.

\section{Chave para as subespécies}

1. Face dorsal da asa posterior com a faixa azul discal três vezes mais larga que a faixa basal na parte superior . . . . . . . . . . evansi

- Face dorsal da asa posterior com a faixa azul discal mais estreita . . . . . . . 2

2. Face dorsal da asa posterior com a faixa azul discal o dobro da largura da faixa basal na parte superior; face dorsal da asa anterior sem azul nas discocelulares; mancha branca em M3-CuA1 ausente ou muito fina . . patrobas

- Face dorsal da asa posterior com a faixa azul discal igual ou pouco mais estreita que a faixa basal na parte superior; face dorsal da asa anterior com azul, ao menos poucas escamas, nas discocelulares; mancha branca em M3-CuA 1 ao menos nítida . . . . . . . . . . . . . . . . 3

3. Face dorsal da asa posterior com a faixa azul discal reduzida a poucas escamas entre CuAl e pouco além de $2 \mathrm{~A}$; espaço $2 \mathrm{~A}-3 \mathrm{~A}$ da face ventral da asa posterior com uma mancha azul junto ao término de $3 \mathrm{~A} \ldots$. . . amazonica

- Face dorsal da asa posterior com a faixa azul discal inteira, normal; espaço 2A-3A da face ventral da asa posterior com duas manchas azuis abaixo das faixas mediana e discal . . . . . . . . . . . . . . . 4

4. Face dorsal da asa anterior com as manchas da faixa azul submarginal bem desenvolvidas entre $\mathrm{R} 5$ e $2 \mathrm{~A} \ldots \ldots \ldots \ldots$ tingo

- Face dorsal da asa anterior com as manchas da faixa azul submarginal estreitas entre M3 (muito difusa) e $2 \mathrm{~A} \ldots \ldots \ldots \ldots \ldots \ldots$

5. Face dorsal da asa posterior com a faixa azul discal o dobro da largura da faixa azul mediana, esta estreitada; asa anterior com a faixa branca mediana com $2,6 \mathrm{~mm}$ de largura máxima . . . . . . . . . . melanina

- Face dorsal da asa posterior com a faixa azul discal igual ou pouco mais larga que a faixa azul mediana, mas não o dobro; asa anterior com a faixa branca mediana com 3,5 a $3,6 \mathrm{~mm}$ de largura máxima . . . . . . . mexicana

Figs 65-68. (65) Elbella intersecta strova, fềmea, Venezuela, Bolivar, Suapure, 21-III-1899, faces dorsal e ventral; (66) Elbella intersecta losca, macho, Brasil, Distrito Federal, Brasília (Ribeirão da Contagem). 25-II-1966, faces dorsal e ventral; (67) Elhella intersecta losca, fềnea, Brasil, Minas Gerais. Corinto, 1-15-X-1979, faces dorsal e ventral: (68) Elbella viriditas viriditas, macho, Paraguai. San Pedro, Nueva Germânia, faces dorsal e ventral. 

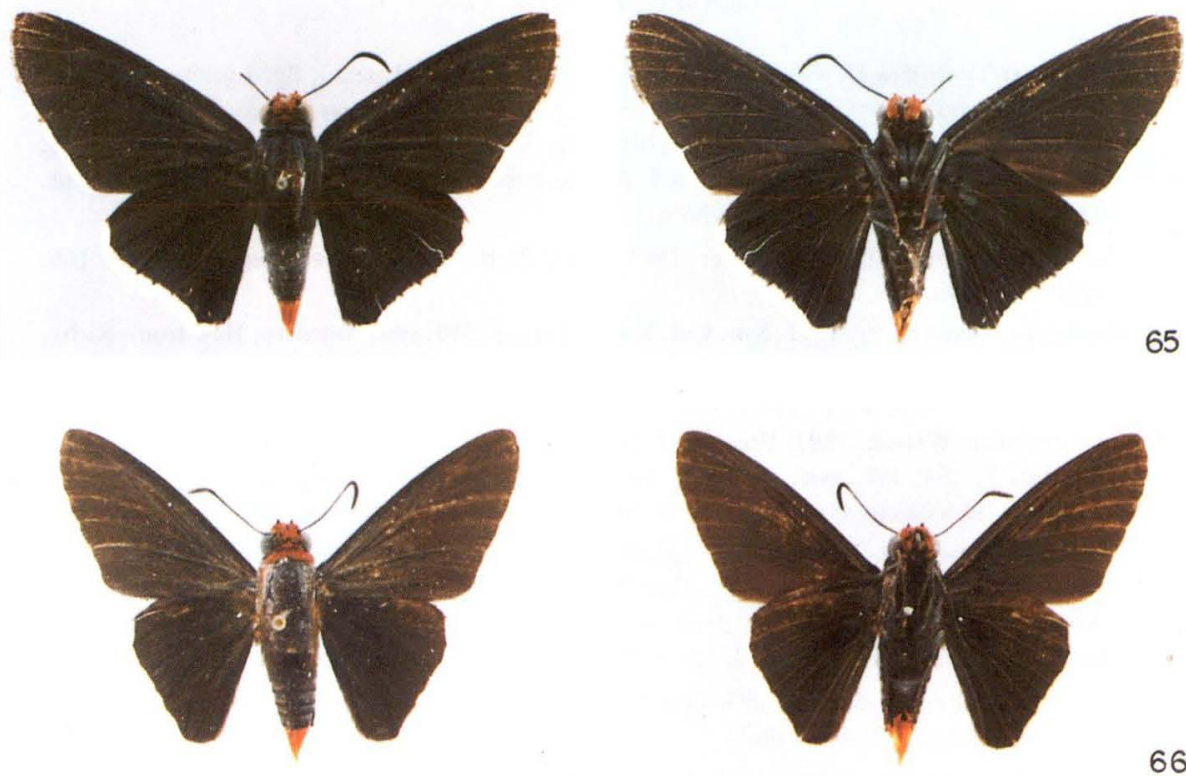

66
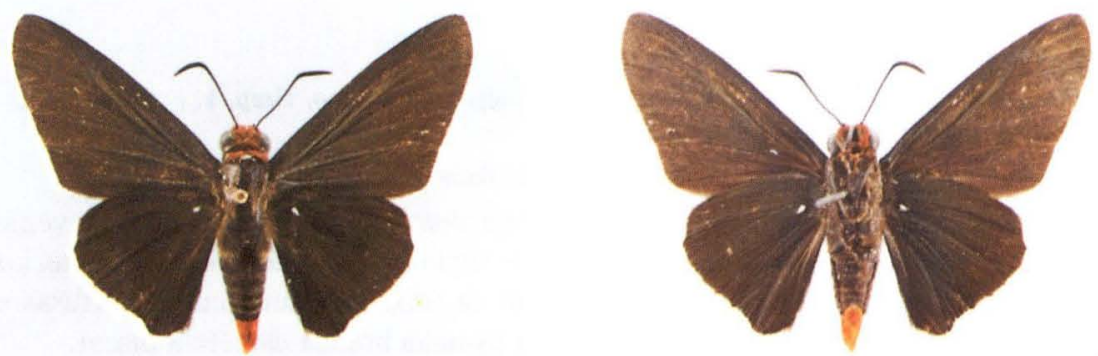

67
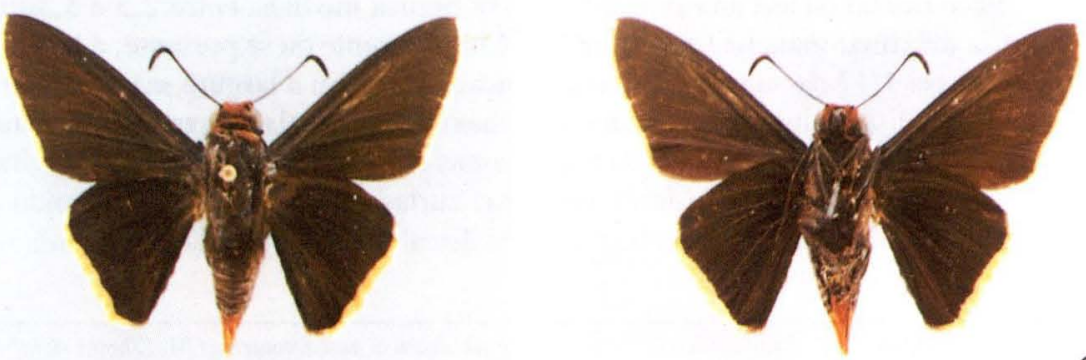

68

Revta bras. Zool. 11 (3): 395 - 586, 1994 


\subsection{Elbella patrobas patrobas (Hewitson, 1857)}

Figs $31,49,122,123$

Pyrrhopyga (sic) patrobas Hewitson, 1857. Exot. Butt. 2, Pyrrho. 1, texto, fig. 1 (como vulcanus); macho e fêmea, New Granada; Col. Hewitson; LECTÓTIPO macho aqui designado (BMNH) [Examinado].- Butler, 1870. Ent. monthly Mag. 7: 58.- Mabille, 1878. Ann. Soc. ent. Belg. 21: 17, 18, 19.- Kirby, 1879. Cat. Coll. Diurn. Lep. Hew., p. 207.- Plötz, 1879. Stett. ent. Ztg. 40: 522; syn.: vulcanus; Hewitson.

Myscelus patrobus (sic); Herrich-Schäffer, 1869. Corr.-Blatt zool.-min. Ver. Regensburg 23: 166: syn.: vulcanus.

Pyrrhopyge patrobas; Kirby, 1871. Syn. Cat. Diurn. Lep., p. 586; syn.: vulcanus; Hewitson.- Kirby, 1880. Proc. r. Jour. Dublin Soc. 2: 327.- Mathew, 1882. Ent. monthly Mag. 19: 19.- Weeks, 1901. III. unfig. Lep., p. 20.- Weeks, 1905. Ill. Diurn. Lep. 1, p. 20.

Jemadia patrobas; Watson, 1893. Proc. zool. Soc. London, p. 14.- Mabille \& Boullet, 1908. Ann. Sc. nat. 7: 193, 196; syn.: vulcanus; Hewitson.- Mabille, 1912. Lep. Cat. 9, p. 10; syn.: vulcanus; Hewitson.- Draudt, 1921, in Seitz, Macrolep. World 5, p. 845, pl. 136b; syn.: vulcanus; Hewitson.- Röber, 1925. Ent. Mitt. 14: 100.- Lindsey, 1925. Denison Univ. Bull., Jour. Sc. Lab. 21 : 74.- Spitz, 1932. Rev. Mus, paulista 17: 867.- Williams \& Hayward, 1944. Acta zool. lill. 2: 82.- Bell, 1946. Jour. N. Y. Ent. Soc. 54: 200; syn.: azeta; Godman \& Salvin; Bell.- Hayward, 1947. Acta zool. lill. 4: 221: syn.: azeta; Godman \& Salvin.

Jemadia azeta; Godman \& Salvin, 1893. Biol. Centr.-Amer., Lep. Rhop. 2 , p. 260, 264; 3, tab. 74. figs. 16, 17 (genitália masculina).

Elhella patrobas patrobas; Evans, 1951. Cat. Amer. Hesp. 1, p. 43, pl. 5 (genitália masculina).Biezanko \& Ruffinelli, 1962. Rev. Fac. Agron., Montevideo 50: 150.- Steinhauser, 1975. Bull. Allyn Mus. 29: 3.

(sem gênero) patrobas: Beattie, 1976. Rhop. Direct., p. 227.

Elbella patrobas; Okano, 1981. Tokurana 1: 52.- Bridges, 1983. Lep. Hesp. 1. p. 90; 2. p. 12.Bridges, 1988. Cat. Hesp. 1: 143; 2, p. 19.

Elbella patroba (sic); DeVries, 1983, in Janzen. Costa Rican Nat. Hist., p. 675.

Diagnose. Face dorsal da asa posterior com a faixa azul discal duas vezes mais larga que a faixa azul mediana na parte superior; face dorsal da asa anterior com as manchas azuis longitudinais, abaixo da faixa mediana, curtas, difusas e não atingindo o nível do limite proximal da mancha branca da célula discal.

Descrição. Macho (Fig. 122) - Comprimento da asa anterior 27 a $29 \mathrm{~mm}$.

Face dorsal da asa anterior com a faixa branca mediana entre 2,5 e 3,3 mm de largura máxima; mancha branca em M3-CuAl ausente ou se presente, a largura não ultrapassa $1 / 17$ da sua altura; faixa branca apical com a largura máxima entre 0,8 e $1,5 \mathrm{~mm}$; discocelulares não azuis; manchas da faixa azul submarginal estreitas entre CuA1 e 2A e somente indicada por escassas escamas em M3-CuA1; manchas azuis longitudinais, abaixo de faixa mediana, curtas, difusas e não alcançando o nível do limite proximal da mancha da célula discal e a superior não expandida na base até $\mathrm{CuA} 2$.

Figs 69-72. (69) Elhella viriditas viriditas, fêmea, Paraguai, faces dorsal e ventral; (70) Elbella viriditas chia, macho, Brasil, Amazonas, São Paulo de Olivença, faces dorsal e ventral; (71) Elbella viriditas chia, fềmea, Brasil. Pará, Óbidos, faces dorsal e ventral; (72) Elbella viriditas boliviana, macho, Bolívia, La Paz. Caranavi, II-III-1989, holótipo, faces dorsal e ventral. 

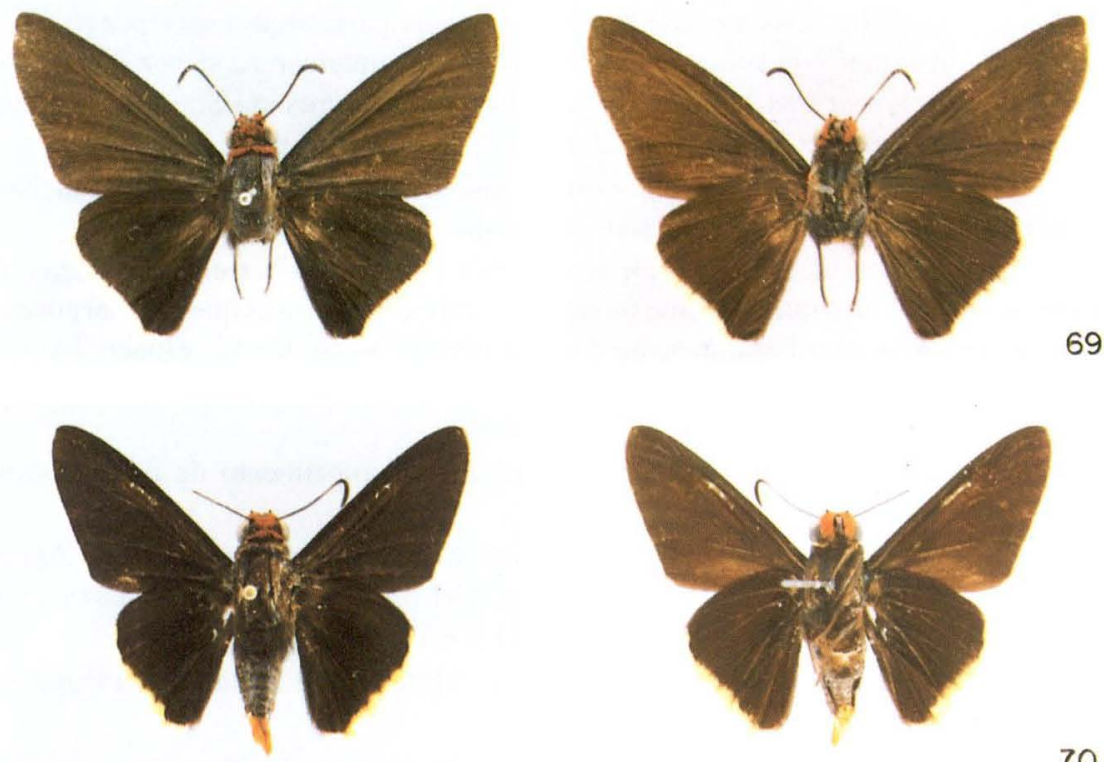

70
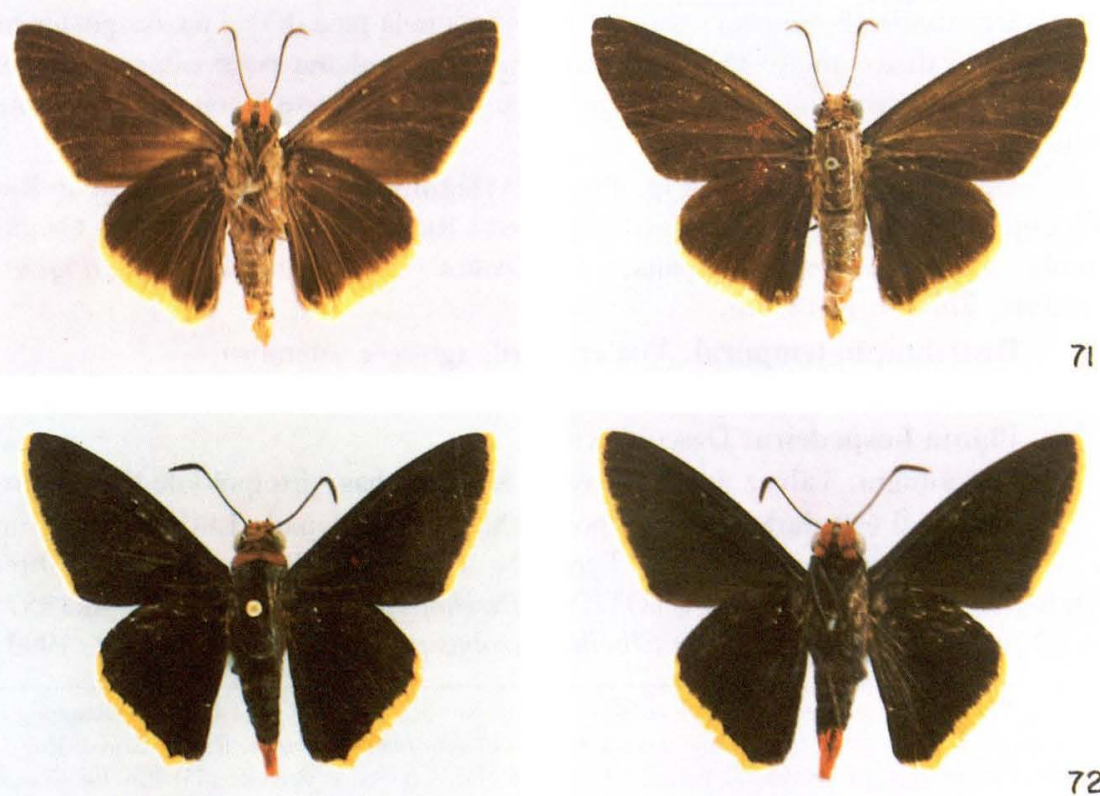

Revta bras. Zool. 11 (3): 395 - 586, 1994 
Face dorsal da asa posterior com as três faixas azuis de larguras diversas, a mediana a mass estreita. a hasal como nas demais espécies e a discal mais larga apicalmente (igual a duas vezes a faixa mediana na parte superior) e penetrando em Sc + R 1-Rs. consequentemente as três faixas distantes entre si por distâncias maiores que a largura da faixa mediana: franjas concolores até $\mathrm{Sc}+\mathrm{R}$ l-Rs e dai passando a brancas até $3 \mathrm{~A}$. com as terminaçós das veias negras.

Face ventral da asa anterior com as discocelulares não azuis; as manchas da faixa azul submarginal pouco mais largas que na face dorsal.

Face ventral da asa posterior com as três faixas azuis estreitas, às vezes, a mediana linear, consequentemente os espaços entre elas maiores que suas larguras; faixas azuis adicionais hasal ausente e distal ausente ou até CuA2; espaço $2 \mathrm{~A}-3 \mathrm{~A}$ com duas manchas azuis paralelas e ahaixo das faixas mediana e discal, oblíquas à margem interna: franjas como na face dorsal.

Fêmea (Fig. 123). Semelhante ao macho. Comprimento da asa anterior $32 \mathrm{~mm}$.

Face dorsal da asa anterior com a faixa hranca mediana entre 3,4 e $3,6 \mathrm{~mm}$ de largura máxima: mancha hranca em M3-CuAl presente: mancha da faixa azul submarginal em M3-CuAl como a em CuAl-CuA2.

Face ventral da asa anterior com as discocelulares negras ou só com algumas escamas escassas azuis.

Face ventral da asa posterior com as faixas azuis adicionais basal até M3 ou CuA2 e distal até CuA2.

Discussão. Subespécie bem caracterizada pela face dorsal da asa posterior com a faixa discal muito larga. enquanto a faixa mediana pode estar até quase ausente e na asa anterior a mancha branca em M3-CuAl ausente ou extremamente reduzida.

Distribuição espacial (Fiğ. 49). Guatemala - Alta Verapaz: Vale do Rio) Polochic. - Honduras. - Nicaragua. - Costa Rica. - Panamá - Zona do Canal: Gambo. Panamá: Cerro Campana. - Colômbia - Meta: Rio Negro. Antióquia: Valdívia. Tolima: Rio Chili.

Distribuição temporal. Voa em abril, agosto e setembro.

Etologia. Desconhecida.

Planta hospedeira. Desconhecida.

Etimologia. Talvez nome alusivo à São Patrohas, discípulo de São Paulo.

Material estudado. Um síntipo macho, aqui designado LECTÓTIPO, com as seguintes etiquetas: / Type/ Type/ N. Granada. Hewitson Coll. 79-69 Pyrhopyga (sic) azeta 5/ LECTOTIPO/Pyrhopyga patrobas Hewitson, 1857 , Lectótipo, O. Mielke det. 1993/Elhella patrohas patrobas, O. Mielke det. 1993/

Figs 73-76. (73) Elhella lampra lampra. macho. Brasil. Rio de Janciro, Rio de Ianciro (Jacarepaguá Três Rios). 10-XII-1960, faces dorsal e ventral: (74) Elhella lampra lampra. têmea, Brasil. Riu de Janciro. Rio de lanciro (Pedra de Itauna). 12-1-1965. faces dorsal e ventral: (75) Elbella lampra alhoctiatla, macho. Brasil. Santa Catarina. Joinvile (Serrinha). 28-XII-1977. holótipo. faces dorsal e ventral: (76) Elluclla lampra allociliata. Remea. Brasil, Santa Catarina. Joinvile. 26-Il-1977. abiotipo. taces dorsal e ventral. 

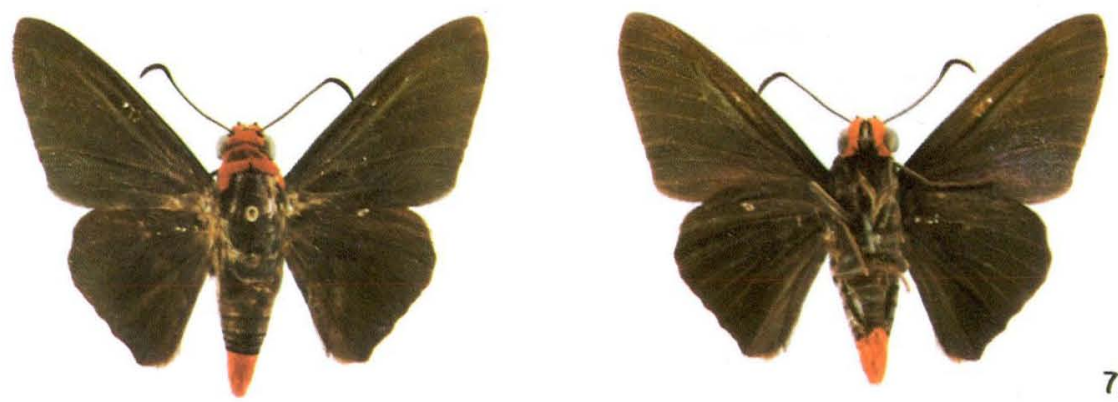

73
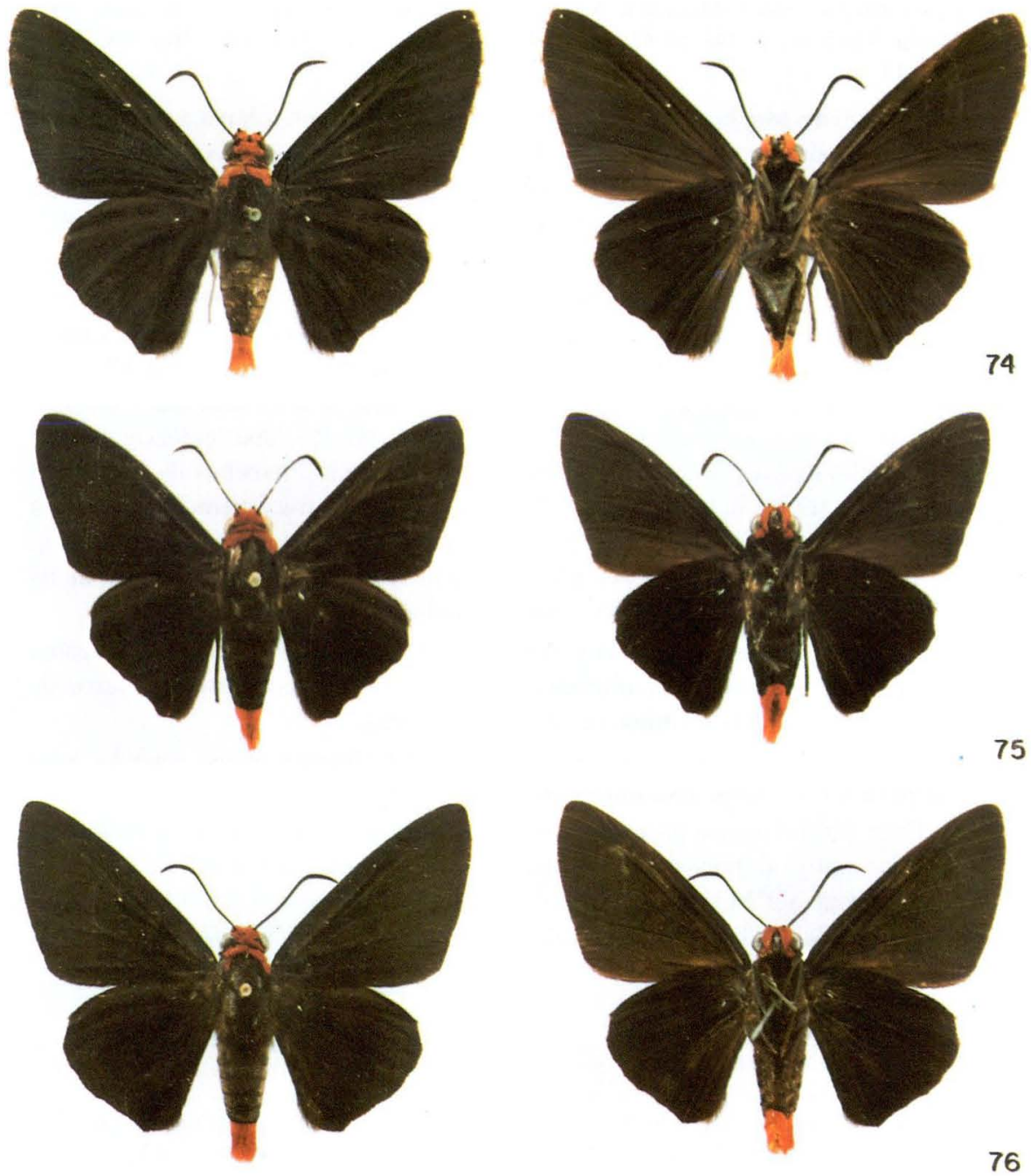
(BMNH). - PANAmá - Pamemia: Cerro Campana. Small lę. . 800m. 15-IX-1967 2 fêmeas, 16-IX-1967 I macho (UFPC-OM): Zona do Canal: Gamboa, Robhins les., 28-IV-1979 I macho (UFPC-OM). - Colòmbia - Meta: Rio Negro, Callaghan leg., 17-VIII-1980 I macho.

\subsection{Elbella patrobas mexicana, ssp.n.}

Figs 49, 124

Elhella parohas: Freman .1966. Jour. Lep. Soc. 20: 227.- Llorente-Bousquets: Luis-Martinez \& Vargas-Fernándes. 1990. Publ. esp. Mus. Zool.. Mexico, $1: 24$.

Elhella patrotas patmolox: J. Maza \& R. Maza. 1985. Rev. Soc. Mex. 1ep. 9: 41-- R. Maza.1987

Marip. Mexican.. p. 143. pl. 63. tig. 4.- J. Maza: White \& R. Maza. 1991. Rev. Six. Mex. 1.ep. 14: 9

Diagnose. Macho - Face dorsal da asa posterior com a faixa azul discal da mesma largura da faixa azul mediana: face dorsal da asa anterior com as manchas azuis longitudinais, ahaixo da faixa hranca mediana, não atingindo o nível do limite proximal da mancha da célula discal e a superior não expandida na hase até CuA2: faixa hranca mediand com 3.5 a $3.6 \mathrm{~mm}$ de larg̨ura máxima.

Descrição. Macho (Fig. 124) - Comprimento da asa anterior $28 \mathrm{~mm}$.

Face dorsal da asd anterior com a taixa hranca mediana entre 3.5 e $3.6 \mathrm{~mm}$ de largura máxima; mancha branca em M3-CuA I com a largura igual a 1/6 a I/2 da sua altura; faixa hranca apical com a largura máxima pouco maior que a mancha anterior; às vezes, com peỵuena mancha hranca em R2-R3; discocelulares azuis, às vezes, reduzidas à presença de escassas escamas azuis; manchas da faixa azul submarginal estreitas entre CuAl e 2A, a em M3-CuAl fracamente indicada e a em M2-M3 composta de poucas escamas; manchas azuis longitudinais azuis, ahaixo da faixa mediana, curtas, não atingindo o nível do limite proximal da mancha da célula discal e a superior não expandida na base até CuA2.

Face dorsal da asa posterior com as três faixas azuis finas e da mesma largura, às vezes, a discal prolongada em $\mathrm{Sc}+\mathrm{R} \mathrm{i}-\mathrm{Rs}$; tranjas hrancas a partir de Rs. interrompidas pelas terminaçóes das velas negras.

Face ventral da asa anterior com as discocelulares azuis: mancha azul suhmarginal em CuAl-CuA2 muito difusa.

Face ventral da asa posterior com as três faixas azuis de larguras uniformes e separadas entre si por distancias maiores que as suas larguras; faixas azuis adiconais basal até M3 ou CuA2 e distal até CuA2; espaço 2A-3A com duas manchas paralelas abaixo das taixas mediana e discal, oblíquas à margem interna; tranjas como na face dorsal.

Fêmea. Descionhecida.

Figs 77-80. (77) Elhella mariae mariae. macho. Brasil. Parana. São José dos Pinhais. 30-I-1989. faces dorsal e ventral: (78) Elbella maria mariac. Rêmea. Brasil. Santa Catarina. São Bento dos Sul (Rio) Vermelho), faces dorsale ventral: (79) Elhelle motria molimai, macho. Brasil. Santa Catarina. Joinvile. 6-II-1972. faees dorsal e ventral: (80) Elhella marae molinat. Kêmea. Brasil. Santa Catarina. Joinvile. 25-XI1- 940 , laces dorsal e ventral 

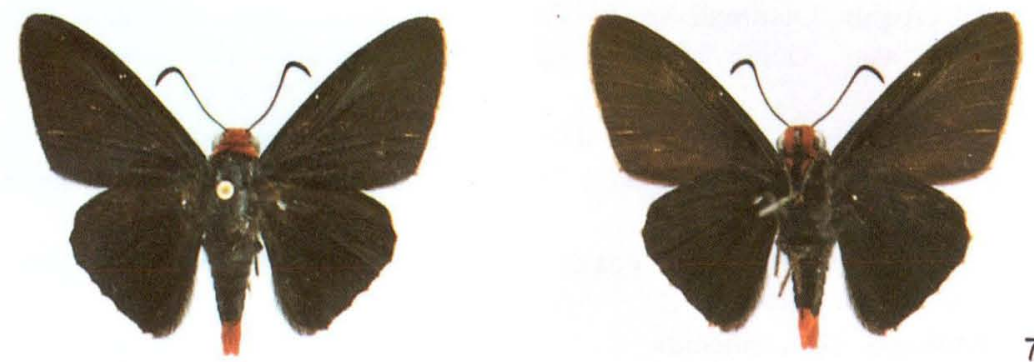

77
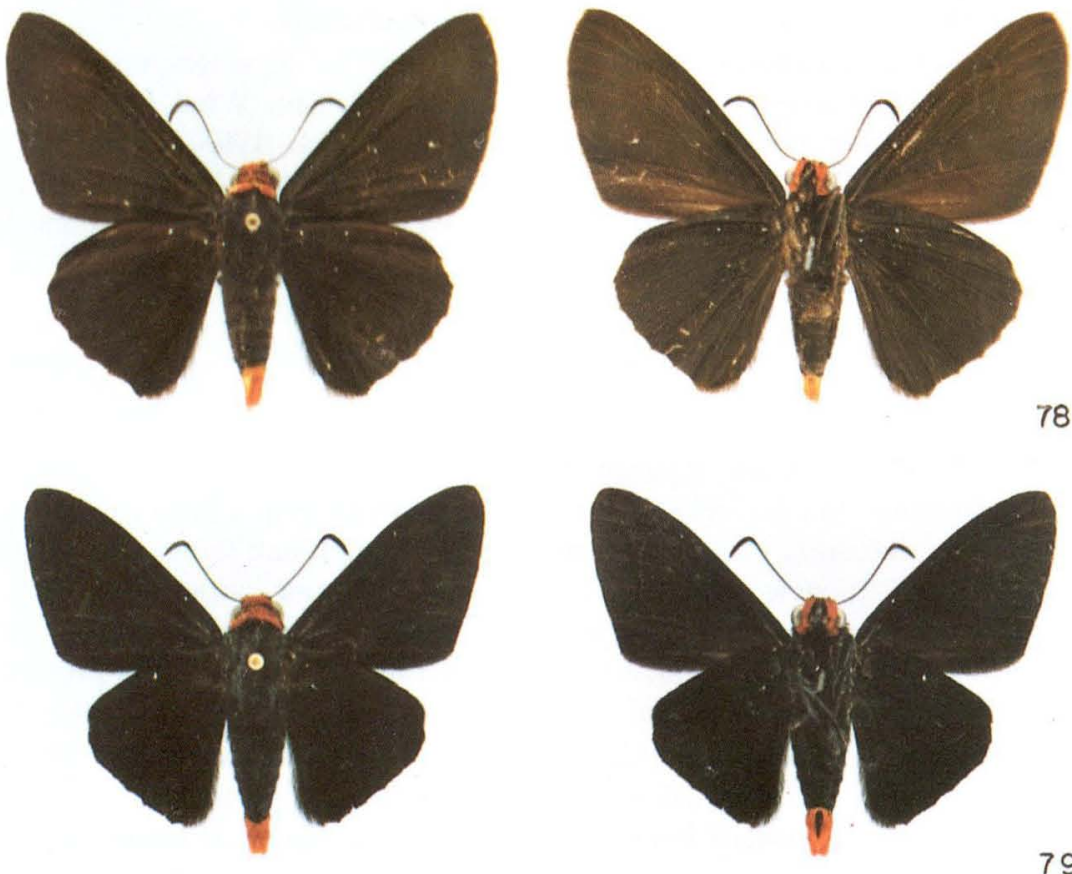

79
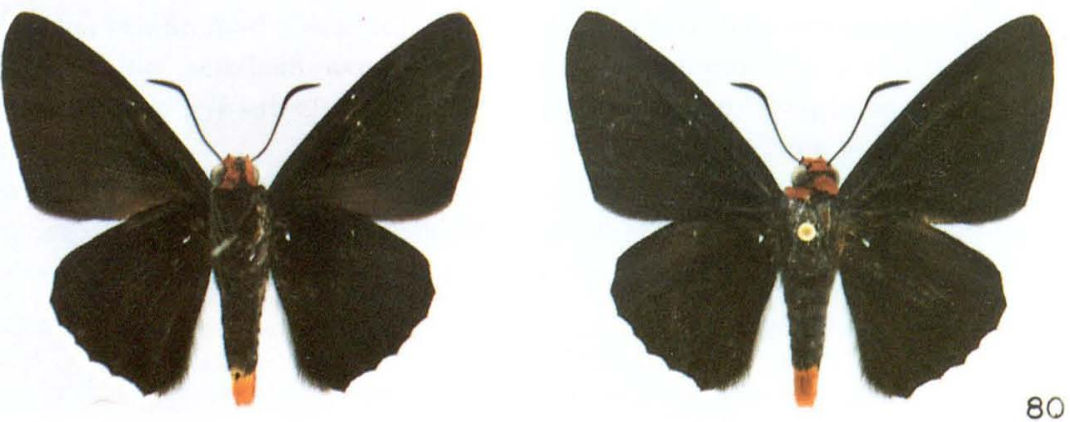

Revta bras. Zool. 11 (3): 395 - 586, 1994 
Discussão. Distingue-se das demais subespécies pelos desenhos azuis e brancos das asas. Ocupa a distribuição mais setentrional das subespécies de patrohas.

Distribuição espacial (Fig. 49). MÉXıCo - Veracruz: Dos Amates: Sierra Blanca; Presídio. Ocaxaca: Metates: Palomares. Chiapas: Chajul; San Quentin. Quintana Roo: Nuevo X-Can.

Distribuição temporal. Voa em junho (FREEMAN 1966), agosto (FREEMAN 1966), setembro e outubro.

Etologia. Deseonhecida.

Planta hospedeira. Desconhecida.

Etimologia. O nome refere-se ao país de ocorrência.

Material estudado. Holótipo macho com as seguintes etiquetas: / HOLOTYPUS/ 3-X-1972 San Quentin. Chiapas. México, Wind leg./ Elbella patrobas mexicana Mielke, Holótipo, O. Mielke det. 1993/OM 33.023/ (UFPC-OM). Parátipos: MÉXICo - Chiapas: San Quentin, X-1977 1 macho (UFPC-OM); Quintana Roo: Nuevo X-Can, Welling leg., 3-IX-1979 1 macho (UFPC-OM).

\subsection{Elbella patrobas evansi, ssp.n.}

Figs 49,125

Elbella parohas melanina: Evans. 1451. Cat. Amer. Ilesp. 1. p. 44.

Diagnose. Macho - Face dorsal da asa posterior com a faixa azul discal. na parte superior, três vezes mais larga que a faixa azul basal; faixa azul mediana fina ou reduzida a poucas escamas; face dorsal da asa anterior com a mancha branca em M3-CuAl ausente ou de largura até $1 / 5$ da sua altura; manchas azuis lonģitudinais, abaixo da faixa mediana, nítidas e não alcançando o nível proximal da mancha hranca da célula discal e a superior não expandida na base até CuA2.

Descrição. Macho (Fig. 125) - Comprimento da asa anterior 28 a $29 \mathrm{~mm}$.

Face dorsal da asa anterior com a faixa hranca mediana entre 2,1 e $3,6 \mathrm{~mm}$ de largura máxima; mancha branca em M3-CuAl ausente ou de largura até 1/5 da sua altura; faixa branca apical com a largura máxima entre 0,9 e $1,2 \mathrm{~mm}$; discocelulares negras ou com algumas escamas azuis; manchas da faixa azul submarginal pequenas e difusas entre M I e M3, maiores e hem nítidas entre M3 e 2A; manchas azuis longitudinass, ahaixo da faixa mediana. nítidas e não alcançando o nível proximal da mancha branca da célula discal e a superior não expandida na hase até CuA2.

Face dorsal da asa posterior com as três faixas azuis de larguras diferentes. a hasal normal, isto é, como nas demais subespécies, a discal muito larga, três

Figs 81-84. (81) Elhella adomis. macho. Brasil. Paraná. Curitiha, 13-1-1971. faces dorsal è ventral; (82) Elhella adonis, fêmea. Brasil. Santa Catarina, Sảo Bento do Sul (Rio Vermelho), 1-1II-1970. fáces dorsal e ventral: (83) Elhella adonis, fêmea (aherrante). Brasil. Paraná, Morretes (Alto da Serra). 21-II-1991. faces dorsal e ventral: (84) Elhella scylla. macho. México. Oaxaca. Candelaria Loxicha. 20-VIII-1973, faces dorsal e ventral. 

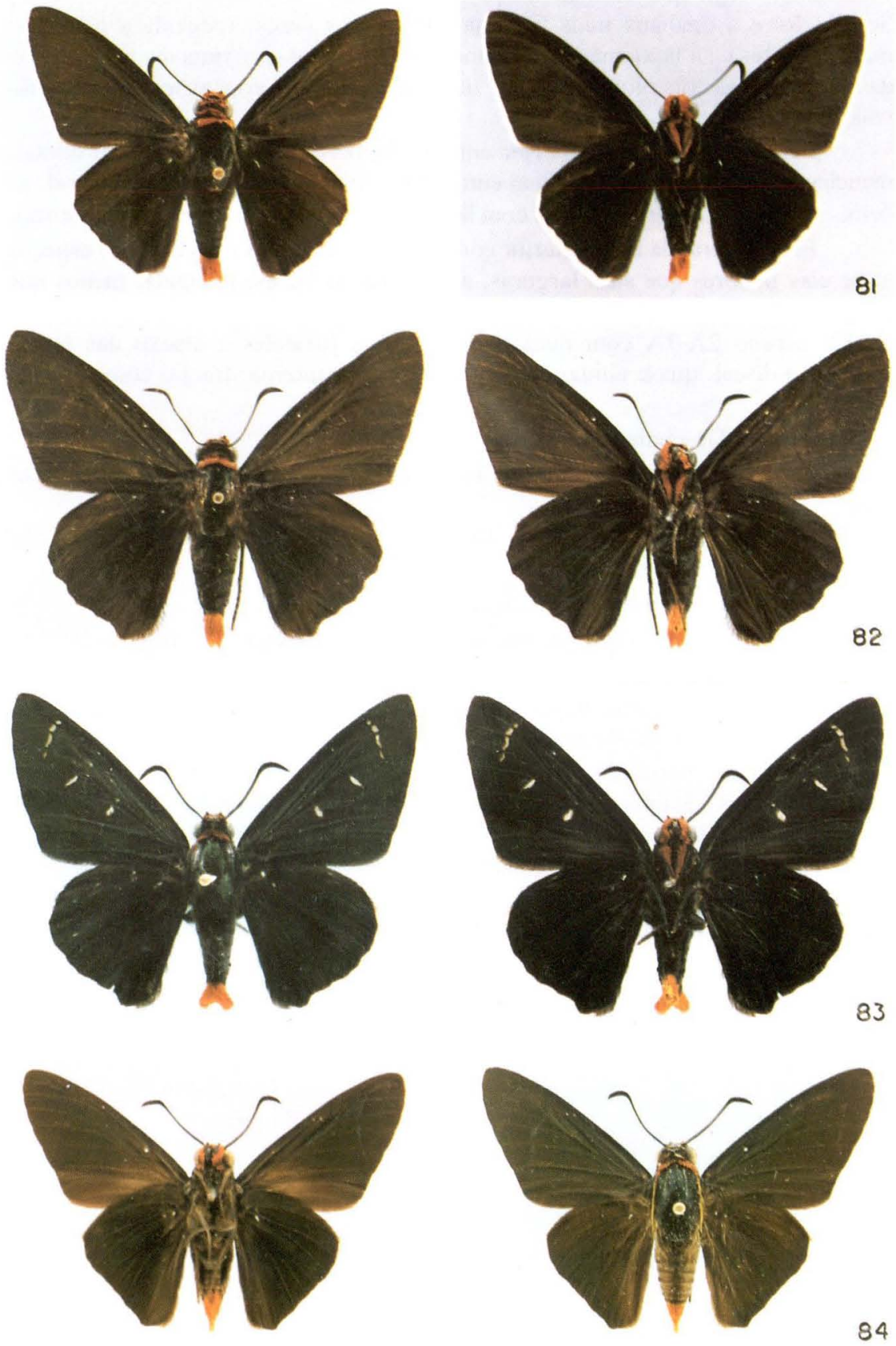
vezes mais larga que a basal na parte superior, continuando nitidamente em $\mathrm{Sc}+\mathrm{Rl}$-Rs e a mediana mais fina que a basal, às vezes, reduzida a pequenas manchas difusas; a faixa mediana, quando presente, mais próxima da distal do que da basal; franjas concolores até Mle dai brancas até $3 \mathrm{~A}$, com as terminações das veias negras.

Face ventral da asa anterior com as discocelulares como na face dorsal; manchas da faixa azul submarginal entre M3 e $2 \mathrm{~A}$ maiores que na face dorsal, as demais ausentes; margem interna com linha azul na metade externa ou só no torno.

Face ventral da asa posterior com as três faixas azuis estreitas e os espaços entre elas maiores que suas larguras, a mediana, às vezes, reduzida, menos que na face dorsal; faixas azuis adicionais basal ausente ou até M3 e distal nítida até CuA2; espaço 2A-3A com duas manchas azuis paralelas e abaixo das faixas mediana e discal, quase unidas e oblíquas à margem interna; franjas como na face dorsal.

Fêmea. Desconhecida.

Discussão. A subespécie caracteriza-se pelas diferenças cromáticas das asas.

Distribuição espacial (Fig. 49). COLÔMBIA - Valle: Rio Dagua. Caldas: Manzanares. Boyaca: Otanche.

Distribuição temporal. Voa em junho e dezembro.

Etologia. Desconhecida, mas deve ser como em patrobas tingo.

Planta hospedeira. Desconhecida.

Etimologia. Nome alusivo ao Brigadeiro W. H. Evans, autor de monumental obra sobre os Hesperiidae.

Material estudado. Holótipo macho com as seguintes etiquetas: / HOLOTIPO/ R. Dagua /Valle/, Colombia, W. Rosenherg /leg. / Rothschild Bequest B.M. 1939.-1./ Elbella patrobas eveansi Mielke, Holótipo, O. Mielke det. 1993/ (BMNH). Parátipos: Colômbia - Caldas: Manzanares, J. Salazar lęg., 18-XII-1992 1 macho (LECR). Boyaca: Otanche, J. Urbina leg., VI-1991 1 macho (sem abdome) (LECR).

Figs 85-88. (8.5) Elhella sey/la, fêmea. México, Veracrus, Catemaco, 19-VIII-1973, faces dorsal e ventral: (86) Elbella dulcinea, macho. Panamá. Zona do Canal. Cerro Campana, 5-VIII-1967, faces dorsal e ventral; (87) Elhella dulcinca, fèmea, Venezuela, Distrito Federal, Caracas (Puente Hierro). 26-XI-1980, faces dorsal e ventral: (88) Elbella luteizona, macho. Brasil. Minas Gerais, Poços de Caldas (Retiro Branco), I-IV-1965, faces dorsal e ventral. 

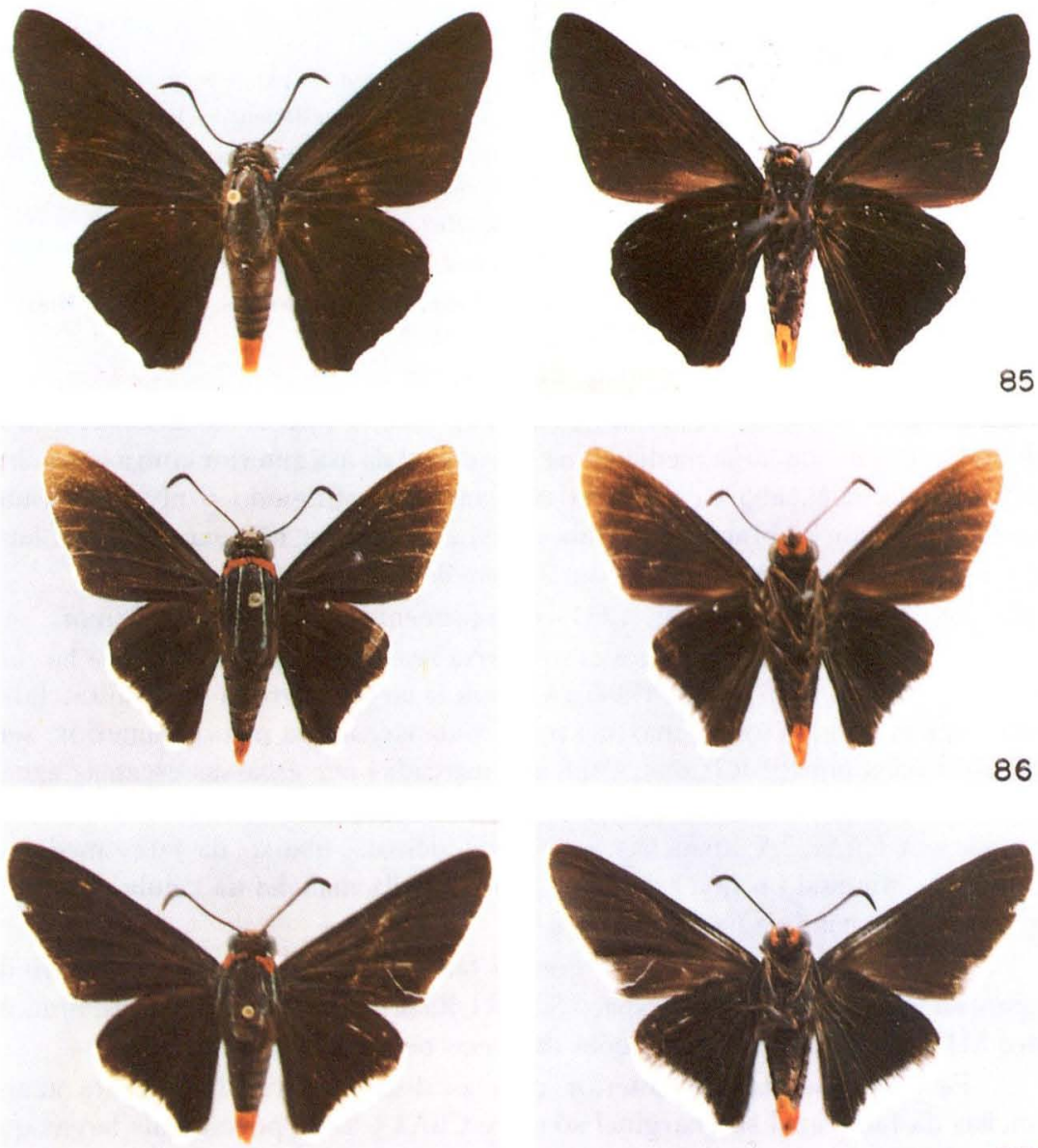

87
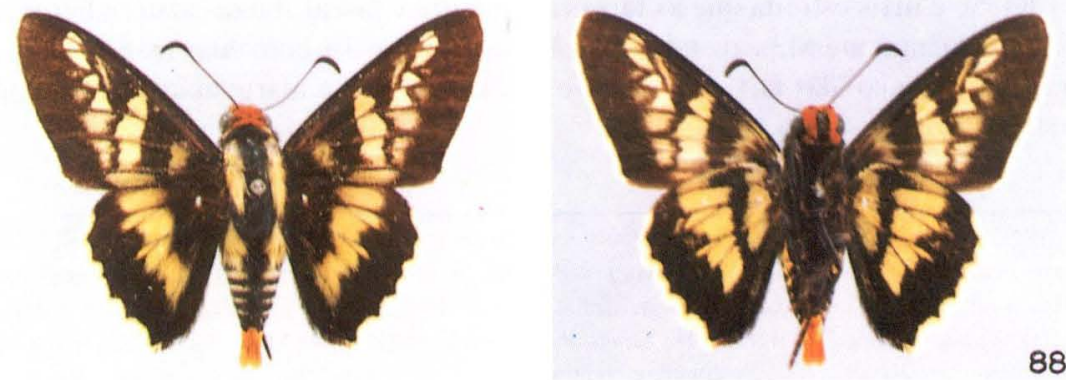


\subsection{Elbella patrobas melanina (Mabille \& Boullet, 1908)}

Figs 49,126

Jemadia azeta var. melamina Mabille \& Boullet. 1908. Am. X́. nat. 7: 143. 196: Bolivia: Col. Mus

Paris 1 macho (Coll. Boullet), 6 machos. Peru: Iectóroro ayui designado |Examinado|

Icmadia asera f. melamina: Draudr, 1921, in Seits. Macrolep. World 5. p. 845. pl. 1632.. Bell. 1933

Jour. X. Y. Ent. Sox. 41:50) - Williams \& Hayward. 1944. Acta zool. lill. $2: \times 1$.

Iemadia azeta melanina: Ureta. 1941. Bol. Mus. Nac. Mist. nat.. Chile. 19:41.

temadia patrohas t. melamina: Hayward. 1947. Acta zool. lill. 4: 222.

Elhella parrohas melanina: Evans, 1951. Cat. Amer. Hesp. 1. p. 44.- Bridges, 1983. Iep. Hesp. 1.

P. 74: 2. P. 12.- Bridges. 1988. Cat. Hesp. 1. p. 116:2. P. 19.

(sem gènero) melamina: Beattic. 1976. Rhop. Direct.. p. 198.

Diagnose. Macho - Face dorsal da asa posterior com as faixas discal e hasal o dohro da largura da faixa mediana; na face dorsal da asa anterior com as manchas azuis longitudinais, ahaixo da faixa mediana, não atingindo o nível do limite proximal da mancha hranca da célula discal e a superior não expandida na hase até CuA2; faixa branca mediana com 2.6 mm de largura máxima.

Descrição. Macho (Fig. 126) - Comprimento da asa anterior $28 \mathrm{~mm}$.

Face dorsal da asa anterior com a faixa hranca mediana $2,6 \mathrm{~mm}$ de largura máxima; mancha branca em M3-CuAl com a largura 1/6 da sua altura; faixa hranca apical com a largura máxima o dohro da largura da mancha anterior; sem mancha branca em R2-R3; discocelulares marcadas por escassas escamas azuis; manchas da faixa azul submarginal estreitas e difusas entre M3 e CuA2 e hem marcada em CuA2-2A; manchas azuis longitudinais, ahaixo da faixa mediana, curtas, não atingindo o nível do limite proximal da mancha da célula discal e a superior não expandida na base até $\mathrm{CuA} 2$.

Face dorsal da asa posterior com as faixas azuis discal e hasal o dobro da larg̨ura da faixa azul mediana; espaço Se + R 1-Rs sem azul; franjas negras, brancas entre $\mathrm{MI}$ e $3 \mathrm{~A}$ e com as terminaçōes das veias negras.

Face ventral da asa anterior com as discocelulares fracamente azuis: manchas da faixa azul submarginal só entre CuAl e $2 \mathrm{~A}$ e pouco mais largas que na face dorsal.

Face ventral da asa posterior com a faixa azul mediana mais fina em $\mathrm{Sc}+\mathrm{RI}$-Sc e mais estreita que as faixas azuis basal e discal; faixas azuis adicionais hasal rudimentar até $\mathrm{M} 3$ e distal até $\mathrm{CuA}$ 2; espaço 2A-3A com duas manchas azuis paralelas, e ahaixo das faixas mediana e discal, oblíquas à margem interna: franjas como na face dorsal.

Fêmea. Desconhecida.

Figs 89-42. (89) Elhella luteroma. macho (com reduça das manchas amarelas nas asas). Brasil. Minas Gerais. Pocos de Caldas (Alto da Santa Cruz). 7-IV-1965. faces dorsal e ventral: (90) Elhella luteizona. macho (sem manchas amarelas nas asas). Brasil. Distrito Federal. Brasilia (Fazenda Água Limpa). 15-1I1-1477, faces dorsal e ventral: (91) Elhella lutezona. Fêmea. Brasil. Minas Gerais. Cananducaia (Monteverde). 9-III-1971. faces dorsal e ventral: (42) Elhella lutcizona. fêmea (com redução de manchas amarelas nas asas). Brasil. Minas Gerais. Poços de Caldas (Alıo da Santa Cruz). 7-IV-1965. faces dorsal e ventral. 

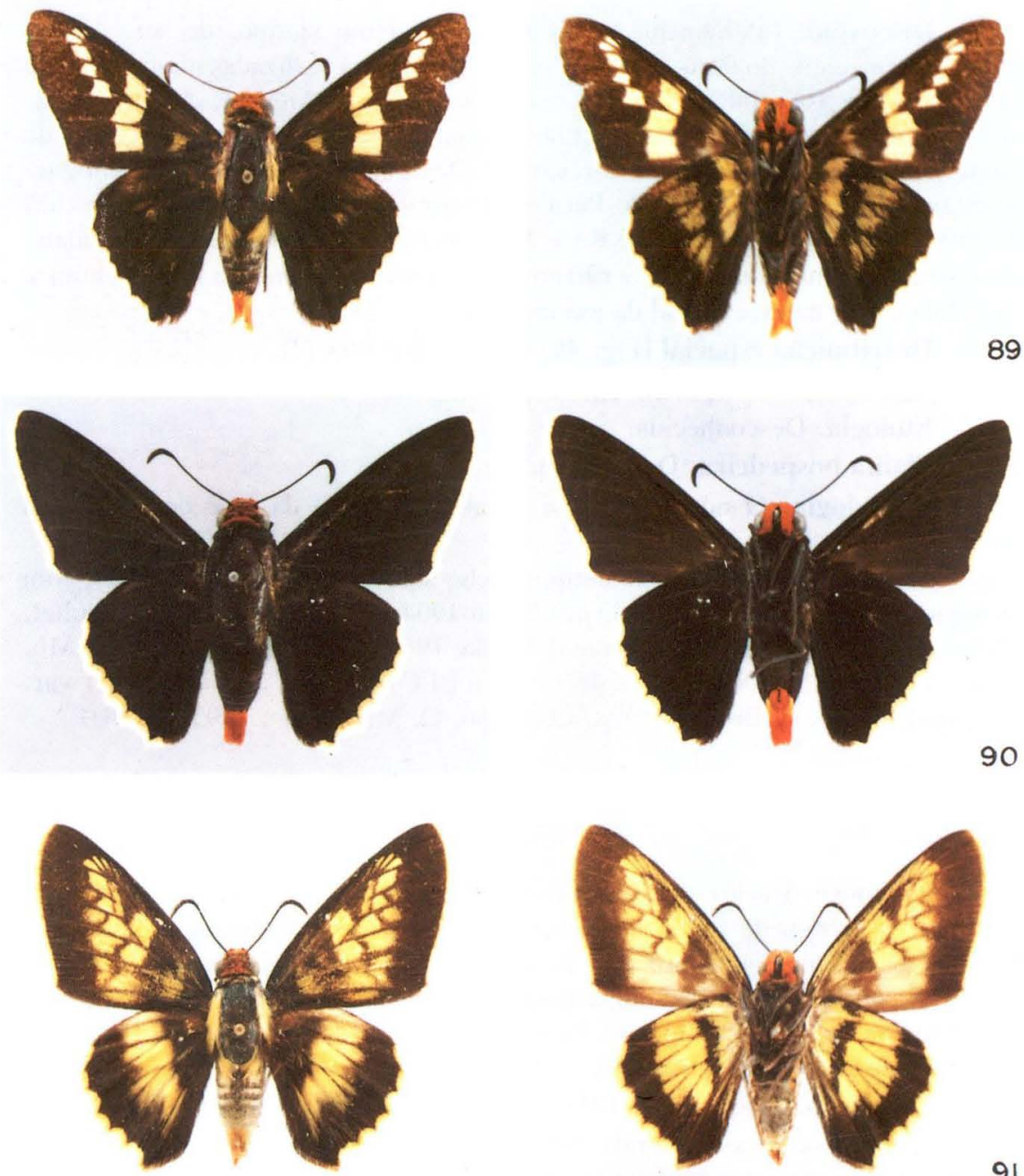

91
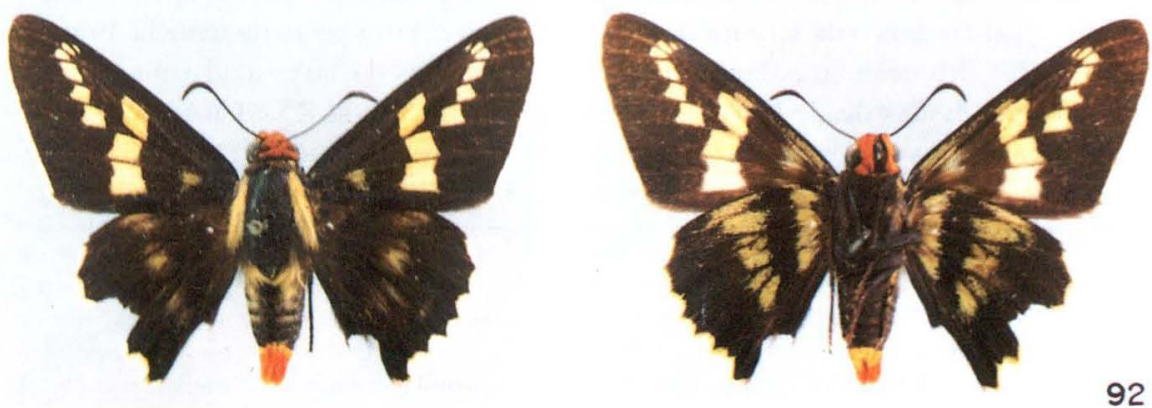
Discussão. Infelizmente só está disponível um síntipo, da série de no mínimo 12 machos. do Perue Bolívia, paises onde foram realizadas muitas coletas. O exemplar se assemelha muito a patrohas mexicana do México, descrito linhas atrás, diferindo pelas faixas azuis da face dorsal da asa posterior e pela largura da faixa hranca mediana da asa anterior, caráter este hastante significativo. Destinguese de parrobas tingo, também do Peru e a seguir descrita, pela falta das manchas da faixa azul suhmarginal entre R.5 e M3 e pelas manchas azuis longitudinats, ahaixo da faixa mediana, curtas e não atingindo o nível proximal da mancha hranca da célula discal na tace dorsal da asa anterior.

Distribuição espacial (Fig. 49). PERU e Bolivia (?).

Distribuição temporal. Desconhecida.

Etologia. Desconhecida.

Planta hospedeira. Desconhecida.

Etimologia. O nome retere-se ao aspecto negro da face dorsal da asa posterior

Material estudado. Um sintipo macho ayui designado LrCTótipo, com as seguintes etiquetas: / Type/ Type/ Perou 1904 O. Staudinger. Coll. Boullet, Museu Paris/gen.|itália| prep.|aradal Mielke 1993/ J. Azeta var. melanina Mb. \& Boull. Ann. Sc. Nat., p. 194 (1908) LECTOTIPO/Jemadia azeta var. melanina Mabille \& Boullet, 1908. Lectótipo, O. Mielke det. 1993/ (MNHP).

\subsection{Elbella patrobas tingo, ssp.n.}

\section{Figs $31,49,127$}

Diagnose. Macho - Face dorsal da asa anterior com a faixa hranca mediana entre 2.7 e 3,2 mm de largura máxima; manchas azuis longitudinais, ahaixo da faxa mediana, grandes, atingindo o nível do limite proximal da mancha hranca da célula discal; a faixa azul suhmarginal com manchas a partir de R4 ou R5, externamente às manchas apicais. Face dorsal da asa posterior com a faixa azul discal pouco mais larga que a faixa azul mediana.

Descrição. Macho (Fig̣. 127) - Comprimento da asa anterior 27 a 30mm.

Face dorsal da asa anterior com a faixa hranca mediana entre 2.7 e $3,2 \mathrm{~mm}$ de largura máxima; mancha hranca em M3-CuAl, com a largura mediana iggual a 1/7 até 1/3 da sua altura: faixa hranca apical com a larg̨ura máxima aproximadamente igual ao dohro da largura da mancha anterior; com pequena mancha branca em R2-R3; discocelulares largamente azuis: manchas da faixa azul submarginal hem desenvolvidas desde CuAl a $2 \mathrm{~A}$ e difusas entre R4 ou R5 e CuAl: manchas azuis longitudinais, ahaixo da taixa mediand, grandes, atinģindo o nível do limite proximal da mancha da célula discal e a superior nào expandida na hase até CuA2.

Figs 93-96. (93) Elhella Inteizona. Fèmea. Brasil. Säo Paulo. Angatuba. III-1917. holotipo de amhomargo. faces dorsal e ventral: (94) Elhella hegesippe. macho. Brasil. Santa Catarina. Säo Bentw do Sul (Rio Vermelho). 15-III-1989. taces dorsal e ventral: (95) Elhella hegesippe. Fémea. Brasil. Paraná. Tijucas do Sul. 13-II-1469. faces dorsal e ventral: (96) Elhella iphnons. macho. Brasil. Rio de Janciro. Itatiaia (Parque Nacional do Itatiaia). 10-1-1973. neotipo de mimetes e ofhello, faces dorsal e ventral. 

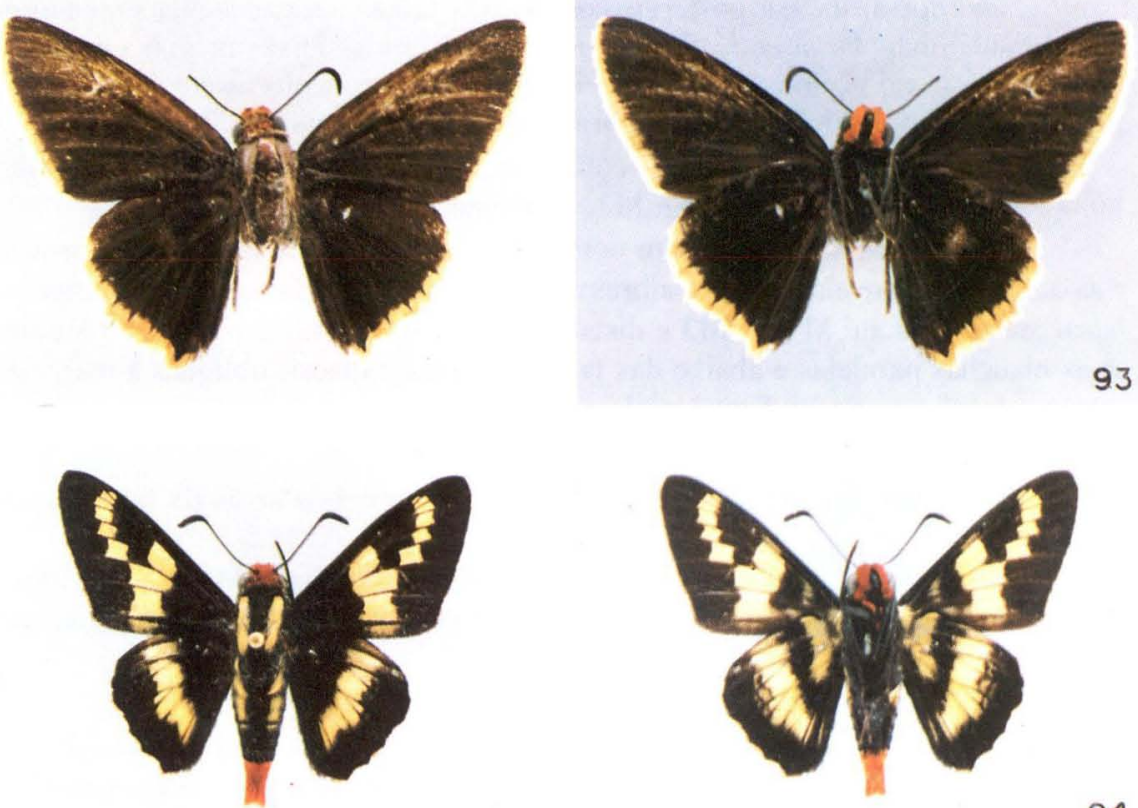

94
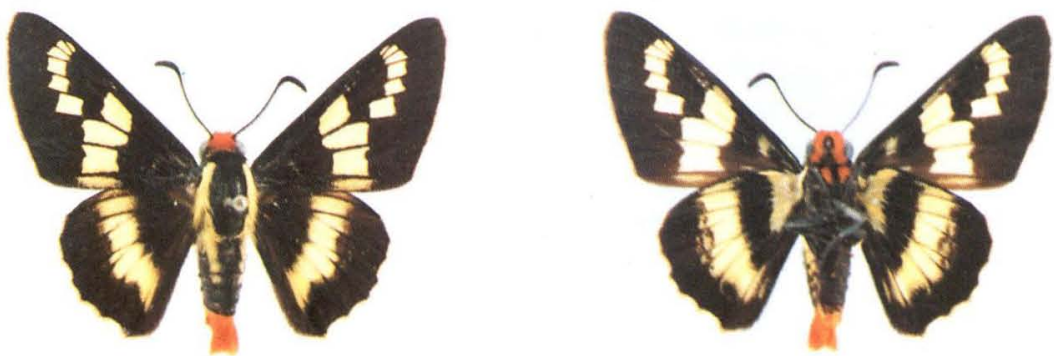

95
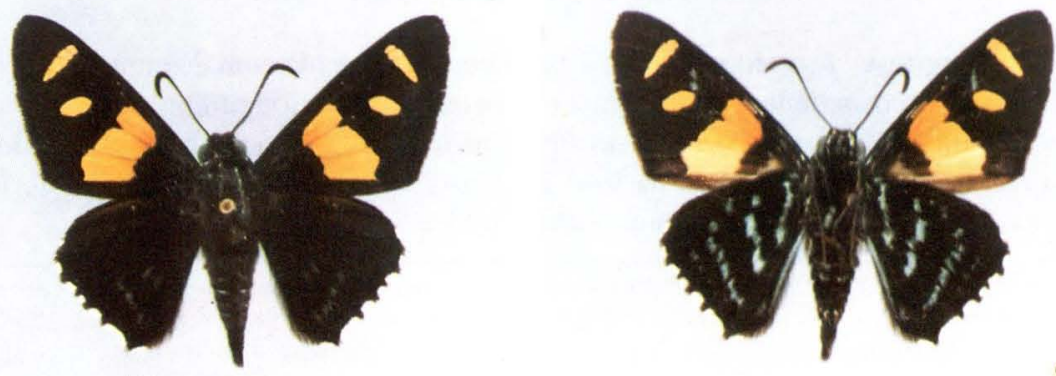
Face dorsal da asa posterior com as três faixas azuis desiguais, sendo a discal pouco mais larga entre $\mathrm{Sc}+\mathrm{R} 1-\mathrm{Rs}$ e $\mathrm{CuAl}$ que as faixas mediana e hasal, às vezes, a discal prolongada em $\mathrm{Sc}+\mathrm{R} 1-\mathrm{Rs}$; franjas concolores até CuAl e dai passando a hrancas até $3 \mathrm{~A}$, com as terminações das veias negras.

Face ventral da asa anterior com as discocelulares azuis; sem manchas da faixa azul suhmarginal entre R4 e M3, as demais como na face dorsal.

Face ventral da asa posterior com as três faixas azuis de larguras uniformes e as distâncias entre elas pouco maiores que as suas larguras; faixas azuis adicionais basal ausente ou até Ml ou M3 e distal até CuAl ou CuA2: espaço 2A-3A com duas manchas paralelas e ahaixo das faixas mediana e discal, oblíquas à margem interna; tranjas como na face dorsal.

Fêmea. Desconhecida.

Discussão. Subespécie caracterizada pelos desenhos azuis da face dorsal da asa anterior.

Distribuição espacial (Fig. 49). PERU - Hucinuco: Tingo Maria 670-850m. Madre de Dios: Parque Nacional de Manu 340m. BRASIL - Rondonia: Pimenta Bueno; Ariquemes $200 \mathrm{~m}$.

Distribuicão temporal. Voa entre agosto e novembro.

Etologia. É um habitante de tlorestas, sendo que os machos pousam em areias úmidas na heira de rios, principalmente em excrementos de aves ou urina.

Planta hospedeira. Desconhecida.

Etimologia. O nome refere-se à procedência de um dos exemplares.

Material estudado. Holótipo macho com as seguintes etiquetas: HOLOTYPUS/Pimenta Bueno, Rondônia, VIII-IX-1970/gen. [itálial prep. [arada] Mielke 1986/Elhella parohas tingo Mielke, Holótipo, O. Mielke det. 1993/ DZ 2993/(UFPC). Parátipos: PERU - Hucimuco: Tingo Maria, 850m, XI-19651 macho (UFPC); Tingo Maria, Büche leg., 670m, 24-II-1993 I macho (UFPC-OM). Madre de Dios: Parque Nacional de Manu (Pakitza), 340m, Lamas leg., 10-X-1991 1 macho (MHNL), - Brasil - Rondonia: Pimenta Bueno, VIII-IX-1970 1 macho (UFPC): Ariquemes, Furtado leg., 16-IX-1978 I macho (UFPC-OM).

\subsection{Elbella patrobas amazonica, ssp.n.}

$$
\text { Figs 31, 49, 128, } 129
$$

Diagnose. Asa anterior com a faixa hranca mediana com $2.6 \mathrm{~mm}$ no macho e 2,3mm na fêmea de largura máxima e as manchas azuis long̨itudinais, ahaixo da faixa mediana, atingindo o nível do limite proximal da mancha branca da célula discal e a superior expandida na hase até $\mathrm{CuA}_{2}$; na face dorsal da asa posterior com a faixa azul discal rudimentar entre CuAl e $2 \mathrm{~A}$.

Figs 97-100. (97) Elhella iphinoss, macho (aherrante, sem manchas alaranjadas nas asas anteriores). Brasil. Rio de laneiro. Resende (Mauá), 18-1-1953, faces dorsaleventral: (98) Elhella iphinors, fêmea, Brasil. Rio de Janciro. Itatiaia, faces dorsal e ventral: (99) Elhella miodesmiala, macho. Colombia. neótipo. faces dorsal e ventral: $(I(K))$ Elhella rondonia. macho. Brasil. Mato Grosso. Diamantino (Farenda São Joăo). 28-1-1978. holótipo. faces dorsal e ventral. 

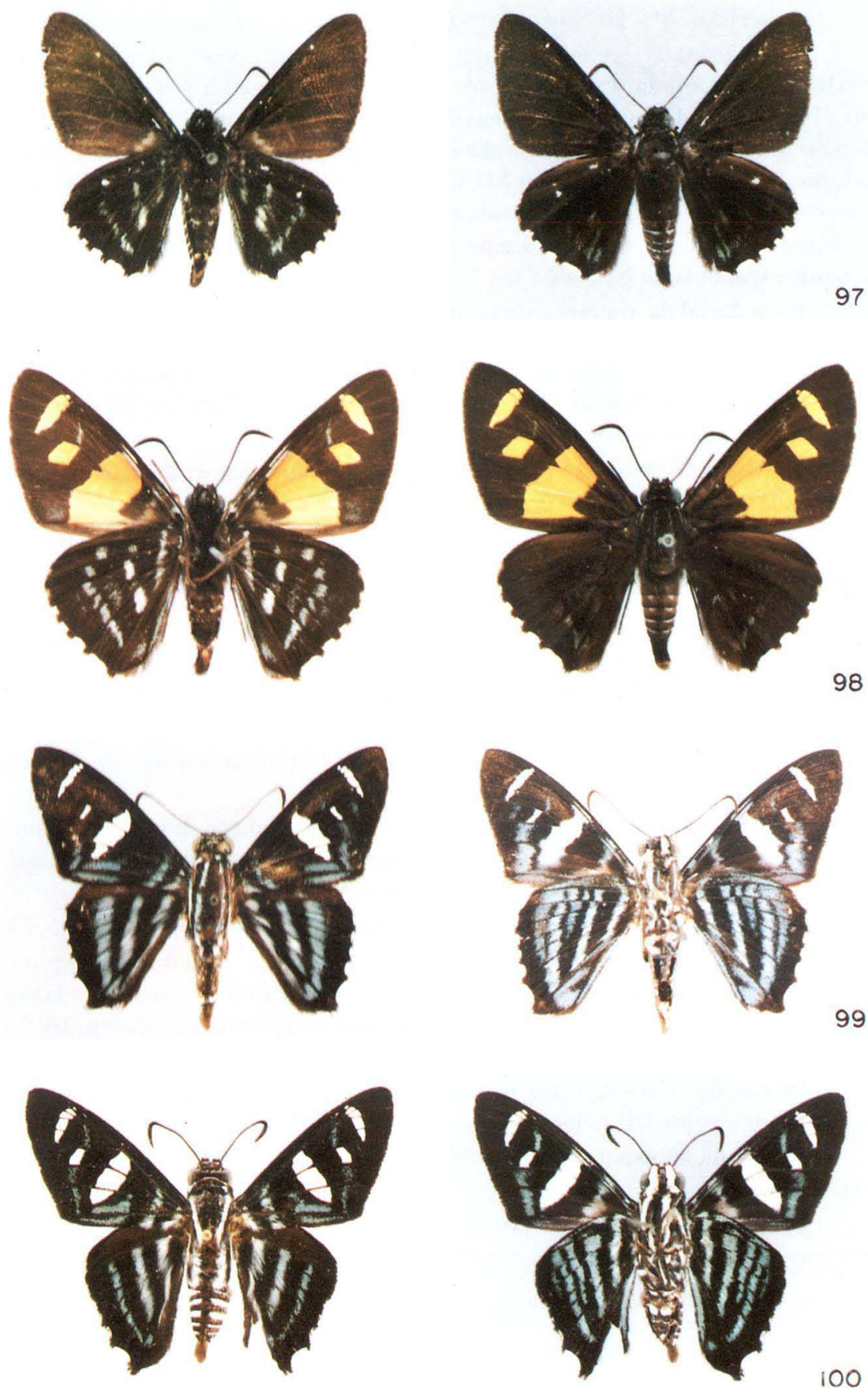
Descrição. Macho (Fiğ. 128) - Comprimento da asa anterior $29 \mathrm{~mm}$.

Face dorsal da asa anterior com a faixa hranca mediana $2.6 \mathrm{~mm}$ de largura máxima; mancha hranca em M3-CuAl com a largura igual a 1/4 da sua altura; faixa hranca apical com a largura máxima igual o dobro da mancha anterior: sem mancha branca em R2-R3: discocelulares azuis: manchas da faixa azul submarginal estreitas entre CuAl e 2A, a em M3-CuAl fracamente indicada e a em M2-M3 composta de poucas escamas; manchas azuis longitudinais, ahaixo da taixa mediana, atingindo o nível do limite proximal da mancha da célual discal e a superior expandida na base até CuA2.

Face dorsal da asa posterior com as faixas azuis hasal e mediana da mesma largura e a azul discal assim entre Rs e CuAl, o restante composto de pequenas manchas de escassas escamas entre CuAl e pouco além de 2A: espaço Se + R I-Rs. sem escamas azuis; tranjas concolores e brancas entre $\mathrm{CuA} 2$ e $3 \mathrm{~A}$, com as terminações das velas neg̨ras.

Face ventral da asa anterior com as discocelulares azuis; mancha da faixa azul submarg̨inal em CuA2-2A pouco mass larg̣a e a em CuAl-CuA2 só representada por escassas escamas.

Face ventral da asa posterior com as três taixas azuis de larguras diferentes, a hasal mais larga. a mediana intermediária e a discal mais fina e composta de manchas de escassas escamas, deixando espaços entre elas bem maiores que as suas larguras; faixas azuis adicionais hasal até Ml e discal, difusa, até CuAl; espaço 2A-3A com uma pequena mancha azul no término de $3 \mathrm{~A}$; franjas como na face dorsal.

Fêmea (Fig. 129). Semelhante ao macho. Comprimento da asa anterior $32 \mathrm{~mm}$.

Face dorsal da asa anterior com a faixa branca mediana $2,3 \mathrm{~mm}$ de largura máxima; discocelulares com escassas escamas azuis; mancha azul lonģitudinal, abaixo da faixa mediana, não expandida na base até CuA2.

Face ventral da asa anterior com pequena mancha hranca apical em R2-R3.

Face ventral da asa posterior com as três faixas azuis estreitas e os espaços entre elas maiores que as suas larguras; faixas azuis adicionais hasal marcada por escassas escamas e distal até CuAl; mancha azul no término de $3 \mathrm{~A}$ em 2A-3A maior que no macho.

Discussão. Caracterizada pelo estreitamento das faixas na face dorsal da asa posterior e pelas faixas longitudinais grandes da face dorsal da asa anterior.

Distribuição espacial (Fig. 49). Brasil - Amazonas: São Paulo de Olivença; Maués.

Distribuição temporal. Voa em outubro.

Figs 101-104. (101) Elbella rondomia, fêmea. Peru, Junin. La Merced (10km W Fos do Rio Colorado). 20-X-1989. alótipo. faces dorsal e ventral: (102) Elhella madeira, macho. Brasil. Mato Grosso. Diamantino (Fa/enda Säo Joào). 23-IX-1978. holótipo. faces dorsal e ventral: (103) Elbella madeira. femea. Peru, Madre de Dios, Puerto Maldonado (J(0)km oseste de Puerto Maldonado. carretera Puerto Maldonado-Cuzco), IX-XI-1992. alótipo, faces dorsale ventral; (I)4) Elhella bicuspis. macho. Brasil. Amazonas. Sảo Paulo de Olivença. taces dorsal è ventral. 

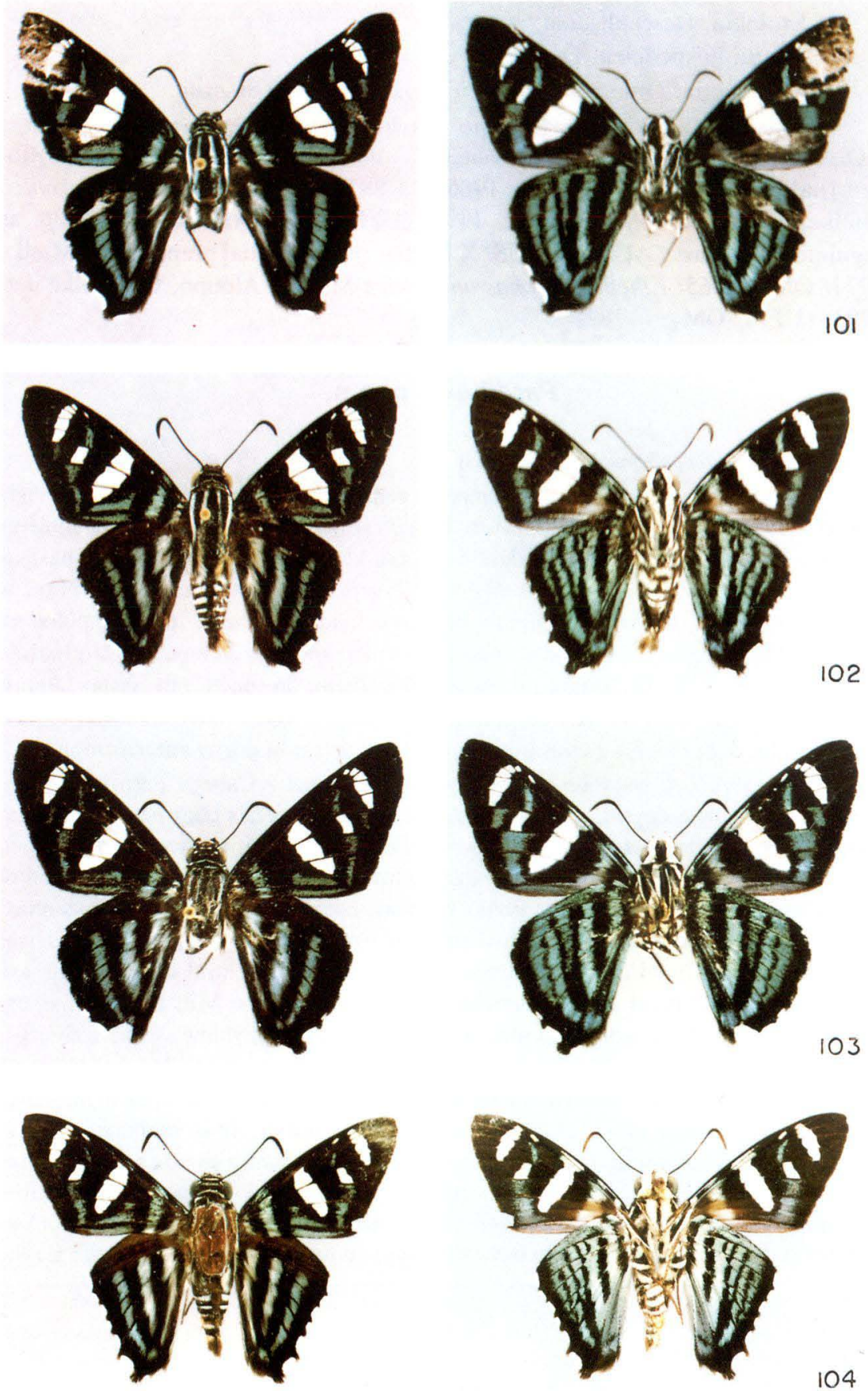
Etologia. Desconhecida.

Planta hospedeira. Desconhecida.

Etimologia. O nome refere-se à região de onde é descrita.

Material estudado. Holótipo macho com as seguintes etiquetas: / HOLOTYPUS/ São Paulo de Olivença, E. do Amazonas, Coll. E. May-Rio/ gen.[itália] prep.|arada] Mielke 1986/ 11.883/ Elbella patrobas amazonica Mielke, Holótipo, O. Mielke det. 1993/ (UFPC-OM). Alótipo fêmea com as seguintes etiquetas: / ALLOTYPUS/X Maués o /gen.[itália] prep.[arada] Mielke 1974/ OM 32.965/Elbella patrohas amazonica Mielke, Alótipo, O. Mielke det. 1993/ (UFPC-OM).

\section{Parelbella, gen.n.}

Espécie tipo: Hesperia polyzona Latreille,|1824]

Diagnose. Antenas brancas na parte ventral da clava; frontoclípeo em vista dorsal, de contorno arqueado, como em Elhella (Fig. 1); face dorsal da asa anterior com mancha apical em Ml-M2 dando à faixa hranca apical quatro manchas; as manchas brancas em M2-M3 e M3-CuAl separadas entre as faixas brancas mediana e apical; tergos abdominais branco-azulados na base, interrompidos na linha mediana; unco de terminação estreita e bífida; apófises do tegumen laminares, curvas, alcançando ou quase alcançando o meio do unco em vista lateral: frontoclípeo em vista dorsal, de contorno arqueado, como em Elhella (Fig. 1); edeago reto, sem carena e com um lóbulo distal dirigido dorso-anteriormente.

Descrição. Caracteres masculinos e femininos - Cabeça com a margem posterior, em vista dorsal, uniformemente côncava e apenas com pequena concavidade no início do quetosemata, como em Elbella (Fig. 1); vértice e frontoclípeo com manchas e linhas transversais brancas a levemente azuladas, as manchas entre as antenas formando uma faixa; genas brancas, com as partes internas castanhas; índice entre a largura do olho e a distância que o palpo se projeta para frente deste, em vista lateral, igual a 2,08; antenas hrancas na parte ventral da clava; na asa anterior, a faixa apical com 4 manchas brancas entre R3 e M2, as manchas em M2-M3 e M3-CuAl isoladas entre as faixas apical e mediana, esta, às vezes, ausente; na asa anterior R4 e R5 livres (Fig. 7); garras tarsais bífidas, com o dente ventral rombudo e mais curto que a metade do ponta dorsal, como em Elbella (Fig. 4); tỉbia protorácica mais longa que a metade do fêmur; tíbia metatorácica, ao menos o esporão distal maior mais curto que a distância entre as inserções dos dois pares de esporões; tíbia metatorácica rebaticla sobre o tarso atingindo no máximo a articulação entre o segundo e o terceiro tarsômeros; tórax dorsalmente com as faixas do mesoscuto alcançando o mesoescutelo e todos os desenhos azuis; tergos

Figs 105-108. (105) Elbella etna, macho, Brasil, Mato Grosso, Diamantino (Fazenda São João), 11-IX-1978, faces dorsal e ventral; (106) Elhella etna, fêmea, Brasil, Mato Grosso, Diamantino (Fazenda São João). 12-IX-1978, faces dorsal e ventral: (107) Elbella patroclus patroclus, macho, Bolivia, La Paz. Caranavi. LX-X-1988. neótipo de umbrata, faces dorsal e ventral: (108) Elbella parroclus acala. macho, sem procedência, faces dorsal e ventral. 

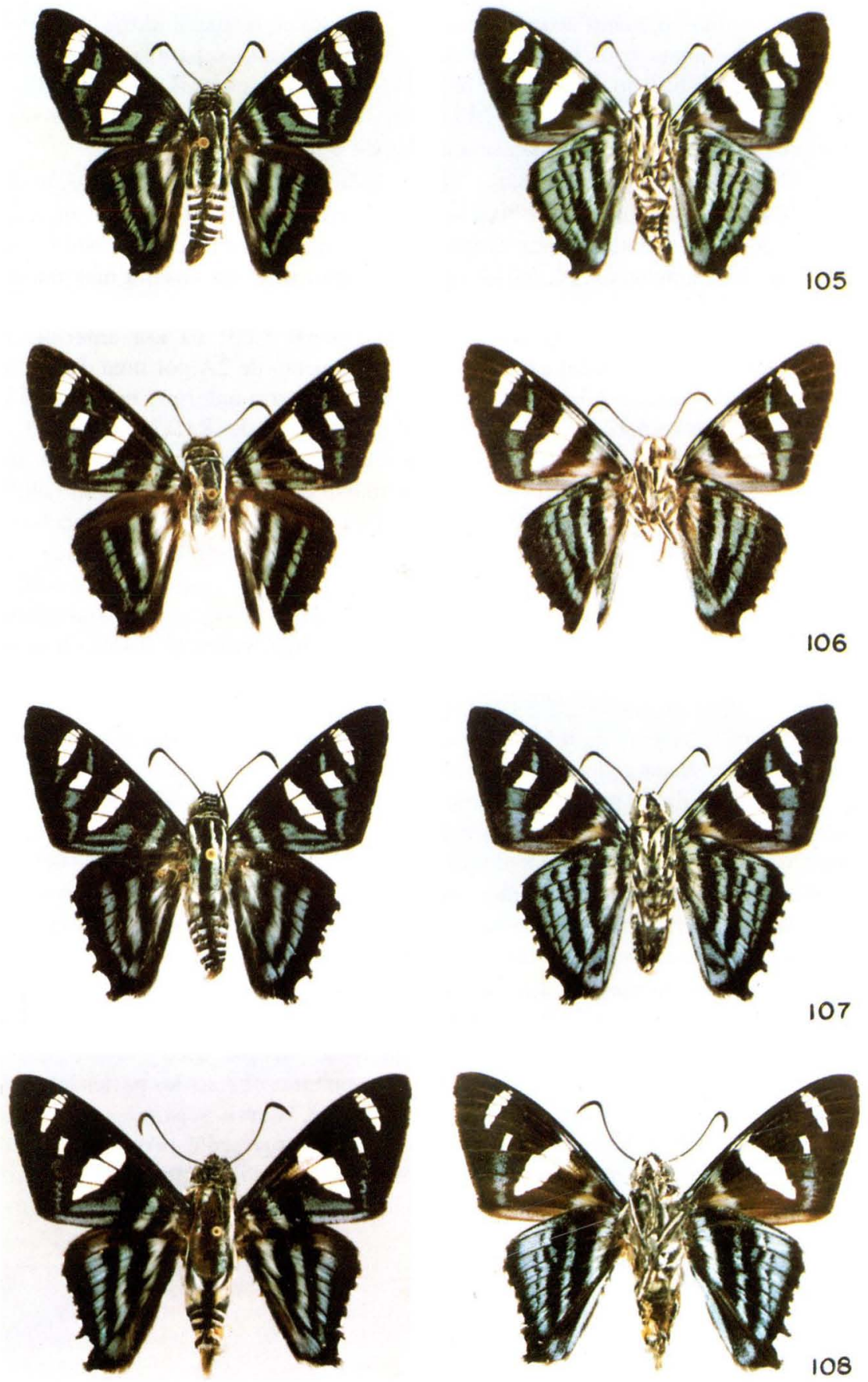
abdominais com manchas azuis separadas pela linha mediana dorsal escura; esternos abdominais com faixas transversais hrancas não separadas pela linha mediana ventral; tufo anal anegrado; na asa anterior a faixa apical com 4 manchas entre R3 e M2, as manchas em M2-M3 e M3-CuAl isoladas entre as faixas apical e mediana (às vezes ausente); na asa anterior R4 e R5 livres (Fig. 7).

Caracteres masculinos. Índice entre a distância interorbital e a projeção do frontoclípeo além da tangente orbital 4,54; índice entre a altura do olho, medida em vista dorsal, e a distância interantenal 1.46; índice entre os comprimentos da haste e da clava antenais 3,14; índice entre o comprimento e a largura máxima da clava antenal 5,53; índice entre os comprimentos da margem costal da asa anterior. medida da base ao ápice em R4, e a haste antenal 3,03; na asa anterior. o comprimento da célula discal excedendo o comprimento de $2 \mathrm{~A}$ por uma distância menor que o das discocelulares mediana e inferior; na asa anterior, m-cu distal à perpendicular imaginária à $2 \mathrm{~A}$ que passa pelo início de $\mathrm{R} 1$; índice entre o comprimento de uma reta da hase da célula discal até o meio entre Ml e M3, na margem externa da asa posterior, e o comprimento entre a base da mesma célula até o ponto de inserção com as discocelulares 2,56: asa posterior com a discocelular superior menor que a metade das discocelulares mediana e inferior; na asa posterior, o ângulo formado pelas discocelulares e M3 $115^{\circ}$; asa posterior com a área anal muito longa, isto é, 2A sobreposta por um compasso centrado na célula basal ultrapassa Rs por uma distância maior que duas vezes as discocelulares mediana e inferior; tíbia mesotorácica com as escamas externas curtas, achatadas e apressas; tíbia metatorácica com as escamas externas delgadas e divergentes, sohrepassando a largura da tíbia; apófises do tegumen presentes, dorsais ao unco, curvas e até a metade do comprimento do unco em vista lateral; apófíses do tegumen só crenuladas nas bordas dorsal e ventral; unco de terminação delgada e bífida; gnato de duas peças, fracamente esclerosadas, como se fossem prolongamentos das apófises ventrais do unco; extremidade distal do edeago com um lóbulo lateral esquerdo, dirigido dorso-anteriormente, aparentemente sustentando a vesica e sem carena lateral; parte dorso-hasal da valva (costa) sem projeção; valva não terminando em processo transversal.

Caracteres femininos. Índice entre os comprimentos da haste e da clava antenais 3,12; índice entre os comprimentos da margem costal da asa anterior. medida da hase até o ápice em R4 e da haste antenal 3,03; oitavo tergoo aparentenmente ausente; esterigma ligado por membrana abaixo das partes laterais do oitavo esterno; oitavo esterno com as suas partes laterais separadas acima do esterigma; esterigma tubular, com a parte ventral largamente projetada e sem lóbulo ou lóbulos dorsais, aparentemente fechando o óstio, ou processos laterais do oitavo esterno; corpo da bolsa bem distinto e curvado em relação ao seu duto.

Figs 109-112. (109) Elhella patroclus acala, fêmea, Colômbia, faces dorsal e ventral: (110) Elhella azeta azela. macho. Brasil. Mato Grosso, Diamantino (Fazenda São Joāo), 26-II-1979, faces dorsal e ventral: (111) Elhella azeta azeta, fêmea, Brasil. Pará, Juruti, XII-1971, faces dorsal e ventral: (112) Elhella azela giffordi. macho. Brasil. Distrito Federal. Brasilia (ESAF), 29-IX-1980, holótipo, Faces dorsal e ventral. 

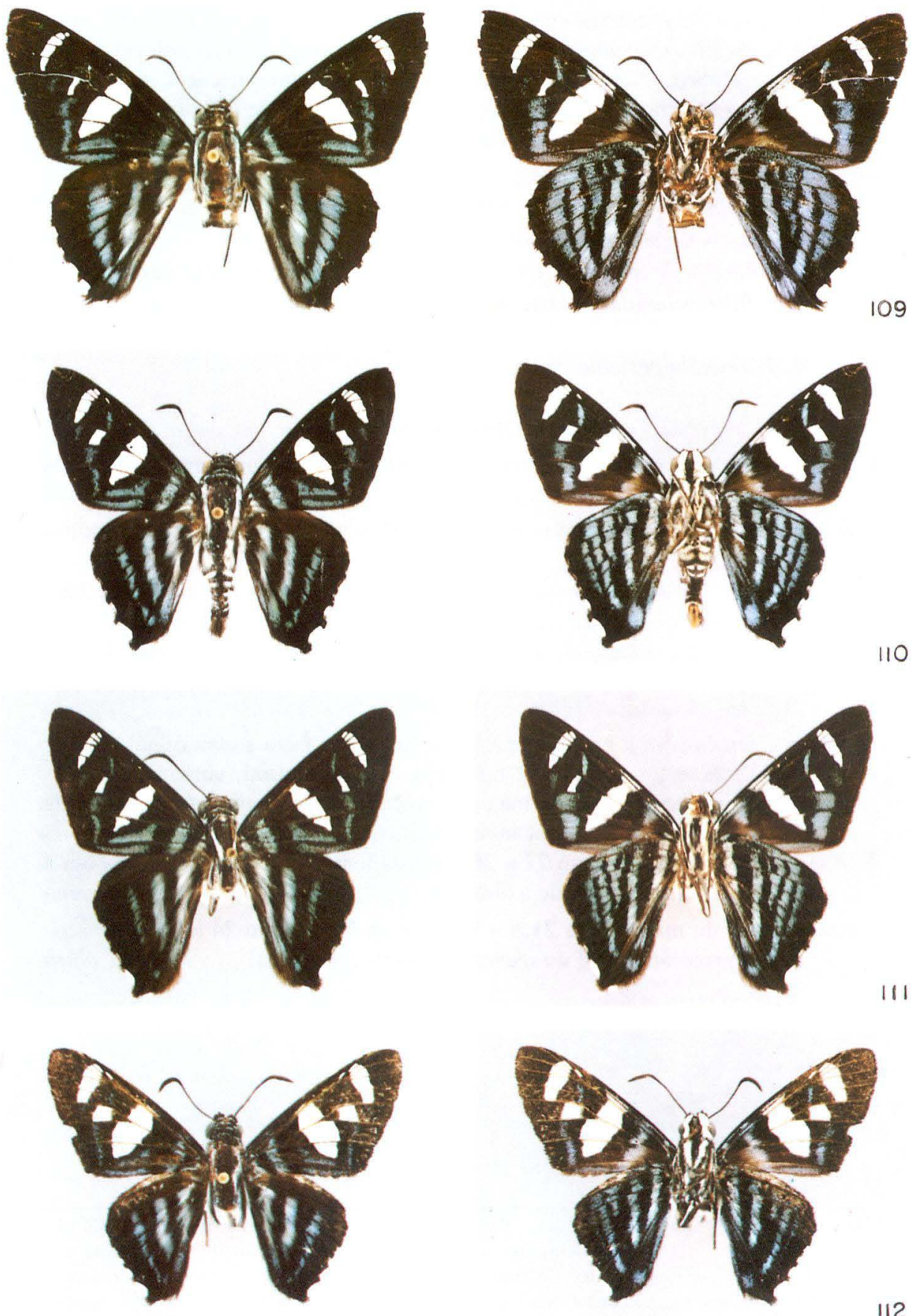
Evans (1951) afirma que todas as espécies aqui incluídas seriam subespécies de polyzona, no entanto devido às diferenças constantes no colorido e nas genitálias masculina e feminina, prefere-se mantê-las como espécies distintas. Os desenhos azuis e brancos são semelhantes aos das espécies de Elbella.

Etimologia. Nome indicando à proximidade com Elbella.

Espécies incluídas:

1. Parelhella polyzona (Latreille, [1824]), comb.n.

2. Parelhella ahira (Hewitson, 1866), comb.n., stat.rev.

2.1. Parelbella ahira ahira (Hewitson, 1866), comb.n., stat.rev.

2.2. Parelhella ahira extrema (Röber, 1925), comb.n.

3. Parelbella macleannani (Godman \& Salvin, 1893), comb.n., stat.rev.

4. Parelbella peruana, sp.n.

\section{Chave para as espécies}

1. Asa anterior com as manchas brancas em M2-M3 e M3-CuA1 muito reduzidas

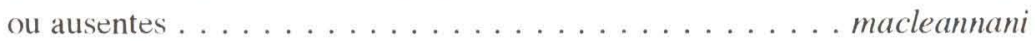

- Asa anterior com as manchas brancas em M2-M3 e M3-CuA1 presentes e grandes

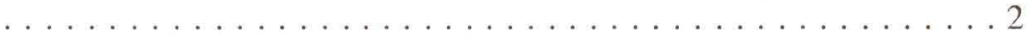

2. Macho: face dorsal das asas com as manchas azuis muito vivas, algo violáceas; a faixa submarginal da face dorsal da asa anterior larga desde a costa até o torno e toda a costa praticamente azul. Fêmea: com o azul como nas demais espécies, mas na face dorsal da asa posterior as faixas azuis aproximadamente da mesma largura . . . . . . . . . . . . polyzona

- Macho e fêmea com a mesma tonalidade de azul; a faixa submarginal a partir de M2 até o torno, quando a partir da margem costal, então de escamas difusas e menores que as manchas apicais. Fêmea com a faixa discal da face dorsal da asa posterior mais estreita que as faixas basal e mediana . .3

3. Asa anterior do macho com 27 a $28 \mathrm{~mm}$ e da fêmea com $30 \mathrm{~mm}$; harpe com a projeção dorsal maior que a distal . . . . . . . . . . . peruana

- Asa anterior do macho com 21,5 a $23 \mathrm{~mm}$ e da fêmea com 24 a $26 \mathrm{~mm}$; harpe com a projeção dorsal do mesmo tamanho que a distal . . . . . . . ahira

Figs 113-116. (113) Elbella azeta giffordi, fềmea. Brasil, São Paulo, Rancharia, XI-1938, alótipo, faces dorsal e ventral; (114) Elbella lustra, macho, Colômbia, Boyaca, Otanche, IV-1992, faces dorsal e ventral: (115) Elbella lustra, fềmea, Colômbia, Boyaca, Otanche, VIII-1985, faces dorsal e ventral; (116) Elhella merops, macho, Brasil, Mato Grosso. Diamantino (Fazenda São João), faces dorsal e ventral. 

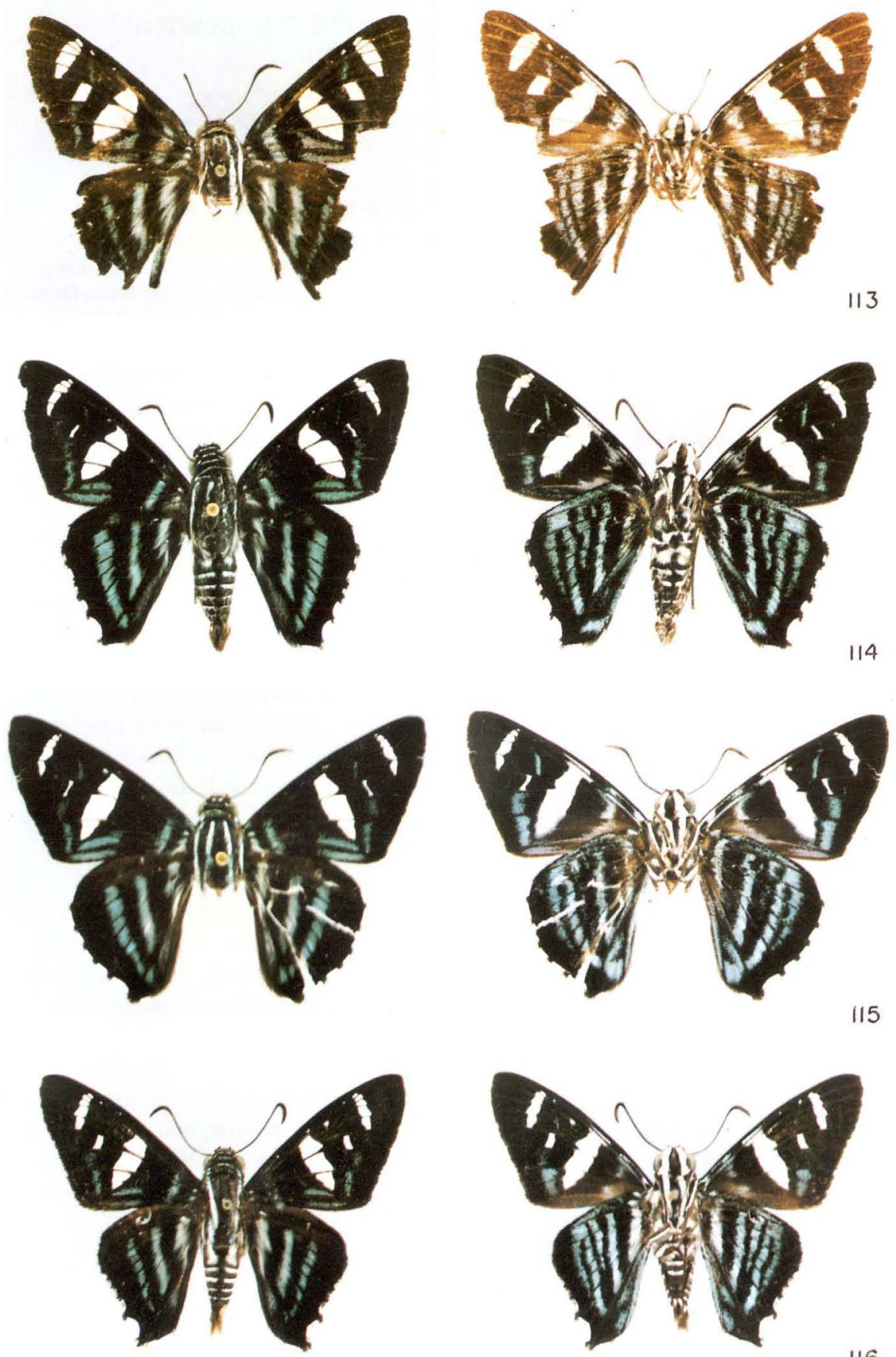


\section{Parelbella polyzona (Latreille, [1824]), comb.n.}

Figs $32,50,130,131$

Hesperia polyzona Latreille, [1824], in Godart \& Latreille. Enc. Méth. 9, p. 715, 736: 1 mache [holótipo]. Brasil, Langsdorff [leg.]: syn.: vulcanus Cramer, pl. 245. figs. C. D. (BMNH) [Exaninado].

Pyrrhopyga (sic) polyzona: Mabille, 1878. Am. Soc. ent. Beig. 21: 17, 18, 19.

Jemadia polyzona: Mahille, 1903, in Wytsman. Gen. Ins. 17, p. 12: syn.: jamina.- Mahille \& Boullet. 1908. Ann. Sc. nat. 7: 192. 196: syn.: jamina.-Mabille, 1912. Lep. Cat. 9. p. 10: syn.: jamina.Draudt, 1921, in Seitz. Macrolep. World 5, p. 844, pl. 163a; syn.: jamina.- Riley, 1926. Trans. ent. Soc. London 74: 232: syn.: zimra, jamina.- Bell. 1933. Jour. N. Y. Ent. Soc. 41: 497.Williams \& Hayward, 1944. Acta zool. lill. 2: 81.

Elhella polyzona polyzoma: Evans. 1951. Cat. Amer. Hexp. 1, p. 47, pl. 5 (genitália masculina).

Elbella polyzona: Bridges, 1983. Lep. IIesp. 1.p. 96; 2. p. 12.- Bridges, 1988. Cat. Hesp. 1, p. 151: 2. p. 19.- Casagrande \& Mielke, 1993. Kevta bras. Zool. 9: 92, fig. 17 (a-d).

Diagnose. Macho - Azul da face dorsal das asas muito vivo, algo violáceo. Fêmea - Na face dorsal da asa posterior as três faixas da mesma largura.

Descrição. Macho (Fig. 130) - Comprimento da asa anterior 24 a $28 \mathrm{~mm}$.

Face dorsal da asa anterior com a faixa branca mediana 1 a $1,5 \mathrm{~mm}$ de largura máxima; manchas brancas em M2-M3 e M3-CuAl com as larguras sempre menores que $1 / 3$ das suas alturas, mas sempre bem marcadas; faixa branca apical de largura máxima na mancha em R5-M1, esta aproximadamente tão larga como a em M2-M3; às vezes, com ponto branco diminuto em R2-R3; desenhos azuis muito vivos, algo violáceos; discocelulares azuis; manchas da faixa azul submarginal grandes entre R4 e 2A; manchas azuis longitudinais, abaixo da faixa mediana, grandes, atingindo o nível do limite proximal da mancha da célula discal e a superior expandida na base até $\mathrm{CuA} 2$; margem costal com manchas azuis difusas, quase unidas, acima das faixas azuis sub-basal, mediana e das discocelulares; franjas castanhas.

Face dorsal da asa posterior com a faixa azul discal igual ou ligeiramente mais larga que as faixas azuis basal e mediana e a distância entre elas aproximadamente igual às suas larguras; centro do espaço 2A-3A com linha branca entre as faixas basal e discal; espaço $\mathrm{Sc}+\mathrm{R}$ 1-Rs algumas vezes com esparsas escamas azuis acima da faixa basal e entre as faixas mediana e discal; franjas brancas, com as terminações das veias negras.

Face ventral da asa anterior com os desenhos azuis mais claros que na face dorsal; as discocelulares azuis; manchas da faixa azul submarginal mais largas entre $\mathrm{CuAl}$ e $2 \mathrm{~A}$ e a margem costal com menos escamas azuis difusas; margem interna esbranquiçada; franjas como na face dorsal e ligeiramente brancas em CuA2-2A.

Figs 117-120. (117) Elhella merops, fêmea, Peru, Loreto, Iquitos, faces dorsal e ventral: (118) Elhella theseus, macho, Peru. Huánuco, Tingo Maria. 20-II-1982. faces dorsal e ventral: (119) Elbella theseus. fềnea. Peru, Madre de Dios, Parque Nacional de Manu (Pakitza). 13-X-1991, faces dorsal e ventral: (120) Elbella blanda, macho, Peru, Loreto, Pebas, fin X.ere \& 1.er Tr. 1880, holótipo, faces dorsal e ventral. 

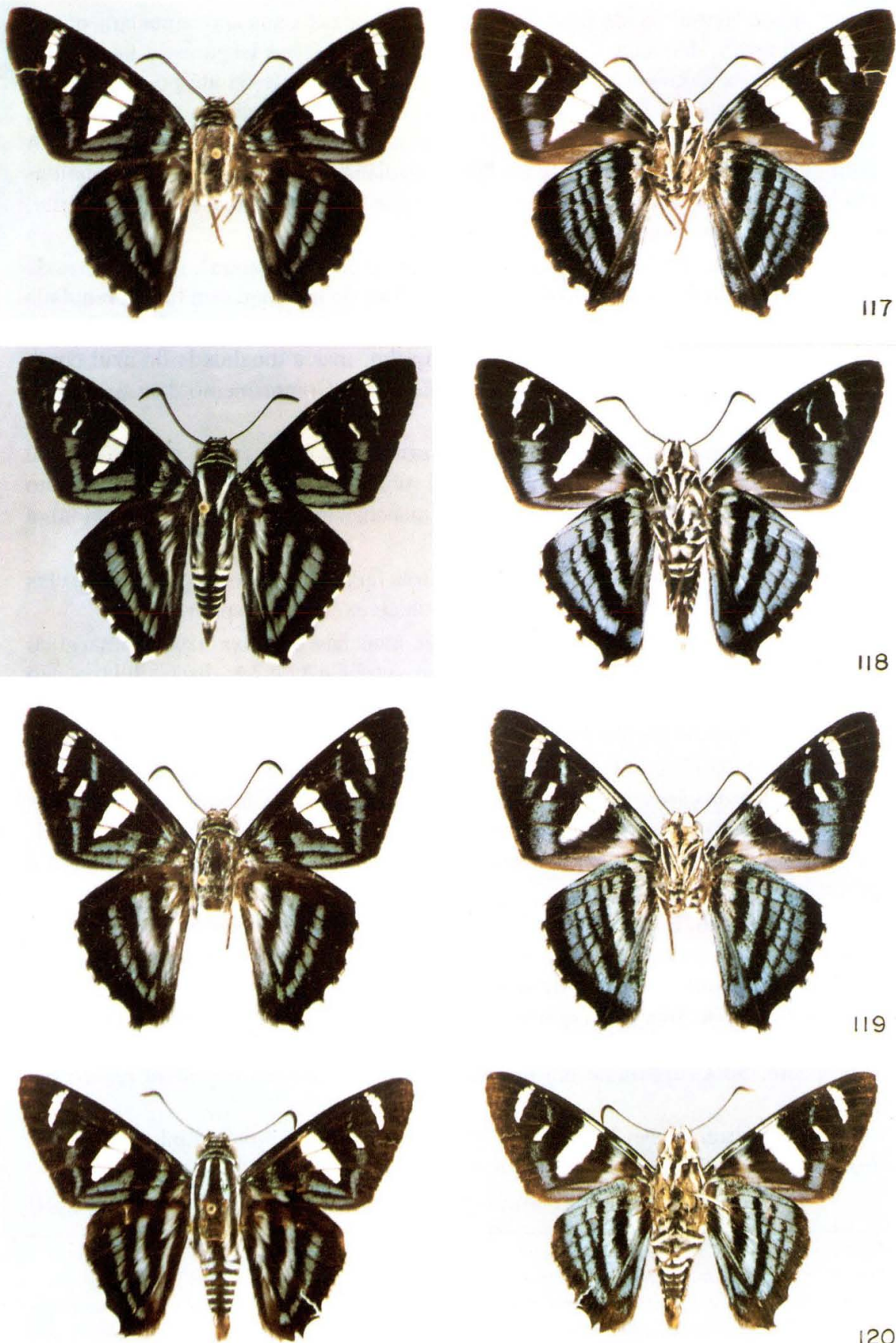
Face ventral da asa posterior com as três faixas azuis aproximadamente da mesma largura, deixando entre elas espaços iguais às suas larguras; a faixa basal até o ângulo umeral; faixas azuis adicionais basal ausente ou até pouco além de M1 e a distal até $2 \mathrm{~A}$ e, muitas vezes, unida à faixa discal, dando a impressão de uma única faixa discal; margem costal com a metade distal azul; espaço 2A-3A com duas manchas azuis abaixo das faixas mediana e discal, estas às vezes unidas em larga mancha única e a base do mesmo espaço, assim como a margem interna, igualmente azuis; franjas como na face dorsal.

Genitália (Fig. 32). Apófises do tegumen, em vista lateral, iguais à metade do comprimento do unco; lado dorsal das apófises do tegumen sem linha crenulada longitudinal; harpe com a projeção distal estreita e menor que a projeção dorsal.

Fêmea (Fig. 131). Semelhante ao macho, mas a tonalidade do azul como nas demais espécies azuis do "Complexo Elbella". Comprimento da asa anterior $30 \mathrm{~mm}$.

Face dorsal da asa anterior com o azul da margem costal restrito à parte acima da faixa basal; manchas da faixa azul submarginal só entre $\mathrm{M} 2$ e $2 \mathrm{~A}$ e muito difusas, assim como as discocelulares e as manchas longitudinais, abaixo da faixa mediana.

Face dorsal da asa posterior com as três faixas azuis e os espaços entre elas da mesma largura. Franjas danificadas no único exemplar disponível.

Face ventral da asa anterior com as manchas da faixa azul submarginal muito apagadas, reduzidas à manchas difusas entre $\mathrm{CuAl}$ e $2 \mathrm{~A}$; discocelulares não azuis,

Face ventral da asa posterior sem faixas azuis adicionais basal e distal.

Genitália (Fig. 32). Em vista lateral, parte basal do esterigma em ângulo reto com a projeção ventral e ambas aproximadamente da mesma largura e esta maior que a altura da parte basal e levemente dilatada no meio; em vista ventral, esterigma largo e reto na base, estreitando-se abruptamente no terço basal para a projeção ventral simétrica.

Discussão. É uma espécie bem caracterizada pela sua coloração e genitália, tanto masculina como feminina. Como a descrição original menciona um macho do Brasil e diz simplesmente que se encontra também no Suriname e talvez Caiena, Guiana Francesa, fica claro que o exemplar encontrado no BMNH é o holótipo. A fêmea, aqui descrita do Espírito Santo, Brasil, poderia ser outra espécie ou subespécie. Só a captura de um macho da mesma procedência poderá resolver o problema.

Distribuição espacial (Fig. 50): BRASIL - Espírito Santo: Linhares. Rio de Janeiro: Rio de Janeiro. Santa Catarina: Joinvile 10-200m.

Distribuição temporal. No Espírito Santo (Linhares) voa em março e abril

Figs 121-124. (121) Elbella blanda, fêmea, Brasil, Espírito Santo, Linhares, XI-1982, faces dorsal e ventral: (122) Elbella patrobas patrohas, macho, Colômbia, Meta, Rio Negro, 17-VIII-1980, faces dorsal e ventral; (123) Elbella patrobas patrobas, fềmea, Panamá, Zona do Canal, Cerro Campana, 15-IX-1967, faces dorsal e ventral: (124) Elbella patrobas mexicana, macho, México. Chiapas, San Quentin, 3-X-1972, holótipo. faces dorsal e ventral. 

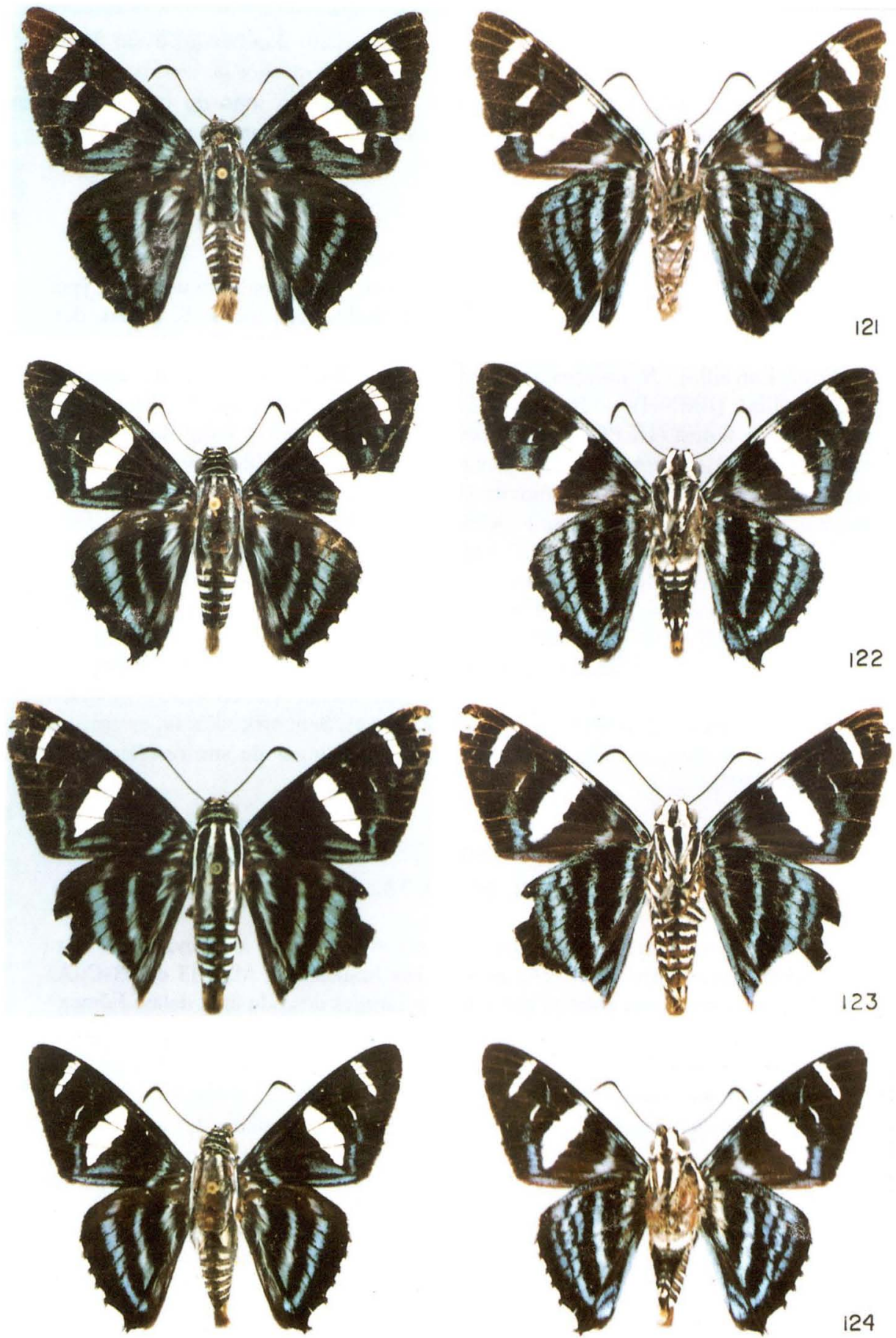
(o exemplar estudado é do início de abril e está muito danificado) e em Santa Catarina (Joinvile) voa desde o início de dezembro até meados de janeiro.

Etologia. Todos os machos foram capturados no topo do morro onde pousavam de asas abertas em folhas numa altura de aproximadamente $3 \mathrm{~m}$ acima do solo. Na época de seu voo, dificilmente se vê mais de três exemplares por dia entre as 10 e 12 horas.

Planta hospedeira. Desconhecida.

Etimologia. Do grego, poly - muitas e zona - faixas.

Material estudado. O holótipo macho com as seguintes etiquetas: / Type/ According to Olaf Mielke (in litt. 1970) the probable type loc. is S. Brazil, det. R. I. Vane-Wright 1976/ R. Oberthür Coll. Brit. Mus. 1931-136/ H. polyzona. (scripsit. Latreille) / H. polyzona Lat. vulcanus Cr. Bres./ cartão com o preparado da genitália/ (BMNH). - BrasiL - Espírito Santo: Linhares, C. Elias leg., 4-IV-1972 1 fềmea (UFPC). Rio de Janeiro: Rio de Janeiro, Langsdorff leg., 1 macho (ZMHB). Santa Catarina: Joinvile (Neudorf, atual Vila Nova), Pohl leg., XII-1939 2 machos (MZSP); Joinvile (Serrinha), 200m, Miers leg, 17-I-1971 2 machos, 28-XII-1977 2 machos, 26-XI-1982 1 macho, 4-I-1983 1 macho (UFPC), 19-XII-1976 5 machos, 26-XII-1987 1 macho, 12-XII-1989 1 macho (UFPC-OM); Joinvile (Serrinha), Mielke \& Miers leg., 26-I-1974 2 machos, 8-II-1974 1 macho, 19-XII-1975 1 macho, 19-XII-1976 1 macho, 26-XII-1976 2 macho, 31-XII-1978 2 machos, 9-XII-1917 1 macho (UFPC), 26-XII-1976 3 machos, 9-XII-1979 1 macho, 10-I-1985 5 machos, 29-XII-1987 1 macho, 5-I-1988 3 machos (UFPC-OM); Joinvile (Serrinha), Mielke leg., 200m, 14-XII-1975 1 macho, 3-I-1981 2 machos, 27-I-1982 1 macho (UFPC-OM). Sem procedência, ex coleção K. Schmith, provavelmente de Joinvile (Serrinha) (lugar de sua residência), 1 macho (UFPC).

\section{Parelbella ahira (Hewitson, 1866), comb.n., stat.rev.}

Figs $33,34,50,132-136$

Diagnose. Macho - Face dorsal da asa anterior com as manchas da faixa azul submarginal entre M2 e 2A; as manchas brancas em M2-M3 e M3-CuA1 grandes, mais próximas entre si que a menor largura de cada uma delas. Fêmea Face dorsal da asa posterior com a faixa azul discal bem mais fina que as faixas azuis basal e mediana.

Descrição. Macho - Comprimento da asa anterior 22 a $23 \mathrm{~mm}$.

Face dorsal da asa anterior com a faixa branca mediana 2,1 a $2,9 \mathrm{~mm}$ de largura máxima; manchas brancas em M2-M3 e M3-CuA1 com a largura no mínimo igual a $1 / 2$ da sua altura; faixa branca apical com a largura máxima entre

Figs 125-128. (125) Elbella patrobas evansi, macho. Colômbia, Valle. Rio Dagua, holótipo, faces dorsal e ventral; (126) Elbella patrobas melamina, macho. Peru, 1904. lectótipo. faces dorsal e ventral; (127) Elbella patrobas tingo, macho, Brasil, Rondônia, Pimenta Bueno, VIII-IX-1970. holótipo, faces dorsal e ventral; (128) Elhella patrobas amazonica, macho, Brasil, Amazonas, Säo Paulo de Olivença, holótipo, faces dorsal e ventral. 

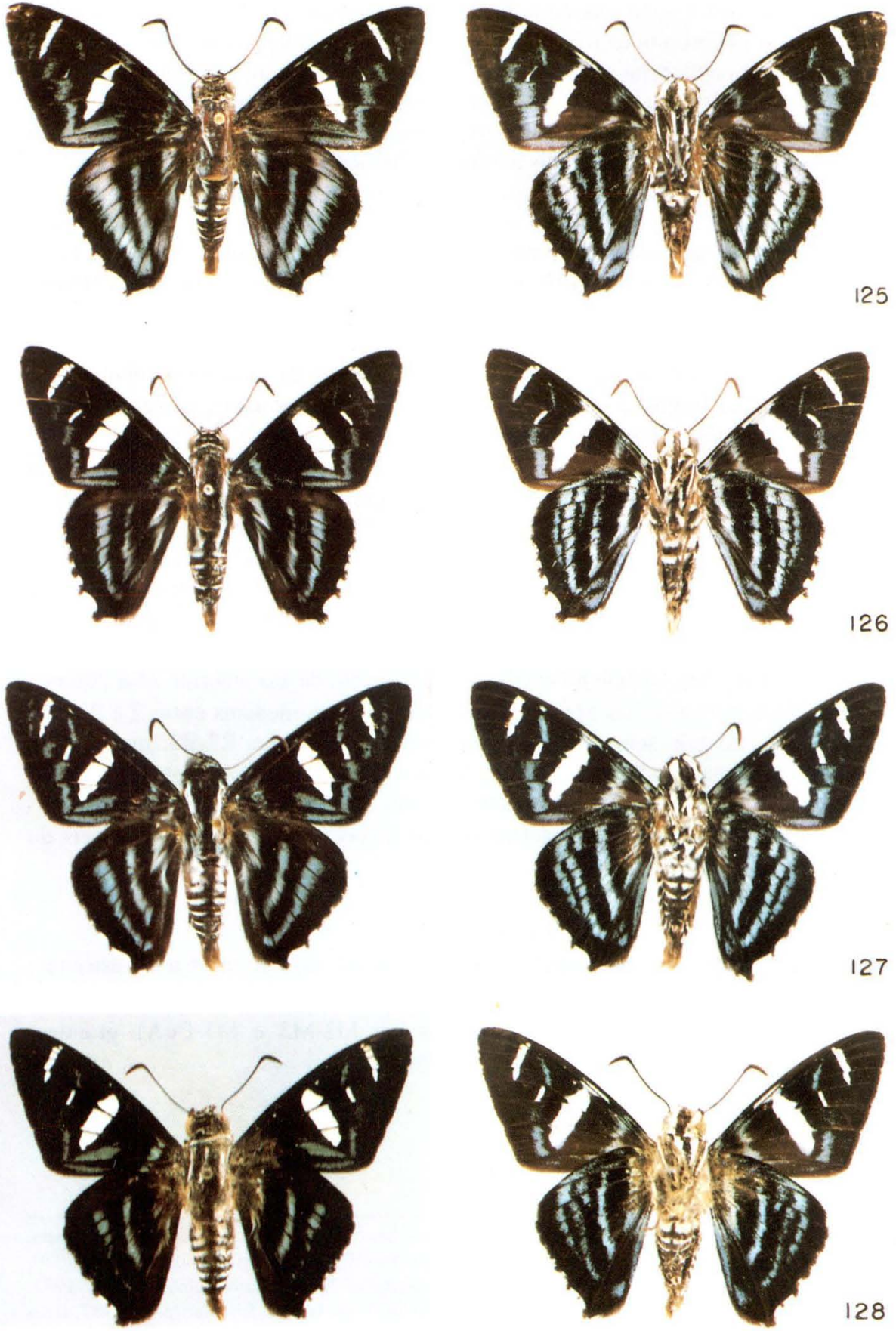
R4-R5 e R5-M 1 e igual à largura mediana das manchas em M2-M3 e M3-CuA1; às vezes, com ponto branco diminuto em R2-R3; os desenhos azuis sem violáceo; discocelulares azuis; manchas da faixa azul submarginal entre R4 ou R5 até 2A; manchas azuis longitudinais, abaixo da faixa mediana, atingindo o limite proximal da mancha da célula discal e a superior expandida na base até $\mathrm{CuA} 2$; margem costal con difusas escamas azuis acima das discocelulares; franjas castanhas.

Face dorsal da asa posterior com a faixa azul discal ligeiramente mais estreita que as faixas azuis basal e mediana e as distâncias entre elas um pouco maiores que as suas larguras; centro de 2A-3A com linha branca, abaixo da faixa basal e, às vezes, até a faixa discal; espaço $\mathrm{Sc}+\mathrm{R} 1-\mathrm{Rs}$ sem escamas azuis; franjas concolores, passando a brancas entre $\mathrm{CuAl}$ e $2 \mathrm{~A}$ e com as terminações das veias negras.

Face ventral da asa anterior com os desenhos da faixa azul submarginal iguais ou mais largos que na face dorsal; discocelulares azuis; margem interna acinzentada; franjas como na face dorsal.

Face ventral da asa posterior com as três faixas azuis aproximadamente da mesma largura e os espaços entre elas da largura das faixas; a faixa basal até o ângulo umeral; faixas azuis adicionais basal até $\mathrm{M} 1 \mathrm{e}$, às vezes, até $\mathrm{CuA} 2$ e a distal ausente ou muito fraca até $\mathrm{CuA} 2$; margem costal com a metade distal azul; espaço 2A-3A com duas manchas azuis, às vezes, pouco marcadas, abaixo das faixas mediana e distal e a base do mesmo espaço, assim como a margem interna igualmente azuis; franjas como na face dorsal.

Fêmea. Semelhante ao macho. Comprimento da asa anterior 24 a $26 \mathrm{~mm}$.

Face dorsal da asa anterior com a faixa branca mediana entre 2 e $2,3 \mathrm{~mm}$ de largura máxima; sempre com ponto branco diminuto em R2-R3; manchas da faixa azul submarginal só entre M2 e $2 \mathrm{~A}$. Face dorsal da asa posterior com franjas, às vezes, brancas desde $\mathrm{Sc}+\mathrm{R} 1-\mathrm{Rs}$ até $2 \mathrm{~A}$, em $2 \mathrm{~A}-3 \mathrm{~A}$ sempre concolores.

Face ventral da asa posterior com as faixas azuis e espaços variáveis de acordo com a subespécie.

\section{Chave para as subespécies}

1. Asa anterior com as manchas brancas em M2-M3 e M3-CuA1 estreitas, paralelas e não contíguas . . . . . . . . . . . ahira

- Asa anterior com as manchas brancas em M2-M3 e M3-CuA1 grandes, aproximadamente quadradas e contíguas . . . . . . . . extrema

Figs 129-132. (129) Elbella patrobas amazonica, fêmea, Brasil, Amazonas, Maués, outubro, alótipo, faces dorsal e ventral; (130) Parelbella polyzona, macho; Brasil, Santa Catarina, Joinvile, 9-XII-1979, faces dorsal e ventral; (131) Parelbella polyzona, fêmea, Brasil, Espírito Santo, Linhares, 4-IV-1972, faces dorsal e ventral; (132) Parelbella ahira ahira, macho, Peru, Loreto, San Martin, LX-1987, faces dorsal e ventral. 

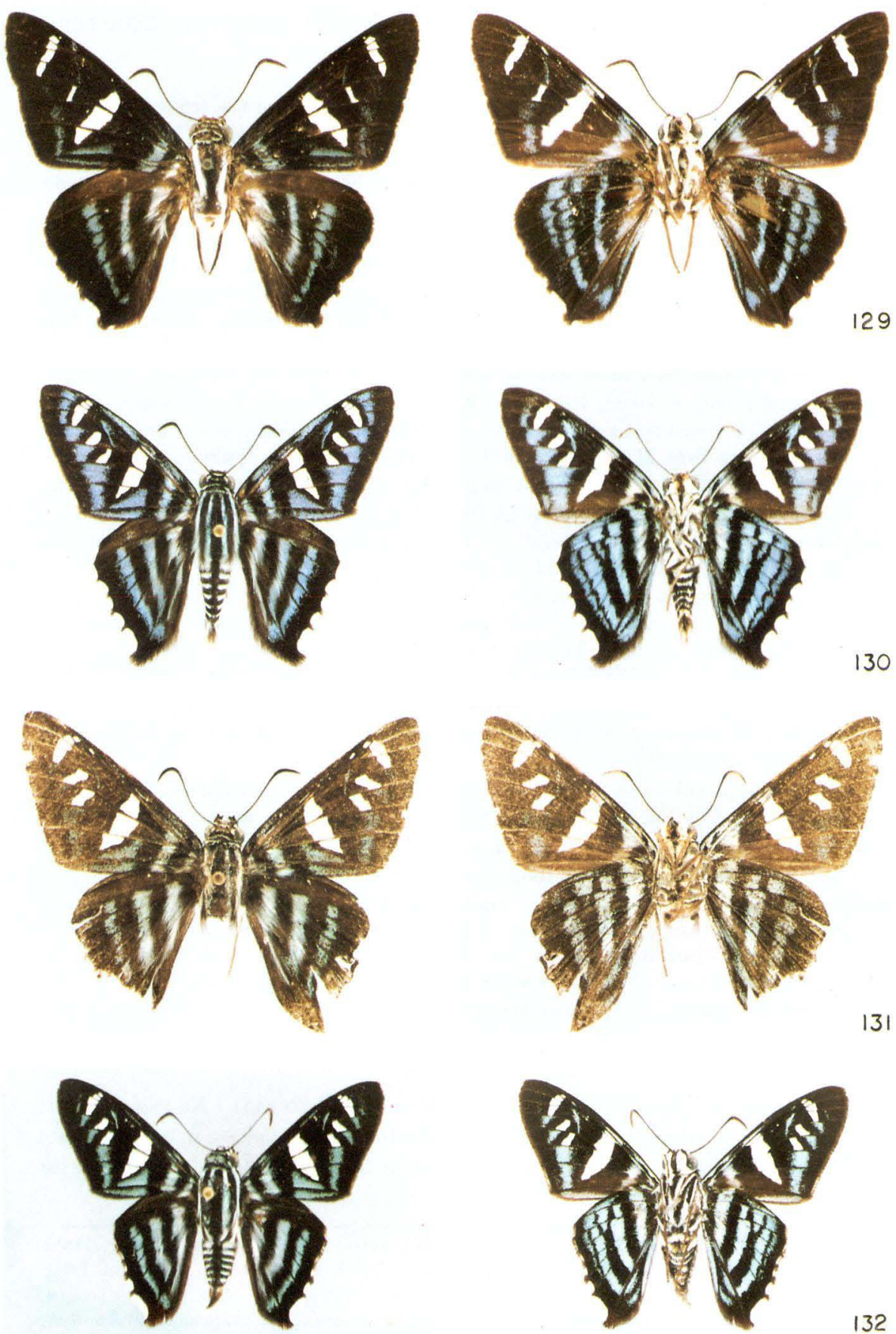


\subsection{Parelbella ahira ahira (Hewitson, 1866), comb.n., stat.rev.}

Figs $33,50,132-134$

Pyrrhopyga (sic) ahira Hewitson, 1866. Trans. ent. Soc. London, p. 479; macho [recte fềmea], Pará, Amazonas; coleção Hewitson: LECTÓTIPO fềmea aqui designado (BMNH) [Examinado].Hewitson, 1871. Exot. Butt. 4, Pyrrho. 2, texto, fig. 9.- Mabille, 1878. Ann. Soc. ent. Belg. 21: 17.- Kirby, 1879. Cat. Coll. Diurn. Lep. Hew., p. 208.- Plötz, 1879. Stett. ent. Ztg. 40: 522.

Erycides ahira: Herrich-Schäffer, 1869. Corr.-Blatt zool.-min. Ver. Regensburg 23: 169.- Kirby. 1871. Syn. Cat. Diurn. Lep., p. 588.- Kirby, 1877. Syn. Cat. Diurn. Lep., Suppl., p. 822.

Pyrrhopyga (sic) jamina Butler, 1870. Trans. ent. Soc. London, p. 499; sem localidade, coll. Kaden in coll. Druce: Lectótipo fềmea aqui designado (BMNH) [Examinado].- Butler. 1873. Lep. Exot.. p. 167; syn.: zimra.- Kirby, 1879. Cat. Coll. Diurn. Lep. Hew., p. 207; syn.: zimra.Plötz, 1879. Stett. ent. Ztg. 40: 521 -- H. Druce, 1876. Proc. zool. Soc. London, p. 248. Syn.n.

Pyrrhopyga (sic) zimra Hewitson, 1871. Exot. Butt. 4, Pyrrho. 2, texto, fig. 11; sem localidade; coleção Hewitson; Lectótipo fêmea aqui designado (BMNH) [Examinado].- Mabille, 1878. Ann. Soc. ent. Belg. 21: 17.- Plötz, 1879. Stett. ent. Ztg. 40: 521. Syn.n.

Pyrrhopyge jamina; Kirby, 1871. Syn. Cat. Diurn. Lep., p. 587.- Kirby, 1877. Syn. Cat. Diurn. Lep., Suppl., p. 820.- Weeks, 1911. Ill. Diurn. Lep. 2, p. XV.

Jemadia jamina; Watson, 1893. Proc. zool. Soc. London, p. 14.- Bell, 1933. Jour. N. Y. Ent. Soc. 41: 498, fig. 28 (genitália masculina); syn.: zimra.

Jemadia zimra; Watson, 1893. Proc. zool. Soc. London, p. 14.- Mabille, 1903, in Wytsman. Gen. Ins. 17, p. 12.- Mabille \& Boullet, 1908. Ann. Sc. nat. 7: 192, 196.- Mabille, 1912. Lep. Cat. 9, p. 10.- Ureta, 1941. Bol. Mus. Nac. Hist. Nat., Chile, 19: 41.

Jemadia ahira: Watson, 1893. Proc. zool. Soc. London, p. 14.- Mabille, 1903, in Wytsman. Gen. Ins. 17, p. 12.- Mabille \& Boullet, 1908. Amm. Sc. nat. 7, p. 192, 196.- Mabille, 1912. Lep. Cat. 9, p. 10.- Draudt, 1921, in Seitz. Macrolep. World 5, p. 845, pl. 163a.- Bell, 1933. Jour. N. Y. Ent. Soc. 41: 509

Jemadia polyzona jamina; Miles Moss, 1949. Acta zool. lill. 7: 36, planta hospedeira.- Silva et al., 1968. Quart. Cat. Ins. viv. Plant. Brasil 2 (1), p. 323, planta hospedeira.

Elbella polyzona ahira; Evans, 1951. Cat. Amer. Hesp. 1, p. 47.- Bridges, 1983. Lep. Hesp. 1, p. 3; 2, p. 12.- Bridges, 1988. Cat. Hesp. 1, p. 4; 2, p. 19.

Elbella polyzona jamina; Evans, 1951. Cat. Amer. Hesp. 1, p. 47, pl. 5 (genitália masculina), syn.: zimra.- Evans, 1955. Cat. Amer. Hesp. 4. Addenda, p. 1.- Ebert, 1968, in Silva et al. Quart. Cat. Ins. viv. Plant. Brasil 2 (2), p. 240.- Bridges, 1983. Lep. Hesp. 1, p. 59, 129: 2, p. 12: syn.: zimra.- Bridges, 1988. Cat. Hexp. 1, p. 93, 204; 2, p. 19; syn.: zimra.

(sem gênero) ahira; Beattie, 1976. Rhop. Direct., p. 70.

(sem gênero) jamina; Beattie, 1976. Rhop. Direct., p. 172.

(sem gênero) zimra; Beattie, 1976. Rhop. Direct., p. 291.

Diagnose e Descrição. Macho e fêmea (Figs 132-134) - Na asa anterior, as manchas brancas em M2-M3 e M3-CuA1 estreitas, paralelas e não se tocando; fêmea com os espaços entre as três faixas azuis da face ventral da asa posterior iguais.

Figs 133-136. (133) Parelbella ahira ahira, fêmea, Brasil, Amazonas, Manaus, IX-1927, faces dorsal e ventral; (134) Parelbella ahira ahira, fềmea (aberrante), Brasil, Pará, lectótipo, faces dorsal (Fig. de Draudt, in Seitz); (135) Parelbella ahira extrema, macho, Brasil, São Paulo, Teodoro Sampaio (Parque Estadual do Morro do Diabo), 22-25-X-1987, neótipo, faces dorsal e ventral; (136) Parelbella ahira extrema, fềmea, Brasil, Paraná, Rolândia, I-1970, faces dorsal e ventral. 

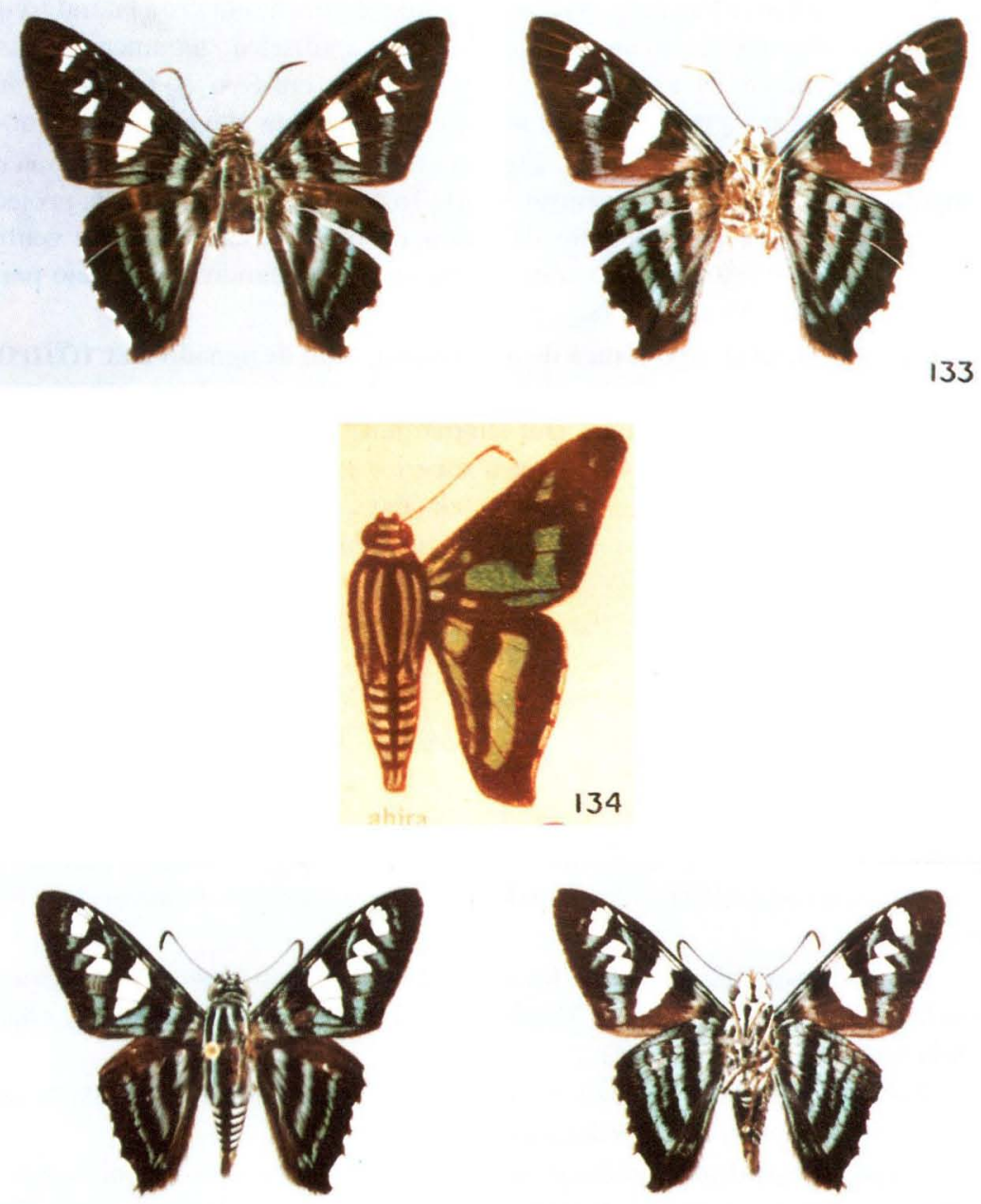

135
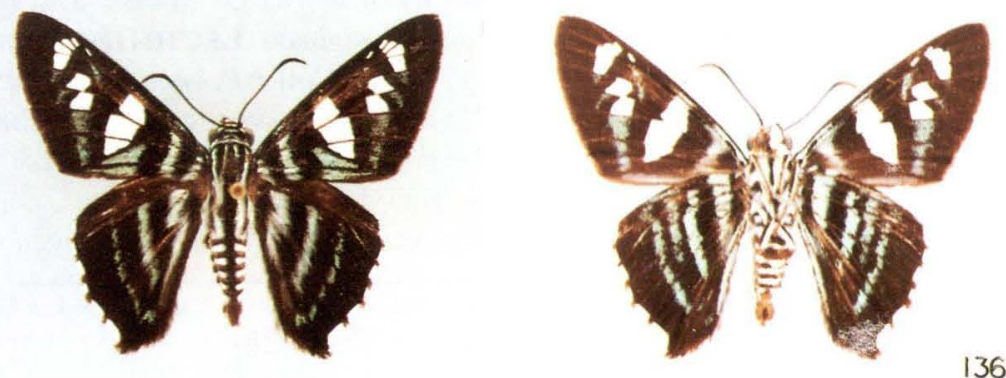
Genitália masculina (Fig. 33). Apófises do tegumen, em vista lateral, iguais à metade do comprimento do unco; lado dorsal das apófises do tegumen com linha crenulada longitudinal e as apótises mais afastadas entre si do que em ahira extrema; harpe com a projeção distal maior e mais estreita que a projeção dorsal.

Genitália feminina (Fig. 33). Em vista lateral, parte basal do esterigma não em ângulo reto com a projeção ventral e parte hasal da mesma largura da projeção ventral e esta do mesmo tamanho da altura da parte hasal; em vista ventral, esterigma largo e profundamente côncavo na base, estreitando-se no meio para a projeção ventral levemente curva.

Discussão. O síntipo fêmea de ahira ahira, aqui designado LeCtótiPo, é um aberrante. onde desapareceram todas as manchas hrancas da asa anterior e na face dorsal as manchas da faixa azul submarginal entre CuAl e $2 \mathrm{~A}$ unidas às manchas azuis longitudinas, sendo que a superior extendida até a faixa subbasal: nas faces dorsal e ventral da asa posterior, as faixas azuis mediana e discal unidas numa larga faixa única. Os nomes jamina e zimra são sinônimos de ahira ahira.

Distribuição espacial (Fig. 50). Colômbĩa - Vaupes: San José del Guaviare. - PERU - Madre de Dios: Parque Nacional de Manu. Hucinuco: Tingo Maria 670m; Junin: La Merced: Perené; Rio Colorado. Loreto: San Martin. - Bolívia - Santa Cruz: Buenavista. - Guiana Francesa - Montagne de Kaw. - Brasil Amazonas: São Paulo de Olivença; Tefé; Manaus. Pará: Óbidos; Santarém. Mato Grosiso: Diamantino 300-400m.

Distribuição temporal. Voa em fevereiro, abril e setembro.

Etologia. É um hahitante de florestas, sendo que os machos pousam em areias úmidas na beira de rios, principalmente em excrementos de aves e provavelmente urina.

Planta hospedeira. MILES Moss (1949) cita como planta hospedeira das larvas Eugenia sp. (Myrtaceae) e Virola sehifera Aublet. (Myristicaceae). citação repetida por SILVA et al. (1968).

Etimologia. ahira - nome bíblico, fillho de Eman, chefe da tribo de Neftali; jamina - desconhecida; zimra - desconhecida.

Material estudado. O síntipo fêmea nec macho) de ahira, aqui designado Lectótipo, com as seguintes etiquetas: / Type/ Para/ Pará. Hewitson Coll. 79-69 Pyrrhopyga (sic) ahira. I./ LECTOTIPO/ Pyrrhopyga ahira Hewitson, 1866, Lectótipo, O. Mielke det. 1993/ Parelhella ahira ahira, O. Mielke det. 1993/ (BMNH).- O síntipo têmea de jamina, aqui designado LECTótrPo, com as seguintes etiquetas: / Type/ Druce Coll. ex. Kaden Coll./ P. jarnina Butl. type/ Godman \& Salvin Coll. 1912.-23./ LECTOTIPO/ Pyrrhopyga jamina Butler, 1870, Lectótipo, O. Mielke det. 1993/ Parelhella ahira ahira, O. Mielke det. 1993/ (BMNH).- O síntipo fêmea de zimra, aqui designado LECTótiPo, com as seguintes etiquetas: /Type/ Type. H. T./ Hewitson Coll. 79-69 Pyrrhopyga (sic)

Figs 137-140. (137) Parelhella macleamnani. macho, Panamá, Zona do Canal. Madden Forest. 28-VIII-1968, faces dorsal e ventral: (138) Parelbella macleannani, fêmea, Ecuador. Inhahura, Paramba. II-1897. faces dorsal e ventral: (139) Parellella perwana, macho, Peru, Junin. Chanchamayo. holótipo, faces dorsal e ventral: (140) Parelhella peruana. fêmea. Peru; alótipo, faces dorsal e ventral 

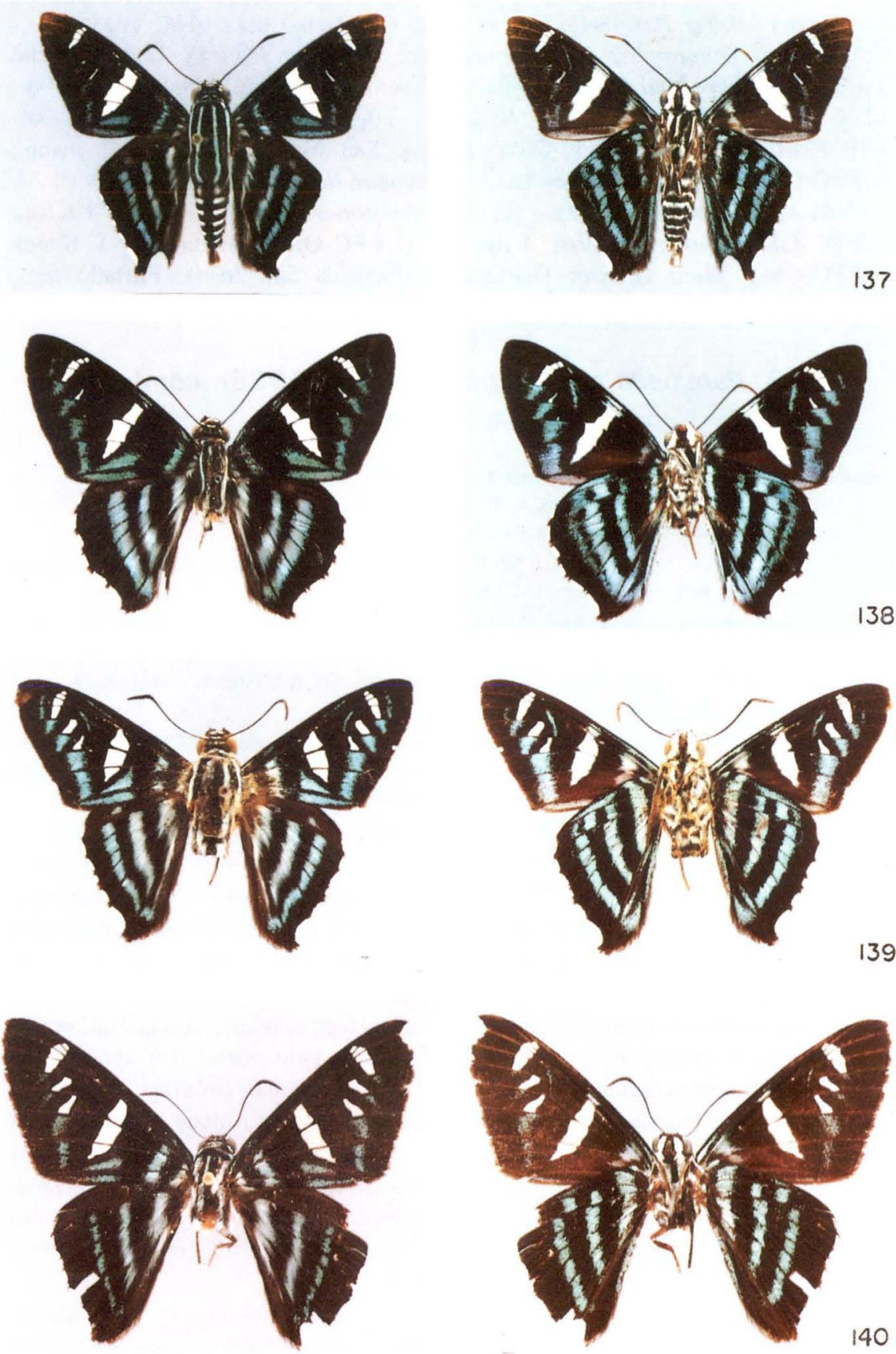
jamina. 1./ LECTOTIPO/ Pyrhopyga zimra Hewitson, 1871, Lectótipo, O. Mielke det. 1993/ Parelbella ahira ahira, O. Mielke det. 1993/ (BMNH). Colômbia - Vaupes: San José del Guaviare, Le Crom leg., IV-1992 I macho (LECR). - PERU - Madre de Dios: Parque Nacional de Manu, Lamas leg., 340m, 14-X-1991 1 macho (MHNL). Huínuco: Tingo Maria, Büche leg., 670m, 4-III-1993 I macho (UFPC-OM). Loreto: San Martin, IX-1987 I macho (UFPC-OM). - Guiana Francesa - Montagne de Kaw: piste de Kaw pk20, 30-VIII-1986 1 fêmea (BREV). - BRAsIL - Amazonas: Manaus, IX-1927 1 fêmea (UFPC-OM). Pará: Óbidos, 1 macho (UFPC-OM); Santarém, 1 fêmea (UFPC-OM). Mato Grosso: Diamantino (Fazenda São João), Furtado leg., 300-400m, 20-II-1978 1 macho (UFPC-OM).

\subsection{Parelbella ahira extrema (Röber, 1925), comb.n.}

Figs $34,50,135,136$

Jemadia zimra: Draudt, 1921, in Seitz. Macrolep. World 5. p. 844, pl. 163a.- Köhler \& Strassberger. 1928. Publ. Breyer. Buenos Aires, p. 4.- Hayward, 1932. Rev. Soc. ent. arg. 5 (1): 31. lám 2. fig. 12.- Hayward. 1934. Rev. Soc. ent. arg. 6 (2-4): 186.

Jemadia extrema Röber. 1925. Ent. Mitt. 14: 157: sem localidade: NEÓTIPO macho aqui designado

|Examinado|.- Bell. 1933. Jour. N. Y. Ent. Soc. 41: 499.

Jemadia jamina: Hayward, 1935. Rev. Soc. ent. arg. 7: 127: syn.: zimra.- Hayward. 1941. Rev.

Mus. La Plata, I. ser., Zool. 2: 234: syn.: zimra-- Hayward. 1942. Bol. Mus. Nac., Rio de

Janeiro, 14-17: 70; syn.: zimra.- Hayward, 1948. Gen. Sp. An. Arg. 1. p. 33, tab. 2. fig. 5 (genitália masculina): tab. 17, fig. 3: syn.: zimra.

Elhella polyzona extrema: Evans, 1951. Cat. Amer. Hesp. 1, p. 48.- Mielke, 1989. Revta bras. Zool. 6: 142.- Bridges, 1983. Lep. Ilesp. 1, p. 42: 2. p. 12.- K. Brown, 1987. An. primer. Simp.

Pantanal. Brasil. p. 166 .- Bridges. 1988. Cat. Hesp. 1. p. 66: 2. p. 19.

Eihella jamina: Hayward, 1973. Op. lill. 23: 14: syn.: zimra: planta hospedeira.

(sem gênero) extrema; Beattie, 1976. Rhop. Direct.. p. 144.

Diagnose e Descrição. Macho e fêmea (Fig̣s 135, 136) - Na asa anterior, as manchas brancas em M2-M3 e M3-CuAl grandes, aproximadamente quadradas e se tocam; fêmea, na face ventral da asa posterior com o espaço entre as faixas azuis hasal e mediana pouco menor que o espaço entre esta e a faixa azul discal.

Genitália masculina (Fig. 34). Apófises do tegumen, em vista lateral, pouco maiores que a metade do comprimento do unco; lado dorsal das apófises do tegumen com linha crenulada longitudinal e as apófises mais próximas entre si do que em ahira ahira; harpe com a projeção distal maior e mais espessa que a projeção dorsal.

Genitália feminina (Fig. 34). Em vista lateral, a parte basal do esterigma não em ângulo reto com a projeção ventral, esta do mesmo comprimento da altura da parte basal; em vista ventral, esterigma largo e suavemente côncavo na base, estreitando-se no meio para a projeção ventral.

Discussão. Embora haja algumas diferenças constantes nas genitálias masculina e feminina, estas não são suficientes para considerar as duas subespécies como espécies distintas. 

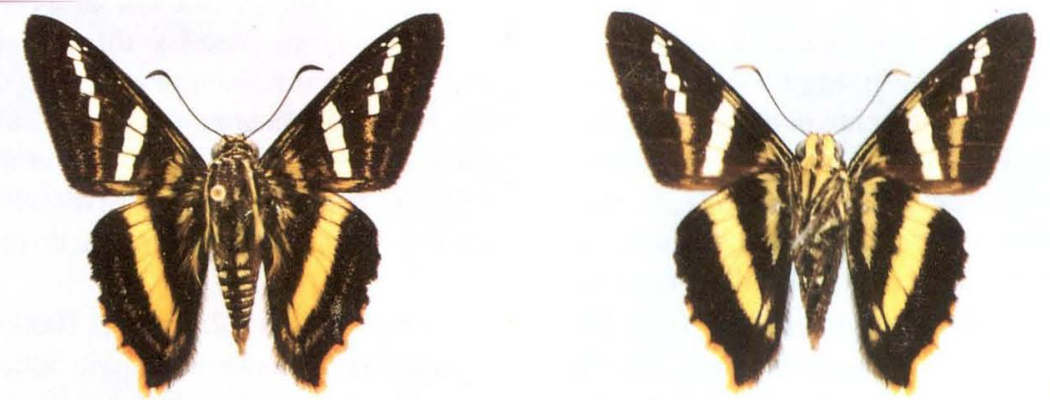

141
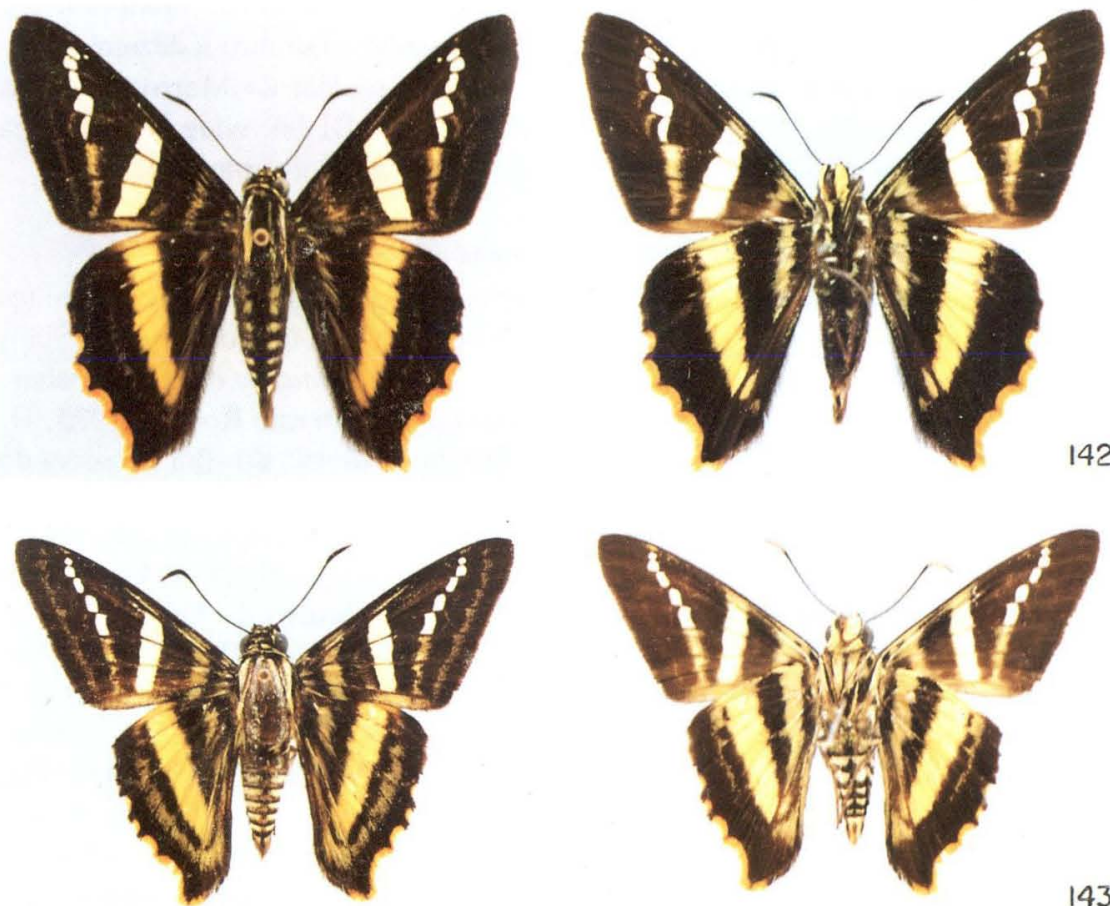

143

Figs 141-143. (141) Pseudocroniades machaon machaon, macho, Brasil, Paraná, Morretes (Alto da Serra), 25-II-1989, faces dorsal e ventral; (142) Pseudocroniades machaon machaon, fềmea, Brasil, Santa Catarina, São Bento do Sul (Rio Vermelho), faces dorsal e ventral; (143) Pseudocroniades machaon seabrai, macho, Brasil, Rio de Janeiro, Rio de Janeiro (Alto da Boa Vista), 20-II-1971, holótipo, faces dorsal e ventral. 
O tipo de ahira extrema está perdido (MIELKE 1989). A descrição original diverge em alguns aspectos, principalmente na envergadura das asas, dita de $58 \mathrm{~mm}$ na fêmea descrita e na presença de uma faixa submarginal na face dorsal da asa posterior que se inicia de modo muito larga na margem costal e diminuindo fortemente até o ângulo anal. Como a envergadura de um exemplar preparado inconvenientemente poderia alcançar os $58 \mathrm{~mm}$, fica a dúvida quanto à faixa da asa posterior. Até hoje não se encontrou nada que enquadre nesta descrição original e assim segue-se a interpretação de Evans (1951) para designar um NEÓTIPO macho, a fim de eliminar estas dúvidas. É mais importante salvar um nome do que deixar algo sem possibilidade de solução.

Distribuição espacial (Fig. 50). BRASIL - Distrito Federal: Brasilia 1000m. Minas Gerais: Paracatu 650m. São Paulo: Porto Cabral; Teodoro Sampaio 500m. Paraná: Rolândia; Guaíra 250m. - PARAguAI - Guairá: Colônia Independência; Villarica. Central: Nueva Itália; Itapé; Molinaspã. - ARgentina - Misiones.

Distribuição temporal. Voa de janeiro a junho e outubro a dezembro.

Etologia. Todos os exemplares do Parque Estadual do Morro do Diabo foram coletados entre 10 e $13 \mathrm{~h}$ no topo do morro do Diabo, onde brigavam na copa de árvores a uma altura de aproximadamente 6 a $8 \mathrm{~m}$ do solo.

Planta hospedeira. Desconhecida.

Etimologia. De extrema (latim) - a mais afastada.

Material estudado. O NEÓTIPO macho aqui designado, com as seguintes etiquetas: / NEOTIPO/ 22-25-X-1987 Morro do Diabo, Teodoro Sampaio, S[ão] P|aulo|. 300-500m, Mielke \& Casagrande leg./ 17.875/ Jemadia extrema Roeber, 1925, Neótipo, O. Mielke det. 1993/ Parelbella ahira extrema Roeber, 1925, O. Mielke det. 1993/ (UFPC-OM). - BRAsIL - Distrito Federal: Brasília (Reserva do Instituto Brasileiro de Geografia e Estatística), Ferreira leg., 1000m, 17-IV-1981 1 fêmea (UFPC-OM). Minas Gerais: Paracatu, Ebert leg., 650m, 15-XII-1968 1 macho (UFPC). Sào Paulo: Porto Cabral, L. Travassos leg., III-IV-1944 1 macho (UFPC-OM); Teodoro Sampaio (Parque Estadual do Morro do Diabo), 500m, Mielke \& Casagrande leg., 22-25-X-1987 14 machos (UFPC-OM). Paraná: Rolândia, Walz leg., I-1970 I fêmea (UFPC-OM); Guaira (Parque Nacional de 7 Quedas - destruído pela represa de Itaipu), Mielke \& Miers leg., 250m, 14-16-II-1978 1 fềmea (UFPC). - PARAGUAI - sem localidade, 1 macho (AMNH); 5 machos (ZSBS). Gucirá: Colônia Independência, XII-1944 1 fêmea (UFPC-OM); Villarica, Anders leg. IV-V-1964 1 macho (UFPC-OM). Central: Nueva Italia, P. Willim leg., 5-VI-1949 1 macho (AMNH); Itapé, Schade leg. . 1-II-1926 1 macho(ZMUC); Molinaspã, Schade leg., XII-1925 1 fêmea (ZMUC).

- Sem procedência: 1 macho (MNRJ).

Figs 144-147. (144) Protelbella alburna alhurna, macho, Peru, Huánuco, Tingo Maria (Rondos). 22-X-1971, faces dorsal e ventral: (145) Protelbella albuma albuma, fêmea, Ecuador, faces dorsal e ventral: (146) Proteleblla alburna brasiliensis, macho. Brasil. Rondonia, Pimenta Bueno. VIII-IX-1970, holótipo, faces dorsal e ventral; (147) Protelhella alburna hrasiliensis, fêmea. Brasil. Amazonas. Tefé. III-1925, alótipo, faces dorsal e ventral. 

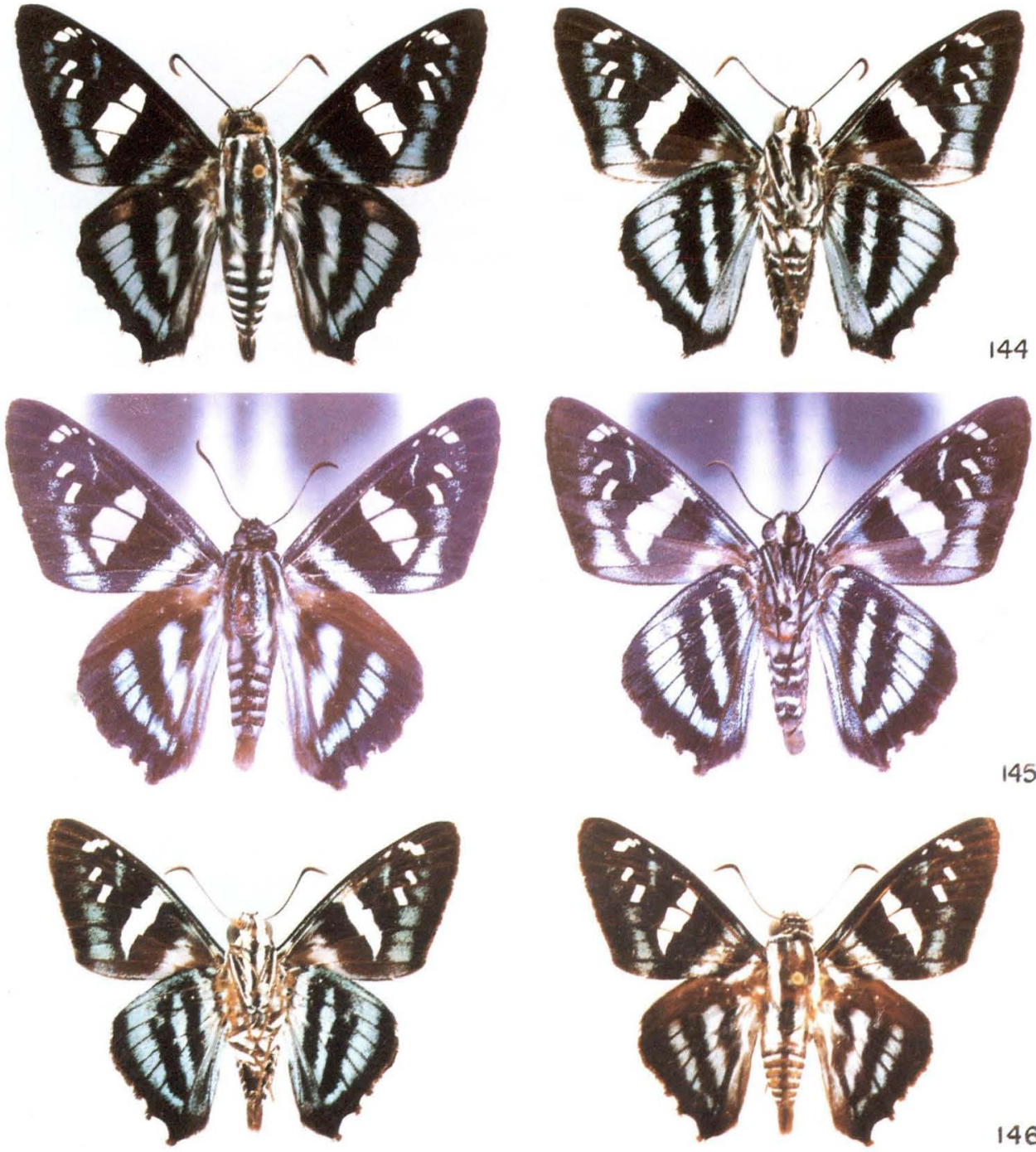

145
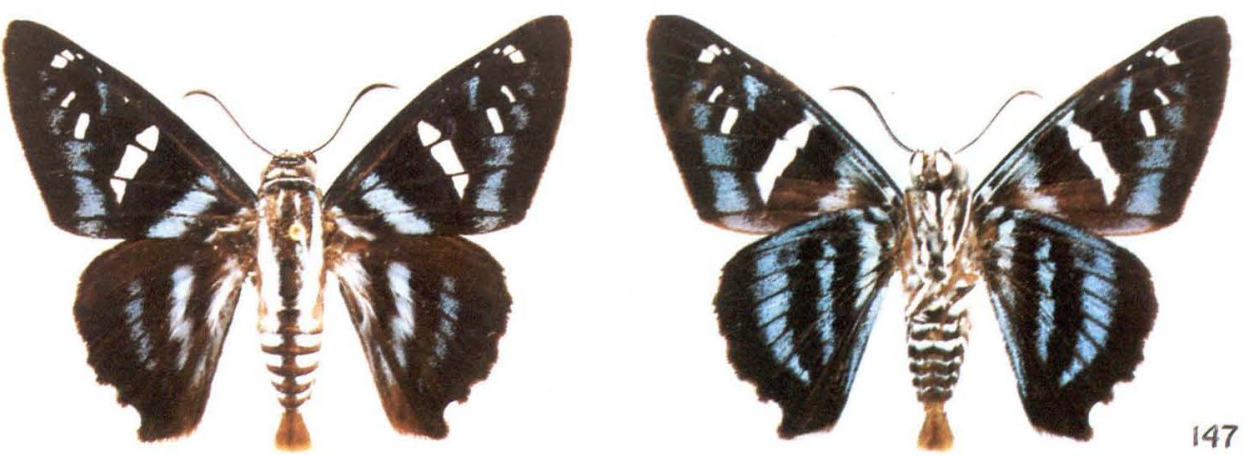


\section{Parelbella macleannani (Godman \& Salvin, 1893), comb.n., stat.rev.}

Figs $35,51,137,138$

Jemadia macleannani Godman \& Salvin, 1893. Biol. Centr.-Amer., Lep. Rhop. 2, p. 260, 262; 3, tah. 74. figs. 10, 11, 12 (genitália masculina); 2 machos, Panamá. Calobre (Arcé leg.) e Lion Hill (McLeannan): LectóTIPO macho aqui designado (BMNH) [Examinado].-- Mabille \& Boullet. 1908. Ann. Sc. nat. 7: 193, 196.- Mahille. 1912. Lep. Cat. 9, p. 10.- Draudt. 1921, in Seitz. Macrolep. World 5. p. 845, pl. 166b.- Bell. 1933. Jour. N. Y. Ent. Soc. 41: 499.- Bell. 1942. An. Esc. Nac. Cien. Biol., Mexico, 2: 456.- Hayward, 1947. Acta zool. lill. 4: 221.

Elhella polyzona macleananni (sic): Evans, 1951. Cat. Amer. Hesp. 1. p. 47. pl. 5 (genitália masculina)-- Bridges, 1983. Lep. Hesp. 1. p. 69; 2, p. 12.- Bridges, 1988. Cat. Hesp. 1, p. 110; 2. p. 20.- J. Maza. White \& R. Maza, 1991. Rev. Soc. Mex. Lep. 14: 9.

(sem gênero) macleannani: Beattie. 1976. Rhop Direct., p. 191.

Elhella macleananni (sic); Llorente-Bousquets; Luis-Martínez \& Vargas-Fernández. 1990. Publ. esp. Mus. Zool., Mexico, 1: 24.

Diagnose. Asa anterior com as manchas brancas em M2-M3 e M3-CuA1 ausentes ou quando presentes, muito estreitas, a sua largura não ultrapassa $1 / 5$ da sua altura.

Descrição. Macho (Figs 137) - Comprimento da asa anterior 23 a $26 \mathrm{~mm}$.

Face dorsal da asa anterior com a faixa branca mediana $2,1 \mathrm{~mm}$ de largura máxima; manchas brancas em M2-M3 e M3-CuA1 ausentes ou presentes, mas a sua largura nunca ultrapassa $1 / 5$ da sua altura; faixa branca apical de largura máxima na mancha em R5-M1, esta com a largura igual à metade da largura máxima da faixa mediana; manchas reduzidas na faixa azul submarginal, difusas entre M2, M3 ou CuA1 até 2A; manchas azuis longitudinais, abaixo da faixa mediana, curtas, atingindo o nível do limite proximal da mancha branca em $\mathrm{CuA} 1-\mathrm{CuA} 2$ e às vezes a superior expandida na hase até $\mathrm{CuA} 2$ e atingindo o nível do limite proximal da mancha da célula discal; margem costal, acima da faixa mediana, normalmente com escassas escamas azul-esbranquiçadas; franjas concolores.

Face dorsal da asa posterior com as três faixas azuis da mesma largura, mas deixando entre elas um espaço pouco maior que as suas larguras; centro do espaço 2A-3A com linha branca entre as faixas basal e discal; espaço Sc + R1-Rs com esparsas escamas azuis entre as faixas mediana e discal; franjas concolores, passando a brancas a partir de M3 até 2A ou só em CuA2-2A, com as terminações das veias negras.

Face ventral da asa anterior com os desenhos azuis também reduzidos; as discocelulares finamente azuis; as manchas da faixa azul submarginal como na face dorsal ou a mancha em $\mathrm{CuA} 2-2 \mathrm{~A}$ maior e, às vezes, azul-esbranquiçada; margem interna esbranquiçada; franjas como na face dorsal.

Face ventral da asa posterior com as três faixas azuis da mesma largura, deixando os espaços entre elas um pouco maiores que as suas larguras; a faixa basal até o ângulo umeral; faixas azuis adicionais basal ausente ou reduzida a um ponto abaixo de Rs e distal até $\mathrm{CuA} 1$ ou $\mathrm{CuA} 2$; margem costal azul na metade ou 
terço distal; espaço 2A-3A com duas manchas azuis abaixo das faixas mediana e distal, às vezes unidas distalmente em mancha larga; margem interna azul; franjas como na face dorsal.

Genitália (Fig. 35). Apófises do tegumen, em vista lateral, iguais à metade do comprimento do unco; lado dorsal das apófises do tegumen sem linha crenulada longitudinal; harpe com a projeção distal igual à projeção dorsal.

Fêmea (Fig. 138). Semelhante ao macho. Comprimento da asa anterior $26 \mathrm{~mm}$.

Face dorsal da asa anterior com a faixa branca mediana $2 \mathrm{~mm}$ de largura máxima; manchas brancas em M2-M3 muito estreita e em M3-CuA1 reduzida a algumas escamas sobre $\mathrm{CuAl}$; manchas da faixa azul submarginal pequenas entre R5 e M2 e bem marcadas entre M2 e 2A; margem costal, acima da faixa mediana branca, com escassas escamas azul-esbranquiçadas.

Face dorsal da asa posterior com a faixa azul discal o dobro da largura da faixa azul mediana, deixando um espaço entre estas igual a largura da última; franjas brancas entre $\mathrm{Sc}+\mathrm{Rs}-\mathrm{R} 1$ até $2 \mathrm{~A}$, com as terminações das veias negras.

Face ventral da asa anterior com os desenhos azuis mais largos que na face dorsal; discocelulares azuis; as manchas da faixa azul submarginal maiores.

Face ventral da asa posterior com a faixa azul discal o dobro da largura da faixa azul mediana e o espaço entre elas da largura da faixa azul discal; faixa azul adicional distal até $\mathrm{CuA2}$; margem costal azul na metade externa; espaço 2A-3A com duas manchas azuis abaixo das faixas mediana e discal.

Genitália (Fig. 35). Em vista lateral, parte basal do esterigma em ângulo reto com a projeção ventral, da mesma largura e esta maior que a altura da parte basal e não dilatada no meio; em vista ventral, esterigma largo e reto na base, estreitando-se abruptamente no terço basal para uma ponta distal simétrica

Discussão. Pelos aspectos cromáticos das asas e da genitália, não há dúvidas em tratar-se de uma espécie distinta, como já mencionado por LLORENTE; LUIS-MARTÍNEZ \& VARGAS FERNÁNDEZ (1990), sem justificativa.

Distribuição espacial (Fig. 51). MÉXICO - Oaxaca: San Miguel (Chimalapa); Rio Sarabia. Veracruz: Catemaco. - Guatemala - El Petén: Sayaxché. PAnamÁ - Zona do Canal: Gamboa; Madden Forest. Veraguas: Calobre. Chepo Herrera: Cerro Montoso. Chiriqui: Bugaba. - COlÔMBIA. - ECUAdor - Imbabura: Paramba.

Distribuição temporal. Voa de janeiro a março e julho a novembro.

Etologia. Desconhecida.

Planta hospedeira. Desconhecida.

Etimologia. Espécie dedicada à McLeannan, coletor de um dos síntipos.

Material estudado. Um síntipo macho aqui designado LeCTótiPo, com as seguintes etiquetas: / Type/ Sp. figured/ Calobre, Panama, Arcé/ B. C. A. Lep.Rhop. Jemadia macleannani, G. \& S./ Godman-Salvin Coll. 1912.-23/ LECTOTIPO/ Jemadia macleannani Godman \& Salvin, 1893, Lectótipo, O. Mielke det. 1993/ Parelbella macleannani, O. Mielke det. 1993/ (BMNH). MÉXICO - Ocxaca: San Miguel (Chimalapa), Escalante leg., VII-1952 2 machos, 
IX-1956 1 macho, IX-1965 1 fềmea (AME); Rio Sarabia, Escalante leg., VIII-1958 2 fêmeas (AME); Veracruz - Dos Amates, 15-IX-1972 1 fêmea. - Guatemala El Petén: Sayaxché, Welling leg., 19-IX-1963 1 macho (AMNH). - NiCARÁGUA - 1 macho (USNM). - PANAMÁ - Zona do Canal: Madden Forest, Small leg., 26-VIII-1968 1 macho (AME), VI-1967 2 machos, 10-VIII-1968 1 macho, 15-VIII-1968 1 macho, 26-VIII-1968 1 macho, 28-VIII-1968 1 macho (UFPC-OM), 24-III-1968 1 macho, 16-VII-1968 3 machos, 26-VIII-1968 1 macho, 30-VIII-1968 1 macho (USNM); Madden Forest, Nicolay leg., 6-II-1968 3 machos, 7-II-1968 1 macho, 2-I-1969 1 macho (USNM); Gamboa, Small leg., 18-X-1978 1 macho (USNM); Gamboa, Robbins leg., 16-IX-1978 3 machos, 21-XI-1978 1 macho, 3-I-1979 1 macho (UFPC-OM); Cerro Galera, Robbins leg., 19-V-1979 1 macho (UFPC-OM); Chiriqui: Bugaba, 1 macho (USNM); Panamá: Cerro Campana, Small leg., 800m, 10-IX-1967 1 macho (UFPC-OM). - ECUADOR - Imbabura: Paramba, Rosenberg leg., 1150m, II-1897 1 fêmea (BMNH).

\section{Parelbella peruana, sp.n.}

Figs $36,51,139,140$

Diagnose. Macho - Azul da face dorsal das asas normal, sem violáceo. Fêmea - Faixa azul discal da face dorsal da asa posterior mais estreita que as faixas azuis basal e mediana.

Descrição. Macho (Fig. 139) - Comprimento da asa anterior $26 \mathrm{~mm}$.

Face dorsal da asa anterior com a faixa branca mediana 1,6 a $2,3 \mathrm{~mm}$ de largura máxima; manchas brancas em M2-M3 e M3-CuA1 estreitas, com as larguras medianas menores que a metade de suas alturas, a em M3-CuA1 mais larga junto à $\mathrm{CuA} 1$, e afastadas entre si por uma distância maior que a largura mediana de cada uma delas; faixa branca apical de largura máxima na mancha em R5-M1, esta tão larga quanto a parte inferior da mancha em M3-CuA1; desenhos azuis não violáceos; discocelulares finamente azuis; manchas da faixa azul submarginal difusas ou bem marcadas entre M2 e $2 \mathrm{~A}$ e rudimentares entre R5 e M2; manchas azuis longitudinais, abaixo da faixa mediana, grandes, atingindo o nível do limite proximal da mancha da célula discal e a superior expandida ou não na base até $\mathrm{CuA} 2$; margem costal com escassa escamas difusas azuis acima das discocelulares e da faixa basal; franjas concolores.

Face dorsal da asa posterior com as três faixas azuis da mesma largura e as distâncias entre elas iguais ou maiores que as larguras das faixas; centro do espaço 2A-3A com linha branca entre as faixas basal e discal; espaço Sc+R1-Rs com escamas azuis acima das faixas mediana e discal; franjas brancas com as terminações das veias negras.

Face ventral da asa anterior com os desenhos azuis da mesma tonalidade da face dorsal; discocelulares azuis ou com escassas escamas azuis; manchas da faixa azul submarginal mais largas entre $\mathrm{CuA} 1$ e $2 \mathrm{~A}$ e sem manchas entre R5 e M1 ou M2; margem interna negra; franjas como na face dorsal.

Face ventral da asa posterior com as três faixas azuis aproximadamente da mesma largura, deixando espaços entre elas um pouco maiores que as suas 
larguras; a faixa azul basal até o ângulo umeral; faixas azuis adicional basal ausente ou difusa até Ml e discal ausente; margem costal azul acima das faixas mediana e discal; espaço 2A-3A com duas manchas azuis rudimentares ou bem desenvolvidas abaixo das faixas mediana e discal; a base do mesmo espaço, assim como a margem interna, azuis; franjas brancas entre $\mathrm{Sc}+\mathrm{R} 1-\mathrm{Rs}$ e $2 \mathrm{~A}$, com as terminações das veias negras.

Genitália (Fig. 36). Apófises do tegumen, em vista latera!, pouco maiores que um terço do comprimento do unco; lados dorsais das apófises do tegumen sem linha crenulada longitudinal; harpe com a projeção distal larga e menor que a projeção dorsal.

Fêmea (Fig. 140). Semelhante ao macho. Comprimento da asa anterior $31 \mathrm{~mm}$.

Face dorsal da asa anterior sem azul na margem anterior e discocelulares; manchas da faixa azul submarginal mais difusas entre M2 e 2A; manchas azuis longitudinais, abaixo da faixa mediana, menores, atingindo o nível do limite proximal da mancha branca em $\mathrm{CuA} 1-\mathrm{CuA} 2$.

Face dorsal da asa posterior com a faixa azul discal mais estreita que as faixas azuis basal e mediana e os espaços entre elas maiores que as suas larguras; centro do espaço 2A-3 A com linha branca entre as faixas basal e mediana; espaço $\mathrm{Sc}+\mathrm{R} 1-\mathrm{Rs}$ sem azul.

Face ventral da asa anterior com escassas escamas azuis nas discocelulares; faixa azul submarginal mais reduzida que na face dorsal.

Face ventral da asa posterior com a faixa azul adicional basal ausente; azul da margem costal restrito a escamas escassas no meio; espaço 2A-3 A sem manchas azuis abaixo das faixas mediana e discal.

Genitália (Fig. 36). Em vista lateral, parte basal do esterigma não em ângulo reto com a projeção ventral e aproximadamente duas vezes mais larga que a mesma projeção, esta mais curta que a altura da parte basal; em vista ventral, esterigma largo e côncavo na base, estreitando-se no meio em direção à projeção ventral levemente curva.

Discussão. Espécie caracterizada pelas genitálias masculina e feminina, assim como pelos caracteres cromáticos das asas.

Distribuição espacial (Fig. 51). PERU - Junin: Chanchamayo 1000m.

Distribuição temporal. Desconhecida.

Etologia. Desconhecida.

Planta hospedeira. Desconhecida.

Etimologia. Nome alusivo ao país onde ocorre a espécie.

Material estudado. Holótipo macho com as seguintes etiquetas: / HOLOTIPO/ Chanchamayo E. Peru $1000 \mathrm{~m} /$ gen.[itália] prep.[arada] Mielke 1993/ OM 33.182/ Parelbella peruana Mielke, Holótipo, O. Mielke det. 1993/ (UFPC-OM). Alótipo fêmea com as seguintes etiquetas: / ALOTIPO/ Peru/ Peru/ gen.[itália] prep.[arada] Mielke 1993/ 14.763/ Parelbella peruana Mielke, Alótipo, O. Mielke det. 1993/ (UFPC-OM). Parátipo: PERU, 1 macho, 14.762 (UFPC-OM). 


\section{Pseudocroniades, gen.n.}

Espécie tipo: Ericides (sic) machaon Westwood, [1852].

Diagnose. Antenas amarelas na parte ventral da clava; manchas em M2-M3 e M3-CuA1 fazendo parte da faixa apical; tíbia mesotorácica com algumas escamas externas finas, longas e sem sobrepassar a largura da tíbia, entre as achatadas e apressas; tergos abdominais amarelos na base, interrompidos na linha mediana dorsal escura; apófises do tegumen ausentes; valva terminando em processo transversal; unco de terminação delgada e bífida, como em Parelbella; edeago com o lóbulo distal lateral esquerdo e dirigido dorso-anetriormente; esterigma com processo ventral.

Descrição. Caracteres masculinos e femininos - Cabeça com a margem posterior, em vista dorsal, uniformemente côncava e apenascom pequena concavidade no início do quetosemata, como em Elbella scylla (Fig. 1); vértice e frontoclípeo com manchas e linhas amarelas; índice entre a largura do olho e a distância que o palpo labial se projeta para frente desta, em vista lateral, igual a 3,0 ; antenas amarelas na parte ventral da clava; na asa anterior, a faixa apical com 6 ou 5 manchas em linha entre R3 ou R4 e CuA1; na asa anterior, R4 e R5 livres (Fig. 8); garras tarsais bifidas, com o dente ventral rombudo e mais curto que a metade da ponta dorsal, como em Elbella (Fig. 4); tíbia protorácica mais longa que a metade do fêmur; tíbia metatorácica, com ao menos o esporão distal maior mais longo que a distância entre as inserções dos dois pares de esporões; tíbia metatorácica rebatida sobre o tarso atingindo no máximo a articulação entre o segundo e o terceiro tarsômeros; tergos abdominais com manchas amarelas separadas pela linha mediana dorsal; esternos abdominais negros, com ou sem pequenas manchas amarelas nos segmentos basais, ou com faixas amarelas transversais interrompidas ao longo da linha mediana ventral; tufo anal negro.

Caracteres masculinos. Índice entre a distância interorbital e a projeção do frontoclípeo além da tangente orbital 6,33; frontoclípeo, em vista dorsal, de contorno arqueado, como em Elbella (Fig. 1); índice entre a altura do olho, medida em vista dorsal, e a distância interantenal 1,5; índice entre os comprimentos da haste e da clava antenais 3,94; índice entre o comprimento e a largura máxima da clava antenal 4,82; índice entre os comprimentos da margem costal da asa anterior, medida da base até o ápice em R4, e a haste antenal 2,49; na asa anterior, o comprimento da célula discal excedendo o comprimento de $2 \mathrm{~A}$ por uma distância menor que o comprimento das discocelulares mediana e inferior; na asa anterior, $\mathrm{m}$-cu distal à perpendicular imaginária à $2 \mathrm{~A}$ que passa pelo início de $\mathrm{R} 1$; índice entre o comprimento de uma reta da base da célula discal até o meio entre M1 e M3 na margem externa da asa posterior, e o comprimento da base da mesma célula até o ponto de inserção com a discocelular 2,25; asa posterior com a discocelular superior maior que a metade das discocelulares mediana e inferior, mas não sobrepassando-as; asa posterior com o ângulo formado pelas discocelulares e M3 $121^{\circ}$; asa posterior com a área anal muito longa, isto é, $2 \mathrm{~A}$ sobreposta por um compasso centrado na célula basal ultrapassa Rs por uma distância maior que duas vezes as discocelulares mediana e inferior; tíbia mesotorácica com algumas 
escamas externas finas, longas e sem sobrepassar a largura da tíbia, entre as achatadas e apressas; tibia metatorácica com as escamas externas delgadas e divergentes, sohrepassando a largura da tíbia: apófises do tegumen ausentes; unco de terminação delgada e bífida; gnato de duas peças muito fracamente esclerosadas, como se fossem prolongamentos das apófises do unco; extremidade distal do edeago com um lóbulo alongado, lateral esquerdo e dirigido dorso-anteriormente, aparentemente sustentando a vesica; parte dorso-basal da valva (costa) sem projeção; valva terminando em processo transversal, um pouco inviezado.

Caracteres femininos. Índice entre os comprimentos da haste e da clava antenais 3,24; índice entre os comprimentos das margens costal da asa anterior, medida da base até o ápice em R4 3,02; oitavo tergo presente e inteiro, embora estreito na linha mediana dorsal e unido às partes laterais do oitavo esterno, estas não contíguas e não ligadas por membrana ao esterigma; esterigma tubular e com processo ventral; corpo da bolsa distinto e em linha reta com o seu duto.

Etimologia. Nome indicando que a espécie incluída é uma falsa espécies de Croniades Mahille, 1903.

Espécie incluída:

1 - Pseudocroniades machaon (Westwood, [1852]), comb.n.

\section{Pseudocroniades machaon (Westwood, [1852]), comb.n.}

Figs $8,37,52,141-143$

Diagnose. Face dorsal da asa anterior com faixas amarelo claras, retas e semihialinas, uma mediana entre a célula e $2 \mathrm{~A}$ e outra apical entre R4 e CuAl: face dorsal da asa posterior com faixa mediana amarela e reta entre a margem costal e pouco além de $2 \mathrm{~A}$, antes do ângulo anal de franjas alaranjadas.

Descrição. Macho - Comprimento da asa anterior 23 a $27 \mathrm{~mm}$. Coloração geral negra. Desenhos da cabeça, tórax e pernas como nas espécies azuis de Elbella, no entanto os desenhos brancos e branco azulados são amarelos claros, manchas nos tergos abdominais menores e o amarelo das pernas reduzido e ausente nas pernas metatorácicas.

Face dorsal da asa anterior com duas faixas amarelas claras, semihialinas e retas, uma mediana entre a célula e $2 \mathrm{~A}$, de largura normalmente uniforme, sendo a mancha em CuA1-CuA2 aproximadamente quadrada, e a outra apical e paralela à margem externa, mais estreita que a faixa mediana e entre $\mathrm{R} 4 \mathrm{e} \mathrm{CuA1}$; mancha diminuta semelhante em R3-R4, sempre presente e, às vezes, outra mancha diminuta em R2-R3, ambas deslocadas para a base em relação à faixa apical; com escassas escamas difusas amarelas formando faixas basal e sub-basal entre a costa e a margem interna; uma mancha amarela alongada na margem interna, abaixo da faixa mediana; manchas amarelas alongadas, como se fossem prolongamento da faixa apical, entre $\mathrm{CuAl}$ e $2 \mathrm{~A}$; uma linha submarginal algo acinzentada, paralela à margem e difusa entre $\mathrm{R} 4$ e $2 \mathrm{~A}$; um traço amarelado, fino e difuso em Sc-RI, acima da faixa mediana; franjas concolores.

Face dorsal da asa posterior com uma faixa amarela, mediana, reta, pouco 
mais larga que a faixa mediana da asa anterior, normalmente cortada por $\mathrm{Sc}+\mathrm{RI}$ e Rs negras, entre a margem costal e pouco além de $2 \mathrm{~A}$, nas proximidades do ângulo anal; com faixa amarelo clara, basal e difusa entre a célula discal e $2 \mathrm{~A}$; franjas concolores e entre Ml e o meio de 2A-3A alaranjadas, com as terminações da veias raras vezes negras.

Face ventral da asa anterior com as mesmas faixas semihialinas e manchas amarelas na base e abaixo da faixa apical; margem interna com escassas escamas difusas amarelas de densidade muito variada, assim como acima da faixa mediana na margem costal; linha submarginal ausente; franjas como na face dorsal.

Face ventral da asa posterior com as faixas amarelas basal nítida, mais estreita que a mediana, entre a margem costal e $2 \mathrm{~A}$ e a mediana como na face dorsal até $2 \mathrm{~A} ; 2 \mathrm{~A}-3 \mathrm{~A}$ com duas manchas amarelas pequenas e difusas abaixo da faixa mediana, a mais próximal geralmente pouco maior; franjas como na face dorsal.

Genitália (Fig. 37). Unco estreito e com duas pequenas pontas; harpe com processo transversal terminal e pouco inviezado; sáculo com um espinho na base; edeago com lóbulo distal, lateral esquerdo, dirigido dorso-proximalmente e mais largo na base que a metade da abertura do edeago.

Fêmea. Semelhante ao macho. Comprimento da asa anterior 26 a $31 \mathrm{~mm}$.

Genitália (Fig. 37). Esterigma caracterizado pelo processo ventral.

Discussão. Espécie bem caracterizada pelos aspectos cromáticos, assim como pelas genitálias masculina e feminina.

\section{Chave para as subespécies}

1. Esternos abdominais inteiramente negros ou com pequenas manchas amarelas nos segmentos basais . . . . . . . . . . . . machaon

2. Todos os esternos abdominais com manchas amarelas, interrompidas ao longo da linha mediana ventral . . . . . . . . . . . . . . . seabrai

\subsection{Pseudocroniades machaon machaon (Westwood, [1852])}

Figs $8,37,52,141,142$

Ericides (sic) machaon Westwood, [4-III-1852], in Doubleday, Westwood \& Hewitson. Gen. Diurn. Lep. 2, pl. 78, fig. 2; Lectótipo macho aqui designado (BMNH) [Examinado].- Hemming, 1941.

Jour. Soc. Bibl. Nat. Hist. 1: 365, 400.- Hemming, 1941. Jour. Soc. Bibl. Nat. Hist. 1: 457.

Pyrrhopyga (sic) machaon; Westwood, [12-VIII-1852]; in Doubleday, Westwood \& Hewitson. Gen.

Diurn. Lep. 2, p. 509; Brazil; BMNH.- Butler, 1870. Ent. monthly Mag. 7: 58.- Kirby, 1879.

Cat. Coll. Diurn. Lep. Hew., p. 207.- Plötz, 1879. Stett. ent. Ztg. 40:525.

Myscelus machaon; Herrich-Schäffer, 1869. Corr.-Blatt zool.-min. Ver. Regensburg 23: 166.

Pyrrhopyge machaon; Kirby, 1871. Syn. Cat. diurn. Lep., p. 586.- Hoffmann, 1934. Ent. Rdsch., 51: 26 .

Mimoniades machaon; Watson, 1893. Proc. zool. Soc. London, p. 14.

Erycides machaon; Mabilde, 1896. Guia Prat., p. 124.- Zikán, 1922. Dtsch. Ver. Wiss. Kunst, S.

Paulo, p. 188.- Zikán, 1927. Dtsch. ent. Ztschr., p. 61.

Croniades machaon; Mabille, 1903, in Wytsman. Gen. Ins. 17, p. 13.- Mabille \& Boullet, 1908. Ann. 
Sc. nat. 7: 204.- Mahille. 1912. Lep. Cat. 9, p. 13.- Draudt, 1921, in Seitz. Macrolep. Word 5. p. 847, pl. 164h.- Bell, 1934. Jour. N. Y. Ent. Soc. 42: 412, pl. 23, fig. 13 (genitália masculina)-- Hayward, 1935. Rev. Soc. ent. arg. 7: 128.- Hayward, 1941. Rev. Mus. La Plata, (n.s.) Zool. 2: 235.- Hayward. 1948. Gen. Sp. An. Arg. 1. p. 45, tab. 2, fig. 13 (genitália masculina); tab. 14, fig. 14.- Evans, 1951. Catt. Amer. Hesp. 1, p. 71. pl. 8 (genitália maseulina).Biezanko \& Ruffinelli, 1962. Rev. Fac. Agmon., Montevideo, 50: 150.- Biezanko, 1963. Arq. Ent.. sér. A. Pèlotas, p. 5.- Ehert, 1969. Jour. Lep. Soc. 23, Suppl. 3: 39.- Biezanko \& Mielke, 1973. Acta biol. paran. 2: 56.- Hayward, 1973. Op. lill. 23: 17; planta hospedeira.

Diagnose e Descrição. Macho e fềmea (Figs 141, 142) - Face dorsal da asa posterior com linha submarginal amarelo-acinzentada estreita entre M 1 e pouco além de 2A, às vezes, ausente; face ventral da asa posterior com a margem interna, o espaço 2A-3A, com exceção das duas manchas abaixo da faixa mediana, e a parte externa à faixa mediana negros; esternos abdominais inteiramente negros ou com pequenas manchas (4 ou 6) amarelos nos segmentos hasais.

Discussão. As subespécies se diferenciam por aspectos cromáticos dasasas e dos esteronos abdominais e pela distribuição geográfica alopátrica.

Distribuição espacial (Fig. 52). Brasil - Minas Gerais: Poços de Caldas 1400-1600m; Passa Quatro 1500m. São Paulo: São Paulo 850m; Salesópolis $850 \mathrm{~m}$. Paraná: Castro $1000 \mathrm{~m}$; Morretes $800 \mathrm{~m}$; Curitiba $900 \mathrm{~m}$; São José dos Pinhais $850 \mathrm{~m}$; Ponta Grossa 1000m; Guarapuava 1000m. Santa Catarina: São Bento do Sul 850m; Joinvile 0-200m; Curitibanos 950m Dalbergia (ex Nova Bremen) 600m; Corupá 600m; Massaranduba 300m; Monte Castelo $800 \mathrm{~m}$. Rio Grande do Sul: Vacaria 950m; Pelotas 10m. - ARgentinA - Misiones.

Distribuição temporal. Voa nos meses de janeiro a abril.

Etologia. É um habitante de florestas, visitando as flores de várias Asteraceae (Eupatorium, Vernonia) nos campos.

Planta hospedeira. Annonaceae (HAYWARD 1973).

Etimologia. Médico grego, filho de Asclépios.

Material estudado. Um síntipo macho aqui designado LECTótiPo, com as segintes etiquetas: /Type/ Type H. T./ Brazil/ Brazil Stevens. 51.-III./ LECTOTIPO/ Ericides machaon Westwood, 1852, Lectótipo, O. Mielke det. 1993/ Pseudocroniades machaon machaon, O. Mielke det. 1993/ (BMNH). Brasil - Minas Gerais: Passa Quatro (Fazenda dos Campos), Zikán leg., 1500m, 1 macho (MNRJ), 28-III-1916 1 fêmea, 27-II-1920 1 macho (IOC); Poços de Caldas (Morro do Ferro), Mielke leg., 1600m, 31-III-1965 1 macho (UFPC-OM); Poços de Caldas (Retiro Branco), Mielke leg., 1400m, 2-IV-1965 1 macho, 2 fêmeas (UFPC-OM). Săo Paulo: São Paulo, 1 macho (MNRJ); Salesópolis (Estação Biológica de Boracéia), J. Oliveira leg., 850m, 7-IV-1968 1 fêmea (MZSP). Paraná: Castro, 1000m, 14-III-1910 1 macho, 25-III-1910 1 fêmea (AME), VII-1987 1 macho 3 fêmeas (USNM); Morretes (Alto da Serra), Mielke leg., 800m, 25-II-1989 3 machos 2 fềmeas (UFPC-OM); Curitiba (Cascatinha), Mielke leg., 900m, 25-I-1966 2 machos, 2-II-1966 1 macho, 4-II-1966 1 macho (UFPC-OM), 29-I-1967 1 macho, 14-II-1967 3 machos, 9-III-1967 7 machos 3 fêmeas, 29-III-1967 1 macho, 1-IV-1967 1 macho, 26-I-1968 1 macho 1 fêmea, 13-II-1968 1 fêmea, 2-III-1968 3 machos, 24-II-1971 2 machos, 14-II-1980 1 
macho (UFPC); São José dos Pinhais, Mielke leg., 850m, 27-II-1986 1 macho, 19-III-1988 1 fềmea, 30-I-1989 2 machos, 20-II-1994 1 fêmea (UFPC-OM); Ponta Grossa, Justus leg., 1000m, II-1942 1 fêmea, III-1942 1 macho 3 fềmeas (UFPC); Guarapuava, Mielke \& Schneider leg., 1000m, 30-III-1971 1 fêmea (UFPC); Guarapuava (Candoi), Moure \& Mielke leg., 1000m, 29-III-1972 1 macho (DZPC); Chopinzinho, Furtado leg., 22-II-1970 (UFPC-OM). Santa Catarina: 1 fềmea (UFPC); São Bento do Sul (Rio Natal), O.\& C. Mielke leg., 500m, 7-III-1987 1 macho (UFPC-OM); São Bento do Sul (Rio Natal), Rank leg., 500m, 1-III-1982 1 fềmea, 10-III-1984 1 macho (UFPC-OM); São Bento do Sul (Rio Vermelho), Rank leg., 850m, 24-I-1971 1 fêmea, 28-III-1971 1 fềmea, 3-III-1973 1 macho, 4-III-1973 1 fêmea (UFPC), 11-III-1973 2 machos 3 fêmeas (UFPC-OM), 13-III-1973 1 fêmea (UFPC), 18-III-1973 1 macho (UFPC-OM), 23-II-1974 1 macho (UFPC-OM), 25-III-1974 3 fềmeas (UFPC) 1 fêmea (UFPC-OM), 15-III-1981 1 fềmea (UFPC-OM), 10-II-1987 1 fềmea (UFPC-OM), 25-II-1988 1 fêmea (UFPC-OM); Joinvile, Miers leg., 0-200m, 10-III-1967 1 macho (UFPC), 8-III-1991 1 macho (UFPC-OM); Joinvile, Mielke \& Miers leg., 0-200m, 2-III-1984 1 fêmea (UFPC-OM); Curitibanos, H. \& H. D. Ebert leg., 800m, 24-II-1973 4 machos 2 fềmeas (UFPC); Monte Castelo, Ebert leg., 800m, 24-II-1973 1 macho (UFPC), Taió, IV-1938 2 machos 1 fềmea (MZSP). Rio Grande do Sul: Garbe leg., 1 fềmea (MZSP); Vacaria (Bela Vista ), Mielke leg., 950m, 27-II-1973 1 macho (UFPC). Sem procedência, 1 macho (MNRJ).

\subsection{Pseudocroniades machaon seabrai, ssp.n}

Figs 52, 143

Diagnose e Descrição. Macho (Figs 143) - Comprimento da asa anterior $26 \mathrm{~mm}$. Face dorsal da asa posterior com linha submarginal amarelo acinzentada da metade da largura da faixa mediana entre Rs e o ângulo anal, onde contorna a faixa mediana; face ventral da asa posterior com a margem interna amarela e o espaço 2A-3A com escassas escamas amarelas e externamente à faixa mediana com outra faixa amarela difusa, mais larga em SC+R1-Rs e dai estreita até CuA1; todos os esternos abdominais com manchas amarelas, interrompidas ao longo da linha mediana ventral.

Fêmea. Desconhecida.

Discussão. Subespécie caracterizada por aspectos cromáticos das asas, dos esternos abdominais e pela dsitribuição geográfica alopátrica.

Distribuição espacial (Fig. 52). BRASIL - Rio de Janeiro: Rio de Janeiro.

Distribuição temporal. Voa em fevereiro.

Etologia. Desconhecida.

Planta hospedeira. Desconhecida.

Etimologia. O nome é em homenagem ao Dr. Carlos Alberto Campos Seabra, grande incentivador da entomologia do Brasil e em cuja casa de veraneio foi coletado o holótipo.

Material estudado. Holótipo macho com as seguintes etiquetas: 
/HOLOTIPO/ 20-II-1971 Alto da Boa Vista, Rio [de Janeiro] [Estado do Rio de Janeiro, Brasil], Pe. Moure leg./ DZ $2037 /$ Pseudocroniades machaon seabrai Mielke, Holótipo, O. Mielke det. 1993/ (UFPC). Parátipo: Rio de Janeiro, 1 macho (UFPC-OM). Parátipo: BRASIL - Rio de Janeiro: Rio de Janeiro (UFPC-OM). Sem procedência, 1 macho (MNRJ).

\section{Protelbella, gen.n.}

Espécie tipo: Pyrrhopyga (sic) albuma Mabille, 1891.

Diagnose. Antenas negras; frontoclípeo, em vista dorsal, de contôrno em ângulo nítido (Fig. 2); face dorsal da asa anterior sem mancha branca apical em M1-M2, se presente então diminuta, compondo a faixa branca apical de três manchas; as manchas brancas em M2-M3 e M3-CuA1 separadas e entre as faixas mediana e apical; unco de terminação larga, bífida; tíbia protorácica mais curta qua a metade do fềmur; tergos abdominais branco-azulados na base, interrompidos na linha mediana dorsal; apófises do tegumen longas e látero-ventrais ao unco; edeago com o lóbulo distal lateral esquerdo e dirigido dorso-posteriormente, aparentemente sustentando a vesica.

Descrição. Caracteres masculinos e femininos - Cabeça com a margem posterior, em vista dorsal, reta e com concavidade acentuadaatrás do quetosemata (Fig. 2); vértice e frontoclípeo com manchas e linhas transversais brancas a levemente azuladas; índice entre a largura do olho e a distância que o palpo se projeta para frente deste, em vista lateral, igual a 2,0; antenas negras; na asa anterior, a faixa apical com duas a três manchas brancas e semihialinas entre R3 ou R4 e M1, M1-M2 normalmente sem mancha, mas se presente então diminuta, as manchas em M2-M3 e M3-CuA1 separadas e entre as faixas brancas mediana e apical; na asa anterior R4 e R5 livres (Fig. 9); garras tarsais hífidas, com o dente ventral rombudo e mais curto que a metade da ponta dorsal, como em Elhella (Fig. 4); tíbia protorácica mais curta que a metade do fêmur; tíbia metatorácica, com ao menos o esporão distal maior mais longo que a distância entre as inserções dos dois pares de esporões; tíbia metatorácica rebatida sobre o tarso atingindo no máximo a articulação entre o segundo e terceiro tarsômeros; tergos abdominais com manchas branco-azuladas separadas pela linha mediana dorsal; esternos abdominais com faixas transversais brancas não separadas pela linha mediana ventral; tufo anal negro.

Caracteres masculinos. Índice entre a distância interorbital e a projeção do frontoclípeo além da tangente orbital 5,55; frontoclípeo em vista dorsal, de contôrno em ângulo nítido (Fig. 2); índice entre a altura do olho, medida em vista dorsal, e a distância interantenal 1,3; índice entre os comprimentos da haste e da clava antenais 3,22; índice entre o comprimento e a largura máxima da clava antenal 5,58; índice entre os comprimentos da margem costal da asa anterior, medida da base até o ápice em R4, e a haste antenal 2,83; asa anterior com o comprimento da célula discal excedendo o comprimento da veia $2 \mathrm{~A}$ por uma distância menor que o das discocelulares mediana e inferior; na asa anterior com m-cu distal à perpendicular imaginária à $2 \mathrm{~A}$ que passa pelo início de $\mathrm{R} 1$; índice 
entre o comprimento de uma reta da base da célula discal até o meio entre M1 e M3, na margem externa da asa posterior, e o comprimento da base da mesma célula até o ponto de inserção com a discocelular 2,61 ; asa posterior com a discocelular superior menor que a metade das discocelulares mediana e inferior; asa posterior com o ângulo formado pelas discocelulares e M3 $125^{\circ}$; asa posterior com a área anal longa, isto é, $2 \mathrm{~A}$ sobreposta por um compasso centrado na célula basal ultrapassa Rs por uma distância entre uma a duas vezes as discocelulares mediana e inferior; tíbia mesotorácica com as escamas externas curtas, achatadas e apressas; tíbia metatorácica com as escamas externas delgadas e divergentes sobrepassando a largura da tíbia; apófises do tegumen presentes e latero-ventrais ao unco, longas, quase alcançando a ponta deste; apófises do tegumen ásperas; unco de terminação larga e bífída; gnato de duas peças, fracamente esclerosadas, como se fossem prolongamentos das apófises ventrais do unco; extremidade distal do edeago com um lóbulo alongado lateral esquerdo e dirigido dorso-posteriormente, aparentemente sustentando a vesica; parte dorso-basal da valva (costa) sem projeção; valva não terminando em processo transversal. Caracteres fémininos Índice entre os comprimentos da haste e da clava antenais 2,14; índice entre os comprimentos das margens costal da asa anterior, medida da base até o ápice em R4 e da haste antenal 3,33; oitavo tergo aparentemente ausente; esterigma fundido ao oitavo esterno; partes laterais do oitavo esterno separadas acima do esterigma; esterigma tubular e sem lóbulo ou lóbulos dorsais, aparentemente fechando o óstio ou processos laterais do oitavo esterno; corpo da bolsa copuladora bem distinto e curvado em relação ao seu duto.

Os desenhos azuis são semelhantes aos das espécies azuis de Elbella, no entanto faltam as manchas longitudinais azuis, abaixo da faixa branca mediana, na face dorsal da asa anterior.

Etimologia. Nome sugerindo, ser a espécie incluída, uma Elbella primitiva.

Espécie incluída:

1 - Protelbella alburna (Mabille, 1891), comb.n.

\section{Protelbella alburna (Mabille, 1891), comb.n.}

Figs 2, 9, 38, 52, 144-147

Diagnose. Espécie facilmente reconhecível pela semelhança com as espécies azuis de Elbella e Parelbella, das quais se destingue por só possuir, na asa anterior, duas manchas apicais maiores em R4-R5 e R5-M1, as em R3-R4 e M1-M2, quando presentes, bem menores e na face dorsal sem as faixas azuis longitudinais, abaixo da faixa branca mediana, em CuA2-2A e na margem interna.

Descrição. Macho - Comprimento da asa anterior 28 a $31 \mathrm{~mm}$. Genas brancas, com as partes internas castanhas; tórax dorsalmente com a faixa azul do mesoscuto alcançando o mesoescutelo e todos os desenhos azuis.

Face dorsal da asa anterior com a faixa branca mediana entre 2,6 e 3,6 mm de largura máxima; manchas brancas em M3-CuA1 e CuA1-CuA2 com a larguras iguais a 1/3 ou 1/2 de suas alturas; faixa branca apical com as manchas em R4-R5 
e R5-M1 pouco mais largas que as larguras das manchas em M2-M3 e M3-CuA1; manchas brancas em R3-R4 e M1-M2, esta, às vezes, ausente, diminutas; às vezes, ainda com mancha branca diminuta em R2-R3, acima das discocelulares azuis; manchas da faixa azul submarginal entre R5 ou M1 até o torno, inicialmente pequenas e difusas, passando a compactas e grandes a partir de CuA l; a faixa azul sub-basal termina na margem interna acima do espaço entre as faixas azuis mediana e discal da asa posterior; franjas concolores.

Face dorsal da asa posterior com as faixas azuis basal e mediana e os espaços entre estas e entre a mediana e a discal aproximadamente iguais; espaço $2 \mathrm{~A}-3 \mathrm{~A}$ com os $4 / 5$ proximais e contíguos à $3 \mathrm{~A}$ e margem interna com escamas difusas azul esbranquiçadas; franjas brancas com as terminações das veias negras, às vezes, só brancas nos espaços entre CuAl e $3 \mathrm{~A}$.

Face ventral da asa anterior como a face dorsal, porém o azul da margem interna difusamente prolongado para a hase ao longo da margem; franjas como na face dorsal.

Face ventral da asa posterior com as faixas azuis basal e mediana e os espaços entre as três faixas aproximadamente iguais; faixa azul discal mais larga, estreitando-se uniformemente para o ângulo anal, em Sc + R1-Rs aproximadamente 2,5 a 3 vezes mais larga que em $\mathrm{CuA2}-2 \mathrm{~A}$; margem costal com difusas escamas azuis mais densas no ápice, acima da faixa discal; espaço 2A-3A com escamas difusas de extensão e intensidade varáveis, às vezes, até o fïm da faixa discal e com o centro negro; margem interna azul; franjas como na face dorsal.

Genitália (Fig. 38). Veja descrição do gênero. Valva com harpe larga, bilobada dorsalmente, provida com fortes espinhos na: margens dorsal e posterior e projeção dorso-hasal curta; ponta distal do edeago com entumescimento lateral direito.

Fêmea. Semelhante ao macho. Comprimento da asa anterior 32 a $35 \mathrm{~mm}$.

Genitália (Fig. 38). Esterigma tubular, pouco maior que duas vezes o seu diâmetro e unido ao e ahaixo do oitavo esterno; óstio arredondado e terminal.

Discussão. Espécie hem caracterizada pelos desenhos alares e pelas genitálias masculina e feminina.

\section{Chave para as subespécies}

1 - Face dorsal da asa posterior com a faixa azul discal mais larga do que a faixa azul mediana no macho e da mesma largura na fêmea . . . . . . . alhurna

- Face dorsal da asa posterior com a faixa azul discal mais estreita e difusa do que a faixa azul mediana, nos dois sexos . . . . . . . . . . . hrasiliensis 


\subsection{Protelbella alburna alburna (Mabille, 1891)}

Figs 2, 9, 38, 52, 144, 145

Pyrrhopyga (sic) alburna Mabille, 1891. Ann. Soc. ent. Belg. 35, CR, p. CX; macho, Chanchamayo; LECTótripo macho aqui designado (ZMHB) [Examinado].

Jemadia alburnia (sic); Mabille \& Boullet, 1908. Ann. Sc. nat. 7: 192, 196.- Mabille, 1912. Lep. Cat. 9, p. 10.- Draudt, 1921, in Seitz. Macrolep. World 5, p. 844, pl. 163b.

Jemadia alburna; Bell, 1933. Jour. N. Y. Ent. Soc. 41: 504, figs 33 (genitália masculina), 46-48.Martin, 1941. Bol. Mus. Hist. Nat. Javier Prado 5: 454.- Williams \& Hayward, 1944. Acta zool. lill. 2: 82: syn.: albumia.

Elbella alburna; Evans, 1951. Cat. Amer. Hesp. 1.p. 48, pl. 5 (genitália masculina).- Bridges, 1983.

Lep. Hesp. 1, p. 4; 2, p. 12.- Jong, 1983. Tijd. Ent. 126: 236.- Bridges, 1988. Cat. Hesp. 1,

p. $7 ; 2$, p. 19.

(sem gênero) alburna: Beattie, 1976. Rhop. Direct., p. 72.

Diagnose e descrição. Macho e fêmea (Figs 144, 145) - Comprimento da asa anterior 28 a $31 \mathrm{~mm}$ no macho e $35 \mathrm{~mm}$ na fêmea. Face dorsal da asa anterior com a faixa azul submarginal nitidamente mais larga em $2 \mathrm{~A}$; face dorsal da asa posterior com a faixa azul discal mais larga do que a faixa azul mediana no macho e da mesma largura na fêmea; franjas brancas com as terminações das veias negras, às vezes, só brancas nos espaços entre $\mathrm{M} 3$ e $3 \mathrm{~A}$ no macho e entre $\mathrm{CuA} 1$ e $3 \mathrm{~A}$ na fêmea.

Discussão. A subespeciação é fundamentada em aspectos cromáticos e na distribuição espacial alopátrica.

Distribuição espacial (Fig. 52). ECUADOR - sem localidade exata. - PERU - San Martin: Yumbatos. Huánuco: Tingo Maria 850m. Junin: Chanchamayo. Madre de Dios: Parque Nacional de Manu (Pakitza) 340m. Loreto: Nauta. Amazonas: Rio Santiago. - Bolívia - La Paz: Caranavi 600 - 1000m. Cochabamba: Alto Palmar 1100m; Cristal Mayo 600m.

Distribuição temporal. Voa em março, maio e setembro a dezembro.

Etologia. É um habitante de florestas, sendo que os machos pousam em areias úmidas na beira dos rios, principalmente em excrementos de aves e urina.

Planta hospedeira. Desconhecida.

Etimologia. Desconhecida.

Material estudado. Um síntipo macho aqui designado LECTótiPo, com as seguintes etiquetas: / LECTOTIPO/ Coll. Staudinger/ Chanchamayo Thamm/ Origin./ Alburna n.sp. (Mab.) / P. alburna Mab./ Alburna Mab./ Pyrrhopyga alburna Mabille, Lectótipo, O. Mielke det. 1993/ Protelbella alburna alburna, O. Mielke det. 1993/ (ZMHB). - ECUADOR - 1 fềmea (AMNH). - PERU - San Martin: Yumbatos, 1 macho (AMNH). Amazonas: Rio Santiago, 5-IX-1914 1 macho (AMNH). Junin: Chanchamayo, 1 macho (ZMUC). Huánuco: Tingo Maria, V-1964 1 macho, 19721 macho (UFPC-OM); Tingo Maria (Rondos), Villegas leg., 850m, 16-20-IX-1971 6 machos, 27-X-1971 5 machos, XI-1971 8 machos (UFPC). - BolíviA - La Paz: Caranavi, Tello leg., 600-1000m, IX-X-1988 3 machos (UFPC-OM). Cochabamba: Alto Palmar, Steinbach leg., 1100m, XII-1976 I macho (UFPC-OM); Cristal Mayo, 600m, 1-III-1958 I macho (USNM). - BRASIL - Paraná (erro de procedência), 1 macho (AMNH). 


\subsection{Protelbella alburna brasiliensis, ssp.n.}

Figs 52, 146, 147

Diagnose e descrição. Macho e fềmea (Figs 146, 147) - Comprimento da asa anterior 28 a $29 \mathrm{~mm}$ no macho e 31 a $32 \mathrm{~mm}$ na fêmea. Face dorsal da asa anterior com a faixa azul submarginal não ou só pouco mais larga em $2 \mathrm{~A}$; face dorsal da asa posterior com a faixa azul discal mais estreita e difusa que a faixa azul mediana, nos dois sexos; franjas brancas nos espaços entre CuAl e $3 \mathrm{~A}$ no macho e em $\mathrm{CuA} 2-2 \mathrm{~A}$ na fêmea.

Discussão. Veja em alburna alhurna.

Distribuição espacial (Fig. 52). Guiana Francesa - Montagne aux Chevaux. - Brasil - Amazonas: Tefé. Rondônia: Pimenta Bueno; Vilhena. Mato Grosso: Diamantino 300-400m; Sinop.

Distribuição temporal. Voa em março, agosto a outubro e dezembro.

Etologia. Desconhecida.

Planta hospedeira. Desconhecida.

Etimologia. O nome é alusivo ao pais de sua procedência.

Material estudado. Holótipo macho com as seguintes etiquetas: I HOLOTIPO/ Pimenta Bueno, Rondônia, VIII-IX-1970/ DZ 1899/ Protelbella alhurna brasiliensis Mielke, Holótipo, O. Mielke det. 1993/ (UFPC). Alótipo fêmea com as seguintes etiquetas: / ALOTIPO/ Teffé, AM[AZONAS] III-1925 Boy leg./ 12.909/Prorelhella alhurna hrasiliensis Mielke, Alótipo, O. Mielke det. 1993/ (UFPC-OM). Parátipos: GUIANA FRANCESA - Montagne aux Chevaux (Route de l'Est), J.-.Y. Gallard leg., 28-X-1990 1 fêmea (UFPC-OM). - BRAsIL - Rondônia: Vilhena, Tangerini leg., X-1987 1 macho (NT). Mato Grosso: Diamantino (Fazenda São João), Furtado leg., 300-400m, XII-1981 I macho (UFPC-OM); Sinop, Alvarenga leg., X-19741 macho (UFPC).

\section{CONCLUSÕES}

Ao "Complexo Elhella" pertencem os seguintes gêneros e espécies:

I - Microceris Watson, 1893

1. variicolor (Ménétriés, 1855)

II - Elhella Evans, 1955

Hegesippe Evans, 1951

1. intersecta (Herrich-Schäffer, 1869)

1.1. intersecta intersecta (Herrich-Schäffer, 1869)

fluminis (Butler, 1873)

semidentata (Mahille, 1877), syn.n.

tiribazus (Plötz, 1879), nom.nud.

ilona Evans. 1951, syn.n.

1.2. intersecta peter Evans, 1951

1.3. intersecta paraensis Mielke, ssp.n.

1.4. intersecta rufitegula Mielke, ssp.n. 
1.5. intersecta strova Evans, 1951

1.6. intersecta losca Evans, 1951

2. viriditas (Skinner, 1920), comb.n.

2.1. viriditas viriditas (Skinner, 1920), comb.n. carriae (Bell, 1931), syn.n.

2.2. viriditas chia Evans, 1951, comb.n.

2.3. viriditas boliviana Mielke, ssp.n.

3. lampra (Hopffer, 1874)

3.1. lampra lampra (Hopffer, 1874) menecrates (Mabille, 1878), syn.n. margimmiscus (Hayward, 1935), syn.n.

3.2. lampra albociliata Mielke, ssp.n.

4. mariae (Bell, 1931)

4.1. mariae mariae (Bell, 1931)

4.2. mariae molinai (Hayward, 1940), nom.rev., comb.n., stat.n.

5. adonis (Bell, 1931)

6. scylla (Ménétriés, 1855)

7. dulcinea (Plötz, 1879)

8. luteizona (Mabille, 1877)

martii (Plötz, 1879)

josepha (Plötz, 1879)

amoena (Röber, 1925)

xamthomargo (Hayward, 1942)

9. hegesippe (Mabille \& Boullet, 1908), comb.n.

10. iphinous (Latreille, [1824])

othello (Plötz, 1879)

mimetes (Mabille, 1909)

var. nigrita (Zikán, 1938)

11. miodesmiata (Röber, 1925), stat.rev.

12. rondonia Mielke, sp.n.

13. madeira Mielke, sp.n.

14. bicuspis Jong, 1983

15. etna Evans, 1951

moda Evans, 1951, syn.n.

16. patroclus (Plötz, 1879), sp.rev.

16.1. parroclus parroclus (Plötz, 1879), sp.rev.

umbrata (Mabille \& Boullet, 1908), syn.n.

16.2. patroclus acala Evans, 1951

17. azeta (Hewitson, 1866)

17.1. azeta azeta (Hewitson, 1866)

17.2. azeta giffordi Mielke, ssp.n. 
18. lustra Evans, 1951, stat.n.

19. merops (Bell, 1933)

20. theseus (Bell, 1933)

21. blanda Evans, 1951, stat.n.

22. patrobas (Hewitson, 1857)

22.1. patrobas patrobas (Hewitson, 1857)

22.2. patrobas mexicana Mielke, ssp.n.

22.3. patrobas evansi Mielke, ssp.n.

22.4. patrobas melanina (Mabille \& Boullet, 1908)

22.5. patrobas tingo Mielke, ssp.n.

22.6. patrobas amazonica Mielke, ssp.n.

III - Parelbella Mielke, gen.n.

1. polyzona (Latreille, [1824]), comb.n.

2. ahira (Hewitson, 1866), comb.n., stat.rev.

2.1. ahira ahira (Hewitson, 1866), comb.n., stat.rev. jamina (Butler, 1870), comb.n. zimra (Hewitson, 1871), comb.n.

2.2. ahira extrema (Röber, 1925), comb.n.

3. macleannani (Godman \& Salvin, 1893), comb.n., stat.rev.

4. peruana Mielke, sp.n.

IV - Pseudocroniades Mielke, gen.n.

1. machaon (Westwood, [1852]), comb.n.

1.1. machaon machaon (Westwood, [1852]), comb.n.

1.2. machaon seabrai Mielke, ssp.n.

V - Protelbella Mielke, gen.n.

1. alburna (Mabille, 1891), comb.n.

1.1. alburna alburna (Mabille, 1891), comb.n.

1.2. alburna brasiliensis Mielke, ssp.n.

Elbella zesta Evans, 1951 é um sinônimo junior de Croniades pieria (Hewitson, 1857), syn.n.. Esta espécie possui fêmeas dimórficas, uma com as manchas amarelas como nos machos e a outra com as manchas azuis (zesta).

AGRADECIMENTOS. Este estudo não teria sido possível sem a ajuda das pessoas e instituições mencionadas no item "Material e Métodos" e os Drs. A. Zinovjev (Zoological Institute, Russian Academy of Sciences, São Petershurgo, Rússia) pelas informações sobre os tipos de Microceris variicolor e Elhella scylla. Gert Hatschbach (Museu Botânico de Curitiba), Armando Cervi (Departamento de Botânica. Setor de Ciências Biológicas, Universidade Federal do Paraná) pelas identificações das plantas e Robert. K. Rohbins. Department of Entomology. National Museum of Natural History. Washington. USA pela permissão para o uso do mapa nas figuras das distribuiçôes geográficas; a eles o meu muito obrigado.

Ao Conselho Nacional de Desenvolvimento Científico e Tecnológico (CNPq). à Coordenação de 
Aperfeiçoamento de Pessoal de Ensino Superior (CAPES), ao Deutscher Akademischer Austauschdienst (DAAD), Bonn, Alemanha, à Royal Society (Londres, Inglaterra), à Royal Geographic Society (Londres, Inglaterra) e ao Programa BIOLAT, Smithsonian Institution, Washington D.C., USA, pelas bolsas e auxílios concedidos, o meu muito obrigado.

Agradeço ainda aos doutores Angelo B. Machado, Arno Lise, Danúncia Urban, Pe. Jesus S. Moure, Jocélia Grazia, Mirna M. Casagrande e Waldemiro Gremski, pela leitura criteriosa e pelas sugestões construtivas que ofereceram.

Aos meus mestres: Drs. Romualdo Ferreira D’Almeida, José Oiticica Filho, Alfredo Rei do Rego Barros e Pe. Jesus Santiago Moure, o meu reconhecimento.

Aos colegas do Departamento de Zoologia, Setor de Ciências Biológicas, Universidade Federal do Paraná, pela contribuição no desenvolvimento deste e outros trabalhos e aos Drs Waldemiro Gremski e Imara Milhoretto, diretor e vice-diretora do Setor de Ciências Biológicas, Universidade Federal do Paraná, pelo apoio, a minha gratidão.

\section{REFERÊNCIAS BIBLIOGRÁFICAS}

Austin, G.T.; J.P. BRoOK \& O.H.H. MielKe. 1993. Ants, birds \& skippers. Trop. Lep., Gainesville, 4, Suppl. 2: 1-11.

Beattie, J.R. 1976. Rhopalocera Directory. Berkeley, J. B. Indexes.

BELL, E.L. 1931. Studies in the Pyrrhopyginae, with descriptions of several new species (Lepidoptera, Rhopalocera, Hesperiidae). Jour. N.Y. Ent. Soc. 39: 417-491.

1932. Studies in the genus Phocides with descriptions of new species (Lepidoptera, Hesperiidae). Trans. Amer. Ent. Soc. 58: 169-199.

1932. Hesperiidae (Lepidoptera, Rhopalocera) of the Roraima and Duida expeditions, with descriptions of new species. Amer. Mus. Novit. 555: 1-16.

1933. Studies in the Pyrrhopyginae, with descriptions of new species (Lepidoptera, Rhopalocera, Hesperiidae). Jour. N.Y. Ent. Soc. 41: 265-295, 481-528.

. 1934. Studies in the Pyrrhopyginae (Lepidoptera, Rhopalocera). Jour. N. Y. Ent. Soc. 42: 393-440.

. 1942. New records and species of Hesperiidae from Mexico (Lep. Hesp.). An. Esc. nac. Cienc. biol., Mexico, 2: 455-468.

. 1946. A catalogue of the Hesperioidea of Venezuela. Bol. Ent. venezol., Caracas, 5 (3-4): 65-203.

. 1946. Some corrections to the "Studies in the Pyrrhopyginae". Jour. N.Y. Ent. Soc. 54: 199-201.

Biezanko, C.M. 1963. VI Hesperiidae da Zona Sueste do Rio Grande do Sul Grande do Sul. Arq. Ent., sér. (A), Pelotas, 24p.

BiEZANKo, C.M. \& A. Rufinelli. 1962. Lepidopteros americanos de la coleccion de la catedra de entomologia. Estudio sobre la colección Herborn. Rev. Fac. Agron., Montevideo, 50: 119-166.

Biezanko, C.M. \& O.H.H. MiELKE. 1973. Contribuição ao estudo faunístico dos Hesperiidae americanos. IV Espécies do Rio Grande do Sul, Brasil, com notas taxonômicas e descrições de espécies novas (Lepidoptera). Acta biol. paran., 
Curitiba, 2 (1-4): 51-102.

BRIDGES, CH.A. 1983. Lepidoptera: Hesperiidae. Notes on species group names. 1 , p. 1-129; 2, p. 1-41; 3, p. 1-62; 4, p. 1-30; 5, p. 1-18. Urbana, edição do autor.

- 1988. Catalogue of Hesperiidae (Lepidoptera: Rhopalocera). 1, p. $1-205 ; 2$, p. 1-67; 3, p. 1-78; 4, p. 1-54; 5, p. 1-20; 6, p. 1-7; App. 1, p. 1; App. 2, p. 1-8; Annot. 1, p. 1; Annot. 2, p. 1; Annot. 3, p. 1-4; Annot. 4, p. 1-2; Annot. 5, p. 1-6. Urbana, edição do autor.

1988. Catalogue of family-group, and genus-group names (Lepidoptera: Rhopalocera). VI p., Part 1, p. 1-8; Part 2, p. 1-3; Part 3, p. 1-4; Part 4, p. 1-141; Part 5, p. 1-33; Part 6, p. 1-68; Part 7, p. 1-18; Part 8, p. 1-61; Part 9, p. 1-20; Part 10, p. 1-8. Urbana, edição do autor. Brown JR., K.S. 1987. Zoogeografia da região do pantanal mato-grossense. An. Prim. Simp. Rec. Nat. e Soc. Econ. Pantanal, EMBRAPA, Brasilia, p. 137-178.

Brown JR., K.S. \& O.H. Mielke. 1967. Lepidoptera of the Central Brazil Plateau. I. Preliminary List of Rhopalocera (Continued): Lycaenidae, Pieridae. Papilionidae, Hesperiidae. Jour. Lep. Soc. 21 (3): 145-168.

- 1968. Lepidoptera of the Central Brazil Plateau. III. Partial list for the Belo Horizonte Area, showing the character of the southeastern "Blend Zone". Jour. Lep. Soc. 22: 147-157.

BUTLER, A.G. 1869-1874. Lepidoptera exotica or descriptions and illustrations of exotic Lepidoptera. London, E. W. Janson, 190 p.

1870. The genera of Hesperidae in the collection of the British Museum. Ent. monthly Mag. 7: 55-58, 92-99.

Hesperiidae. Trans. ent. Soc. London, p. 485-520. $151-177$.

. 1877. List of Lepidoptera recently collected by Mr. Walter Davis in Peru, with descriptions of a new genus and several new species. Ann. \& Mag. nat. Hist. 20 (4): 177-129.

Campos R.F. 1927. Catalogo preliminar de los lepidopteros del Ecuador. Primera parte Ropaloceros. Rev. Col. Nac. Vicente Rocafuerte, Guayaquil, 9 (27-28): 3-106.

Cardoso, A. 1949. Lepidópteros de Alagoas. Rev. Ent., Rio de Janeiro, 20: 427-436.

Cock, M.J.W. 1984. Lepidoptera notes 1-6. Living World, 1983-1984, p. 35-37.

Comstock, J.A. \& L. VÁzQuez G. 1961. Estudios de los ciclos biológicos en Lepidópteros mexicanos. An. Inst. Biol. Univ., Mexico, 31: 349-448, 54 figs.

CRESSON JR., E.T. 1926. List of new genera and species described by Henry Skinner. Ent. News 37: 246-249.

DEVRIES, PH.J. 1983. Checklist of Butterflies, p. 654-678. In: D. H. JANZEN (ed.). Costa Rican Natural History. Chicago e London, The University of Chicago 
Press.

Doubleday, E.; J.O. WestwoOd \& W.C. Hewitson. 1846-1852. The genera of diurnal Lepidoptera, comprising their generic characters, a notice of their habits and transformations, and a catalogue of the species of each genus; illustrated with 86 plates by W. C. Hewitson. London, Longman, $534 \mathrm{p}$.

DRAUDT, M. 1921. Hesperidae [não a parte geral], pp. 836-1011, 1046-1055, pls. 113B, 160-193. In A. SEITZ. The Macrolepidoptera of the World 5. Stuttgart, A. Kernen.

DruCE, H.H. 1908. Descriptions of some new Hesperiidae from Central and South America. Trans. ent. Soc. London, p. 375-386.

DRUCE, H. 1876. List of the butterflies of Peru, with descriptions of new species. With some notes by Edward Bartlett. Proc. zool. Soc. London, p. 205-250.

EBERT, H. 1969. On the frequency of butterflies in eastern Brazil, with a list of the butterfly fauna of Poços de Caldas, Minas Gerais. Jour. Lep. Soc. 23, Suppl. 3: 1-48.

Evans, W.H. 1941. An interesting case of development of certain South American Hesperiidae (Lep. Rhopalocera). Proc. roy. ent. Soc. London (A) 16: 21-23. . 1951. A catalogue of the American Hesperiidae, indicating the classification and nomenclature adopted in the British Museum (Natural History). Part I, Pyrrhopyginae. London, British Museum (Natural History), $\mathrm{VII}+92 \mathrm{p}$.

Freeman, H.A. 1966. New Hesperiidae records from Mexico. Jour. Lep. Soc. 20 (4): 226-228.

Gibson, W.W. \& J.L. CaRIllo S. 1959. Lista de insetos en la coleccion entomologica de la oficina de estudios especiales, S. A. G. Folleto Misc., Secret. Agric. Ganad., Oficina Estudios Especiales, Mexico, 9: I-XVIII, 1-254.

Gillham, N.W. \& P.R. Ehrlich. 1955. The butterfly type of Henry Skinner and co-authors in the Academy of Natural Sciences of Philadelphia (Lepidoptera: Papilionoidea and Hesperioidea). Trans. Amer. Ent. Soc. 80: 91-117.

Godman, F.D. 1907. Notes on the american species of Hesperiidae described by Plötz. Ann. \& Mag. Nat. Hist. (7) 20: 132-155.

Godman, F.D. \& O. Salvin. 1879-1901. Biologia Centrali-Americana. Insecta. Lepidoptera-Rhopalocera. 1 (1879-1886), p. 1-487; 2 (1887-1901), p. $1-782 ; 3$.

1880. A list of diurnal Lepidoptera collected in the Sierra Nevada of Santa Marta, Colombia, and the vicinity. Trans. ent. Soc. London, p. 119-132.

HAYWARD, K.J. 1932. Lepidopteros argentinos. Familia Hesperidae. I Subfamilia Pyrrhopyginae. Rev. Soc. ent. arg. 5 (1): 19-35, 2 pls.

1934. Lepidopteros argentinos. Familia Hesperidae. IV Subfamilia Pamphilinae. V Resúmen, Clave, Apéndices e Indice. Rev. Soc. ent. arg. 6: 97-233. 
1935. Revision de especies argentinas de Pyrrhopyginae (Lep. Hesp.).

Rev. Soc. ent. arg. 7: 123-129.

Some Hesperiidae from Yungas of Bolivia (Lep.). Rev. Ent. . Rio de Janeiro, 8: 106-111.

1940. A new species of Pyrrhopyge (Lep. Hesp.). Rev. chil. Hist. nat. 44: 33-41, fig.

1941. Hesperiidarum Argentinae Catalogus. Rev. Mus. La Plata (n. ser.), Zoologia 2: 227-340, 1 fig.

1942. Notes on Hesperiidae in the collection of the Museu Nacional do

Brasil. Bol. Mus. Nac., Rio de Janeiro, 14-17: 65-75.

1945. Hesperiidae (Lep.) capturados em Porto Cabral durante uma excursão à margem paulista do rio Paraná. Pap. Av. Dep. Zool.. São Paulo, 5 (21): 197-202.

1947. Catalogus Hesperiidarum Rei Publicae Colombianae. Acta zool. lill. 4: 201-392.

1948. Insecta, Lepidoptera (Rhopalocera), familia Hesperiidarum, subfamiliae Pyrrhopyginarum et Pyrginarum. Gen. Spec. Anim. Argent.

1. Tucuman, Instituto Miguel Lillo, 389p.

1973. Catalogo de los ropaloceros argentinos. Op. lill. 23: 1-318.

Hemming, F. 1941. The dates of publication of the several portions of Doubleday (E.) "Genera of Diurnal Lepidoptera" and of the continuation thereof by Westwood (J. O.). Jour. Soc. Bihliogr. nat. Hist. London, 1: 335-411.

1941. The dates of publication of the specific names first published in Doubleday (E.) "Genera of Diurnal Lepidoptera" and in the continuation thereof hy Westwood (J. O.). Jour. Soc. Bibliogr. nat. Hist.. London, 1: 447-464.

1967. The generic names of the butterflies and their type-species (Lepidoptera: Rhopalocera). Bull. Brit. Mus. (Nat. Hist.), Ent., Suppi. 9: $1-509$.

Heppner, J.B. \& G. LAMAs. 1982. Acronyms for World Museum Collections of Insects, with Emphasis on Neotropical Lepidoptera. Bull. Ent. Soc. Amer. 28 (3): $305-315$.

HERRICH-SCHÄFFER, G.A.W. 1864-1871. Prodromus Systematis Lepidopterorum - Versuch einer systematischen Anordnung der Schmetterlinge. Corr.-Blatt zool.-min. Ver. Regenshurg 18 (1864): 89-112, 123-136, 148-152, 173-181; 19 (1865): 63-76, 84-92, 100-108; 21 (1867): 100-106, 124-128, 138-144, 161-172; 22 (1868): 119-138, 172-176; 23 (1969): 56-64, 67-77, 130-141. 163-172, 184-204; 24 (1870): 154-160; 25 (1871): 103-104.

HEWITSON, W.C. 1851-1877. Illustrations of new species of exotic butterflies, selected chiefly from the collection of W. Wilson Saunders and William C. Hewitson. 5 vols. London, V. Voorst, texto e planchas. 1866. Descriptions of new Hesperidae. Trans. ent. Soc. London (3) 2: 479-501.

HoffmanN, C.C. 1940-1941. Catalogo sistemático y zoogeográfico de los lepi- 
dópteros mexicanos. Primera parte Papilionoidea. Segunda parte Hesperioidea. An. Inst. Biol., Mexico, 11 (1940): 639-739, 2 mapas; 12 (1941): 237-294.

Hoffmann, F. 1934. Beiträge zur Lepidopterenfauna von Sta. Catarina (Südbrasilien). Ent. Rdsch., Stuttgart, 51: 13-15, 25-28, 62-64, 71-74, 248-251, 265-268, 272-277.

HopfFER, C. 1874. Neue Lepidopteren von Peru. Stett. ent. Ztg. 35: 329-371.

JONG, R. DE. 1983. Annotated list of the Hesperiidae (Lepidoptera) of Surinam, with descrition of new taxa. Tijd. Ent. 126: 233-268.

Kaye, W.J. 1915. Pyrrhopygid ova and imagines. Proc. ent. Soc. London 5: CXIX.

KIRBY, W.F. 1871. A Synonymic Catalogue of Diurnal Lepidoptera. London, Voorst, p. VI+1-690.

- 1877. A Synonymic Catalogue of Diurnal Lepidoptera. Supplement. London, Voorst, p. VI+691-884.

1879. Catalogue of the Collection of Diurnal Lepidoptera formed by the late William Chapman Hewitson, of Oatlands, Walton-on-Thames, and bequeathed by him to the British Museum. London, Voorst, IV + 246p.

- 1880. Catalogue of the Lepidoptera (Rhopalocera, Sphingidae, Castniidae, and Uraniidae) in the Museum of Science and Art, Dublin, with remarks on new or interesting species. Proc. r. Dublin Soc. (2) 2: 292-340.

KöHLER, P. 1923. Fauna argentina. Lepidoptera e collectione Alberto Breyer. I

Teil. Rhopalocera. Systematischer Katalog und Studien, Berichtigungen u.

Neubeschreibungen. Zeitschr. wiss. Insektenbiol., Berlin, 18, Sondierheft, $34 p$.

Köhler, P. \& R. Strassberger. 1928. Catálogo de lepidópteros argentinos.

Enumeracion sistemática de lepidópteros diurnos y parte de nocturnos (de

Sphingidae hasta Noctuidae (Heliothinae). Buenos Aires, Publ. Breyer, 12p.

LAMAS, G. 1969. Lista de Ropaloceros (Lepidoptera) peruanos citados en la obra

"Die Gross-Schmetterlinge der Erde" de Adalbert Seitz. Biota, Lima, 7 (58): 265-328; (59): 329-354.

- 1981. La fauna de mariposas de la reserva de Tambopata, Madre de

Dios, Peru (Lepidoptera, Papilionoidea y Hesperioidea). Rev. Soc. Mex. Lep.

6 (2): 23-40.

- 1983. Adiciones y recorrecciones a la lista de mariposas de la Reserva Tambopata. Rev. Soc. Mex. Lep. 8 (1): 13-24.

Tambopata, Peru. Rev. Soc. Mex. Lep. 8 (2): 49-51.

LAMAS, G.; R.K. Robbins \& D. HARVEY. 1991. A preliminary survey of the butterfly fauna of Pakitza, Parque Nacional de Manu, Peru, with an extimate of its species richness. Publ. Mus. Hist. nat., UNMSM (A), Lima, 40: 1-19.

Lamas, G.; O.H.H. Mielke \& R.K. RobBins. 1993. The Ahrenholz technique for attrackting tropical skippers (Hesperiidae). Jour. Lep. Soc. 47 (1): 8 0-82. Latreille, P.A. \& J.B. Godart. 1819-[1824]. Encyclopédie Methodique. 
Histoire Naturelle. 9. Entomologie. 828p.

LESSE, H. DE \& K.S. BROWN JR. 1971. Formules chromosomiques de Lepidoptères Rhopalocères du Brésil. Bull. Soc. ent. France 76: 131-137.

LEWIS, H.L. 1973. Mariposas del mundo. Barcelona, Omega, XVI+312p.

LindSEY, A.W. 1925. The Cornell University Expedition to South America of 1919-1920. Scientific Results. No. 2: Hesperioidea. Denison Univ. Bull., Jour. Sc. Lab. 21: 71-113.

- 1925. The types of Hesperioid genera. Ann. Ent. Soc. Amer. 18: 75-106.

Llorente-Bousquets, J.; A. Luis-Martínez \& I. Vargas-Fernández. 1990. Catalogo sistematico de los Hesperioidea de Mexico 1990. Publ. esp. Mus. Zool., Mexico, 1: 1-70.

MABILDE, A. 1896. Guia pratica para os principiantes coleccionadores de insetos contendo a descripção fiel de perto de 1000 borboletas com 280 figuras lythographadas em tamanho, formas e dezenhos conforme o natural. Porto Alegre, Gundlach \& Schludt, 238 p.

MaBILLE, P. 1877-1878. Descriptions de Lepidoptéres nouveaux du groupe des Hespérides. Pet. Nouv. Ent. 2: 161-162 (1877), 165-166 (1877), 197-198 (1878), 201-202 (1878), 205 (1878), 229-230 (1878), 233-234 (1878), 237-238 (1878), 242 (1878), 261 (1878).

. 1878. Catalogue des Hespérides du Musée Royal D’Histoire Naturelle de Bruxelles. Ann. Soc. ent. Belg. 21: 12-44.

1891. Description d'Hespérides nouvelles. Ann. Soc. ent. Belg. 35, CR: LIX-LXXXVIII, CVI-CXXI, CLXVIII-CLXXXVII.

1903-1904. Lepidoptera Rhopalocera. Fam. Hesperidae, p.1-78 (1903); 79-210, 4 pls. (1904). In: P. WYTSMAN. Genera Insectorum 17. Bruxelles, Verteneuil \& Desmet.

1909. Note sur l’Hesperia Iphinous Latr. (Lep. Hesperidae). Bull. Soc. ent. France, p. 334-335.

1912. Lepidopterorum Catalogus. Pars 9. Hesperiidae; Subfamilia Pyrrhopyginae. Berlin, Junk, 18p.

Mabille, P. \& E. Boullet. 1908. Essai de révision de la famille des Hespérides. Ann. Sc, nat. (Zool.) (9) 7: 167-207.

1912. Essai de révision de la famille des Hespérides. Ann. Sc. nat. (Zool.) (9) 16: 1-159.

Martin, M. DE. 1941-1942. La coleccion de lepidópteros del Museo. Bol Mus. Hist. nat. J. Prado, Lima, 5 (1941): 46-61, 197-208, 343-352, 447-457; 6 (1942) 67-70, 223-228, 343-348.

Mathew, G.F. 1882. Remarks on some central american species of Pyrrhopyge, Hübn. Ent. monthly Mag. 19: 18-19.

MAZA E., J. DE LA \& R. DE LA MAZA E. 1985. La fauna de mariposas de Boca de Chajul, Chiapas, Mexico (Rhopalocera). Parte 1. Rev. Soc. Mex. Lep. 9: 23-44.

Maza E., J. De La; A. White L. \& R.G. de la Maza E. 1991. La fauna de 
mariposas de México. Parte 2. Hesperioidea (Lepidoptera: Rhopalocera). Rev. Soc. Mex. Lep. 14: 3-44.

MAZA R., R. DE LA. 1987. Mariposas mexicanas. Guia para su colecta y determinación. Mexico, Fundo de Cultura Económica, 302p.

MAZA E., R.G. DE LA. 1976. Notas sobre lepidopteros de Rancho Viejo y Tepoztlan, Morelos, Mexico. Segunda parte: Hesperidos, Megatimidos y Castnidos. Rev. Soc. Mex. Lep. 2: 15-23.

MAZA E., R.G. DE LA \& A. WhIte L. 1990. Rhopalocera de la Huasteca Potosina, su distribución, composición, origen y evolución. Rev. Soc. Mex. Lep. 13 (2): $31-88$.

Maza E., R.G. de la Maza \& D.G. Carbonell. 1992. Ropaloceros de Quintana Roo, su distribucion, origen y evolucion. Rev. Soc. Mex. Lep. 15 (1): 1-43; Anexo 1: 1-14.

MÉNÉTRIÉS, E. 1855-1863. Enumeratio Corporum Animalium Musei Imperialis Academiae Scientiarum Petropolitanae. Classis Insectorum, Ordo Lepidopterorum. Pars 1 (1855), 15+102p.; Pars 2 (1857), 6+90p.; Pars 3 (1863), 4+20p., Petropoli, Typis Academiae Scientiarum Imperialis.

MiELKE, O.H.H. 1967. Lepidópteros do planalto central brasileiro. IV: Notas complementares sôbre os Hesperiidae da região e descrição de cinco espécies novas (Lepidoptera, Hesperiidae). Rev. Bras. Biol. 27 (2): 125.-134.

1968. Contribuição ao estudo faunístico dos Hesperiidae brasileiros. I. Resultados de uma excursão à Foz de Iguaçu, Paraná, Brasil, com notas taxonômicas (Lepidoptera). Atas Soc. Biol. Rio de Janeiro 12 (2): 73-78.

1971. As espécies de Hesperiidae descritas por J. F. Zikán (Lepidoptera). Rev. Bras. Biol. 31 (2): 249-262.

- 1980. Contribuição ao estudo faunístico dos Hesperiidae americanos. V. Nota suplementar às espécies de Pyrrhopyginae e Pyrginae do Rio Grande do Sul, Brasil (Lepidoptera). Acta biol. paran. 8-9: 7-17.

1989. Sobre os tipos de Hesperiidae descritos por Roeber (Lepidoptera).

Revta bras. Zool. 6: 131-146.

Mielke, O.H.H. \& M.M. Casagrande. 1988. Sobre os tipos de Lepidoptera depositados em museus brasileiros. XX. Pieridae descritos por C. M. Biezanko e H. Fruhstorfer e Hesperiidae por K.T. [recte J.] Hayward. Revta bras. Ent. 32 (2): 115-118.

Miles Moss, A. 1949. Biological notes on some Hesperiidae of Pará and the Amazon (Lep. Rhop.). Acta zool. IIII. 7: 27-79.

OKANO, K. 1981. Studies on the mexican Butterflies (1). Additions and revisions to the Hoffmann's "Catalogo sistematico y zoogeografico de los Lepidopteros mexicanos". Part 1: Hesperiidae (Lepidoptera: Rhopalocera). Tokurana 1: 23-139.

PALlister, J.C. 1956. Skippers taken on the Frank C. Johnson Entomological Expedition to Peru, with distribuition and ecological notes. Amer. Mus. Novit. 1763: $1-69$.

Plötz, C. 1879. Die Hesperiinen-Gattung Pyrrhopyga (sic) und ihre Arten. Stett. 
ent. Ztg. 40: 520-538.

RaymOnd, TH. 1982. Mariposas de Venezuela. Caracas, Corpoven, 275p.

RILEY, N.D. 1926. On the identity of certain Hesperiidae (Lep.) described by Latreille. Trans. ent. Soc. London 74: 231-241.

Röber, J. 1925. Neue südamerikanische Falter (Lep.). Ent. Mitt., Berlin, 14: 85-100, 156-162.

ShePard, H.H. 1931. Lepidopterorum Catalogus 47. Hesperidae: Subfamilia Pyrginae I. Berlin, Junk, 144p.

. 1936. Lepidopterorum Catalogus 74. Hesperidae: Subfamilia Pyrginae IV. 's-Gravenhage, Junk, p.561-679.

Silva, A.G. D'A.; C.R. Gonçalves; D.M. Galväo; A.J.L. Gonçalves; J. Gomes; M. DO N. SiLva \& L. DE Simoni. 1967-1968. Quarto catálogo dos insetos que vivem nas plantas do Brasil, seus parasitos e predadores. Parte 1 (1-2) (1967) Bibliografia entomológica brasileira, XIII+906p.,; Parte 2 (1) (1968) Insetos, hospedeiros e inimigos naturais, XXVI+622p.; Parte 2

(2) (1968) Índice de insetos e índice de plantas, VIII + 265p., Rio de Janeiro, Laboratório Central de Patologia Vegetal.

SkINNER, H. 1920. Descriptions of new species of Hesperidae. Ent. News 31: 132-134.

SPITZ, R. 1932. Catalogo das coleções dos mac rolepidopteros do Museu Paulista, com anotações, até 1929. Rev. Mus. paulista 17 (2): 833-893.

STAUDINGER, O. 1884-1888. Exotische Tagfalter in systematischer Reihenfolge mit Berücksichtigung neuer Arten 1. Fürth, Löwensohn. 333p.

Steinhauser, S.R. 1975. An annotated list of the Hesperiidae of El Salvador. Bull. Allyn Mus. 29: 1-34.

. 1986. A review of the skippers of the narcosius group of species of the genus Astraptes Huebner (sensu Evans, 1952) and erection of a new genus. Lepidoptera: Hesperiidae. Bull. Allyn Mus. 104: 1-43, 79 figs.

Ureta R., E. 1941. Lepidopteros ropaloceros de Bolivia. Bol. Mus. Nac. Hist. nat., Chile, 19: 31-41.

WATSON, E. Y. 1893. A proposed classification of the Hesperiidae, with a revision of the genera. Proc. zool. Soc. London, p.3-132.

WEEKS JR., A.G. 1901. Illustrations of hitherto unfigured Lepidoptera. 32p. 1905. Illustrations of diurnal Lepidoptera, with descriptions 1. Boston, Univ. Press, $12+117 \mathrm{p}$.

1911. Illustrations of diurnal Lepidoptera 2. Boston, Univ. Press, $\mathrm{XVI}+37 \mathrm{p}$.

Weidemeyer, J.W. 1864. Catalogue of North-American Butterflies. Proc. ent. Soc. Philad. 2: 513-542.

Williams, R.C. \& K.J. Hayward. 1944. Hesperiidarum Rei Publicae Aequatoris catalogus. Acta zool. IIII. 2: 63-246.

ZIKÁN, J.F. 1922. Unsere Heliconisat-Arten. Dtsch. Ver. Wiss. Kunst, São Paulo, p. 183-193. 


\section{Ztschr., p.58-82.}

1927. Biologie der Heliconisa-Arten (Lep. Saturnid.). Dtsch. ent. - 1928. Die Macro-Lepidopteren des Itatiaya (Südabhang bei Campo Bello). Ent. Rdsch., Stuttgart, 45: 7-8, 10-11, 13-14, 19-20, 22-23, 26, 32, 35-36, 38-39, 46.

- 1938. Novos lepidopteros brasileiros da familia Hesperidae. Rev. Ent., Rio de Janeiro, 9 (3-4): 321-336.

ZIKÁN, J.F. \& W. ZIKÁN. 1968. Inseto-fauna do Itatiaia e da Mantiqueira. III. Lepidoptera. Pesq. agropec. bras. 3: 45-109.

\section{ÍNDICE}

acala, Elbella patroclus . . . . . . . . . . . . 416, 490, 494, 574 adonis, Elbella . . . . . . . . . . . . . . 416, 417, 452, 574

ahira, Parelbella . . . . . . . . . . . . . . 542, 548, 575

ahira, Parelbella ahira . . . . . . . . . . . . 542, 550, 552, 575

albociliata, Elbella lampra . . . . . . . . . . . . . . 416, 440, 444, 574

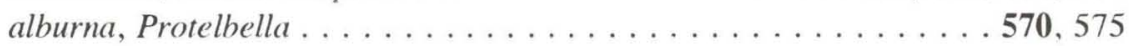

alburna, Protelbella alburna . . . . . . . . . . 571, 572, 575

alburnia (sic), Jemadia . . . . . . . . . . . . . . . . . . . . . . . . 572

amazonica, Elbella patrobas . . . . . . . . . 416, 518, 534, 575

amoena, Sarbia . . . . . . . . . . . . . . . . . . . . 463, 574

azeta, Elbella . . . . . . . . . . . . . . . . . 417, 496, 574

azeta, Elbella azeta . . . . . . . . . . . . . . . . 416, 497, 574

azeta, Jemadia . . . . . . . . . . . . . . . . . . . . 510,520

bicuspis, Elbella . . . . . . . . . . . . . 416, 417, 484, 574

blanda, Elbella .................. 416, 417, 510, 574

boliviana, Elbella viriditas . . . . . . . . . . . . . 416, 436, 438, 574

brasiliensis, Protelbella alburna . . . . . . . . . . . . 571, 573, 575

carriae, Pyrrhopyge . . . . . . . . . . . . . . . . . . 437, 574

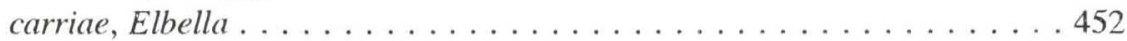

chia, Elbella viriditas . . . . . . . . . . . . . 416, 436, 438, 574

dulcinea, Elbella . . . . . . . . . . . . 4 416, 417, 460, 574

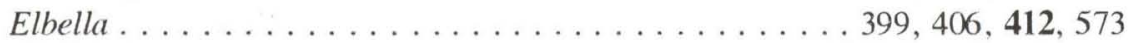

Elbella, chave para as espécies . . . . . . . . . . . . . . 416

Elbella, chave para os gêneros do "complexo" . . . . . . . . . . . . . 406

Elbella, "complexo" .................4406, 415, 573

Elbella, espécies incluídas . . . . . . . . . . . . . . . 415

etna, Elbella . . . . . . . . . . . . . . 416, 417, 486, 574

evansi, Elbella patrobas . . . . . . . . . . 416, 518, 526, 575

extrema, Parelbella ahira . . . . . . . . . . . . . 542, 550, 556, 575

fluminis, Pyrrhopyga (sic) . . . . . . . . . . . . . . 424,573

giffordi, Elbella azeta . . . . . . . . . . . . 416, 497, 500, 575 
Hegesippe. $412,415,573$

hegesippe, Elbella $416,417,467,574$

ilona, Elbella intersecta. 425,573 intersecta, Elbella $417,419,424,425,573$ intersecta, Elbella intersecta. $415,424,425,573$ iphinous, Elbella. $416,417,470,574$ jamina, Jemadia. 556,575 jamina, Pyrrhopyga (sic) 552 josepha, Pyrrhopyga (sic) 462,574 lampra, Elbella . $417,440,574$ lampra, Elbella lampra . $416,441,574$ lampros (sic), Pyrrhopyge 441 lamprus, Pyrrhopyge . . . . . . . . . . . . . . . . . . . 441 lamprus, Elbella. 444 lateizona (sic), Sarbia 463 losca, Elbella intersecta. $416,424,434,574$ lustra, Elbella $416,417,502,575$ luteizona, Elbella. $416,417,462,574$ machaon, Pseudocroniades. 565,575 machaon, Pseudocroniades machaon 566,575 macleananni (sic), Elbella polyzona 560 macleannani, Parelbella. $542, \mathbf{5 6 0}, 575$ madeira, Elbella $416,417,482,574$ margimiscus (sic), Pyrrhopyge margimmiscus, Pyrrhopyge . 441,574 mariae, Elbella $417,446,574$ mariae, Elbella mariae. $416,447,448,574$ martii, Pyrrhopyga (sic) 462,574 martyii (sic), Sarbia . 463 melanina, Elbella patrobas . $416,518,526,530,575$ menecrates, Pyrrhopyga (sic) $441,442,574$ merops, Elbella . $416,417,504,575$ mexicana, Elbella patrobas . $416,518,524,575$ Microceris 399, 406, 573 mimetes, Mimoniades 470,574 miodesmiata, Elbella $416,417,478,574$ moda, Elbella etna. 486,574 molinai, Elbella mariae $416,447,450,574$ nigrita, Mimoniades othello var. 471,574 othello, Pyrrhopyga (sic) . 470,574 paraensis, Elbella intersecta $.415,424,432,573$ Parelbella $399,406,538,575$ 
Parelbella, chave para as espécies . . . . . . . . . . . . . . .542

patroba (sic), Elbella . . . . . . . . . . . . . . . . . . . 520

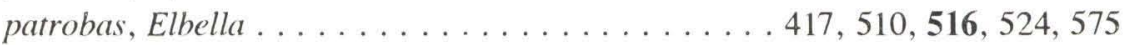
patrobas, Elbella patrobas . . . . . . . . . 4 416, 518, 520, 524, 575 patrobas, Jemadia . . . . . . . . . . . . . . . . . . 494, 510 patrobus (sic), Myscelus . . . . . . . . . . . . . . . . . . 520

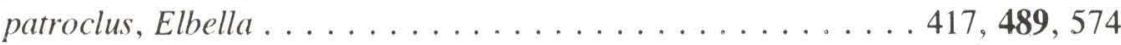
patroclus, Elbella patroclus . . . . . . . . . . . . . 416, 490, 574 peruana, Parelbella . . . . . . . . . . . . . . 542, 562, 575 peter, Elbella intersecta . . . . . . . . . . 415, 424, 430, 432, 573 pieria, Croniades . . . . . . . . . . . . . . . . . . 399, 575 polemon, Pyrrhopyge . . . . . . . . . . . . . . . . . 450 polyzona, Elbella . . . . . . . . . . . . . . . . . . . 506 polyzona, Parelbella . . . . . . . . . . . . . . . 542, 544, 575 Protelbella . . . . . . . . . . . . . . . . 399, 406, 569, 575 Pseudocroniades . . . . . . . . . . . . . . . 399, 406, 564, 575 rondonia, Elbella . . . . . . . . . . . . . 416, 417, 480, 574

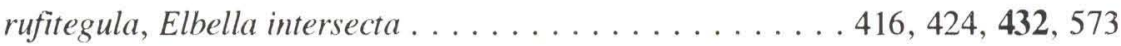
scylla, Pyrrhopyge . . . . . . . . . . . . . . . . . . 460 scylla, Elbella . . . . . . . . . . . . . 407, 417, 417, 456, 574 seabrai, Pseudocroniades machaon . . . . . . . . . . . . 566, 568, 575 semidentata, Pyrrhopyga (sic) . . . . . . . . . . . . 424, 425, 573 strova, Elbella intersecta . . . . . . . . . . . . .416, 424, 434, 574

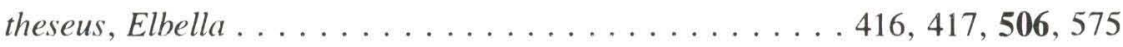

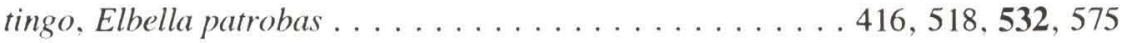
tiribazus, Pyrrhopyga (sic) . . . . . . . . . . . . . . . . . 425, 573 umbrata, Jemadia . . . . . . . . . . . . . . . . . . . . . . . . . . . . 490, 574 variicolor, Microceris . . . . . . . . . . . . . . . . . . 408, 573 variicolov (sic), Microceris . . . . . . . . . . . . . . . . . . . . . 408

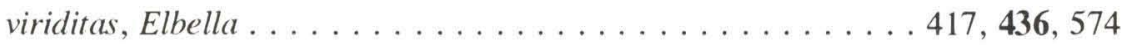

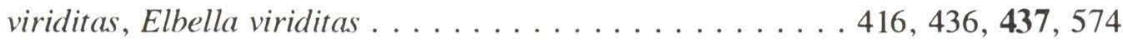
xanthomargo, Pyrrhopyge . . . . . . . . . . . . . . 463, 574 zesta, Elbella . . . . . . . . . . . . . . . . . . 399, 575 zimra, Jemadia . . . . . . . . . . . . . . . . . . 556, 575 zimra, Pyrrhopyga $($ sic) . . . . . . . . . . . . . . . . 552 